\title{
DETERMINAÇÃO DOS PARÂMETROS DA CURVA DE CRESCIMENTO DE ANIMAIS DA RAÇA GUZERÁ E SEUS CRUZAMENTOS ALIMENTADOS A PASTO, COM E SEM SUPLEMENTAÇÃO
}

\author{
LUÍS ORLINDO TEDESCHI
}

Dissertação apresentada à Escola Superior de Agricultura "Luiz de Queiroz", da Universidade de São Paulo, para obtenção do título de Mestre em Agronomia, Área de Concentração: Ciência Animal e Pastagens.

P I R A C I C A B A

Estado de São Paulo - Brasil

Outubro de 1996 


\title{
DETERMINAÇÃO DOS PARÂMETROS DA CURVA DE CRESCIMENTO DE
} ANIMAIS DA RAÇA GUZERÁ E SEUS CRUZAMENTOS ALIMENTADOS A PASTO, COM E SEM SUPLEMENTAÇÃO

\author{
LUÍS ORLINDO TEDESCHI \\ Engenheiro Agrônomo
}

Orientador: Prof. Dr. Celso Boin

Dissertação apresentada à Escola Superior de Agricultura "Luiz de Queiroz", da Universidade de São Paulo, para obtenção do título de Mestre em Agronomia, Área de Concentração: Ciência Animal e Pastagens.

P I R A C I C A B A

Estado de São Paulo - Brasil

Outubro de 1996 


\section{Dados Internacionais de Catalogação na Publicação (CIP)}

DIVISĀO DE BIBLIOTECA E DOCUMENTAÇĀO - Campus "Luiz de Queiroz"/USP

Tedeschi, Luis Orlindo

Determinação dos paràmetros da curva de crescimento de animais da raça guzerá e seus cruzamentos alimentados a pasto, com e sem suplementação. / Luis Orlindo Tedeschi. - - Piracicaba, 1996.

140 p. : il.

Dissertação (mestrado) - - Escola Superior de Agricultura Luiz de Queiroz, 1996.

Bibliografia.

1. Bovino - Alimentação 2. Bovino - Crescimento - Equação não linear 3. Estatistica aplicada 4. Gado Guzerá - Cruzamento I. Titulo 


\section{DETERMINAÇÃO DOS PARÂMETROS DA CURVA DE CRESCIMENTO DE ANIMAIS DA RAÇA GUZERÁ E SEUS CRUZAMENTOS ALIMENTADOS A PASTO, COM E SEM SUPLEMENTAÇÃO}

LUÍS ORLINDO TEDESCHI

Aprovada em: $\underline{03 \text { de Dezembro de } 1996}$

Comissão julgadora:

Prof. Dr. Celso Boin

Prof. Dr. Irineu Umberto Packer

Dr. Alexander George Razook
EMBRAPA/CNPGC

ESALQ/USP

IZ/Sertãozinho

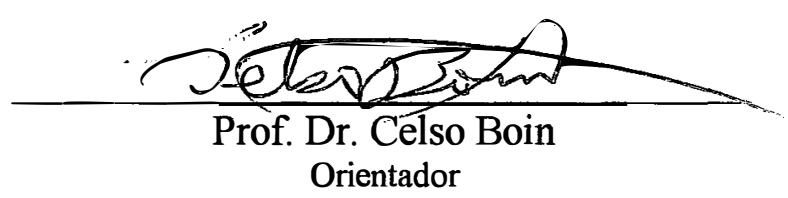


Aos meus pais, Naur e Dolores, e meus irmãos, Fábio Antônio e

Adriana,

pelo amparo e otimismo em todos os momentos da minha vida,

\title{
DEDICO
}

\begin{abstract}
À Eloisa,
minha eterna musa e doce

companheira,
\end{abstract}

OFEREÇO

"Sábio é aquele que sabe tudo de alguma coisa e alguma coisa de tudo" 


\section{AGRADECIMENTOS}

Em primeira instância agradeço aos meus pais por tornarem todos os meus sonhos realidade, incluindo essa obra, sem medirem esforços. São a eles, os verdadeiros autores de todos os meus intentos sem os quais nada seria exeqüível, que agradeço muito.

Ao professor Celso Boin por ter sido um exímio orientador, pela confiança e oportunidade na realização dessa obra, pelos seus ensinamentos magistrais, seus hábeis conselhos e toda a sua valiosa dedicação para o meu aprendizado.

Aos pesquisadores Romeu F. Nardon e Paulo R. Leme que, magnificamente, conduziram a parte de campo desse experimento nas dependências da Estação Experimental de Zootecnia de Andradina (SP) e permitiram que os dados obtidos fossem utilizados para confeccionar essa obra.

Ao suporte financeiro da Fundação Coordenação de Aperfeiçoamento de Pessoal de Nível Superior (CAPES) para o aprimoramento de meus estudos e realização dessa obra.

Aos auxiliares técnicos José Carlos M. Rasteiro, Mitsuharu Kuriama e Valfrido V. Lemos, aos campeiros Deraldo Manoel, Elízio Alves e Adércio Palomares, e aos tratadores Pedro Daniel e Sebastião F. do Amaral pela importante ajuda na condução desse experimento.

A todas as pessoas que de uma forma ou de outra ajudaram na elaboração dessa obra. $A$ todos sou extremamente grato, porque sem vocês nada seria factível.

Agradeço. 


\section{SUMÁRIO}

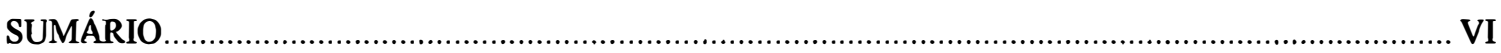

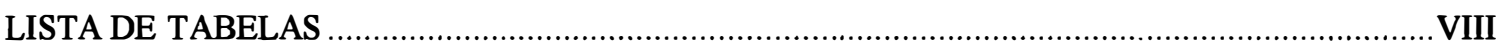

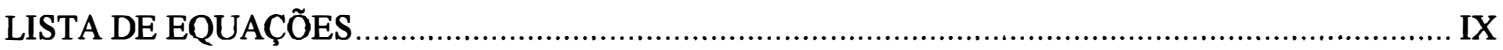

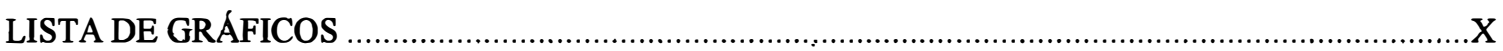

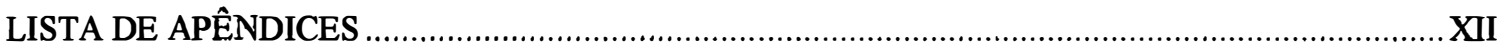

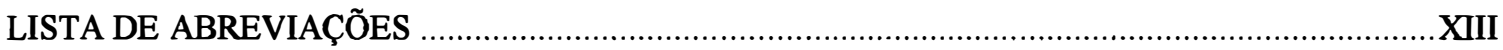

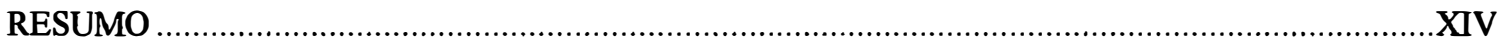

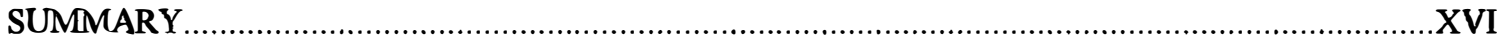

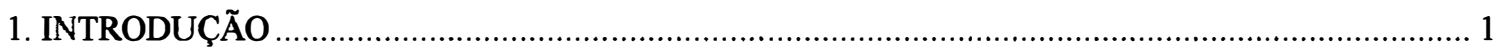

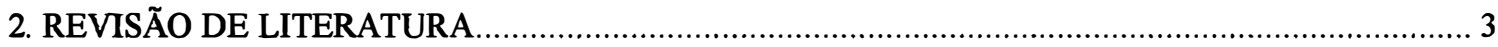

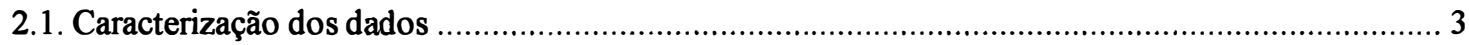

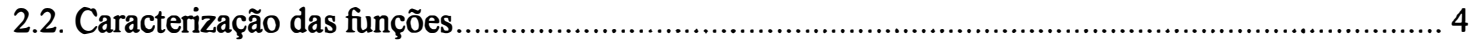

2.2.1. Interpretação biológica dos parâmetros das funções............................................................13

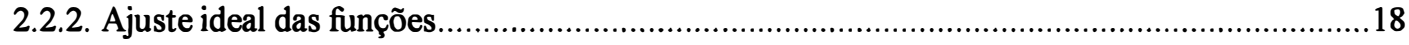

2.3. Relações entre os parâmetros das funções................................................................................21

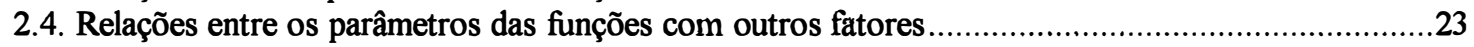

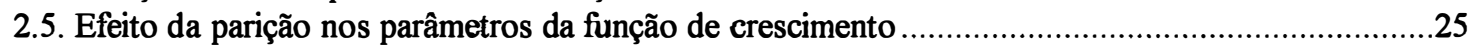

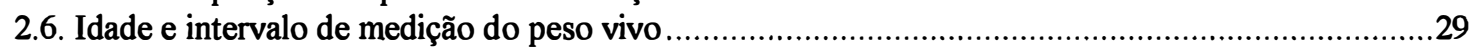

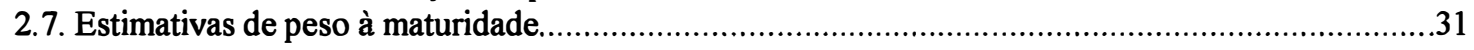

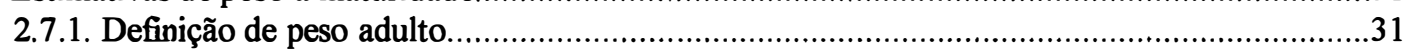

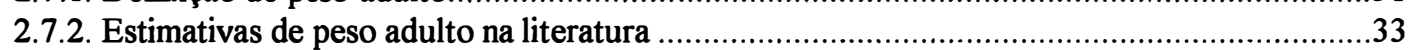

2.7.3. Alguns aspectos de herdabilidade $\left(\mathrm{h}^{2}\right)$ para os parâmetros das funções.................................40

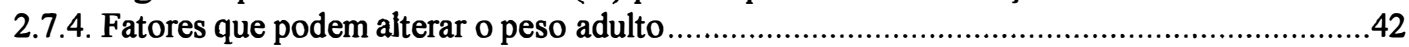

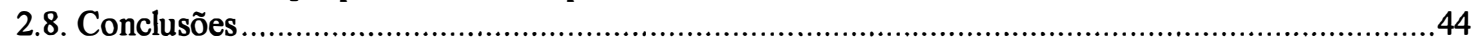

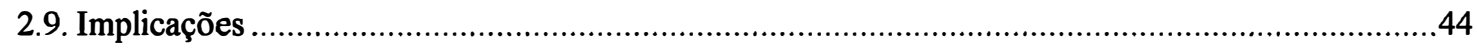

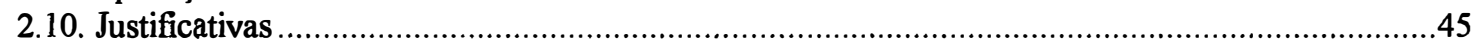

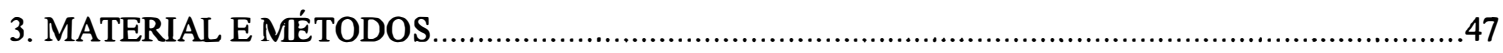

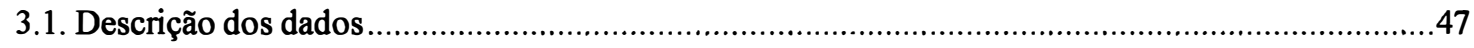

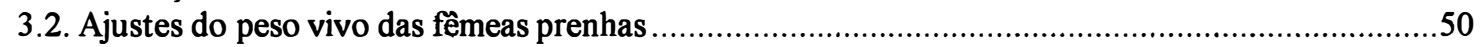

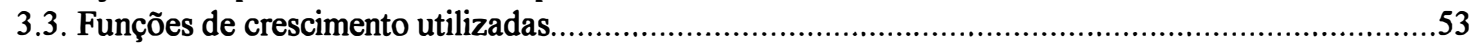

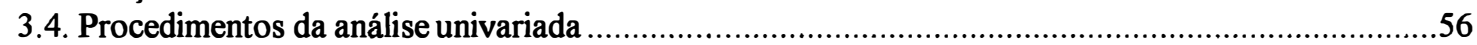

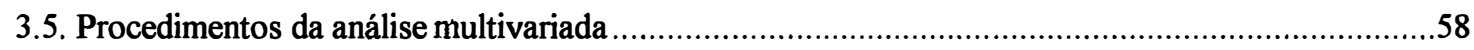

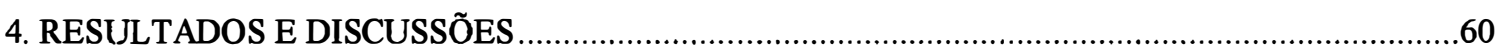

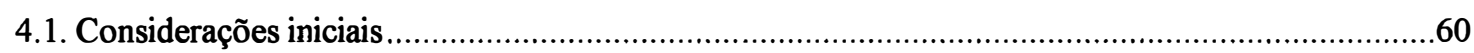

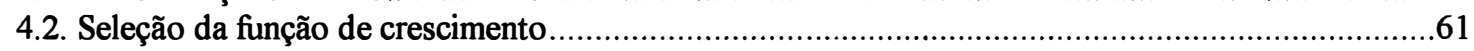

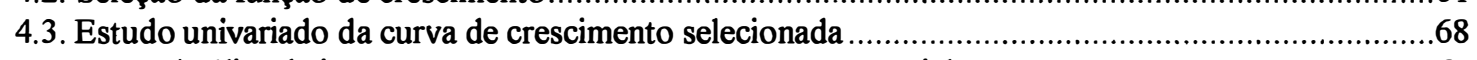

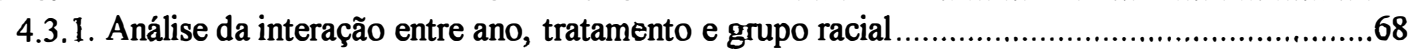


4.3.2. Análise da interação entre grupos raciais e sexos.............................................................72

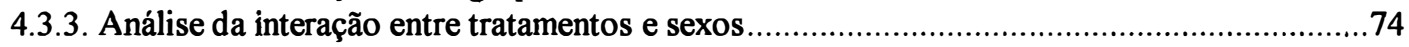

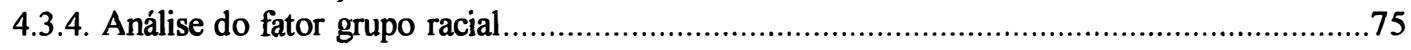

4.3.5. Estudo do efeito de parição nos parâmetros da função de crescimento ..................................76

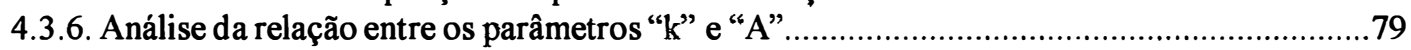

4.3.7. Comparação entre a média dos parâmetros e os parâmetros médios ....................................83

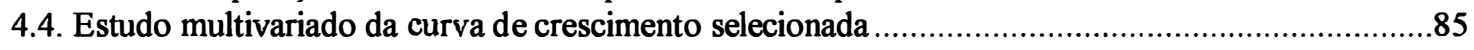

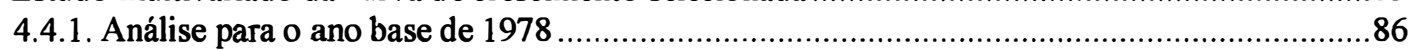

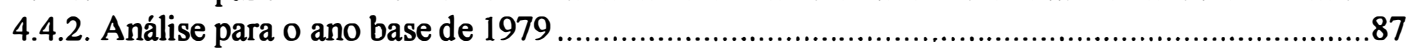

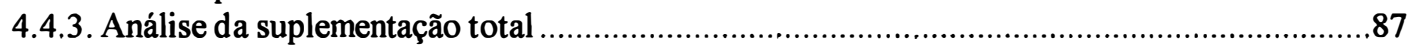

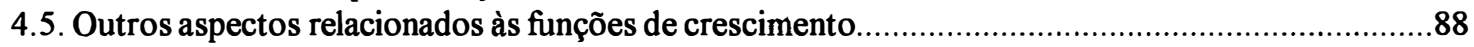

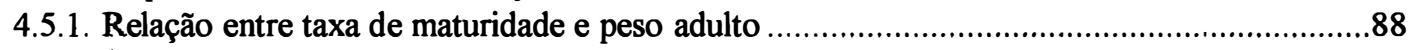

4.5.2. Comparação entre os métodos de estimativa da taxa de maturidade ....................................91

4.5.3. Cálculo do número de repetições para experimentos futuros .............................................92

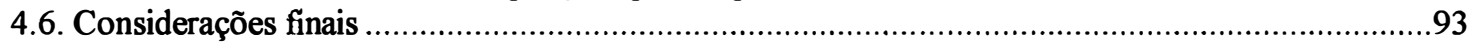

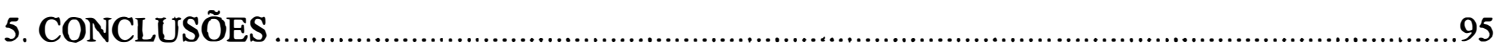

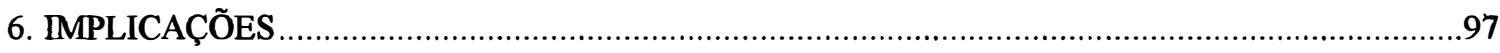

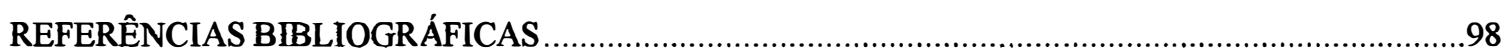




\section{LISTA DE TABELAS}

Tabela 1. Polinômio para ajuste de peso em relação a idade.

Tabela 2. Modelo matemático de três estágios para descrever crescimento de bovinos............................. 7

Tabela 3. Variância residual do ajuste de funções de crescimento para animais $1 / 4$ Zebu $\times 3 / 4$ Holstein. ......... 7

Tabela 4. Equações e propriedades para os casos especiais da função de Richards. ................................12

Tabela 5. Taxas de crescimento médias e instantâneas da função de Richards. .......................................14

Tabela 6. Médias ajustadas por quadrado mínimo do peso adulto e taxa de maturidade em diversas idades para grupos de parição e geral.

Tabela 7. Médias ajustadas por quadrado mínimo para peso adulto e taxa de maturidade para relação idade e grupo de parição.

Tabela 8. Peso adulto e taxa de maturidade estimados de acordo com a função empregada e freqüência de pesagens.

Tabela 9. Peso de referência padrão possíveis (SRW, kg) para a predição de composição corporal de ganhos de peso vazio de várias raças de bovinos.

Tabela 10. Resultados das funções de crescimento de machos e fềmeas Nelore........................................34

Tabela 11. Efeito de raças na eficiência produtiva durante três anos........................................................37

Tabela 12. Coeficientes de regressão das características maternais em relação ao peso adulto de vacas Red Poll.

Tabela 13. Número de animais utilizados para ajuste individual das funções de crescimento......................50

Tabela 14. Funções de crescimento utilizadas para ajuste dos dados. ....................................................54

Tabela 15. Cálculo das percentagens de convergência dos machos para cada função fixando-se o valor máximo de peso adulto.

Tabela 16. Cálculo das percentagens de convergência das fềmeas sem correção de peso fetal e tecidos anexos da placenta para cada função fixando-se o valor máximo de peso adulto.

Tabela 17. Cálculo das percentagens de convergência das fềmeas com correção de peso fetal e tecidos anexos da placenta para cada função fixando o valor máximo de peso adulto.

Tabela 18. Níveis de significância entre as variáveis para seleção da função e dos parâmetros das funções de crescimento.

Tabela 19. Médias ajustadas dos fatores para seleção da função de crescimento.

Tabela 20. Efeito de tratamento dentro de grupo racial nas variáveis peso adulto e taxa de maturidade para o ano de 1978.

Tabela 21. Efeito de tratamento dentro de grupo racial nas variáveis peso adulto e taxa de maturidade para o ano de 1979.

Tabela 22. Efeito de grupo racial dentro de tratamento para os parâmetros peso adulto e taxa de maturidade nos anos de 1978 e 1979

Tabela 23. Efeito de grupo racial dentro de sexo para os parâmetros de peso adulto e taxa de maturidade.

Tabela 24. Efeito de sexo dentro de grupo racial para os parâmetros de peso adulto e taxa de maturidade

Tabela 25. Efeito de sexo dentro de tratamento e de tratamento dentro de sexo para os parâmetros taxa de maturidade e o fator de integração.

Tabela 26. Quadro de análise de variância com o fator de parição..........................................................76

Tabela 27. Efeito de grupo racial na taxa de maturidade e no fator de integração em cada sexo para 0 modelo estatístico com efeito de parição.

Tabela 28. Diversos valores para as variáveis da Equação 17

Tabela 29. Coeficientes obtidos para o numerador da Equação 20.

Tabela 30. Comparação entre a média dos parâmetros para cada animal e os parâmetros médios estimados para os grupos de animais.

Tabela 31. Valores para as variáveis da Equação 17 para todas as funções Ajustadas.

Tabela 32. Estimativa do número necessário de repetições para experimentos futuros, variando o nível de significância e poder do teste para três diferenças percentuais entre tratamentos. 


\section{LISTA DE EQUAÇÕES}

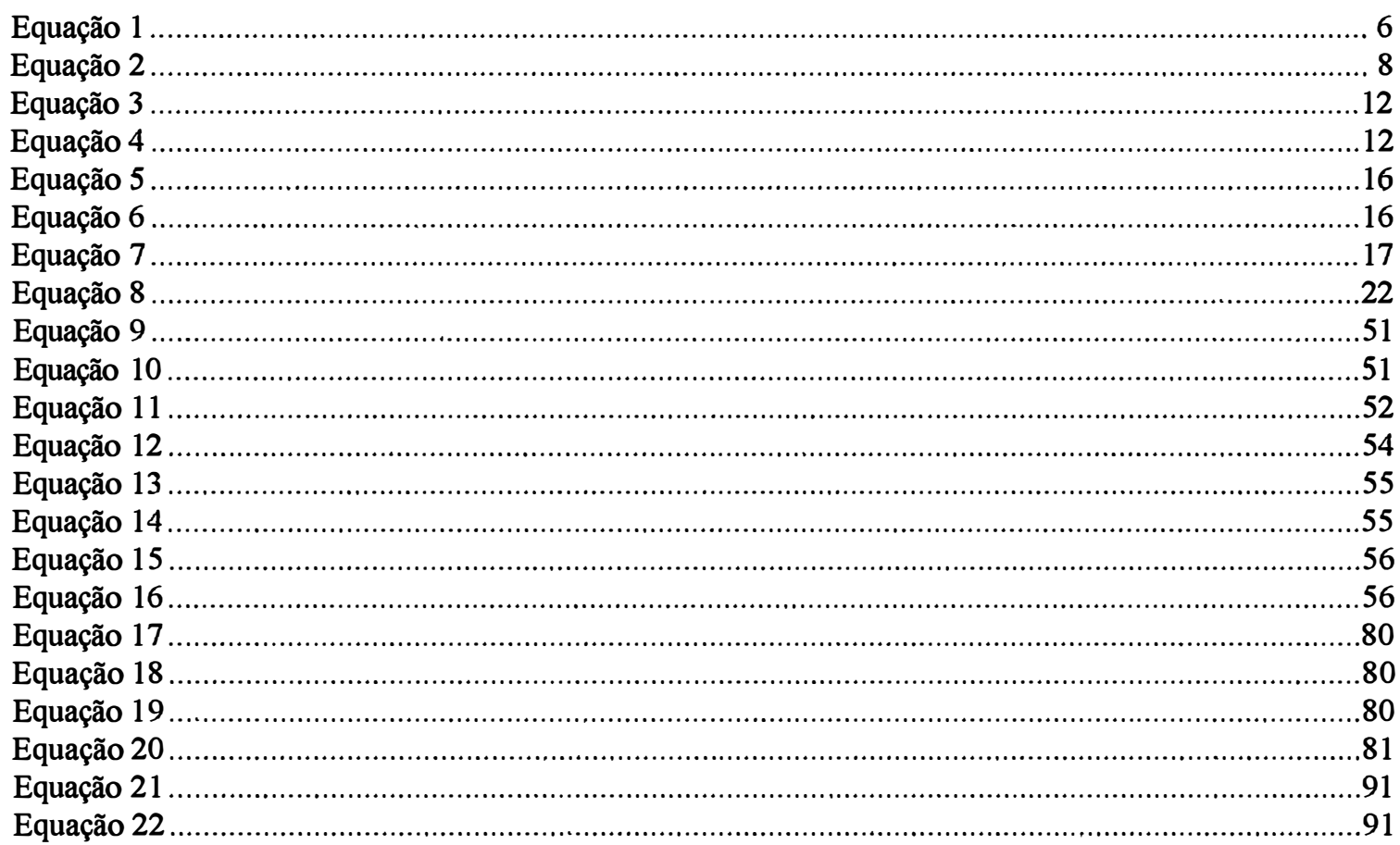




\section{LISTA DE GRÁFICOS}

Gráfico 1. Estimativa da evolução do peso do feto e dos tecidos anexos da placenta..................................52

Gráfico 2. Regressão entre o peso adulto (A) e a taxa de maturidade (k)...........................................82

Gráfico 3. Curvas da relação entre o peso adulto (A) e a taxa de maturidade (k) das funções de

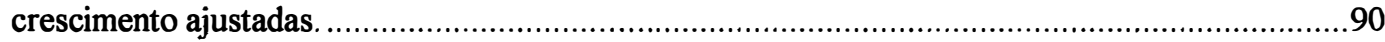

Gráfico 4. Curva de crescimento da raça Guzerá (G) sem suplementação (S1) e com suplementação na seca (S2), ano de 1978

Gráfico 5. Curva de crescimento da raça $3 / 4$ Guzerá x $1 / 4$ Pardo Suíço ( $3 / 4 \mathrm{GS}$ ) sem suplementação (S1) e com suplementação na seca (S2), ano de 1978.

Gráfico 6. Curva de crescimento da raça 1/2Nelore x 1/4Guzerá x 1/4Pardo Suíço (1/2N(SG)) sem suplementação (S1) e com suplementação na seca (S2), ano de 1978 .....................................116

Gráfico 7. Curva de crescimento da raça $1 / 2$ Guzerá $x 1 / 2$ Pardo Suíço (SG) sem suplementação (S1) e

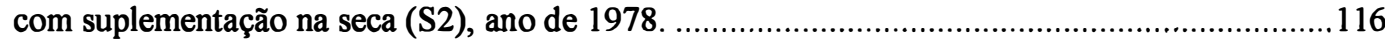

Gráfico 8. Curva de crescimento da raça $1 / 2$ Chianina $\times 1 / 4$ Guzerá $x$ 1/4Pardo Suíço (1/2C(SG)) sem suplementação (S1) e com suplementação na seca (S2), ano de 1978

Gráfico 9. Curva de crescimento da raça Guzerá (G) sem suplementação (S1), com suplementação na seca (S2) e durante o ano (S3), ano de 1979.

Gráfico 10. Curva de crescimento da raça $3 / 4$ Guzerá x $1 / 4$ Pardo Suíço (3/4GS) sem suplementação (S1), com suplementação na seca (S2) e durante o ano (S3), ano de 1979

Gráfico 11. Curva de crescimento da raça $1 / 2$ Nelore x $1 / 4$ Guzerá x $1 / 4$ Pardo Suíço $(1 / 2 \mathrm{~N}(\mathrm{SG}))$ sem suplementação (S1), com suplementação na seca (S2) e durante o ano (S3), ano de 1979.

Gráfico 12. Curva de crescimento da raça $1 \frac{1}{2}$ Guzerá $x$ 1/2Pardo Suíço (SG) sem suplementação (S1) e com suplementação na seca (S2), ano de 1979.

Gráfico 13. Curva de crescimento da raça $1 / 2$ Chianina x $1 / 4$ Guzerá x $1 / 4$ Pardo Suíço $(1 / 2 C(S G))$ sem suplementação (S1) e com suplementação na seca (S2), ano de 1979.

Gráfico 14. Curva de crescimento da raça $1 / 2$ Caracú $x$ 1/2Guzerá (KG) sem suplementação (S1) e com suplementação na seca (S2), ano de 1979.

Gráfico 15. Curva de crescimento da raça $1 / 2$ Caracú $x$ 1/4Guzerá x $1 / 4$ Pardo Suíço ( $1 / 2 \mathrm{~K}(\mathrm{SG})$ ) sem suplementação (S1) e com suplementação na seca (S2), ano de 1979.

Gráfico 16. Curva de crescimento das raças G, 3/4GS, 1/2N(SG), SG e 1/2C(SG) sem suplementação (S1), ano de 1978.

Gráfico 17. Curva de crescimento das raças $\mathrm{G}, 3 / 4 \mathrm{GS}, 1 / 2 \mathrm{~N}(\mathrm{SG}), \mathrm{SG}^{1} 1 / 2 \mathrm{C}(\mathrm{SG})$ com suplementação na seca (S2), ano de 1978.

Gráfico 18. Curva de crescimento das raças $\mathrm{G}, 3 / 4 \mathrm{GS}, 1 / 2 \mathrm{~N}(\mathrm{SG}), \mathrm{SG}, 1 / 2 \mathrm{C}(\mathrm{SG}), \mathrm{KG}$ e $1 / 2 \mathrm{~K}(\mathrm{SG})$ sem suplementação (S1), ano de 1979.

Gráfico 19. Curva de crescimento das raças G, 3/4GS, 1/2N(SG), SG, $1 / 2 \mathrm{C}(\mathrm{SG}), \mathrm{KG}$ e $1 / 2 \mathrm{~K}(\mathrm{SG})$ com

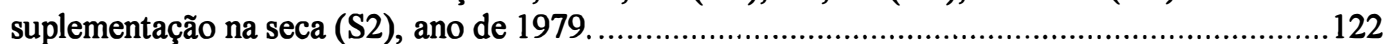

Gráfico 20. Curva de crescimento das raças G, $3 / 4 \mathrm{GS}$ e $1 / 2 \mathrm{~N}(\mathrm{SG})$ com suplementação durante o ano (S3), ano de 1979.

Gráfico 21. Curva de crescimento dos machos (M) das raças G, 3/4GS, 1/2N(SG), $\mathrm{SG}, 1 / 2 \mathrm{C}(\mathrm{SG}), \mathrm{KG}$ e $1 / 2 \mathrm{~K}(\mathrm{SG})$.

Gráfico 22. Curva de crescimento das fềmeas sem correção $(F)$ do peso fetal e tecidos anexos da placenta das raças G, 3/4GS, 1/2N(SG), SG, $1 / 2 \mathrm{C}(\mathrm{SG}), \mathrm{KG}$ e $1 / 2 \mathrm{~K}(\mathrm{SG})$..

Gráfico 23. Curva de crescimento das fềmeas com correção $\left(F_{a j}\right)$ do peso fetal e tecidos anexos da

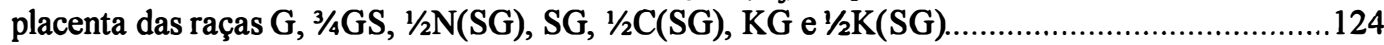

Gráfico 24. Curva de crescimento da raça Guzerá $(G)$ para os machos $(M)$, fềmeas sem $(F)$ e com $\left(F_{a j}\right)$ correção do peso fetal.

Gráfico 25. Curva de crescimento da raça $3 / 4$ Guzerá x $1 / 4$ Pardo Suíço $(3 / 4 \mathrm{GS})$ para os machos $(\mathrm{M})$, fêmeas sem $(F)$ e com $\left(F_{a j}\right)$ correção do peso fetal.

Gráfico 26. Curva de crescimento da raça $1 / 2$ Nelore $\times 1 \frac{1}{4}$ Guzerá $\times 1 / 4$ Pardo Suíço (1/2N(SG)) para os machos $(M)$, fềmeas sem $(F)$ e com $\left(F_{a j}\right)$ correção do peso fetal. 
Gráfico 27. Curva de crescimento da raça $1 / 2$ Guzerá x $1 / 2$ Pardo Suíço (SG) para os machos (M), fêmeas $\operatorname{sem}(\mathrm{F})$ e com $\left(\mathrm{F}_{\mathrm{aj}}\right)$ correção do peso fetal..

Gráfico 28. Curva de crescimento da raça $1 / 2$ Chianina $\times 1 / 4$ Guzerá $x$ 1/4Pardo Suíço $(1 / 2 C(S G)$ ) para os machos $(\mathrm{M})$, fêmeas sem $(\mathrm{F})$ e com $\left(\mathrm{F}_{\mathrm{aj}}\right)$ correção do peso fetal...

Gráfico 29. Curva de crescimento da raça $1 / 2$ Caracú x $1 / 2$ Guzerá $(K G)$ para os machos $(\mathrm{M})$, fềmeas sem

(F) e com $\left(F_{a j}\right)$ correção do peso fetal.

Gráfico 30. Curva de crescimento da raça $1 / 2$ Caracú x 1/4Guzerá x $1 / 4$ Pardo Suíço ( $1 / 2 \mathrm{~K}(\mathrm{SG})$ ) para os machos $(\mathrm{M})$, fêmeas sem $(\mathrm{F})$ e com $\left(\mathrm{F}_{\mathrm{aj}}\right)$ correção do peso fetal.........................................128

Gráfico 31. Curva de crescimento dos machos $(M)$, fêmeas sem $(F)$ e com $\left(F_{a j}\right)$ correção do peso fetal sem suplementação.

Gráfico 32. Curva de crescimento dos machos $(M)$, fêmeas sem $(F)$ e com $\left(F_{a j}\right)$ correção do peso fetal com suplementação na seca.

Gráfico 33. Curva de crescimento dos machos $(M)$, fêmeas sem $(F)$ e com $\left(F_{a j}\right)$ correção do peso fetal com suplementação durante o ano. ....

Gráfico 34. Curva de crescimento dos machos (M) sem suplementação (S1), com suplementação na

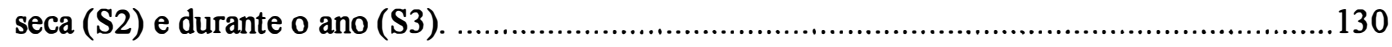

Gráfico 35. Curva de crescimento das fêmeas sem correção do peso fetal (F) sem suplementação (S1),

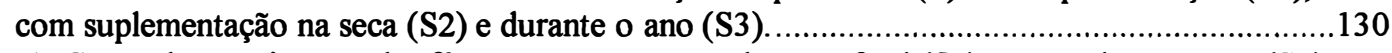

Gráfico 36. Curva de crescimento das fêmeas com correção do peso fetal $\left(\mathrm{F}_{\mathrm{aj}}\right)$ sem suplementação $(\mathrm{S} 1)$,

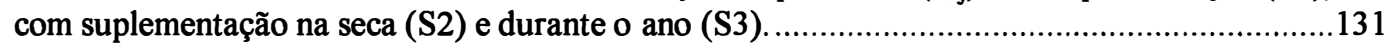

Gráfico 37. Curva de crescimento das raças G, 3/4GS, $1 / 2 \mathrm{~N}(\mathrm{SG}), \mathrm{SG}, 1 / 2 \mathrm{C}(\mathrm{SG}), \mathrm{KG}$ e $1 / 2 \mathrm{~K}(\mathrm{SG}) \ldots \ldots \ldots \ldots \ldots . . . .131$

Gráfico 38. Curva de crescimento das fêmeas sem correção (F) do peso fetal para animais sem parição (P1), parição aos 3 anos (P2) e aos 3 e 4 anos (P3).

Gráfico 39. Curva de crescimento das fêmeas com correção $\left(\mathrm{F}_{\mathrm{aj}}\right)$ do peso fetal para animais sem parição (P1), parição aos 3 anos (P2) e aos 3 e 4 anos (P3).

Gráfico 40. Curva de crescimento dos machos e das fềmeas sem $(F)$ e com $\left(F_{a j}\right)$ correção do peso vivo para o peso fetal e tecidos anexos para o ano de 1978.

Gráfico 41. Curva de crescimento dos animais sem suplementação (S1) e com suplementação durante o inverno (S2) para o ano de 1978.

Gráfico 42. Curva de crescimento dos machos e das fềmeas sem $(F)$ e com $\left(F_{a j}\right)$ correção do peso vivo para o peso fetal e tecidos anexos para o ano de 1979.

Gráfico 43. Curva de crescimento dos grupos raciais G, 3/4GS e 1/2N(SG) para o ano ed 1979 considerando os três níveis de suplementação.

Gráfico 44. Curva de peso-idade de fềmeas $\left(\mathrm{F}_{\mathrm{aj}}\right)$ da raça Guzerá $(\mathrm{G})$, nascidas em 1978, para os três tipos de suplementação ( $\mathrm{S} 1, \mathrm{~S} 2$ e S3).

Gráfico 45. Curva de peso-idade de fêmeas $\left(F_{a j}\right)$ da raça $3 / 4$ Guzerá $x$ 1/4Pardo Suíço $(3 / 4 \mathrm{GS})$, nascidas em 1978, para os três tipos de suplementação (S1, S2 e S3)...

Gráfico 46. Curva de peso-idade de fêmeas $\left(\mathrm{F}_{\mathrm{aj}}\right)$ da raça $1 / 2$ Nelore x $1 / 4$ Guzerá x $1 / 4$ Pardo Suíço $(1 / 2 \mathrm{~N}(\mathrm{SG})$ ), nascidas em 1978, nos três tipos de suplementação ( $\mathrm{S} 1, \mathrm{~S} 2$ e $\mathrm{S} 3$ ).

Gráfico 47. Curva de peso-idade de fềmeas $\left(\mathrm{F}_{\mathrm{aj}}\right)$, nascidas em 1977, das raças $\mathrm{G}, 3 / 4 \mathrm{GS}, 1 / 2 \mathrm{~N}(\mathrm{SG}), \mathrm{SG}$ e

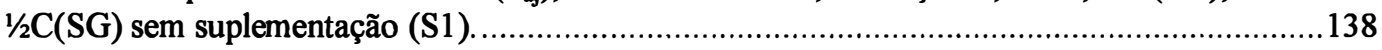

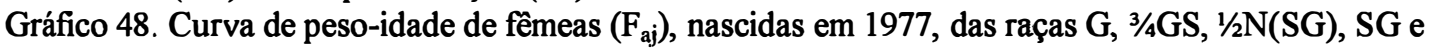

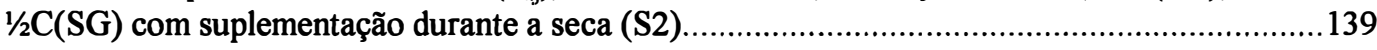

Gráfico 49. Curva de peso-idade de fềmeas $\left(\mathrm{F}_{\mathrm{aj}}\right)$, nascidas em 1978, das raças $\mathrm{G}, 3 / 4 \mathrm{GS}, 1 / 2 \mathrm{~N}(\mathrm{SG}), \mathrm{SG}$,

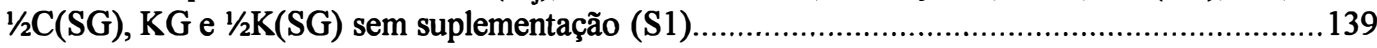

Gráfico 50. Curva de peso-idade de fềmeas $\left(\mathrm{F}_{\mathrm{aj}}\right)$, nascidas em 1978, das raças $\mathrm{G}, 3 / 4 \mathrm{GS}, 1 / 2 \mathrm{~N}(\mathrm{SG}), \mathrm{SG}$, $1 / 2 \mathrm{C}(\mathrm{SG}), \mathrm{KG}$ e $1 / 2 \mathrm{~K}(\mathrm{SG})$ com suplementação durante a seca (S2). ...................................... 140

Gráfico 51. Curva de peso-idade de fềmeas $\left(\mathrm{F}_{\mathrm{aj}}\right)$, nascidas em 1978, das raças $\mathrm{G}, 3 / 4 \mathrm{GS}, 1 / 2 \mathrm{~N}(\mathrm{SG}), \mathrm{SG}$, $1 / 2 \mathrm{C}(\mathrm{SG}), \mathrm{KG}$ e $1 / 2 \mathrm{~K}$ (SG) com suplementação durante o ano (S3). 


\section{LISTA DE APÊNDICES}

Apêndice 1. Derivadas primeira das funções de crescimento. 109

Apêndice 2. Quadro de análise de variância e nivel de significância de cada parâmetro das sete funções estudadas. .

Apêndice 3. Coeficientes de correlação de Pearson entre os parâmetros das sete funções de crescimento estudadas.

Apêndice 4. Parâmetros médios para cada grupo racial através da função de Gompertz.

Apêndice 5. Gráficos das funções de crescimento de Gompertz.

Apêndice 6. Resumo dos parâmetros peso adulto e da taxa de maturidade de várias raças e sexos para diferentes funções de crescimento encontrados por diversos pesquisadores.

Apêndice 7. Gráficos de peso-idade médio dos animais estudados. 


\title{
DETERMINAÇÃO DOS PARÂMETROS DA CURVA DE CRESCIMENTO DE ANIMAIS DA RAÇA GUZERÁ E SEUS CRUZAMENTOS ALIMENTADOS A PASTO, COM E SEM SUPLEMENTAÇÃO
}

\author{
Autor: Luís Orlindo Tedeschi \\ Orientador: Prof. Dr. Celso Boin
}

\section{RESUMO}

O presente trabalho teve por finalidade estudar o comportamento dos parâmetros da curva de crescimento de 151 machos e 147 fêmeas dos grupos raciais Guzerá, 3/4Guzerá x 1/4Pardo Suíço, 1/2Nelore x 1/4Guzerá x 1/4Pardo Suíço, 1/2Guzerá x 1/2Pardo Suíço, 1/2Chianina x 1/4Guzerá x 1/4Pardo Suíço, 1/2Caracú x 1/2Guzerá e 1/2Caracú x 1/4Guzerá x 1/4Pardo Suíço submetidos a três tipos de suplementações: sem, com suplementação durante o período da seca e com suplementação durante o ano todo. Para tanto foram ajustados as seguintes funções de crescimento: Brody, Gompertz, Logística, von Bertalanffy, Richards e algumas variações de Brody e Gompertz. A função de Gompertz foi selecionada por apresentar menor desvio de regressão, menor variação residual, maior coeficiente de determinação, menor variação entre os parâmetros dos animais, maior convergência e valor do peso assintótico (" $A$ ") compatível com o peso adulto observado dos animais. De forma geral, as suplementações no inverno e durante o ano, não afetaram a estimativa de peso adulto, entretanto, a taxa de maturidade ("k") foi modificada. Foram verificadas interações significativas entre os efeitos de ano, suplementação e raça, e raça e sexo para o peso adulto e para a taxa de maturidade. Para a taxa de maturidade e para o parâmetro de integração ("b") foram verificadas interações significativas entre suplementação e sexo. O efeito de raça foi significativo apenas para o parâmetro de integração. O peso adulto, taxa de maturidade e o parâmetro "b" das fêmeas estimados a partir do peso vivo corrigido para o peso fetal e dos tecidos anexos da placenta, não foi estatisticamente diferente das fêmeas sem correção. A parição afetou o peso adulto e a taxa de 
maturidade, de forma que as fêmeas que não pariram apresentaram maior peso adulto e menor taxa de maturidade. A relação entre peso adulto e taxa de maturidade apresentou alta correlação e uma equação alométrica para estimar a taxa de maturidade através do peso adulto foi obtida. As regressões entre peso adulto e taxa de maturidade para todas as funções de crescimento não apresentaram o mesmo comportamento, entretanto, conforme o peso adulto aumentava a taxa de maturidade diminuía. 


\title{
DETERMINATION OF THE GROWTH CURVES PARAMETERS OF GUZERA AND THEIR CROSSBREEDS FED UNDER GRAZING WITH OR WITHOUT SUPPLEMENTATION
}

\author{
Author: Luís Orlindo Tedeschi \\ Adviser: Prof. Dr. Celso Boin
}

\section{SUMMARY}

This work was conducted to evaluate the influence of feed supplementation (without, dry season and during whole year) on nonlinear growth curve parameters of 151 male and 147 female from Guzera bred and their crossbreeds $\left(\frac{3}{4}\right.$ Guzera $x \quad 1 / 4$ Brown Swiss, $1 / 2$ Nelore $x$ $1 / 4$ Guzera $x$ 1/4B Brown Swiss, 1/2Guzera $x$ 1/2Brown Swiss, 1/2Chianina $x$ 1/4Guzera $x$ $1 / 4$ Brown Swiss, $1 / 2$ Caracu $x \frac{1}{1 / 2 G u z e r a}$ and $1 / 2$ Caracu $x \quad 1 / 4$ Guzera $x$ 1/4Brown Swiss). The following nonlinear growth curves were used: Brody, Gompertz, Logistic, von Bertalanffy, Richards and some variations from Brody and Gompertz. The Gompertz growth curve showed small regression deviation, residual sum of squares and difference between parameters among animals, and large $\mathrm{R}^{2}$ and curve convergence. The Gompertz mature weight estimates were closer of animals mature weight observed than other curves. The feed supplementation trials did not influence the estimate of mature weight however the maturing rate was changed. There were significant statistics interactions to year, supplementation and crossbreed effects, and crossbreed and sex effects on mature weight (" $A$ ") and maturing rate (" $k$ "). Supplementation and sex effects on " $k$ " and integration parameter (" $b$ "); and crossbreed effect on " $b$ ". The female weights were adjusted to gravid uterus, nevertheless no significant differences were observed between adjusted and no adjusted female mature weights, maturing rate and integration parameter. Calving status changed mature weights and maturing rates. The regression between mature weights and maturing rates was significant and showed high $\mathrm{R}^{2}$ therefore allometric relation between mature weights and maturing rates was derived from all data. When mature weight increases, the maturing rate decreases to all growth curves, however, the regression parameters' values were different between growth curves. 


\section{INTRODUÇÃO}

o conhecimento e controle dos mecanismos de crescimento e desenvolvimento dos ruminantes, principalmente dos bovinos, é um assunto que vem sendo pesquisado através dos tempos, e que ainda permanece um tanto quanto obscuro, sem um domínio completamente definido. Sabe-se que muitas variáveis podem modificar o crescimento do animal, tanto genéticas (sexo e raça) como ambientais (estação de parição e manejo de alimentação). Dessa forma o conhecimento dos padrões de crescimento de uma determinada raça, em várias condições de crescimento, pode ajudar no manejo de alimentação, além do uso dos dados para simulações com projeções de interesse econômico.

Uma das principais finalidades desse conhecimento, através da modelagem dos dados das curvas, é a estimativa da exigência nutricional, a qual pode ser fornecida pela simulação da composição corporal durante as diversas fases de crescimento do animal. Essa simulação não seria possível sem o prévio conhecimento dos parâmetros de crescimento do grupo de animais, tanto do peso adulto como das respectivas taxas de crescimento relativas.

Funções de crescimento são equações não lineares que tentam refletir as relações de crescimento inerente de várias partes do organismo animal, até a sua finalização com a maturidade, durante a sua vida em situações ambientais distintas.

De forma geral, as funções de crescimento condensam grande quantidade de informações inerente ao animal durante toda a sua vida em, no máximo, 4 parâmetros não lineares que podem ser interpretados biológicamente. Portanto, a associação desses parâmetros às características produtivas, geram dados que permitem o conhecimento das exigências do animal (WEBSTER et al., 1982), e quando associados às 
características reprodutivas permitem 0 controle de programas de seleções de raças para uma determinada característica desejada (Brown et al., 1972; Fitzhugh 1976; Rosa et al., 1979).

Existem algumas razões para o estudo das funções de crescimento e suas possíveis mudanças na forma da curva, dentre elas estão: (1.) solução dos problemas genéticos entre o crescimento rápido e eficiente das progênies até o abate com menor tamanho corporal e baixo custo de mantença dos pais, (2.) melhoria na eficiência através do aumento da taxa de maturidade - menor tempo para atingir o peso adulto e conseqüentemente a composição corporal desejada, (3.) redução de distocia devido a redução do tamanho do bezerro, ao nascimento, relativo ao tamanho da mãe, (4.) menor idade na primeira cobertura através da diminuição da maturidade sexual e, finalmente, (5.) diminuição da percentagem de gordura na carcaça devido ao aumento do tempo da maturidade química, assumindo que existe uma correlação genética positiva entre precocidade de maturidade e avanço na composição corporal ou mesmo hormonal do animal.

Com isso, os objetivos desse estudo são de prover um conhecimento dos parâmetros que descrevem o crescimento de bovinos, fornecendo ferramentas para avaliar taxas de crescimento adequada e parâmetros genéticos para avaliação de programas de melhoramento, efetuando também, uma comparação entre épocas de suplementação e o seu efeito nos parâmetros de crescimento.

Nesse trabalho serão utilizadas várias funções ou curvas de crescimento apenas para ajuste dos dados e seleção da função apropriada, sendo que não é de interesse a comparação na eficiência de convergência entre as funções ajustadas, uma vez que, a quantidade de dados não é suficientemente grande para suportar esse nível de análise. 


\section{REVISÃO DE LITERATURA}

\subsection{Caracterização dos dados}

As funções de crescimento geralmente lembram curvas sigmóides para representar a sequiência de medidas de tamanho em relação ao tempo. Entretanto, um termo mais correto seria a utilização da denominação funções de peso-idade, pois nem todas as funções que serão abordadas possuem um formato sigmóide tal como a função de Richards (Richards, 1959) .

Os dados que são utilizados para determinações das funções pesoidade podem ser de origem univariada, quando, apenas dados de peso em determinadas idades são obtidas, ou multivariadas quando mais de uma variável é medida na mesma idade. Nesse caso podemos ter peso, altura, largura, etc. Tanto uma quanto a outra, são categorizadas em três classes distintas de dados e suas respectivas combinações (Fitzhugh, 1976):

Estática: quando uma medida é tomada apenas uma única vez para um determinado grupo de animais, sendo que todos possuem a mesma idade ou estágio de crescimento. Como exemplo temos a coleta de pesos à desmama para estimar a sua herdabilidade.

Representativo: cada individuo é medido apenas uma única vez, entretanto, as mesmas medidas são feitas em outras idades em animais distintos da mesma população. Como exemplo temos a estimativa de composição corporal, que é realizada através de abates consecutivos (comparativos) de animais da mesma população, sendo esses considerados homogêneos. 
Longitudinal: nesse caso, todas as medidas utilizadas são obtidas do mesmo animal em todas as idades avaliadas. Esses tipos de dados compreendem todas as informações que podem ser obtidas com dados estáticos ou representativos mais a variação individual.

Além desses três tipos básicos de dados podemos obter dados mistos, geralmente associados com perdas de animais ou idades, ou ambos. A recomendação para análise desses tipos de dados é a eliminação de dados perdidos, e análise normal como se fossem um dos três casos citados acima, embora existam algumas formas de se analisar dados perdidos, cujos métodos podem ser encontrados em Tanner ${ }^{1}$.

É evidente que, os dados longitudinais são os dados que apresentam maiores informações e portanto, são os que mais interessam do ponto de vista de ajuste de curvas peso-idade, resguardando a sua dificuldade de obtenção.

\subsection{Caracterização das funções}

Os principais objetivos do ajuste das funções peso-idade são as informações descritivas, as quais contém informações sobre o crescimento de determinado grupo de animais e a confecção de equações de predição, que servem para estimar taxas de crescimento, exigência de alimentos e repostas à seleção entre outras (Fitzhugh, 1976). Entretanto, alguns requisitos devem ser seguidos para que a função seja aceita como descritiva ou prognóstico de uma relação peso-idade. Entre esses requisitos, os parâmetros devem ser biologicamente interpretáveis e o ajuste dos dados deve ser adequado (desvios pequenos), sendo que a 
dificuldade computacional também deve ser considerada. Há casos onde as funções podem ser ajustadas matematicamente mas não apresentam uma interpretação biológica (Fitzhugh, 1976) .

o crescimento de um animal é inerente ao crescimento das partes do organismo que o compõem. Dessa forma, num determinado tempo, a função peso-idade irá representar a composição das funções de crescimento das partes do organismo que contribuem para o desenvolvimento do animal (Fitzhugh, 1976). Portanto, a melhor relação entre um determinado componente do crescimento (por exemplo: gordura) não é, necessariamente, a melhor relação para outra parte (por exemplo: proteína). Pode-se observar melhor esse fato nos modelos de simulação de composição corporal (Keele et al., 1992; Williams et al., 1992, 1995a, 1995b, 1995c). Os dados de convergência de diversos tecidos internos e externos de carneiros, mostram que a taxa de maturidade da proteína $\left(2,51 \times 10^{-4}\right)$ é maior do que a gordura $\left(2,34 \times 10^{-4}\right)$. De forma geral, as taxas de maturidade de órgãos necessários para a sobrevivência e ao metabolismo são maiores do que a de órgãos de locomoção e armazenamento (Jenkins \& Leymaster, 1993).

As funções utilizadas para ajustar peso em relação à idade podem ser tanto lineares múltiplas como não lineares. Essas últimas fornecem parâmetros, cuja, interpretação biológica é a sua principal característica.

Em 1985, Moore (1985) apresentou uma função genérica (Equação 1) para estimar a curva de crescimento de animais desde a fase embrionária até a maturidade.

Liski (1987) analisando dados de 2.136 touros da raça Ayrshire, 338 da raça Finncattle e 238 da raça Friesan entre os anos de 1965 e 1977, com intervalo de coleta de peso a cada 30 dias, comparou modelos

\footnotetext{
${ }^{1}$ TANNER,J.M. Some notes on the reporting of growth data. Human Biology, v. 23, p. 93-100, 1951.
} 
polinômiais associados a termos logarítmicos para tentar estabelecer funções de crescimento padronizadas.

\section{EQUAÇÃo 1}

$$
P V=A \cdot\left(1+e^{\left(\frac{-p_{n} \cdot \ln (t-3,5)}{A^{0,27}}\right)}\right)^{\left(\frac{-1}{0,27}\right)}
$$

onde:

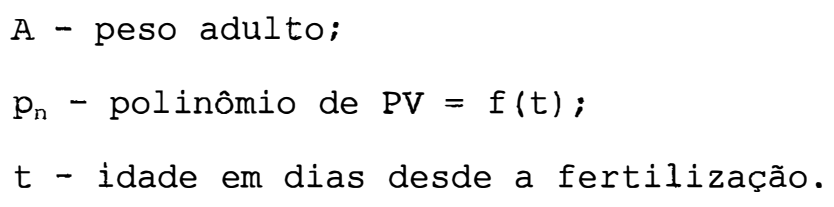

Entre as 6 funções que foram estudadas por Liski (1987), a quarta equação da Tabela 1 gerou os melhores resultados.

TAbela 1. Polinômio para ajuste de peso em relação a IDADE.

\begin{tabular}{cc}
\hline Equação & Função \\
\hline 1 & $P V=b_{0}+b_{1} \cdot t+b_{2} \cdot \ln (t)+\varepsilon$ \\
3 & $P V=b_{0}+b_{1} \cdot t+b_{2} \cdot \ln (t)+\frac{b_{3}}{t}+\varepsilon$ \\
4 & $P V=b_{0} \cdot t-b_{0}+\frac{t}{\varepsilon} \cdot t+b_{2} \cdot t^{2}+b_{3} \cdot \ln (t)+\varepsilon$ \\
5 & $P V=b_{0} \cdot t^{\left(b_{1}\right)} \cdot e^{\left(b_{2} \cdot t+b_{3} \cdot t^{2}\right)}+\varepsilon$ \\
6 & $P V=b_{0} \cdot t^{\left(b_{1}\right)} \cdot e^{\left(b_{2} \cdot t\right)}+\varepsilon$
\end{tabular}


Para a quarta função, os valores de $b_{1}, b_{2}, b_{3}$ são respectivamente 1,98; - 0,0012 e -57,44; sendo que $b_{0}$ representa o peso no tempo zero, ou seja, peso ao nascer e $\varepsilon$ representa o erro aleatório não observável (Liski, 1987).

Outro estudo conduzido por Menchaca (1990), trabalhando com funções de estágios múltiplos para descrever a relação peso-idade com 16 novilhos $3 \frac{4}{4}$ ebu $x$ 3/4Holstein, desde o nascimento até o peso adulto, está representado pela Tabela 2 .

TABEla 2. MOdelo MATEMÁtico de TRÊs ESTÁGIOS PARA DESCREVER CRESCiMENTO de BOVINOS.

\begin{tabular}{|c|c|}
\hline Estágio - idade & Modelo \\
\hline 0 até 120 dias & $\mathrm{PV}=\mathrm{PN} \cdot \mathrm{e}^{(\mathrm{rl} \cdot \mathrm{dias})}$ \\
\hline 120 até 240 dias & $P V=k \cdot e^{\left\{\log \left[\frac{P N \cdot e^{(r 1.120)}}{k}\right] \cdot e^{[-r 2 \cdot(t-120)]}\right\}}$ \\
\hline 240 até 780 dias & $\left\{\frac{\log \left[\mathrm{PN} \cdot \mathrm{e}^{(\mathrm{r} 1.120)}\right]}{\mathrm{k}} \cdot \mathrm{e}^{[-\mathrm{r} 2 \cdot(120-240)]}+\mathrm{b} \cdot\left\{1-\mathrm{e}^{[-\mathrm{r} 3 \cdot(\text { dias }-240)]}\right\}\right.$ \\
\hline
\end{tabular}

- PN - peso ao nascer; r1,r2 e r3 são parâmetros relacionados com a taxa de crescimento; $\mathrm{k}$ e b são parâmetros da função. Fonte: Menchaca (1990)

Quando foram comparados com os valores ajustados pelas funções de Gompertz e Richards, a função de três estágios mostrou menor variação residual (Menchaca, 1990), conforme mostrado pela Tabela 3.

TABEla 3. VARIÂNCIA RESIDUAL Do AJUSTE DE FUnÇões DE CRESCIMENTO PARA ANIMAIS $1 / 4 Z$ ZEU $X$ 3/4HOLSTEIN.

\begin{tabular}{lccr}
\hline \multicolumn{1}{c}{ Função } & Repetição & GL & \multicolumn{1}{c}{ SQ residuo } \\
\hline Gompertz & 11 & 123 & 95,10 \\
Richards & 11 & 112 & 85,70 \\
Três estágios & 11 & 68 & 46,60 \\
Gompertz & 16 & 185 & 139,90 \\
Três estágios & 16 & 105 & 51,30 \\
\hline
\end{tabular}

Fonte: Menchaca (1990) 
Esse tipo de modelo (Tabela 2) apresenta dois inconvenientes: (1으 a existência de heterogeneidade de variância provocada pela relação entre a variação no peso na troca de idade e (2º) a existência de possíveis fatores afetando a taxa de crescimento devido a flutuação nas extrapolações do sistema, como por exemplo os efeitos sazonais no sistema de pastejo (Menchaca, 1992).

Seguindo uma linha de raciocínio parecida com Liski (1987), esse pesquisador propôs outros três modelos de funções de crescimento: (1우) um modelo linear intrínseco (Menchaca, 1991a), (2º) um modelo multiplicativo, idêntico ao primeiro, entretanto considerando variáveis ambientais na função (Menchaca, 1991b) e (3ㅇ) um modelo multiplicativo em estágios, idêntico ao segundo mas apresentando um modelo diferente para 3 estágios diferentes de crescimento, semelhante ao mostrado na Tabela 2 (Menchaca, 1992).

Menchaca et al. (1993) efetuaram o estudo do crescimento de touros da raça Holstein em pastagem de Coastcross com dados desde os 230 e até os $410 \mathrm{~kg}$ de peso vivo através do modelo proposto por Menchaca (1992). O modelo estatístico está esquematizado na Equação 2

\section{EQUaÇão 2}

$$
P V=A \cdot e^{\left(b \cdot t+c \cdot t^{2}\right)}+P+L+\varepsilon
$$

onde:

$$
\begin{aligned}
& \text { PV - peso vivo; A - peso adulto; b e c - coeficientes; } \\
& \text { t - tempo em dias; P - efeito do bimestre do ano; } \\
& \text { L - efeito inerente ao animal; } \\
& \boldsymbol{\varepsilon} \text { - erro estatístico aleatório não observável. }
\end{aligned}
$$


Menchaca et al. (1993) concluíram que todos os efeitos do modelo foram significativos $(P<0,001)$ apresentando $u m R^{2}=98,7 \%$. O ponto de inflexão foi obtido aos 511 dias com $287 \mathrm{~kg}$ de peso vivo e o ganho de peso médio instantâneo foi de $0,638 \mathrm{~kg} / \mathrm{d}$. Devido a alta significância do fator $\mathrm{P}$ (bimestre), os autores sugeriram $O$ estudo do uso de suplementação durante o ano em determinados bimestres.

Outro modelo difásico gerado a partir de equações alométricas foi estabelecido por Koops \& Grossman (1991). Entretanto, os autores não obtiveram muito sucesso devido aos problemas de dados relacionados entre estágios, conforme citado acima.

Molina et al. (1992) ajustaram funções de 1으, 2으, 3을 4음 graus para relacionar peso com idade em touros da raça Retinta, obtendo $\mathrm{R}^{2}$ de $90,4 \% ; 90,1 \% ; 90,1 \%$ e $90,1 \%$ respectivamente. A função logística apresentou um coeficiente de determinação inferior às demais funções $(85,3 \%)$. Essas funções foram ajustadas para pesos até 200 dias após o nascimento.

Um fator extremamente limitante que está relacionado a esses tipos de modelos (polinômios) é que essa regressão só é válida dentro da faixa de idade utilizada para ajustar a função e nem sempre é representativa, ou seja, existe um intervalo adequado de descrição do crescimento e as vezes não podem ser utilizadas para predizer pesos em outras idades fora do intervalo do qual foi ajustada.

Para evitar esses problemas de intervalos de tempo em que as funções lineares são válidas, as funções não lineares foram estudadas para ajustarem melhor os dados nas respectivas curvas de crescimento.

Essas funções não lineares devem levar em consideração pelo menos dois parâmetros básicos. O primeiro parâmetro refere-se ao peso padrão do animal em uma determinada idade, geralmente, o peso adulto (" $A$ ") é esse peso de referência. É esse parâmetro que caracteriza o tamanho 
corporal do animal, que foi classificado em grande, médio ou pequeno por Fitzhugh (1976) em 1976 e, atualmente, foi reavaliado por Fox \& Black (1984). Esses autores subdividiram cada categoria de Fitzhugh (1976) em três sub-categorias, obtendo-se dessa forma 9 classes de tamanho corporal. o segundo parâmetro básico é a taxa de crescimento relativa ao tamanho corporal, ou melhor, a um determinado peso. Quando é utilizado o peso adulto, temos um índice de eficiência de crescimento, denominado de taxa de maturidade (" $k$ "). Taylor (1965) obteve uma relação significativa entre essa taxa de maturidade e o peso adulto elevado ao expoente 0,27. Em 1968, Taylor (1968) confirmou esse expoente quando analisou diferentes raças e linhagens dentro de uma mesma espécie e, também, para diferentes sexos dentro de uma mesma raça. Já em 1971, Taylor \& Fitzhugh (1971), encontraram o valor de 0,30 analisando dados de fêmeas Hereford utilizadas no trabalho de Brinks ${ }^{2}$.

Além desses dois parâmetros, um outro é utilizado para dividir a curva peso-idade em duas fases distintas de crescimento. A primeira chamada de "fase de crescimento acelerado" e a segunda de "fase de crescimento inibitório" (Brody, 1945), onde, a velocidade da taxa de crescimento é aumentada e reduzida, respectivamente. Exatamente no ponto de mudança está o ponto de inflexão $(" m$ "). Durante esse intervalo de transição teórica, as funções de crescimento se apresentam lineares (geralmente está entre 6 até 18 meses de idade para bovinos) e podem ser variáveis dependendo apenas da função utilizada e não do animal. Subrt et al. (1994) citam o ponto de inflexão de $234 \mathrm{~kg}$ aos 279 dias para animais cruzados $1 / 2$ Limousin $x$ 1/2Bohemian Red Pied.

Outro aspecto que deve ser lembrado é de que as funções de crescimento, geralmente levam em conta o aumento do peso vivo conforme avança a idade do animal. Entretanto, deve-se lembrar que com o passar

\footnotetext{
${ }^{2}$ BRINKS,J.S.; CLARK,R.T.; KIEFFER,N.M.; URICK,J.J. Estimates of genetic, environmental and phenoptypic
} 
do tempo, ou seja, aumento da idade do animal, o peso vivo não deve necessariamente aumentar, ou seja, a idade por si só não modifica o peso do animal (Fitzhugh, 1976). A ingestão acumulada de nutrientes, ou mesmo a ingestão acumulada de matéria seca seria uma alternativa como variável independente das funções em lugar da idade do animal. Isso poderia corrigir a variação de peso devido a qualidade e quantidade do alimento ingerido pelo animal (energia e/ou proteína), por exemplo, no período seco do ano (Joandert \& Cartwright, 1969). Entretanto esses dados são de difícil coleta e portanto o fator idade ainda é o mais utilizado.

A função de Richards (Richards, 1959) possui quatro parâmetros para ajustar a curva de peso-idade dos animais. As demais funções são casos especiais dessa. A Tabela 4 mostra os casos especiais da função de Richards e o peso vivo no PI (ponto de inflexão).

Em sua comparação entre as cinco funções de crescimento descritas na Tabela 4, Brown et al. (1976) ajustando dados de fêmeas Jersey e cruzamentos entre Brahman, Hereford e Angus concluíram que as três funções: von Bertalanffy, Gompertz e Logística superestimam os pesos durante as fases iniciais de crescimento e que a função Logística subestima o peso adulto, ao passo que a função de Richards é a que melhor descreve o crescimento dos animais, embora tenha mostrado maior dificuldade computacional para o ajuste. A função de Brody cuja facilidade de ajuste computacional é maior, se comparada com a função de Richards, apresenta bons resultados de convergência apenas após aos 6 meses de idade dos animais. 
TABELA 4. EQUAÇÕES E PROPRIEDADES PARA OS CASOS ESPECIAIS DA FUNÇÃo DE RICHARDS.

\begin{tabular}{llcc}
\hline \multicolumn{1}{c}{ Função } & \multicolumn{1}{c}{ Equação } & PV no PI & m \\
\hline Brody & A. $\left(1-\mathrm{b} . \mathrm{e}^{-\mathrm{k} \cdot \mathrm{t}}\right)$ & - & 1 \\
von Bertalanffy & A. $\left(1-\mathrm{b} \cdot \mathrm{e}^{-\mathrm{k} \cdot \mathrm{t}}\right)^{3}$ & $0,2963 \cdot \mathrm{A}$ & 3 \\
Logística & A. $\left(1+\mathrm{b} \cdot \mathrm{e}^{-\mathrm{k} \cdot \mathrm{t}}\right)^{-1}$ & $0,5 \cdot \mathrm{A}$ & -1 \\
Gompertz & A.e $\mathrm{e}^{\left(-\mathrm{b} \cdot \mathrm{e}^{-\mathrm{k} \cdot \mathrm{t}}\right)}$ & $\mathrm{e}^{-1} \cdot \mathrm{A}$ & $\infty$ \\
Richards & A. $\left(1-\mathrm{b} \cdot \mathrm{e}^{-\mathrm{k} \cdot \mathrm{t}}\right)^{\mathrm{m}}$ & $\left(\frac{\mathrm{m}-1}{\mathrm{~m}}\right)^{\mathrm{m}} \cdot \mathrm{A}$ & variável
\end{tabular}

1- Valor do peso vivo no ponto de inflexão (PI), ou seja, peso vivo na idade em que a taxa de crescimento é máxima. No caso da função de Brody a taxa de crescimento máxima é no tempo zero. Fonte: Fithugh (1976)

Uma variação interessante é proposta por Silveira Júnior et al. (1993) onde à função de Brody é adicionado um componente que tenta explicar as variações sazonais que influenciam o crescimento do animal. Ao invés de trabalhar com o peso vivo os autores preferiram utilizar a raiz cúbica do peso vivo, devido a facilidade de cálculo e da transformação que foi necessária devido a relação significativa entre a variância e a média dos dados. As equações são mostradas abaixo:

\section{EQUAÇÃo 3}

$$
\sqrt[3]{\mathrm{PV}}=\mathrm{A}-\mathrm{b} \cdot \mathrm{e}^{(-\mathrm{k} \cdot \mathrm{t})}+\mathrm{z}(\mathrm{t})
$$

\section{EQUAÇÃO 4}

$$
z(t)=p 0+p 1 \cdot \cos \left(\frac{360 \cdot t}{13}\right)+p 2 \cdot \cos \left(\frac{360 \cdot t}{6,5}\right)+q 1 \cdot \operatorname{sen}\left(\frac{360 \cdot t}{13}\right)+q 2 \cdot \operatorname{sen}\left(\frac{360 \cdot t}{6,5}\right)
$$

onde:

A - representa a raiz cúbica do peso adulto; p0, p1, p2, q1 e q2 são parâmetros estimáveis; $z(t)$ é $O$ efeito do tempo sobre 0 crescimento dos animais. 
Os autores concluem que o ajuste da curva de crescimento poderá ser efetuado independentemente das estações sazonais, ou seja, a Equação 3 pode ser utilizada sem necessariamente estimar o componente $z$ (t) mostrado na Equação 4 .

Nesse ponto serão abordados alguns aspectos de interpretação e utilização das funções não lineares de crescimento para descrever a relação peso-idade, sendo que a função de Richards será utilizada para a interpretação biológica de cada parâmetro, dessa forma as demais equações podem ser, por comparação, interpretadas da mesma forma (Fitzhugh, 1976).

\title{
2.2.1. Interpretação biológica dos parâmetros das funções
}

\author{
O parâmetro " $A$ " é o valor assintótico da função quando " $t$ " \\ (tempo, nesse caso idade) tende ao infinito. Genericamente esse valor \\ representa o peso adulto do animal independentemente de problemas de \\ flutuações de alimentação ou mesmo de efeitos climáticos. o parâmetro \\ " $b$ " ou constante de integração é utilizada para adequar o valor inicial \\ do peso vivo, nesse caso peso ao nascer, da função utilizada. o \\ parâmetro " $k$ " é uma função entre a taxa máxima de crescimento e o peso \\ adulto do animal, geralmente, sendo referido como taxa de maturidade \\ (Fitzhugh, 1976). Portanto, quanto maior esse valor mais precoce é o \\ animal e vice-versa (Brown et al., 1976) em termos de crescimento. \\ Taylor (1965) refere-se a $\mathrm{k}^{-1}$ como sendo $\mathrm{O}$ intervalo de maturidade. \\ Finalmente o parâmetro " $m$ " refere-se ao ponto de inflexão da curva, e \\ determina o grau de maturidade no ponto de inflexão (Fitzhugh, 1976). É \\ importante lembrar que o parâmetro assintótico " $A$ " fornece um valor \\ médio do peso quando o tempo se aproxima do infinito. Portanto o valor \\ " $A$ " não é necessariamente o maior peso observado do animal, uma vez que \\ esse valor tende a flutuar conforme modifica a composição corporal
}


(Brown et al., 1976). Dessa forma, esse valor tende a ser o peso adulto quanto mais constantes forem as condições ambientais. O esquema de desempenho de crescimento, segundo Commonwealth Scientific and Industrial Research Organisation - CSIRO (1990), que está esquematizado na página 211 do livro, mostra esse conceito de "flutuação" do peso corporal.

o grau de maturidade refere-se a proporção do peso vivo atual em relação ao peso adulto do animal. Os dados do trabalho de Warren (1977) mostram que o grau de maturidade e $\circ$ peso à mesma idade estão correlacionados positivamente, mas essa relação torna-se negativa conforme $\circ$ intervalo de idade entre o grau de maturidade e peso aumenta.

Outros índices dessas funções podem ser obtidos através das derivadas relativas que estão representados na Tabela 5.

TABEla 5. TAXAS de CREscimento MÉdias E INSTANTÂNEAS DA FUNÇÃO DE RICHARDS.

\begin{tabular}{ccc}
\hline Descrição & Taxa média & Taxa instantânea no PI \\
\hline Crescimento absoluto & $\frac{0,5 \cdot \text { A.m.k }}{2 \cdot \mathrm{m}-1}$ & $\frac{\mathrm{m} \cdot \mathrm{k}}{\mathrm{m}-1} \cdot \mathrm{PVpi}$ \\
Maturidade absoluta & $\frac{0,5 \cdot \mathrm{m} \cdot \mathrm{k}}{2 \cdot \mathrm{m}-1}$ & $\mathrm{k} \cdot\left(\frac{\mathrm{m}-1}{\mathrm{~m}}\right)^{\mathrm{m}-1}$ \\
Crescimento relativo & $\frac{\mathrm{m} \cdot \mathrm{k}}{\mathrm{m}-1}$ & $\frac{\mathrm{m} \cdot \mathrm{k}}{\mathrm{m}-1}$ \\
\hline
\end{tabular}

Fonte: Fitzhugh (1976)

A taxa de crescimento absoluta instantânea, de cada animal, pode ser obtida através da primeira derivada da equação em relação ao tempo. Notar que esse ganho é relativo ao valor da unidade de tempo usada, se em mês ou se em dias. O Apêndice 1 mostra todas as derivadas primeira para as funções utilizadas. 
Existem outros trabalhos mostrando mais detalhes sobre as utilizações da função de Richards, como por exemplo, Nath \& Moore (1992), afirmando que maiores informações do crescimento do animal podem ser obtidas através das derivadas segunda e terceira da função de Richards ao invés do uso da função propriamente dita.

Com relação à utilização dos parâmetros para seleção de animais, Webster et al. (1982) afirmam que de nada adianta muita ênfase em selecionar animais com alta taxa de crescimento absoluto (GPV) e habilidade de "acabamento" (teor de gordura final). Como não existe associação direta entre taxa de crescimento absoluto e eficiência de utilização de alimentos, a seleção para os parâmetros citados acima não possuem embasamento teórico nem técnico. Dessa forma, se esses parâmetros de seleção forem adotados para um determinado peso ou uma determinada idade, serão selecionados os maiores animais, sem necessariamente selecionar os mais eficientes. O principal fator para determinar alta eficiência de utilização de alimentos (eficiência alimentar) é o estágio de maturidade, pois, a taxa de maturidade (k) declina com o peso à maturidade do animal (A). Portanto o conhecimento da taxa de maturidade é de suma importância para a seleção eficiente de animais.

Torre et al. (1990) confirmaram essas suposições com dados de produção de bezerros e parâmetros de crescimento. Eles afirmam que vacas de grande tamanho corporal são menos produtivas que vacas de tamanho corporal menor; ou seja, animais que apresentam taxa de maturidade maior (" $k$ ") - provavelmente associados com menor peso adulto (" $A$ ") - são mais eficientes porque produzem bezerros de mesmo peso à desmama que outros animais, mas com uma taxa de peso do bezerro por peso da vaca maior, portanto mais eficiente do ponto de vista produtivo. 
Dada a importância desse parâmetro de maturidade (" $k$ "), foi obtida uma estimativa da taxa de maturidade sem necessariamente ajustar a função de crescimento, o que facilita o conhecimento instantâneo desse parâmetro.

Inicialmente, Doren et al. (1989), estimaram os parâmetros das funções de crescimento de touros de várias raças e seus cruzamentos, através da função de crescimento de Richards (Tabela 4) e a seguinte função de Brody simplificada:

\section{EQUAÇÃo 5}

$$
P V=A-B \cdot e^{(-k \cdot t)}
$$

Essa equação é semelhante à equação descrita na Tabela 4, apenas que o parâmetro " $b$ " tende a ser diferente devido ao ajuste que cada equação suporta. Dividindo-se os dois lados da equação pelo peso adulto (" $A^{\prime \prime) ~ o b t e ́ m-s e ~ a ~ e q u a c ̧ a ̃ o ~ d a ~ T a b e l a ~ 4 . ~ A ~ e q u a c ̧ a ̃ o ~ a c i m a ~ f o i ~ d e s e n v o l v i d a ~}$ por Brody (1945) apenas para descrever o crescimento que ocorre após o ponto de inflexão ou, como descrito anteriormente, fase de "crescimento inibitório". Entretanto, os autores estudaram uma alternativa para o ajuste ideal na fase pré-ponto de inflexão, e como resultado a Equação 6 foi obtida (Doren et al., 1989).

\section{EQUAÇÃo 6}

$$
P V=A-\left(A-y_{0}\right) \cdot e^{\left(-k \cdot\left(t-t_{0}\right)\right)}
$$

onde:

$$
\text { Yo - peso do animal no tempo inicial; } t_{0} \text { - tempo inicial. }
$$


Com base nessa função e alguns ajustes matemáticos uma estimativa do parâmetro "k" pôde ser obtida sem a necessidade de ajustar a função. Dessa forma o valor de " $k$ " estimado poderia ser fixo na equação de crescimento e apenas o parâmetro " $A$ " seria ajustado. Doren et al. (1989) mostraram, através de extensas transformações matemáticas, como se pode estimar o valor da taxa de maturidade através de dois períodos consecutivos de crescimento do animal (Equação 7) •

\section{EQUAÇÃo 7}

$$
k=\frac{2 \cdot(b-G \cdot a)}{\left(G \cdot a^{2}+b^{2}\right)}
$$

onde:

$\mathrm{k}$ - taxa de maturidade;

G - é a relação de ganho de peso vivo entre o segundo período e o primeiro período avaliado;

a - é o tempo gasto no primeiro período avaliado;

b - é o tempo gasto no segundo período avaliado.

Os valores de "a" e "b" devem ser maiores do que 20 dias para permitirem uma boa estimativa de " $k$ " devido às variações de peso vivo nesse intervalo. Quando o valor do parâmetro " $k$ " foi estimado e fixado na função, a soma de quadrados da regressão foi menor em relação à função sem fixar o parâmetro " $k$ ", mostrando que o uso do parâmetro " $k$ " estimado e fixo na função não reproduz as estimativas de quadrados mínimos do modelo sem fixar o parâmetro " $k$ ". Entretanto, os valores de peso adulto (" $\mathrm{A}$ "), para $O$ uso do parâmetro " $k$ " estimado através da Equação 7 foram mais "aceitáveis", segundo os dados de Doren et al. (1989) . 
Aparentemente esse método de fixar um parâmetro parece ser útil quando não se tem uma boa estimativa do peso adulto. Dessa forma, fixase o parâmetro de taxa de maturidade através da Equação 7, a curva é reajustada. Entretanto, Doren et al. (1989) alertaram que esse método para produzir um modelo com um parâmetro estimado não é funcional quando se deseja ajustar o peso adulto de um animal que não tem os valores de peso vivo próximos ao valor assintótico da função (peso adulto). Geralmente isso ocorre para machos que não alcançaram o peso adulto, devido ao abate em idades precoces.

Essa mesma função (Equação 6) é utilizada pelo CSIRo (1991) e o tempo inicial adotado é igual a zero, portanto, o yo é o próprio peso ao nascer do animal, resultando na equação Brody2 do Apêndice 1.

\subsubsection{Ajuste ideal das funções}

Os testes usuais para avaliação do ajuste das funções envolvendo a análise de resíduos da variância não são apropriados para dados longitudinais devido aos erros correlacionados entre as observações repetidas para o mesmo animal no tempo. Esse erro é composto principalmente por medidas de peso vivo, que flutuam devido ao crescimento compensatório, efeitos do clima sob a disponibilidade de alimentos e estresses. Além desses tipos de problemas, outro erro induzido pode ocorrer, como por exemplo, o uso da função logística, que calcula o peso no ponto de inflexão como sendo 50\% do peso adulto. Os valores de peso vivo ao redor desse ponto podem estar subestimado ou superestimado se esse peso, na realidade, ocorrer aos $60 \%$ ou $40 \%$ do peso adulto (Fitzhugh, 1976). Portanto existe um erro associado à escolha da equação.

Vários autores sugeriram métodos para escolha da melhor função para ajuste dos dados, entre eles o desvio entre o valor predito e o 
valor observado em pontos estratégicos da curva, como por exemplo no PI, ou mesmo a diferença entre o peso adulto estimado e o peso adulto observado após alguns anos de coleta de dados. Outro método é uma inspeção na curva plotada para escolha do melhor ajuste (Fitzhugh, 1976). De forma geral, a função de Richards apresenta melhor ajuste para dados de crescimento de bovinos (Brown et al., 1976). A função de Brody apresenta um bom ajuste apenas acima de 6 meses de idade, talvez devido à falta de ponto de inflexão dessa curva, o que prejudica o ajuste antes desse tempo (Brown et al., 1976). As conclusões de Goonewardene et al. (1981) comparando as funções Brody e Richards concordam com os fatos citados acima, pois a função de Richards apresentou melhor acurácia no ajuste tanto dos dados de fêmeas Hereford como para fêmeas cruzadas entre Charolais, Angus e Galloway. A função de Brody apresentou o segundo melhor ajuste. As fêmeas Hereford apresentaram melhor convergência em relação aos outros animais.

É difícil de se avaliar os valores estimados e os valores observados em determinadas idades, pois o peso adulto só é possível de ser obtido à campo em animais cujas idades ultrapassem 7 ou 8 anos. Já os pesos no ponto de inflexão parecem ser mais complicados ainda, porque é difícil a escolha do parâmetro que deve ser levado em conta na sua obtenção, para comparação.

Para os casos em que são feitas transformações, por exemplo do tipo log-log, McCuen (1985) alerta que os critérios de avaliação de melhor ajuste para esse modelo transformado vale apenas para esse modelo e não podem ser transportados para a análise dos dados originais. McCuen (1985) cita os principais métodos de seleção de funções como sendo: coeficiente de correlação, erro padrão da estimativa e análise do quadro de variâncias, com especial atenção para o valor de significância de ' $F$ '. 
Outro parâmetro que pode ser utilizado para avaliação da qualidade de ajuste é o $r^{2}$ ou $R^{2}$ (coeficiente de determinação) ajustado para o número de parâmetro da regressão (SAS®, 1987):

$$
\begin{gathered}
\mathrm{R}^{2}=1-\frac{\mathrm{SQr}}{\mathrm{SQt}} \\
\left.\mathrm{R}_{\text {ajustado }}^{2}=1-\frac{(\mathrm{n}-\mathrm{i}) \cdot\left(1-\mathrm{R}^{2}\right)}{(\mathrm{n}-\mathrm{p})}\right]
\end{gathered}
$$

onde:

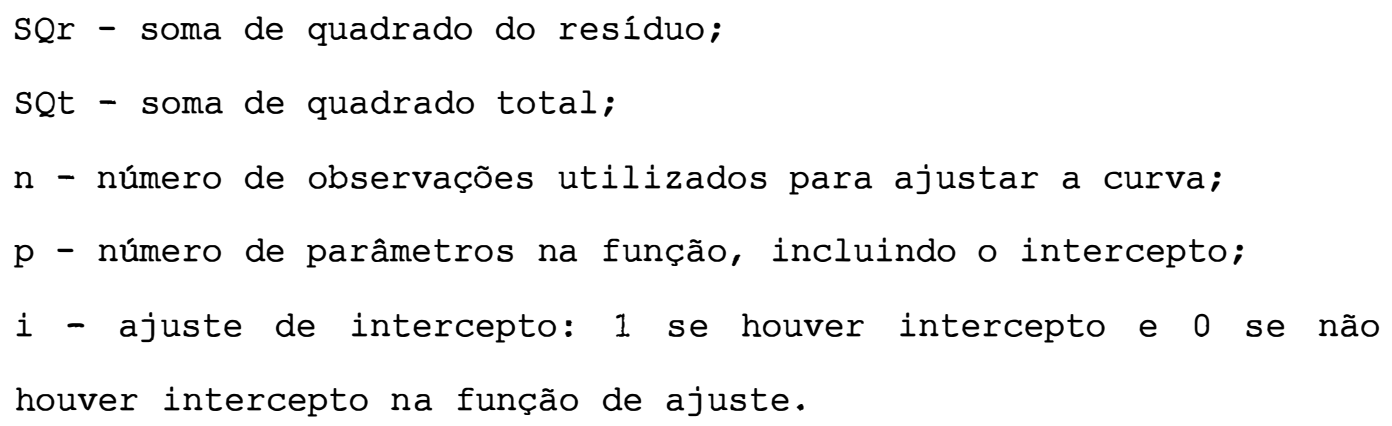

Além dos parâmetros descritos acima, a dificuldade de ajuste, embora não seja indicativo de melhor ajuste, também deve ser considerada, uma vez que quanto mais difícil o ajuste da função menor o número de curvas a serem obtidas. A função de Richards, entre as funções citadas até agora, possui maior dificuldade computacional de ajuste dos dados.

Existem vários métodos iterativos de ajuste que utilizam o quadrado mínimo como medida de regressão não linear. De forma geral o mais utilizado tem sido o método de Gauss-Newton ou série de Taylor (SAS®, 1987). Em geral, os métodos de convergência não devem produzir valores diferentes para os mesmos parâmetros. De fato, o método de Gauss-Newton e Marquardt não mostraram valores significativamente 
diferentes entre si, segundo o estudo de Elias ${ }^{3}$ analisando dados de crescimento de fêmeas Guzerá, através do Proc NLIN do SAS® (1987) .

McCallum \& Dixon (1990) afirmam que os métodos utilizados para estimar o parâmetro " $m$ " da função de Richards subestimam o valor desse parâmetro. Esse erro diminui conforme aumenta a freqüência de amostragem durante a fase de crescimento rápido.

Pasternak \& Shalev (1994) citam que o ajuste das funções de crescimento não lineares é ineficiente, uma vez que a magnitude dos desvios aleatórios do peso vivo aumentam com a idade (distúrbios da regressão heterocedásticas). Os autores concluem que a regressão não linear ponderada é mais eficiente do que a regressão não linear simples.

\subsection{Relações entre os parâmetros das funções}

Existem basicamente dois tipos de correlações entre parâmetros, uma que é a correlação entre parâmetros de significado biológico similar entre funções e outra que é a correlação entre parâmetros da mesma função (Fitzhugh, 1976). Como conhecimento geral, os parâmetros estimados de significado biológico similares possuem correlação positiva, especialmente os valores para o peso adulto (" $A$ "), embora essa correlação não seja tão grande quanto esperada segundo o estudo de Brown et al. (1976).

Outro problema aparece na interpretação das correlações dos parâmetros da mesma função. Sabe-se que a idade no ponto de inflexão pode ser calculada pela Equação 8 mostrada abaixo:

\footnotetext{
${ }^{3}$ ELIAS,A.M. - E.S.A. "Luiz de Queiroz" / USP, Departamento de Zootecnia, comunicação pessoal.
} 


\section{EQUAÇÃO 8}

$$
\text { Idade no PI }=\frac{\ln (m \cdot b)}{k}
$$

Baseado na Equação 8, é de se esperar que a correlação entre a idade no PI e os parâmetros $\mathrm{m}, \mathrm{b}$ e $\mathrm{k}$ seja positiva, positiva e negativa, respectivamente. Entretanto, os valores encontrados por Brown et al. (1976) foram de 0,30; $-0,28$ e 0,44 respectivamente.

As correlações encontradas por Brown et al. (1976) indicam que vários parâmetros de diferentes funções de crescimento tendem a medir características similares. Segundo as análises desses autores, o ajuste da função de von Bertalanffy apresentou-se muito parecido com a de Gompertz e desse com a Logística, com exceção do peso adulto nessa última comparação.

Outra relação que pode ser estudada é a estimativa entre os valores de alguns parâmetros de mesma função entre animais diferentes. Um caso especial que é de interesse seria a relação entre peso adulto de machos e peso adulto de fêmeas utilizando-se a mesma função.

Doren et al. (1989) citam que a relação entre o peso adulto de machos não castrados e fêmeas, encontrados por eles, é da ordem de 1,54; enquanto que Williams et al. (1995a) citam a utilização do valor de 1,30 para converter o peso desengordurado ("Fat-Free Matter Empty Body Weight") de fêmeas em machos nos modelos de composição corporal. CSIRO (1990) utiliza como relação entre peso adulto padrão (SRW "Standard Reference Weight") de machos não castrados e fêmeas o fator 1,4 e a relação entre machos castrados e fêmeas o fator 1,2 para qualquer raça. Veja os valores na Tabela 9, na página 32. 


\subsection{Relações entre os parâmetros das funções com outros fatores}

Uma sequência interessante de trabalhos realizados por Butts et al. (1984) sobre os padrões de crescimento de animais da raça Angus, Hereford e Sorthorn mostraram que as estimativas de peso adulto das vacas estavam associadas, significativamente, com o peso ao nascer e o peso aos 205 dias de seus respectivos bezerros, tanto para os machos como para as fêmeas. Os coeficientes de regressão entre esses dois fatores mostraram que havia um aumento no peso ao nascer de 1 a $2 \mathrm{~kg}$ conforme o peso adulto das vacas aumentava em $100 \mathrm{~kg}$ e o peso ao nascer aumentava cerca de 0,5 a $0,8 \mathrm{~kg}$ conforme a taxa de maturidade das vacas aumentava em 0,01 unidades (tempo em meses). Já aos 205 dias de idade, o peso vivo era aumentado em 7 a $12 \mathrm{~kg}$ conforme ocorria o aumento do peso adulto das vacas em $100 \mathrm{~kg}$ e 2,7 a 5,2 kg conforme a taxa de maturidade das vacas aumentava em 0,01 unidades.

Milburn et al. (1992) estudando 28 novilhas Hereford (H), 40 Brahman-Hereford (BH) e 39 Swiss-Hereford (SH) citam que, tanto o peso adulto quanto a taxa de maturidade, afetam o peso das vacas no período da estação de monta $(P<0,10)$ para as vacas que nasceram na primavera. Para as vacas que nasceram no outono, apenas o peso adulto teve influência no peso durante a estação de monta. O peso adulto e a taxa de maturidade também afetaram o peso vivo médio das vacas no período de 12 meses antes do primeiro desmame $(P<0,10)$, independente do tipo de cruzamento utilizado. O peso adulto e a taxa de maturidade das novilhas foram respectivamente de $453^{\mathrm{b}}$ e $0,045^{\mathrm{b}} ; 531^{\mathrm{a}}$ e $0,055^{\mathrm{a}}$; e $505^{\mathrm{a}} \mathrm{kg}$ e $0,050^{\mathrm{ab}} \mathrm{kg} / \mathrm{kg}$.dia para $\mathrm{H}, \mathrm{BH}$ e $\mathrm{SH}$ (as letras diferentes acima dos valores indicam diferença estatística ao nível de 5\% entre peso adulto e entre taxa de maturidade). 
Johnson et al. (1995) avaliaram o efeito genético e ambiental de vários parâmetros sobre o peso adulto e a taxa de maturidade de animais da raça Angus. Os parâmetros utilizados foram: peso ao nascer, peso ajustado aos 205 dias, peso ajustado aos 365 dias, peso ajustado aos 550 dias, GPV da desmama até sobreano, GPV relativo do nascimento até a desmama e da desmama até sobreano. As correlações genéticas com o peso adulto foram respectivamente de 0,$86 ; 0,97 ; 0,96 ; 0,99 ; 0,88 ;-0,11$ e 0,56 enquanto que para a taxa de maturidade, as correlações genéticas foram $-0,35 ; \quad-0,14 ; 0,06 ;-0,12 ;-0,01 ; 0,39$ e $-0,20$. Com as correlações ambientais, o peso adulto obteve os seguintes valores: 0,$02 ;-0,16 ;-0,24 ;-0,16 ;-0,24,-0,16$ e $-0,16$ e para a taxa de maturidade foram: $-0,09 ; 0,26 ; 0,63 ; 0,44 ; 0,62 ; 0,23$ e 0,45 . Esses dados mostram que o peso adulto está mais associado com os fatores genéticos da mesma forma que a taxa de maturidade está com os fatores ambientais.

Animais da raça Brahman foram separados em três classes de tamanhos corporais diferentes (grande, médio e pequeno) para ajustar os parâmetros da função de crescimento descrito por Menchaca (1992): estágio 1 (peso vivo desde o nascimento até a desmama), estágio 2 (peso vivo desde a desmama até 32 meses de idade) e estágio 3 (após 32 meses de idade até a maturidade, apenas para vacas). Para os estágios 1 e 2 as funções de crescimento utilizadas foram exponenciais de polinômios e para o estágio 3 foi utilizada a função de Brody. Os seguintes resultados foram obtidos: em geral, dentro de classes de tamanho corporal (CTC), os efeitos de touros não foram significativos ( $P$ > 0,05), mas os efeitos de estação de pesagem (primavera e verão) foram significativos $(P<0,05)$. No estágio 1 , a forma das curvas diferiram entre CTC $(P<0,05)$; sexo não influenciou a forma das curvas, entretanto, bezerros machos obtiveram maior peso do que as fêmeas. No 
estágio 2, as formas das curvas não diferiram entre CTC (P > 0,05); 0 peso vivo diferiu entre as CTC, sendo maior para os animais de tamanho corporal grande, seguido pelos animais de TC médio e, finalmente, pelos animais de TC pequeno $(P<0,05)$; o sexo também afetou a forma das curvas $P<0,05)$. No estágio 3, a forma das curvas foram diferentes entre CTC $(P<0,05)$, vacas de TC grande obtiveram maior peso vivo assintótico do que vacas de $T C$ pequena $(P<0,05)$. Em resumo, O TC afetou a forma das curvas dos animais do estágio 1 e 3 e o sexo afetou apenas a forma do estágio 2 (Menchaca et al., 1995, 1996). Nesse experimento os autores não continuaram com os machos até o terceiro estágio, para comparação entre sexos, devido ao abate dos animais.

\subsection{Efeito da parição nos parâmetros da função de crescimento}

Conforme comentado anteriormente, existem fatores externos ao animal, como por exemplo, a disponibilidade e qualidade de alimentos, que podem modificar o comportamento do seu crescimento. o efeito de parição, também, parece afetar o perfil de crescimento do animal. Alguns estudos do efeito da parição tem sido analisados.

Morrow et al. (1978) separaram vacas Hereford em 3 grupos classificados por parição, criando 3 grupos de parição, a saber: (1) animais que pariram aos 2 e aos 3 anos de idade, (2) animais que pariram apenas aos 3 anos de idade e (3) animais que pariram apenas aos 2 anos da idade. Os autores encontraram uma interação positiva entre idades de ajuste do peso vivo e esses grupos de parição, tanto para o parâmetro " $A$ " como para o parâmetro " $k$ " $(P<0,01)$. Quando ajustaram 0 peso adulto aos 3 anos de idade, ou seja, utilizaram apenas os dados de crescimento até os 3 anos de idade, o grupo 2 apresentou maior peso adulto do que os animais do grupo 1 e 3, ou seja, os animais que não 
pariram aos 2 anos de idade apresentavam maior peso adulto do que os demais animais. Para esse grupo de animais (2) as estimativas de " $A$ " tendiam a diminuir e as estimativas de " $k$ " tendiam a aumentar ao longo dos 7 anos de idade, enquanto que, ocorria o contrário para os animais do grupo 3. A Tabela 6 mostra a evolução desses dois parâmetros tanto para os grupos de parição e a média geral ajustada por quadrado médio mínimo.

Tabela 6. Médias ajustadas por quadrado mínimo do Peso adulto e taXa de MATURIDADE EM DIVERSAS IDADES PARA GRUPOS DE PARIÇÃO E GERAL.

\begin{tabular}{|c|c|c|c|c|c|c|c|c|}
\hline \multirow[t]{2}{*}{ Grupo } & & \multicolumn{7}{|c|}{ Ano } \\
\hline & & 2 & 3 & 4 & 5 & 6 & 7 & 8 \\
\hline \multirow[t]{2}{*}{1} & "A" & 457 & 449 & 459 & 470 & 483 & 493 & 444 \\
\hline & "k" & 0,076 & 0,078 & 0,073 & 0,068 & 0,061 & 0,056 & 0,082 \\
\hline \multirow[t]{2}{*}{2} & "A" & 653 & 535 & 503 & 500 & 493 & 493 & 577 \\
\hline & "k" & 0,048 & 0,057 & 0,066 & 0,065 & 0,067 & 0,066 & 0,056 \\
\hline \multirow[t]{2}{*}{3} & "A" & 468 & 450 & 516 & 536 & 528 & 519 & 513 \\
\hline & "k" & 0,078 & 0,079 & 0,06 & 0,055 & 0,057 & 0,058 & 0,060 \\
\hline \multirow[t]{2}{*}{ Geral } & "A" & 520 & 471 & 486 & 493 & 500 & 498 & 520 \\
\hline & "k" & 0,075 & 0,072 & 0,066 & 0,064 & 0,062 & 0,061 & 0,064 \\
\hline
\end{tabular}

- Grupo 1: animais que pariram aos 2 e 3 anos de idade, Grupo 2: animais que pariram apenas aos 3 anos de idade e Grupo 3: animais que pariam apenas aos 4 anos de idade.

Fonte: Morrow et al. (1978)

Quando esses dados foram analisados após a inclusão de outras variáveis de estação de pesagem, a saber: (1) peso do ano todo, (2) apenas pesos do verão, (3) apenas pesos da primavera e (4) apenas pesos de inverno, os animais com pesos apenas de inverno, apresentavam maior " $A$ " $(522 ; P<0,05)$ e " $k$ " $(0,0545 ; P<0,05)$. Em relação aos grupos de parição, os animais do grupo 2 obtiveram maior " $A$ " tanto para os ajustes da vida inteira do animal como para apenas os primeiros 5 anos de idade, respectivamente 513 e 516, em relação ao grupo de parição 1, respectivamente 493 e 465 ( $P<0,05)$. Com relação aos 
valores de "k" esses parecem um tanto quanto dúbios (McLaren et al., 1982). Os dados estão representados na Tabela 7.

TABEla 7. MÉDIAS AJUSTADAS POR QUADRADO MINIMO PARA PESO ADULTO E TAXA DE MATURIDADE PARA RELAÇÃO IDADE E GRUPO DE PARIÇÃO.

\begin{tabular}{cccc}
\hline Grupo & Parâmetro & Primeiro 5 anos & Vida inteira \\
\hline 1 & " $A$ " & 465 & 493 \\
& " $k$ " & 0,065 & 0,058 \\
2 & " $A$ " & 516 & 513 \\
& " $k$ " & 0,064 & 0,059 \\
3 & " $A$ " & 500 & 488 \\
& " $k$ " & 0,058 & 0,064 \\
\hline
\end{tabular}

Os autores acreditam que possa ter existido efeitos de gestação e de lactação aos 2 anos de idade. As vacas que não pariram aos 2 anos de idade (grupo de parição 2) cresceram rapidamente até parirem no 3 ㅇ ano. Essa pseudo-precocidade pode ter sido a causa de um " $k$ " maior em relação ao valor do " $k$ " estimado para a vida inteira (McLaren et al., 1982) •

Da mesma forma que o estudo de Morrow et al. (1978), Beltran et al. (1991) estudando a função de Brody no efeito de parição em vacas da raça Angus com mais de 4,5 anos de idade, concluíram que tanto o peso adulto como a taxa de maturidade foram influenciados pela seqüencia de parição $^{4}(010,011,101$ ou 111). Os animais que pariram apenas no segundo ano (010) apresentaram significativamente menor grau de maturidade (menor peso vivo em relação ao peso adulto) para os três anos em relação aos demais animais $(0,49 ; 0,73$ e 0,85 em relação a 0,57; 0,81 e 0,91 respectivamente para 0 1ㅇ, 2으 e 3 을 anos de idade). Os autores concluíram que a parição mais cedo parece ser afetada pelo grau de maturidade, ou seja, animais que apresentam maior peso vivo 
proporcional ao peso adulto parecem parir mais cedo, e que a forma da curva de crescimento é influenciado pelo efeito da parição na taxa de maturidade.

Ajustando os dados de 50 vacas da raça Retinta usando as equações não lineares de Brody, Richards e von Bertalanffy, Torre et al. (1990, 1992) também separaram as vacas em grupos de parição (aos 3 e 4 anos ou apenas ao 3을 ano de idade) e encontraram diferenças estatísticas tanto para peso adulto como para taxa de maturidade entre vacas com fertilização natural à pasto e vacas com inseminação artificial (IA) . Os pesos e taxas de maturidade foram respectivamente de 633 e 675; 0,0013 e $0,0012(P<0,05)$. Vacas que apresentaram parição nos 3으 e 4으 anos de idade não diferiram em peso adulto $(645$ e $634 ; \mathrm{P}<0,05)$ mas diferiram em taxa de maturidade $(0,0013$ e 0,0012; $\mathrm{P}<0,05)$ em relação às vacas com parição apenas no 3 으 ano de vida. As vacas que pariram entre $\circ 5^{\circ}$ e $8^{\circ}$ anos de vida consecutivamente não diferiram das vacas que apresentavam algumas falhas de parição nesse mesmo período tanto para peso adulto como para taxa de maturidade. A média geral foi de 650 kg para peso adulto e 0,0013 para a taxa de maturidade entre os animais com fertiliazação à pasto e IA.

Aparentemente os animais que apresentam falhas de parição em idades precoces apresentam alterações nos parâmetros das funções de crescimento (Morrow et al., 1978; McCurley et al., 1984), enquanto que animais que apresentam falhas de parição em idades avançadas não apresentam mudanças nos parâmetros (Torre \& Rankin, 1978; Torre et al. 1990). O fato do grau de maturidade ser elevado parece não afetar muito os parâmetros das funções de crescimento (Torre et al., 1990).

De forma geral, a época de pesagem e a performance reprodutiva dos animais devem ser definidas e consideradas na função, pois existem

\footnotetext{
${ }^{4}$ Durante três anos consecutivos, usando os códigos 0 para vacas vazias e 1 para vacas prenhas após 2 anos de idade.
} 
interações entre esses fatores e os parâmetros das funções de crescimento (Fitzhugh et al., 1967; Morrow et al., 1978; Ludwig et al., 1981; McLaren et al., 1982).

\subsection{Idade e intervalo de medição do peso vivo}

Os dados de Morrow et al. (1978) mostram claramente a relação entre ajustes do peso adulto e da taxa de maturidade em relação à idade do animal. A análise de correlação entre essas medidas no tempo mostrou que as 102 vacas Angus apresentavam estabilidade no peso adulto entre os 3,5 a 4,5 anos de idade, enquanto a taxa de maturidade demorava mais um ano para se estabilizar (4,5 a 5,5 anos de idade). Os valores de correlações entre os pesos adultos e taxa de maturidade mostravam que à medida que o animal era mais velho maior era a correlação.

No trabalho de Beltran et al. (1992) as vacas Angus que apresentavam maior peso adulto atingiram o peso adulto após os 5,5 anos de idade ao passo que as vacas de maior taxa de maturidade atingiram o peso adulto aos 4,5 anos.

Dessa forma, animais com mais de 4,5 anos de idade devem apresentar uma estimativa de peso adulto e taxa de maturidade estabilizadas e representativa de uma determinada população.

Outra fonte de variação na determinação dos parâmetros das funções de crescimento é o intervalo entre coletas de peso vivo, uma vez que esse intervalo de medição pode interferir na dificuldade de convergência da função, ou mesmo alterando significativamente os valores estimados, devido à "distância" em tempo entre as medidas. O período crítico de maior necessidade de pesagens está ao redor do ponto de inflexão, o que ocorre geralmente aos 150 a $200 \mathrm{~kg}$ de peso vivo. 
Ludwig et al. (1981) estudando 244 fêmeas e 187 machos Nelore, encontraram que quando $o$ intervalo de pesagens excedia 3 meses, o animal apresentava alta estimativa de ganho de peso e a estimativa de peso adulto apresentava-se muito elevada, e que na média, o peso adulto tendia a aumentar com o aumento do número de pesagens.

Quaas (1983) notou que as pesagens semestrais de 906 vacas Hereford durante 5 anos, apresentaram uma variação significativa para a taxa de maturidade através da função de Brody (Equação 5) quando comparado com pesagens mensais.

Utilizando 955 animais da raça Nelore, possuindo pesos mensais desde o nascimento até aos 24 meses de idade, Nobre et al. (1987) analisaram quatro funções de crescimento (Tabela 8) e concluíram não haver diferenças nos ajustes dos parâmetros das funções estudadas quando utilizava-se períodos mensais, bimestrais ou trimestrais para convergência das funções. Embora a tendência de ajuste do peso adulto e da taxa de maturidade, conforme aumentava-se o tempo de coleta dos dados, não foram constantes entre as funções ajustadas.

Tabela 8. Peso adulto e taxa de maturidade estimados de acordo COM A FUNÇÃO EMPREGADA E FREQŨÊNCIA DE PESAGENS.

\begin{tabular}{lcccccc}
\hline \multicolumn{1}{c}{ Função } & \multicolumn{2}{c}{ Mensal } & \multicolumn{2}{c}{ Bimestral } & \multicolumn{2}{c}{ Trimestral } \\
& $\mathrm{A}$ & $\mathrm{k}^{\mathrm{l}}$ & $\mathrm{A}$ & $\mathrm{k}$ & $\mathrm{A}$ & $\mathrm{k}$ \\
\hline Brody & 529,22 & 0,0420 & 541,93 & 0,0410 & 554,83 & 0,0390 \\
Bertalanffy & 350,00 & 0,2700 & 353,51 & 0,2900 & 362,00 & 0,3100 \\
Logística & 365,00 & 0,2140 & 367,00 & 0,2087 & 364,00 & 0,2371 \\
Richards & 414,84 & 0,1100 & 413,85 & 0,1050 & 412,98 & 0,1180 \\
\hline
\end{tabular}

-Ajustado para tempo em meses.

Fonte: Nobre et al. (1987)

Portanto, de forma geral os animais podem ser pesados em até 3 meses de intervalo de pesagens (Ludwig et al., 1981; Nobre et al., 1987) mas devem possuir pelo menos uma idade de 4,5 anos ou mais para 
possuírem estimativas constantes dos parâmetros das funções (Morrow et al., 1978) .

\subsection{Estimativas de peso à maturidade}

\subsubsection{Definição de peso adulto}

Peso adulto (" $A$ ") é um parâmetro bastante complicado de ser obtido, pois os valores do parâmetro " $A$ " são estimativas de pesos assintóticos das funções que descrevem o crescimento do animal, nem sempre gerando dados reais.

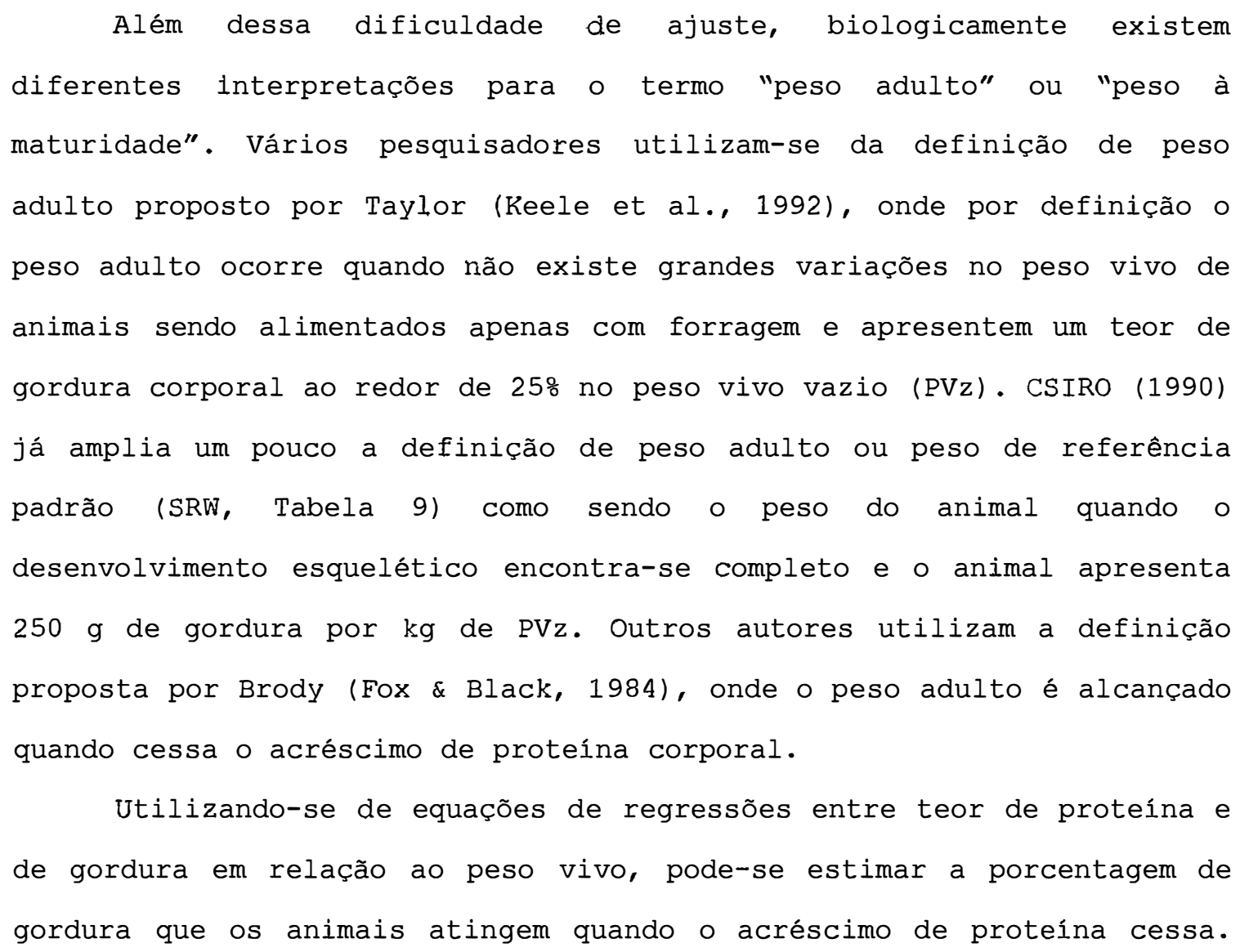


Analisando os dados de Simpfendorfer $(1974)^{5}$, Owens et al. (1995) obtiveram peso adulto de $904 \mathrm{~kg}$ de PVz e um teor de 52,44\% de gordura. Com dados mais recentes, Owens et al. (1995) obtiveram peso adulto de $746 \mathrm{~kg}$ de PVz com um teor de $36,2 \%$ de gordura, o que difere bastante do valor de 25 utilizado por Taylor.

Esses valores sugerem que os animais modernos apresentam menor peso adulto e menor proporção de gordura (Owens et al., 1995) em relação aos padrões antigos.

Tabela 9. Peso de Referência padrão possíveis (SRW, KG) PaRa a PRedição de composição CORPORAL DE GANHOS DE PESO VAZIO DE VÁRIAS RAÇAS DE BOVINOS.

\begin{tabular}{lcccc}
\multicolumn{1}{c}{ Raça } & Fêmeas & Castrados & Não castrados \\
\hline Chianina & 700 & 840 & 980 \\
$\begin{array}{l}\text { Charolais, Maine Anjou, Simmental } \\
\text { Angus, Blonde d'Aquitane, Brahman, Brahman x Hereford, }\end{array}$ & 650 & 780 & 910 \\
$\begin{array}{l}\text { Hereford, Morray Grey, Limousin, Lincoln Red, Friesin, South } \\
\text { Devon }\end{array}$ & 550 & 660 & 770 \\
$\begin{array}{l}\text { Beef ShortHorn, Dairy ShortHorn, Devon (Red), Galloway, } \\
\text { Red Poll }\end{array}$ & 500 & 600 & 700 \\
$\begin{array}{l}\text { Ayrshire, Guernsey, AMZ, Sahiwal } \\
\text { Jersey }\end{array}$ & 450 & 540 & 630 \\
\hline Fonte: CSIRO(1990) & 400 & 480 & 560 \\
\hline
\end{tabular}

As estimativas de parâmetros das funções tem sido um grande problema, pois, parâmetros que são considerados idênticos possuem valores completamente distintos para o mesmo grupo de animais entre sistemas de estimativas diferentes. Dessa forma o peso adulto para o mesmo animal pode variar apenas devido à interpretação do significado de peso adulto entre dois sistemas distintos.

Arnold \& Bennett (1991a, 1991b) avaliando quatro modelos de crescimento e composição de bovinos concluiram que os modelos apresentam boa performance quando são utilizados os parâmetros que os

${ }^{s}$ SIMPFENDORFER,S. Relationship of body type, size, sex, and energy intake on the body composition of cattle. 
originaram. Assim é de se esperar que cada modelo deva estimar corretamente quando é utilizado a definição de peso adulto assumido para cada modelo e não um valor numérico idêntico a todos. Quando esses quatro modelos foram comparados usando três dados experimentais diferentes daqueles de origem, nenhum deles predisseram corretamente. Todos foram muito deficientes nas determinações tanto de composição corporal como de ingestão de matéria seca. Apenas o PVz obteve boa estimativa pelos modelos. Variações médias de 20 até $25 \%$ entre dados observados e preditos foram observados. Com isso, as conclusões são muito pessimistas em torno da capacidade de predição dos modelos quando as definições não são bem estabelecidas. Os autores concluem que nenhum dos quatro modelos estudados podem ser utilizados para tomada de decisões econômicas.

Korver et al. (1988), apresentando outro modelo de simulação de crescimento, composição corporal e exigência de nutrientes, também afirma que existe falta de informações precisas para que modelos dessa categoria sejam melhores avaliados.

\title{
2.7.2. Estimativas de peso adulto na literatura
}

\begin{abstract}
Em 1972, Mischan ajustou as funções Logística, Mitcherlich e Gompertz usando dados de desenvolvimento ponderal de bovinos de diferentes raças. Para esses dados a função de Gompertz apresentou maior coeficiente de determinação e menor variação dos desvios em relação aos demais modelos.

Crócomo (1973) estudando três raças diferentes (Canchim, Nelore e Charolais) concluiu que a função não linear de Gompertz ajustava-se melhor aos dados do que uma equação quadrática. Também em 1973, Cortarelli (1973), analisando os dados de animais da raça Nelore
\end{abstract}

Ithaca, 1974. 193 p. Thesis (Ph. D.) - Cornell University. 
utilizando as funções de Brody, von Bertalanffy, Logística e Gompertz selecionou a função de Gompertz.

A função de Gompertz também foi escolhida em relação a logística por apresentar menor variação dos desvios em animais da raça Holandesa, segundo Vieira (1975).

Duarte (1975) ajustando 5 funções de crescimento não lineares em touros e fêmeas Nelores obteve os resultados apresentados na Tabela 10. Esses dados mostram claramente que as funções de Brody, Richards, von Bertalanffy e Logística apresentam respectivamente estimativas decrescentes para o peso adulto.

TABELA 10. RESUltados das FUNÇÕES DE CRESCIMENTO de MACHOS E FÊMEAS NELORE.

\begin{tabular}{|c|c|c|c|c|c|c|c|c|}
\hline \multirow[t]{2}{*}{$\operatorname{Sexo}^{1}$} & \multicolumn{2}{|c|}{ Brody } & \multicolumn{2}{|c|}{ Richards } & \multicolumn{2}{|c|}{ von Bertalanffy } & \multicolumn{2}{|c|}{ Logística } \\
\hline & "A" & $" k "$ & "A" & $" k "$ & $" A "$ & "k" & " $A$ " & $" k "$ \\
\hline $\mathbf{M C}$ & 918,56 & 0,0008 & 817,18 & 0,0016 & 768,87 & 0,0017 & 719,81 & 0,0025 \\
\hline $\mathrm{MñC}$ & 1039,60 & 0,0008 & 850,52 & 0,0016 & 849,45 & 0,0016 & 790,54 & 0,0025 \\
\hline F & 755,58 & 0,0007 & 617,31 & 0,0013 & 589,29 & 0,0015 & 541,02 & 0,0024 \\
\hline
\end{tabular}

- MñC - machos não castrados, MC - machos castrados e F - fềmeas.

Fonte: Duarte (1975)

Silveira Júnior (1976) e Silveira Júnior \& Moraes (1978) testando - algoritmo descrito por Hartley (1961) nas funções Logística, Brody, von Bertalanffy e Gompertz com animais da raça Ibajé, concluíram que as funções de Brody e von Bertalanffy mostraram menor variação dos desvios e maior coeficiente de determinação.

Ludwig (1977) utilizando pesagens bimestrais do peso vivo de animais da raça Nelore, ajustou as funções de Brody, von Bertalanffy, Gompertz e Logistica. As funções foram convertidas a uma sequência linear através da série de Taylor e a técnica dos quadrados mínimos internos também foi utilizada. O autor concluiu que entre as funções estudadas, a função de Brody apresentou maior dificuldade de convergência, entretanto, todas as funções foram consideradas 
eficientes, pois o coeficiente de determinação $\left(R^{2}\right)$ foi próximo de $99 \%$ Deve-se levar em consideração que a época em que tais ajustes foram feitos não havia microcomputadores tão eficazes como os que temos à disposição atualmente.

Torre \& Rankin (1978) ajustando dados de peso-idade de 74 vacas Hereford e 83 vacas Brangus usando a função de Brody, encontraram peso adulto de 443,4 e 432,4 $\mathrm{kg}$ sem diferença estatística, mas, a taxa de maturidade foi de 0,0020 e $0,0024(P<0,05)$ respectivamente. O local de permanência (diferentes estábulos) dos animais e o ano afetaram significativamente o crescimento dos animais Hereford mas não dos animais Brangus, sugerindo alta susceptibilidade daqueles animais ao fator ambiental.

Em 1981, o trabalho de Goonewardene et al. (1981), mostrou que as funções de Richards e Brody apresentaram melhor ajuste em relação às funções de von Bertalanffy e Logística. As duas últimas apresentam ponto de inflexão fixos, apresentando ajuste muito ruim para o peso ao nascer, pesos finais e peso adulto, sendo que o peso ao nascer é superestimado e os pesos finais são subestimados devido as características de convergência antes do ponto ideal. Os autores concluíram que as fêmeas Hereford foram 28\% mais precoces do que as fêmeas cruzadas de Charolais, Angus e Galloway.

Os pesos adultos de quatro raças de touros estimados através da função de Brody simplificada (Equação 5) usando Hereford, Aberdeen Angus, Friesin Inglês e Charolais com os dados obtidos entre os 500 até 2000 dias de idade foram de $947 \pm 13 ; 1002 \pm 43,1000 \pm 18$ e $1113 \pm 8$ respectivamente (Webster et al., 1982).

Existe uma forte correlação entre peso adulto de vacas e peso à desmama dos bezerros segundo Carpenter et al. (1971) citados por Marshall et al. (1984). Entretanto, para manter uma vaca de maior peso 
existe o gasto energético adicional, ou seja, mais alimento. Com isso surge uma questão com relação ao tamanho da matriz. Foram vários os autores que estudaram o efeito desse tamanho sobre a eficiência do rebanho e os resultados são muito controvertidos. Uma das respostas encontradas é que o tamanho da matriz depende diretamente do cruzamento (Marshall et al., 1984). De fato, os resultados de eficiência produtiva $^{6}$ estimados por Green et al. (1993), mostram que o cruzamento de fêmeas Hereford e/ou Angus com Bos indicus (Brahman e Sahiwal) foi 6\% mais eficiente do que com Bos taurus (Hereford e Pinzgauer). O peso adulto estimado para as fêmeas cruzadas com Sahiwal, Hereford, Pinzgauer e Brahman foram respectivamente 545; 550; 562 e $590 \mathrm{~kg}$. Os autores citam que em outros experimentos, as fêmeas de menor peso adulto apresentaram maior eficiência produtiva, devido principalmente a menor exigência de energia para mantença por unidade de peso adulto. Outro estudo conduzido por Jenkins e Ferrell (1993) com nove raças no Centro de Pesquisas de Bovinos de Corte (MARC) em Nebraska - EUA, mostrou que os animais de maior peso adulto apresentaram melhor eficiência produtiva conforme mostra a Tabela 11. Esses dados devem ser comparados com os valores de peso adulto publicados pelo MARC, os quais estão listados no Apêndice 6 (Jenkins et al., 1993). A heterose pode ter modificado o valor médio do peso adulto desses animais. Nesse mesmo experimento, os animais submetidos aos tratamentos com quantidades de energia disponível reduzidas (130; 170; 210 e 250 Kcal/PM) appresentaram maior eficiência produtiva $(0,028 ; 0,026 ; 0,022$ e 0,022 kg/Mcal; respectivamente). Pelos resultados mostrado acima, pode-se concluir que animais de menor peso adulto ou disponibilidade de energia reduzida podem apresentar maior eficiência produtiva.

\footnotetext{
${ }^{6} \mathrm{EP}=\frac{(\mathrm{PV} \text { do bezerro desmamado }+0,55 * \mathrm{PV} \text { vaca de descarte })}{\text { (Ingestao de energia do bezerro e da vaca, } \mathrm{Mcal})}$
} 
TABela 11. Efeito de raÇAS na eficiênCia produtiva DURANTE TRÊS ANOS.

\begin{tabular}{lc}
\hline Raça & $\begin{array}{c}\text { Eficiência produtiva } \\
(\mathrm{kg} / \text { Mcal })\end{array}$ \\
\hline Angus & 0,022 \\
Braunvieh & 0,026 \\
Charolais & 0,025 \\
Gelbvieh & 0,025 \\
Hereford & 0,022 \\
Limousin & 0,025 \\
Red Poll & 0,026 \\
Pinzgauer & 0,025 \\
Simmental & 0,023 \\
\hline Fonte: Jenkins \& Ferrell $(1993)$.
\end{tabular}

Marshall et al. (1984) estudaram 116 vacas Red Poll durante um período de 16 anos usando a função de Brody generalizada obtendo peso adulto de $554 \mathrm{~kg}$ e taxa de maturidade de $0,0020 \mathrm{~kg} / \mathrm{kg}$.dia. As curvas de eficiência encontradas estão apresentadas na Tabela 12. Através dessas curvas pode-se concluir que o peso adulto que maximiza essas equações está ao redor de 610 e $630 \mathrm{~kg}$.

TABELA 12. COEFICIENTES DE REGRESSÃO DAS CARACTERÍSTICAS MATERNAIS EM RELAÇĀo AO PESO ADULTO de VACAS RED POLL.

\begin{tabular}{|c|c|c|c|}
\hline Características & $\begin{array}{c}\text { Intercepto' } \\
b_{0}\end{array}$ & $\begin{array}{c}\text { Linear } \\
b_{1}\end{array}$ & $\begin{array}{c}\text { Quadrático } \\
\mathrm{b}_{2}\end{array}$ \\
\hline Peso total de desmama dos bezerros & $6799,000^{\circ}$ & $26,900^{*}$ & $-0,022^{\prime}$ \\
\hline Produção total de carne ${ }^{2}$ & $-6799,000^{*}$ & $27,900^{*}$ & $-0,022^{*}$ \\
\hline 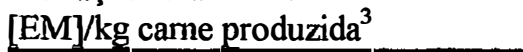 & $39,800^{* *}$ & $0,057^{* *}$ & \\
\hline \multicolumn{4}{|c|}{$\begin{array}{l}\text { - y= } \mathrm{b}_{0}+\mathrm{b}_{1} \text {.(Peso Adulto) }+\mathrm{b}_{2} \text {.(Peso Adulto); } \\
\text { - Peso médio do bezerro mais peso adulto da vaca; } \\
\text { - } \text { - Energia Metabolizável (MJ) utilizada; } \\
\text { e mostram significância do coeficiente a } 1 \% \text { e } 5 \% \text { respectivamente diferem de zero. }\end{array}$} \\
\hline
\end{tabular}

Outro estudo conduzido por Doren et al. (1989) utilizando a função de crescimento de Brody modificada genérica (Equação 6) avaliando touros da raça Angus, Brahman, Hereford, Holstein, Jersey e seus cruzamentos obteve respectivamente os valores de $682,7 \pm 20,0$; 
$715,2 \pm 22,1 ; 707,7 \pm 14,7 ; 822,0 \pm 14,9$ e $599 \pm 17,2$ para peso adulto e de $0,0033 \pm 0,0004 ; 0,0023 \pm 0,0002 ; 0,0025 \pm 0,0002 ; 0,0029 \pm 0,0002$ e 0,0029 $\pm 0,0004$ para a taxa de maturidade.

Johnson et al. (1990, 1991) estudando vacas Angus e Hereford, obtiveram peso adulto e taxa de maturidade de 412 e 0,0019, e 479 e 0,0016 ; respectivamente.

Estudando quatro funções de crescimento (Richards, Brody, Gompertz e Logística) para animais das raças Holstein, Ayrshire e 3/2Holstein x 32Ayrshire, Perotto et al. (1992) concluíram que a função de Brody parece superestimar o valor do peso adulto enquanto a função Iogistica parece subestimar em relação às funções de Richards e Gompertz. Essa conclusão está de acordo com Duarte (1975). A taxa de crescimento absoluto médio (AGR) foi significativamente maior para a função de Richards em relação às demais funções $(P<0,01)$ para todos os animais. Os pesos adultos dos animais foram de $613,2 \pm 3,38 ; 537,1 \pm$ 3,96 e 586,5 $\pm 3,89$, e as taxas de maturidade foram de 0,0022 \pm 0,$00004 ; 0,0024 \pm 0,00005$ e 0,0023 $\pm 0,00005$ para Holstein, Ayrshire e seu cruzamento, respectivamente. Esses dados mostram a superioridade do peso adulto do cruzamento em relação ao valor médio dos pais ( $\mathrm{P}$ < 0,001). Entretanto não possuem taxa de maturidade superior à média dos pais $(P<0,01)$ (Perotto et al., 1992). Por ter apresentado menor soma de quadrado residual, a função de Richards foi escolhida devido à sua melhor predição da curva de crescimento dos animais (Perotto et al., 1992). Ainda, com esse grupo de animais, Perotto et al. (1994) analisando os efeitos genéticos nos parâmetros da função de Richards encontraram que os efeitos aditivos da raça Holstein foram superiores aos da raça Ayrshire para a performance individual apenas para o parâmetro peso adulto. Portanto, o peso adulto do indivíduo pode ser aumentado sem modificar os demais parâmetros de crescimento (" $k$ ", por 
exemplo), apenas aumentando a contribuição genética de uma raça (Holstein). Entretanto, os efeitos dominantes individuais tendem a diminuir o peso adulto, ou seja, os animais tendem a crescer mais rapidamente em relação ao peso adulto. Os efeitos de heterose mostraram que os animais cresceram mais rapidamente sem aumento do peso adulto. Maiores detalhes sobre os modelos genéticos utilizados por Perotto et al. (1994) estão no trabalho de Koch et al. (1985).

Freitas et al. (1995) ajustaram as funções Logística, de Brody e de Richards em 85 fêmeas Holandesas com pesagens mensais desde o nascimento até 24 meses de idade. Os valores para os parâmetros A, b e $k$ foram respectivamente de 549, 6,98, 0,0057; 660, 1,13, 0,0019 e 703, $0,72,0,0027$. O valor de " $m$ " (parâmetro de inflexão) foi de 3,77 para a função de Richards. O ano de nascimento das novilhas influenciou as estimativas de peso à maturidade para a função Logística $(P<0,05)$. Foram observadas correlações negativas entre os parâmetros da função, principalmente entre a taxa de maturidade e o peso adulto. Os animais pareciam ser muito jovens para poder ajustar as funções de crescimento. Quanto à escolha da função adequada, a função de Brody, em bovinos, parece ser a mais adequada para estudos de aspectos genéticos de peso e de taxa de maturidade (Brown et al., 1972; Duarte, 1975; Silveira Júnior, 1976 e Ludwig, 1977). A função de Brody gerou melhores resultados de estimativa de peso vivo em vacas Angus com mais de 18 meses de idade, entretanto apresentou maior quadrado médio residual do que a função de Richards devido a superestimativa dos pesos vivos antes dos 18 meses de idade (Beltran et al., 1992).

A dificuldade de ajuste é maior para a função de Richards em relação à de Brody e às demais funções, talvez devido a variabilidade do ponto de inflexão da função de Richards. A função de Richards é 
melhor que as demais em termos de menor soma de quadrados do resíduo (DeNise \& Brinks, 1985).

No Apêndice 6 está sumariado todos os pesos adultos e as taxas de maturidade encontrados por diversos pesquisadores citados nessa revisão.

\subsubsection{Alguns aspectos de herdabilidade $\left(h^{2}\right)$ para os parâmetros das funções}

Os dados de Calo et al. (1976) mostram que a herdabilidade para o peso vivo de garrotes $1 \frac{1}{2} \mathrm{Holstein} \times \frac{1}{2}$ Friesian está ao redor de $83 \%$, para ganho de peso vivo absoluto está próximo de $44 \%$ e para ganho de peso vivo em porcentagem do peso vivo está ao redor de $46 \%$

Em 1977, Fries, trabalhando com melhoramento de bovinos de corte cita que a $\mathrm{h}^{2}$ para o peso adulto de vacas está entre 50 e 70\%, portanto apresentando alta herdabilidade.

Os resultados de Quaas (1983) com 906 vacas Hereford mostram que os valores de herdabilidade para peso adulto e taxa de maturidade estão ao redor de $56 \%$ e $20 \%$, respectivamente.

Johnson et al. (1990) observaram valores bem menores de estimativa de herdabilidade para peso adulto e taxa de maturidade (valores médios de 0,30 e 0,19 para vacas da raça Angus, Hereford, Polled Hereford, Red Poll e Charolais).

Oliveira et al. (1994) estudando as relações entre os parâmetros da função de crescimento de von Bertalanffy para fêmeas da raça Guzerá, concluiram que $O$ peso adulto apresenta alta herdabilidade $(0,63)$ enquanto que a taxa de maturidade apresenta baixa herdabilidade $(0,08)$. A correlação entre " $A$ " e " $k$ " foi alta e negativa $(-0,85)$, concordando com Ahunu et al. (1994). Correlações genéticas entre os pesos aos 240, 367 e 550 dias de idade com o peso adulto e com a taxa de maturidade indicaram que seleção para peso nessas idades resultarão em animais de 
grande peso adulto e pequena taxa de maturidade. As correlações entre idade à primeira parição, intervalo entre partos e número de parição com 0 peso adulto e a taxa de maturidade foram 0,$27 ;-0,53 ; 0,34$ e 0,$67 ; 0,48 ; 0,52$ respectivamente.

Inversamente ao resultado de herdabilidade encontrado por Oliveira et al. (1994), Souza \& Bianchini Sobrinho (1994) ajustando dados de machos castrados Nelore através da função de von Bertalanffy encontraram baixa herdabilidade para o peso adulto $(0,06)$ e para a taxa de maturidade $(0,22)$. De forma geral essa tendência de baixa herdabilidade sempre existiu para as outras funções utilizadas pelos autores. Esses dados de baixa herdabilidade também foram encontrados por Carrijo (1988) e Bianchini Sobrinho \& Duarte (1991). Os autores afirmaram que a seleção de animais não deve ser efetuada apenas com os parâmetros da função de crescimento. As demais funções utilizadas nesse experimento estão minuciosamente descritas em Bianchini Sobrinho (1984) .

Esses resultados implicam pouca variação genética na taxa de maturidade, portanto, qualquer seleção voltada para a tentativa de alterar a forma das curvas de crescimento pode ser ineficiente (Quaas, 1983). Já para Smith \& Cundiff (1976), analisando 477 novilhos das racas Angus, Hereford e Shorthorn, o uso da taxa de crescimento relativa (RGR) entre 200 até 452 dias e entre 0 até 452 dias parecem ser um critério efetivo na modificação da forma da curva de crescimento, basicamente devido às herdabilidades encontradas (25\% e 64\%, respectivamente). Num trabalho mais detalhado conduzido por Smith et al. (1976), ficou estabelecido que os valores de herdabilidade para peso vivo e grau de maturidade eram de 68\% e 73\% ao nascer, 59\% e 64\% aos 200 dias, $87 \%$ e 55\% aos 396 dias, $82 \%$ e $21 \%$ aos 550 dias, $41 \%$ e $-26 \%$ aos 3 anos e $44 \%$ e $40 \%$ na puberdade. Dessa forma, seleção para 
aumentar a taxa de crescimento, em qualquer intervalo de idade, tanto em termos absolutos como relativos, tenderiam a alterar a forma da curva de crescimento. Os autores também concluíram que a seleção para taxa de crescimento absoluta (AGR), em qualquer intervalo de idade, deverá aumentar o peso em todas as idades enquanto que a seleção para taxa de crescimento relativa antes do desmame (RGR) tenderia a diminuir o peso ao nascer e o peso acima de 550 dias, mas devendo aumentar os pesos aos 200,396 e 550 dias.

Os resultados de estimativas de herdabilidade tem sido controvertidos devido às suas variações, ora muito altos ora muito baixos. Deve-se lembrar que entre os parâmetros básicos de herdabilidade destaca-se um que diz respeito à variação da herdabilidade, ou seja, a $h^{2}$ varia com a espécie animal, com a mesma espécie em diferentes condições, de local para local e com o tempo (gerações). Portanto, para se trabalhar com diferentes rebanhos, devese calcular a $\mathrm{h}^{2}$ para cada um e esta só será válida para as condições na qual foi gerada (Giannoni \& Giannoni, 1989) •

\subsubsection{Fatores que podem alterar o peso adulto}

Certamente, o tamanho adulto pode ser alterado através de meios de seleção genética ou de manejo, como demonstrado por Jenkins et al. (1981) e Ferrell \& Jenkins (1984). Além dessas informações, animais que são submetidos a dietas à base de concentrado prematuramente, parecem reduzir o tamanho corporal adulto (Coleman et al., 1993). Enquanto uns citam que o excesso de energia na alimentação pode reduzir o peso adulto, outros afirmam que a falta de energia também pode fazê-lo. O'Donovan (1984), Ryan (1990) e Hogg (1991) estudando efeitos do crescimento compensatório em bovinos, afirmam que pode existir uma diminuição do peso adulto devido às restrições de alimentação se a 
extensão de restrição for muito grande. Esses animais não chegam a apresentar crescimento compensatório e tendem a possuir um peso adulto menor do que outros animais geneticamente idênticos mas que não passaram por restrição alimentar.

Dados de peso adulto, estimados à partir da função de Gompertz modificada (Tabela 14), utilizando-se animais que passaram por período de restrição alimentar, mostram que $O$ peso adulto pode estar subestimado em relação ao dos animais sem restrição alimentar. Vera (1991) cita peso adulto de $350^{\mathrm{a}} ; 332^{\mathrm{ab}} ; 325^{\mathrm{b}} ; 320^{\mathrm{b}} \mathrm{kg}$ e taxa de maturidade de 0,0019; 0,0025; 0,0027; 0,0027 para tratamentos com alta $(2,72)$; média $(1,94)$; baixa $(1,45)$ e baixa $(1,45)$ taxa de lotação (unidades animais/ha) com fêmeas da raça Brahman. Esses valores são muito diferentes dos valores citados por Doren et al. (1989) de $500 \mathrm{~kg}$ de peso vivo e de Menchaca et al. (1996) de 524, 569 e 579 kg para tamanho corporal respectivamente: pequeno, médio e grande com fêmeas Brahman sem restrição alimentar.

Bailey \& Mears (1990) analisando peso ao nascer de bezerros das raças Hereford, Holstein e Angus encontraram uma possível ligação entre o peso ao nascer e o peso adulto. O peso ao nascer estava positivamente correlacionado com o ganho de peso vivo pós-desmama e negativamente correlacionado tanto com a eficiência energética como com a proporção de gordura na carcaça. Essas relações parecem ser devido a uma possível correlação entre peso ao nascer e peso adulto a um dado intervalo de peso vivo, pois, os animais de maior peso adulto ganharam mais peso vivo e depositaram menos gordura do que os animais de peso adulto inferior. Os autores citam o trabalho de Dickinson? que observou essa mesma relação.

\footnotetext{
${ }^{7}$ DICKINSON,A.G. Some genetic implications of maternal effects - an hypothesis of mammalian growth. Journal of Agricultural Science. v. 54, p. 378-90. 1960.
} 


\subsection{Conclusões}

Mostrou-se que existem diferentes tipos de dados que podem ser coletados para ajustar as curvas de crescimento. Os dados longitudinais parecem ser os ideais. As curvas de crescimento não lineares de três ou quatro parâmetros são as mais utilizadas devido à facilidade de associação desses parâmetros com fatores biológicos, embora existam outras funções com componentes exponenciais ou logísticos. De todos os parâmetros discutidos, a taxa de maturidade (" $k$ ") apresenta interesse ímpar em relação aos demais parâmetros devido à sua associação com o perfil da curva de crescimento (precocidade). O método de seleção de melhor convergência de cada modelo ainda deve ser melhor estudado, principalmente do ponto de vista estatístico. Efeitos genotípicos (raças) e ambientais (nutrição) podem modificar os parâmetros das curvas bem como os efeitos fisiológicos (parição). A revisão mostrou que existe alta variação tanto no peso adulto quanto na taxa de maturidade de animais de mesma raça (veja fêmeas Angus: $443 \pm 18,18$ e $0,0022 \pm 0,0005$; para peso adulto e taxa de maturidade respectivamente) que podem estar associados tanto aos procedimentos de ajuste como de manejo dos animais. Nessa revisão foram encontradas altas e baixas herdabilidades para o peso adulto e taxa de maturidade, respectivamente, embora existam muitas variações nesses valores.

\subsection{Implicações}

Os resultados observados na literatura sugerem uma gama enorme de variação nos valores dos parâmetros das curvas de crescimento utilizadas que podem estar associado, principalmente, ao fator 
ambiental expresso pelo efeito de nutrição e/ou manejo que parecem ser o principal responsável por essa variação. Conforme discutido, a idade não é uma boa variável independente para ajuste dos dados de peso vivo. Talvez o uso da disponibilidade de energia/proteína poderia resultar em dados com menor variabilidade. Entretanto, para comparação de graus de maturidade deve-se ajustar o peso em relação à idade. Portanto, experimentos com controle de ingestão energética/protéica através de abates comparativos podem ajudar na elucidação das dúvidas dos parâmetros das curvas de crescimento. O conhecimento do peso adulto e da taxa de maturidade de uma determinada população, pode ajudar na pressão de seleção para animais mais eficientes em termos de produção de $\mathrm{kg}$ de carne (bezerro desmamado) por $\mathrm{kg}$ de matriz ou mesmo na forma de energia consumida. Nesse tipo de enfoque, animais com maior taxa de maturidade (geralmente com menor peso adulto) são mais eficientes.

\subsection{Justificativas}

Sabe-se que animais de mesmo grau de maturidade tendem a apresentar composição corporal semelhantes (Owens et al., 1995) e consequentemente exibem a mesma exigência de energia e proteína para um mesmo ganho de peso (NATIONAL RESEARCH COUNCIL - NRC, 1996); ou seja, animais de mesmo grau de maturidade irão alcançar o mesmo ganho de peso com a mesma quantidade de energia líquida para ganho independentemente do peso adulto. Portanto, o conhecimento do peso adulto de animais de raças diferentes é indispensável para a correta estimativa de exigência de nutrientes obtidos com os modernos sistemas de recomendação (NRC, 1996). Outro parâmetro de grande importância que pode ser obtido através das curvas de crescimento é a taxa de maturidade. Esse parâmetro indica quão precoce um determinado animal é em relação a 
outro animal nas mesmas condições de crescimento ou pode indicar qual animal é mais eficiente em determinadas situações de crescimento.

No âmbito da modelagem e simulação, o conhecimento do peso adulto e taxa de maturidade (principalmente da gordura) permitem que sistemas de recria e engorda entre diferentes raças possam ser comparados no sentido de alcançar maior rentabilidade para o produtor. Os resultados tem mostrado que a escolha da raça/cruzamento não é influenciada pelo método de retorno econômico mas pode ser influenciada pelos diferentes sistemas de classificação de carcaça ("carcass grading"), custos de produção e pelos sistemas de produção utilizado (williams \& Bennett, 1995). Independente do método de avaliação do retorno econômico (\$/rotação ou \$/dia) para os quatro (4) sistemas de pagamento baseados na classificação de carcaça, o Gelbvieh e o Chianina apresentaram os maiores retornos. Para o sistema de produção acelerado, o Charolais apresentou maior \$/animal enquanto que o Maine-Anjou foi melhor para o sistema convencional. Esses conhecimentos quando utilizados harmonicamente permitem que a alocação de raças diferentes em sistemas de pastejo distintos possam alcançar os melhores desempenhos tanto de crescimento quanto de qualidade de carcaça (Camfield et al., 1996a, 1996b) .

o presente trabalho teve por finalidade selecionar a melhor função matemática para descrever a curva de crescimento da raça Guzerá e seus cruzamentos com Nelore, Pardo Suíço, Chianina e Caracú. A função selecionada foi utilizada para avaliar os efeitos de sexo, grupo racial, suplementação e de prenhez no peso adulto e na taxa de maturidade. 


\section{MATERIAL E MÉTODOS}

Este estudo analisa o conjunto de dados obtidos pelo projeto IZ14.012/78 - "Pastejo contínuo pós-desmama com e sem suplementação protéica nas secas", da Divisão de Bovinos de Corte do Instituto de Zootecnia/CPA/SAA.

\subsection{Descrição dos dados}

o ajuste das funções de crescimento para peso-idade foi estudado para machos e fêmeas da raça Guzerá e vários cruzamentos denominados de grupos raciais (1. Guzerá, G; 2. 3/4Guzerá x 3/4Pardo Suíço, 3/4GS; 3. 1/2/2Nelore x 1/4Guzerá x 1/4Pardo Suíço, 1/2N(SG)；4. 1/2Guzerá x 1/2Pardo Suíço, SG; 5. 1/2Chianina $x$ 1/4Guzerá $x$ 1/4Pardo Suíço, $1 / 2 C(S G) ; 6$. 1/2Caracú $x$ 1/2Guzerá, KG e 7. 1/2Caracú x 1/4Guzerá x 1/4Pardo Suíço, 1/2K(SG)), em dois anos consecutivos de nascimento denominados de anos bases (1. para 1978 (A1) e 2. para 1979 (A2), caracterizando $\circ$ ano de início da suplementação) e com três situações de alimentação estratégica denominados de tratamentos (1. sem suplementação (S1); 2. com suplementação apenas no período ("das secas") do inverno (S2) e 3. com suplementação durante o ano todo (S3)) •

No experimento 1 (ano base de 1978) estudou-se os grupos raciais G, $3 / 4 G S, 1 / 2 N(S G), \quad S G$ e $1 / 2 C(S G)$ com os tratamentos $S 1$ e S2 sendo compostos de $0,5 \mathrm{~kg}$ de farelo de soja por animal por dia. o farelo de soja utilizado continha $54 \%$ de $\mathrm{PB}$ na matéria seca. Nesse experimento foram utilizados 63 machos $(205,5 \pm 4,56 \mathrm{~kg})$ e 60 fêmeas $(191,9 \pm 4,56 \mathrm{~kg})$ com data de nascimento média de 22/09/1977 e 25/09/1977, respectivamente. Os machos foram estudados até 03/06/1980 ( \pm 33 meses 
de idade) e as fêmeas até 20/10/1981 ( \pm 50 meses de idade). Ao início do experimento os animais apresentavam idade média de 255,4 $\pm 2,5$ dias. Nesse experimento os machos receberam suplementação apenas no primeiro período de seca pós-desmama (devido ao abate) enquanto que as fêmeas receberam durante quatro períodos de seca pós-desmama consecutivos.

No experimento 2 (ano base de 1979) os grupos raciais estudados foram $G, 3 / 4 G S, \frac{1}{2} \mathrm{~N}(\mathrm{SG}), \mathrm{SG}, 1 / 2 \mathrm{C}(\mathrm{SG}), \mathrm{KG}$ e $1 / 2 \mathrm{~K}(\mathrm{SG})$ com os tratamentos $\mathrm{S} 1$, S2 e S3. No tratamento $\mathrm{S} 2$ todos os animais receberam 1,5 $\mathrm{kg}$ de concentrado por animal por dia. No tratamento 53 apenas os grupos raciais G, $3 / 4 G S$ e $1 / 2 \mathrm{~N}(\mathrm{SG})$ obtiveram suplementação de $1,5 \mathrm{~kg}$ por animal por dia. 0 concentrado era composto por 69,10\% de farelo de trigo; 29,60\% de milho; 1,3응 de uréia apresentando 21을 de $\mathrm{PB}$ na matéria seca. Nesse experimento foram utilizados 91 machos $(220,3 \pm 2,97 \mathrm{~kg})$ e 90 fêmeas $(202,7 \pm 2,99 \mathrm{~kg})$, com data de nascimento média de 23/09/1978 e 26/09/1978, respectivamente. Os machos foram estudados até 02/06/1981 ( \pm 33 meses de idade) e as fêmeas até 12/01/1982 ( \pm 40 meses de idade). Ao início do experimento os animais apresentavam idade média de 268,2 \pm 1,9 dias de idade. Os machos receberam suplementação durante dois períodos de seca pós-desmama consecutivos enquanto que as fêmeas receberam durante três períodos de seca pós-desmama consecutivos.

Todos os animais foram mantidos em pastagem de capim colonião sob pastejo contínuo na Estação Experimental de Zootecnia de Andradina e no Posto Experimental de Castilho do Instituto de Zootecnia/CPA/SAA. A suplementação era oferecida apenas uma vez durante o dia, pela manhã, em cochos adequados à alimentação dos animais.

Os dados de ingestão de pastagem por animal não foram medidos, assim como, não foram feitas as análises bromatológicas dos suplementos nem do pasto. 
Os animais foram vacinados, vermifugados e banhados contra carrapatos periodicamente. As pesagens foram feitas a cada 28 dias, com os animais submetidos ao jejum de alimento e água por aproximadamente 18 horas antes das pesagens.

Os períodos de suplementações para o tratamento s2 durante os dois anos de coleta de dados, seguiram o seguinte cronograma:

Experimento 1, ano base de 1978:

- Machos: 06/06/1978 até 07/11/1978 (154 dias)

- Fêmeas: 06/06/1978 até 07/11/1978 (154 dias); 05/06/1979 até 23/10/1979 (140 dias); 06/05/1980 até $21 / 10 / 1980$ (168 dias) e 02/06/1981 até 20/10/1981 (140 dias).

Experimento 2, ano base de 1979:

- Machos: 19/06/1979 até 09/10/1979 (112 dias) e 20/05/1980 até 04/11/1980 (168 dias)

- Fêmeas: 19/06/1979 até 09/10/1979 (112 dias); 20/05/1980 até $04 / 11 / 1980$ (168 dias) e 02/06/1981 até $17 / 11 / 1981$ (168 dias).

A suplementação durante o ano todo (S3) iniciou-se em 19/06/1979 tanto para os machos como para as fêmeas e encerrou-se em 21/04/1981 para os machos e 12/01/1982 para as fêmeas.

Com relação à seleção dos animais, os que apresentaram curvas não padronizados com a média do grupo ou apresentaram problemas externos de forma que a curva de crescimento fosse alterada, foram eliminados. Nesse caso encontram-se os animais que apresentaram problemas de crescimento durante o período de coleta de dados que por um motivo ou outro não conseguiram acompanhar os demais, portanto não sendo 
representativo da média do lote. A Tabela 13 mostra o total de animais que foram utilizados para ajuste das curvas individuais já excluidos os animais problemáticos.

Apenas para informação, os 6 animais que foram excluidos da Tabela 13 por não apresentarem curva de crescimento padronizada com os outros animais foram: animal 29 (A1, F, 1/2N(SG), S1); animal 96 $\left(\mathrm{A} 2, \mathrm{M}, \frac{1}{1 / 2 \mathrm{~N}}(\mathrm{SG}), \mathrm{S} 3\right) ; \quad$ animal $121 \quad\left(\mathrm{~A} 2, \mathrm{~F}, \frac{1}{2} \mathrm{C}(\mathrm{SG}), \mathrm{S} 1\right) ; \quad$ animal 330 $\left(\mathrm{Al}, \mathrm{M}, 3 \frac{3}{4} \mathrm{GS}, \mathrm{S} 1\right)$; animal $408(\mathrm{Al}, \mathrm{M}, \mathrm{G}, \mathrm{S} 1)$ e animal 435 (A1, F, G, S2).

TABEla 13. NÚMERo DE ANIMAIS UTILIZAdos PARA AJUSTE INDIVIdUAL DAS FUNÇôES DE CRESCIMENTO.

\begin{tabular}{|c|c|c|c|c|c|c|c|c|c|c|}
\hline \multirow[t]{2}{*}{$\mathrm{A}^{\mathrm{T}}$} & \multirow[t]{2}{*}{$T$} & \multirow[t]{2}{*}{$S$} & \multicolumn{7}{|c|}{ Grupos } & \multirow[t]{2}{*}{ Total } \\
\hline & & & $G$ & $3 / 4 \mathrm{GS}$ & $1 / 2 \mathrm{~N}(\mathrm{SG})$ & SG & $1 / 2 \mathrm{C}(\mathrm{SG})$ & $\mathrm{KG}$ & $1 / 2 \mathrm{~K}(\mathrm{SG})$ & \\
\hline \multirow[t]{6}{*}{ A1 } & S1 & Machos & 7 & 8 & 10 & 2 & 2 & & & 29 \\
\hline & S2 & Machos & 9 & 8 & 9 & 3 & 3 & & & 32 \\
\hline & S3 & Machos & & & & & & & & \\
\hline & S1 & Fêmeas & 8 & 9 & $\underline{6}$ & 2 & 4 & & & 29 \\
\hline & S2 & Fêmeas & I & 9 & 7 & 2 & 4 & & & 29 \\
\hline & S3 & Fêmeas & & & & & & & & \\
\hline \multirow[t]{6}{*}{ A2 } & S1 & Machos & 4 & 8 & 9 & 2 & 4 & 6 & 4 & 37 \\
\hline & S2 & Machos & 3 & 7 & 9 & 4 & 2 & 6 & 4 & 35 \\
\hline & S3 & Machos & 3 & 7 & $\underline{8}$ & & & & & 18 \\
\hline & S1 & Fêmeas & 5 & 8 & $\overline{5}$ & 3 & $\underline{8}$ & 5 & 2 & 36 \\
\hline & S2 & Fêmeas & 4 & 8 & 6 & 3 & 9 & 4 & 2 & 36 \\
\hline & S3 & Fêmeas & 4 & 7 & 6 & & & & & 17 \\
\hline
\end{tabular}

Dessa forma o total de machos foi de 61 para o ano 1 e de 90 para o ano 2, totalizando 151 animais. Para as fêmeas foi 58 para o ano 1 e 89 para o ano 2, totalizando 147 animais.

\subsection{Ajustes do peso vivo das fêmeas prenhas}

Uma hipótese a ser testada é se o peso que provem do feto mais os tecidos anexos da placenta, das fêmeas prenhas, afeta 
significativamente os parâmetros da curva de crescimento dessas fêmeas. Dessa forma foram estudados equações que predizem o peso do feto, dado o número de dias de prenhez da vaca. Uma vez que a data de parição é conhecida e que o período de gestação das vacas foi considerado como sendo 290 dias, foi possivel estimar o período em dias para cada animal em cada pesagem para serem utilizados nas funções de estimativa de peso fetal e tecidos anexos. De fato, Randel (1990) cita três fontes de período de gestação de Nelore, Nelore ou Guzerá e Nelore ou Gir ou Guzerá os quais estão ao redor de 291,4; 292,9 e 292 dias; com uma média de 292, 1 dias de período de gestação o que está bastante próximo ao valor de 290 utilizado para ajuste do peso da fêmea corrigido para o peso fetal e de tecidos anexos.

Os dois modelos para cálculo do peso fetal e tecidos anexos da placenta analisados foram: Ferrell et al. (1976a, 1976b), Equação 9 e Prior \& Laster (1979), Equação 10.

\section{EQUAÇÃo 9}

$$
\text { Ptotal }=0,7439 \cdot e^{\left(0,02 \cdot t-0,0000143 \cdot t^{2}\right)}
$$

\section{EQUAÇÃo 10}

$$
\begin{gathered}
\text { Pfeto }=0,000683 \cdot \mathrm{e}^{\left(0,0738 \cdot \mathrm{t}-0,0001249 \cdot \mathrm{t}^{2}\right)} \\
\text { Pfluido }=-4,15+0,0521 \cdot \mathrm{t} \\
\text { Pcotiledones }=1,497 \cdot \mathrm{e}^{\left(0,05614 \cdot \mathrm{t}-0,0001031 \cdot \mathrm{t}^{2}\right)} \\
\text { Pplacenta }=6,133 \cdot \mathrm{e}^{\left(0,04378 \cdot \mathrm{t}-0,000076 \cdot \mathrm{t}^{2}\right)} \\
\text { Putero }=55,208 \cdot \mathrm{e}^{\left(0,02475 \cdot \mathrm{t}-0,00003479 \cdot \mathrm{t}^{2}\right)} \\
\text { Ptotal }=\text { Pfeto + Pfluido + Pcotiledones + Pplacenta + Putero }
\end{gathered}
$$


O modelo de Bell et al. (1995), Equação 11, estima apenas o peso do feto e dos tecidos anexos da placenta entre 190 e 270 dias de gestação e foi utilizado apenas como comparação.

\section{EQUAÇĀo 11}

$$
\text { Ptotal }=0,664 \cdot \mathrm{t}-102
$$

O modelo de Ferrell et al. (1976a, 1976b) consiste de uma equação exponencial que calcula o peso do útero grávido - o qual consiste de feto, fluídos, membranas e útero - (Equação 9, em kg) e o modelo de Prior \& Laster (1979) consiste de uma soma de vários componentes para se obter o peso total - cuja soma consiste de feto, fluídos, cotilédones, placenta e útero - (Equação 10, em kg). O Gráfico 1 está mostrando a evolução de peso do feto e dos tecidos dos três modelos.

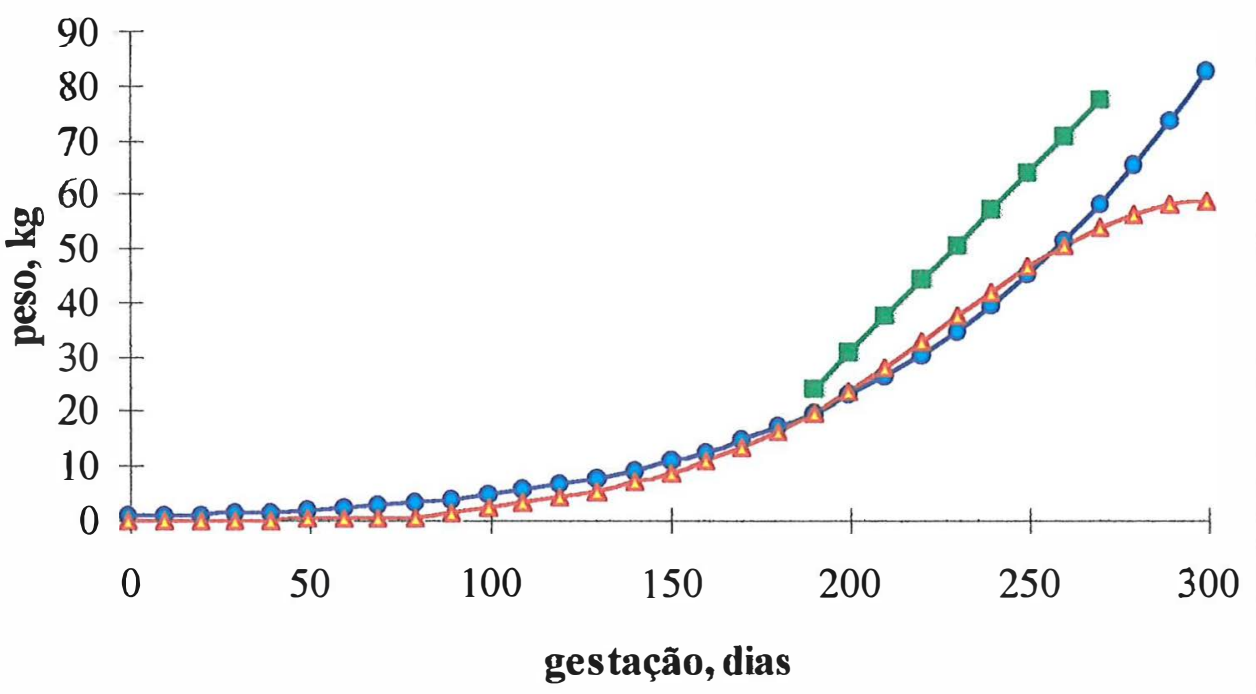

$\multimap$ Ferrell et al. (1976) $\triangle$ Prior \& Laster (1979) $\rightarrow-$ Bell et al. (1995)

GRÁfiCo 1. ESTIMATIVA DA EVOLUÇẢo do PESO DO FETO E DOS TECIDOS ANEXOS DA PLACENTA. 
Ferrel et al. (1976a, 1976b) utilizaram 96 fêmeas, sendo a maioria Hereford. Prior \& Laster (1979) utilizaram fêmeas Hereford, Angus e Red Poll cruzadas com touros Pardo Suíço. Bell et al. (1995) utilizaram fêmeas Holstein.

A estimativa de peso fetal total dos dois primeiros modelos é bastante próxima, diferindo apenas após 265 dias de gestação, onde a função de Ferrell et al. (1976a, 1976b) continua com acréscimo de peso e o modelo de Prior \& Laster (1979) tende a ficar constante conforme está esquematizado no Gráfico 1.

Segundo Bell et al. (1995), as vacas Holstein utilizadas no experimento estavam bem alimentadas e, talvez, devido a isso o peso do concepto está superestimado em relação a outros animais da mesma raça. De fato, Ferrell (1993) cita que a nutrição materna entre outros fatores, realmente afeta o crescimento do feto, principalmente no final da gestação quando a exigência nutricional do feto é maior.

Para efeito de correção, apenas a função de Prior \& Laster (1979) foi utilizada para corrigir o peso das fêmeas que estavam prenhas durante o período de análise dos dados para ajustar as curvas de crescimento. A função de Ferrel et al. (1976a, 1976b) não foi utilizada por superestimar o valor do peso ao nascimento. A partir desse instante ficaram determinados três sexos, a saber: (M) - para machos, (F) para fêmeas sem correção de peso fetal e tecidos anexos da placenta e ( $\left.F_{a j}\right)$ para fêmeas com correção de peso fetal e tecidos anexos da placenta.

\subsection{Funções de crescimento utilizadas}

As funções de crescimento utilizadas para convergir os dados de peso em relação à idade, tanto para animais individuais como grupal, estão listados na Tabela 14 . 
A função de Gompertz modificada não apresenta o componente peso adulto, entretanto, esse pode ser facilmente computado se assumirmos que o peso adulto é o peso vivo do animal quando o tempo tende ao infinito. Dessa forma o peso adulto dessa equação, é obtido através da Equação 12 .

TABEla 14. Funções de CRescimentoutilizadas para AJUSTe dos dados.

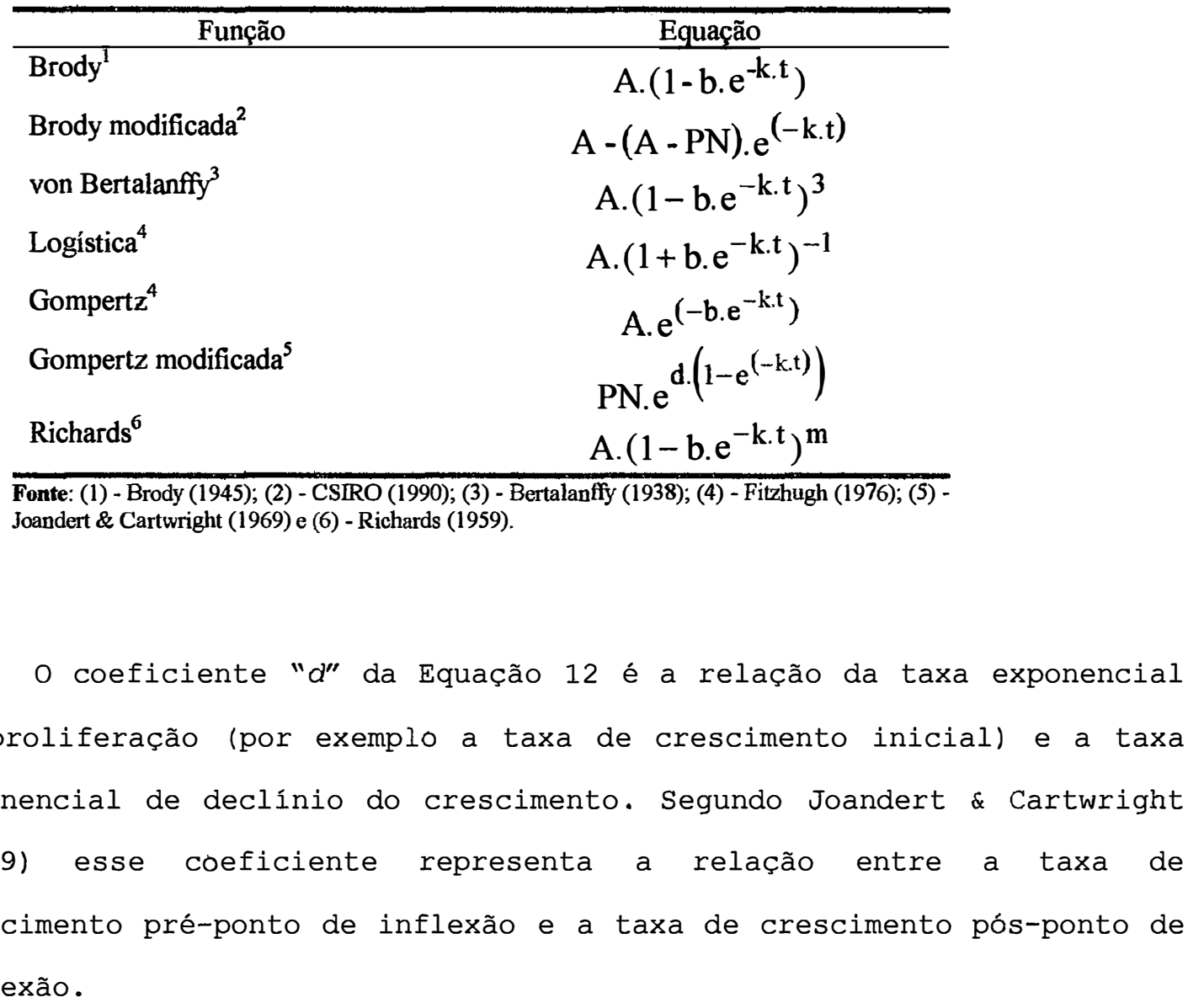

\section{EQUAÇÃo 12}

$$
A=P N \cdot e^{d}
$$


Uma variação da função de Gompertz, que também é muito utilizada, está mostrada na Equação 13 (Brown et al., 1976):

\section{EQUAÇÃo 13}

$$
\mathrm{PV}=\mathrm{PN} . \mathrm{e}^{\left(\frac{\mathrm{L} \cdot\left(1-\mathrm{e}^{-k . t}\right)}{\alpha}\right)}
$$

onde:

$$
\begin{aligned}
& \text { L - mede a inclinação da curva; } \\
& \alpha \text { - mede a taxa de declínio. }
\end{aligned}
$$

Através da Equação 13 pode-se notar que o coeficiente " $d$ " descrito na Equação 12 é a relação entre os coeficientes " $L$ " e " $\alpha$ " da Equação 13.

A Equação 14 representa outra forma de expressar a função de Gompertz segundo Ratkowsky (1990).

\section{EQUAÇÃo 14}

$$
P V=A \cdot e^{\left(-e^{(\beta-k . t)}\right)}
$$

Sabendo-se que o ponto de inflexão da Equação 14 é representada por $\beta / k$ (Ratkowsky, 1990), pode-se estimar o ponto de inflexão da função de Gompertz mostrada pela Tabela 14 como sendo In(b)/k.

Ratkowsky (1990) mostra outras variações possíveis para cada função não linear citada nesse trabalho que podem facilitar a convergência, como por exemplo a Equação 15. 


\section{EQUAÇÃo 15}

$$
\mathrm{PV}=\mathrm{A} \cdot\left(1-\mathrm{e}^{\left(-\beta \cdot \mathrm{x}^{\gamma}\right)}\right) \text { tendo } \mathrm{PI}=\left(\frac{\gamma-1}{\beta \cdot \gamma}\right)^{\left(\frac{1}{\gamma}\right)}
$$

\subsection{Procedimentos da análise univariada}

Uma vez obtidos todos os parâmetros inerentes a cada função de crescimento foi realizado uma seleção dos animais que obtiveram convergência e peso adulto ("A") não superior a $1000 \mathrm{~kg}$. Esse peso limite foi estabelecido conforme análise prévia dos dados existentes na literatura e por ser bastante condizente com o tamanho corporal dos animais utilizados.

As análises estatísticas foram efetuadas pelo software SAS® (1987) utilizando-se os procedimentos GLM, REG, NLIN, MEANS, CLUSTER, UNIVARIATE e TTEST. No Procedimento GLM, a soma de quadrados analisada foi a do tipo III. No procedimento NLIN o método empregado para convergência dos dados foi o de Gauss-Newton, descrito por Hartley (1961) e por Lawton et al. (1972).

Uma vez ajustado cada função não linear, as variáveis foram analisadas univariadamente através do modelo estatístico descrito pela Equação 16. Esse modelo mostra apenas os efeitos do fatores principais, entretanto todas as interações possíveis entre esses fatores também foram incluídas nesse mesmo modelo estatístico:

\section{EQUAÇÃo 16}

$$
\mathrm{Y}_{\mathrm{ijklm}}=\mu+\mathrm{Ano}_{\mathrm{i}}+\text { Tratamento }_{\mathrm{j}}+\text { Sexo }_{\mathrm{k}}+\text { Raca }_{1}+\text { Funcao }_{\mathrm{m}}+\varepsilon_{\mathrm{ijklm}}
$$


Após a seleção da função não linear, a qual apresentou-se mais adequada aos dados, o mesmo modelo estatístico (Equação 16) foi utilizado sem o efeito de Modelom e suas interações. Conforme procedimento padrão da análise estatística, quando dois ou mais efeitos apresentaram interações significativas, o efeito dos fatores isolados não foram analisados e cada fator da interação foi analisado dentro de cada nível do segundo fator e vice-versa.

Os procedimentos para gerar as curvas não lineares foram montadas conforme Pereira \& Arruda (1987) e SAS® (1987). As estimativas das derivadas primeira de cada parâmetro necessário para a convergência foram calculadas e são apresentadas no Apêndice 1. Na análise de significância, para comparação múltipla entre médias dos parâmetros de cada modelo foi utilizado o teste de contrastes REGWF (Teste de 'F' múltiplo de Ryan-Einot-Gabriel-Welsh) conforme sugerido pelo próprio SoftWare SAS ${ }^{\circledR}$ (1987) devido ao melhor controle do erro tipo II ( $\beta$, aceitar $H_{0}$ sendo esta falsa). A estrutura de análise de todos os modelos estatísticos seguiram recomendações descritas por SAS® (1987) e a montagem dos modelos seguiram os esquemas propostos por Montgomery (1984).

Devido à grande quantidade de animais que não apresentavam convergência em algumas funções, principalmente na de Richards, pelo SoftWare SAS® (1987), outro SoftWare específico, desenvolvido apenas para ajuste de curvas, Jandel Scientific (1994), também foi utilizado. Embora esse último não mostrasse a convergência dos dados, foi possível verificar que a estimativa do erro padrão dos parâmetros era maior que o próprio valor da estimativa do parâmetro, portanto mostrando que não era um valor confiável. O SAS® (1987) foi tão eficiente quanto o Jandel Scientific (1994). Devido à dificuldade de alimentação e obtenção dos 
dados desse último SoftWare, O SAS ${ }^{\circledR}$ (1987) foi utilizado para ajuste das curvas.

Os dados de pesagens foram coletados em determinadas datas e, certamente, os animais não possuíam a mesma idade. Quando os ajustes das curvas individuais foram efetuados, cada animal teve a data de pesagem corrigida para a data de nascimento. Entretanto quando foi efetuado o ajuste por grupo as idades foram ajustadas para a idade média de nascimento dos animais dentro de cada ano (1978 e 1979) gerando duas datas de nascimento média.

\subsection{Procedimentos da análise multivariada}

Para testar as curvas de crescimento no âmbito multivariado, os parâmetros: peso adulto (A), taxa de maturidade ( $k$ ) e parâmetro de integração (b) de todos os animais, foram analisados pelo SoftWare SAS® (1987) através do procedimento GLM, com a opção MANOVA e RANDOM. As somas de quadrados analisadas foram do tipo III. As comparações entre médias foram elaboradas através de contrastes ortogonais multivariados através do procedimento GIM.

A análise multivariada foi separada por ano, principalmente devido a dificuldade de separar os efeitos de cada fator através do uso de contrastes ortogonais para a interação de $3 \circ$ grau. 0 ano base de 1978 possuía 5 grupos raciais (G, 3/4GS, 3/2N(SG), SG, $1 / 2 \mathrm{C}(\mathrm{SG})$ ) para machos (M) e fêmeas sem (F) e $\operatorname{com}\left(F_{a j}\right)$ ajuste do peso vivo para o peso fetal e tecidos anexos da placenta sob dois tratamentos diferentes: sem suplementação (S1) e com suplementação durante o inverno (S2). 0 ano base de 1979 possuía 7 grupos raciais (G, 3/4GS, $1 / 2 N(S G), \quad S G, 1 / 2 C(S G), K G$, $1 / 2 K(S G))$ para machos e fêmeas $\left(F\right.$ e $F_{a j}$ ) sob dois tratamentos diferentes: sem suplementação (S1) e com suplementação durante o inverno (S2) . 
Nesse mesmo ano, apenas aos grupos raciais: G, $3 / 4 G S$ e $1 / 2 N(S G) \quad$ foi avaliado outro tratamento, suplementação durante o ano todo (S3). Esses dados permitiram que duas análises estatisticas fossem conduzidas: (1.) os animais foram separados por ano e analisados os efeitos de tratamento (S1 e S2), grupo racial e sexo. (2.) os grupos raciais $G, \frac{3}{4} G S, 3 / 2 N(S G)$ foram considerados como efeitos aleatórios e analisados para os efeitos de tratamento (S0, s1 e s2), grupo racial e sexo. 


\section{RESULTADOS E DISCUSSÕES}

\subsection{Considerações iniciais}

A análise das idades no início do experimento como covariável, para os dados de peso grupal (quando os animais com os mesmos tratamentos foram alocados), mostrou que a idade tem influência sobre o peso dos animais do ano 1 desde a $1^{\text {a }}$ data de pesagem até a $24^{\text {a }}$ data de pesagem ( 815 dias de idade; $\mathrm{P}<0,01$ ) e da 25ạ (843 dias de idade) até a 26a pesagem (871 dias de idade; $P<0,05)$. Já para o ano 2 a idade foi correlacionada significativamente com os pesos desde a $1^{\text {a }}$ pesagem até a última pesagem (1206 dias de idade); ou seja, tanto para o ano 1 como para o ano 2 os animais apresentavam idades significativamente diferentes, portanto o ajuste de idade dos animais em grupo através de uma idade média por ano apresenta dependência do valor da covariável idade. A análise multivariada, através da opção REPEATED, mostrou que o efeito dos fatores do modelo estatístico não poderiam ser analisados para cada data de pesagem, pois o teste de esfericidade foi altamente significativo $(\mathrm{P}<0,001)$, ou seja, a matriz de variâncias e covariâncias não era homogênia.

A análise de normalidade dos dados foi realizada através da PROC UNIVARIATE (SAS®, 1987) dentro de cada data de pesagem, quando os animais foram agrupados na mesma idade através do ajuste da idade média de cada ano. Todas as idades apresentaram dados com distribuição normal e uma análise de média-variância mostrou que as variâncias, dentro de cada idade grupal (Ano de 1978 e 1979) para cada idade de coleta de peso entre os diversos fatores, apresentaram-se homogêneas, ou seja, nesses dados não houve heterocedasticidade de variância, não necessitando de transformação dos dados. Embora a variância ao longo 
das pesagens fosse aumentada, conforme as características desse tipo de dado.

\subsection{Seleção da função de crescimento}

Após o ajuste dos dados de peso-idade para estimar os parâmetros de cada função foram elaborados três tabelas para descrever o comportamento de cada modelo em relação ao ajuste do peso adulto, de forma que fixando-se valores de peso adultos máximos (limites), obtinha-se a quantidade de animais que convergiram com peso adulto até esse valor. Dessa forma é possível avaliar a complexidade de convergência e a tendência média do valor do peso adulto.

A Tabela 15 (para machos) mostra a percentagem de animais que convergiram quando o limite de aceitação do peso adulto variava. Conforme aumentava-se o limite de peso adulto para aceitação, a quantidade de animais que convergem era aumentada.

Tabela 15. Cálculo das Percentagens de ConvergênCia dos machos para Cada função FIXANDO-SE O VALOR MÁXIMO DE PESO ADULTO.

\begin{tabular}{|c|c|c|c|c|c|c|c|c|c|c|c|c|}
\hline \multirow[t]{2}{*}{ Função } & \multicolumn{12}{|c|}{ Pesos Adulto } \\
\hline & 500 & 550 & 600 & 650 & 700 & 750 & 800 & 850 & 900 & 950 & 000 & 1050 \\
\hline & & 3,3 & 4,6 & 9,27 & 12,58 & 38 & 25,83 & 75 & 45,70 & 56,95 & 2,25 & $\overline{7,55}$ \\
\hline & & 2 & 3 & 0 & 9,27 & 26 & 13,91 & & 27,81 & 32,45 & 37,75 & 43,71 \\
\hline & 18,54 & 41,06 & 76,16 & 90,07 & 94,04 & 03 & 97,35 & 97 & 98,68 & 99,34 & 99,34 & 99,34 \\
\hline & 5,96 & 16,56 & 34,44 & 59,60 & 77,48 & 86,09 & 90,73 & 92,72 & 94,70 & 96,03 & 96,03 & 96,69 \\
\hline ffy & 3,97 & 10,60 & 18,54 & 37,09 & 55,63 & 73,51 & 78,15 & 84,77 & 88,08 & 90,73 & 91,39 & 92,72 \\
\hline Rich & 0,00 & 0,00 & 0,66 & 0,66 & 1,99 & 2,65 & 2,65 & 2,65 & 3,31 & 3,97 & 4,64 & 5,96 \\
\hline Gomp $\mathbf{M}$ & 45,70 & 72,19 & 96,03 & 100,00 & 100,00 & 100,00 & 100,00 & 00,00 & 00,00 & 100,00 & 100,00 & 100,00 \\
\hline
\end{tabular}

- Os números em negrito indicam percentagem maior do que $50 \%$.

De forma geral existiram dois grupos de convergência: no primeiro grupo estariam as funções de Brody modificada, Brody e Richards que apresentaram uma estimativa de peso adulto maior em relação ao segundo grupo de convergência que seriam as funções Logística, Gompertz, von 
Bertalanffy e Gompertz modificada. De forma geral a convergência para o primeiro grupo foi muito baixa.

Com relação às fêmeas com peso sem correção para peso fetal e tecidos anexos da placenta (F), pôde-se claramente notar que a percentagem de convergência é muito maior do que para os machos (Tabela 16).

TABEla 16. CÁlCUlo das PERCENTAGENS de CONVERGÊNCIA dAS FÊMEAS SEM CORREÇÃo de PESO FETAL E TECIDOS ANEXOS DA PLACENTA PARA CADA FUNÇÃo FIXANDO-SE O VALOR MÁXIMO DE PESO ADULTO.

\begin{tabular}{lllllllllllll}
\hline \multirow{2}{*}{ Função } & \multicolumn{10}{c}{ Pesos Adulto } & \multicolumn{1}{c}{} \\
\cline { 2 - 11 } & 500 & 550 & 600 & 650 & 700 & $\mathbf{7 5 0}$ & $\mathbf{8 0 0}$ & 850 & 900 & 950 & 1000 & 1050 \\
\hline Brody_M & 40,82 & $\mathbf{5 6 , 4 6}$ & $\mathbf{7 2 , 7 9}$ & $\mathbf{7 7 , 5 5}$ & $\mathbf{8 1 , 6 3}$ & $\mathbf{8 6 , 3 9}$ & $\mathbf{8 8 , 4 4}$ & $\mathbf{9 1 , 1 6}$ & $\mathbf{9 3 , 2 0}$ & $\mathbf{9 3 , 2 0}$ & $\mathbf{9 3 , 2 0}$ & $\mathbf{9 5 , 9 2}$ \\
Brody & 46,94 & $\mathbf{6 0 , 5 4}$ & $\mathbf{7 4 , 1 5}$ & $\mathbf{7 8 , 9 1}$ & $\mathbf{8 2 , 9 9}$ & $\mathbf{8 6 , 3 9}$ & $\mathbf{8 9 , 1 2}$ & $\mathbf{9 1 , 8 4}$ & $\mathbf{9 2 , 5 2}$ & $\mathbf{9 3 , 2 0}$ & $\mathbf{9 3 , 8 8}$ & $\mathbf{9 4 , 5 6}$ \\
Logística & $\mathbf{8 7 , 0 7}$ & $\mathbf{9 3 , 8 8}$ & $\mathbf{9 5 , 9 2}$ & $\mathbf{9 7 , 2 8}$ & $\mathbf{9 7 , 9 6}$ & $\mathbf{9 7 , 9 6}$ & $\mathbf{9 8 , 6 4}$ & $\mathbf{9 9 , 3 2}$ & $\mathbf{9 9 , 3 2}$ & $\mathbf{1 0 0 , 0 0}$ & $\mathbf{1 0 0 , 0 0}$ & $\mathbf{1 0 0 , 0 0}$ \\
Gompertz & $\mathbf{7 4 , 1 5}$ & $\mathbf{8 7 , 0 7}$ & $\mathbf{9 3 , 8 8}$ & $\mathbf{9 5 , 2 4}$ & $\mathbf{9 5 , 9 2}$ & $\mathbf{9 5 , 9 2}$ & $\mathbf{9 7 , 2 8}$ & $\mathbf{9 7 , 9 6}$ & $\mathbf{9 7 , 9 6}$ & $\mathbf{9 7 , 9 6}$ & $\mathbf{9 8 , 6 4}$ & $\mathbf{9 8 , 6 4}$ \\
Bertalanffy & $\mathbf{6 8 , 7 1}$ & $\mathbf{8 4 , 3 5}$ & $\mathbf{8 9 , 1 2}$ & $\mathbf{9 3 , 8 8}$ & $\mathbf{9 5 , 2 4}$ & $\mathbf{9 5 , 2 4}$ & $\mathbf{9 5 , 9 2}$ & $\mathbf{9 5 , 9 2}$ & $\mathbf{9 7 , 2 8}$ & $\mathbf{9 7 , 2 8}$ & $\mathbf{9 7 , 9 6}$ & $\mathbf{9 7 , 9 6}$ \\
Richards & 12,24 & 17,01 & 18,37 & 19,05 & 20,41 & 20,41 & 21,09 & 21,09 & 21,77 & 21,77 & 21,77 & 21,77 \\
Gomp M & $\mathbf{8 7 , 7 6}$ & $\mathbf{9 5 , 9 2}$ & $\mathbf{9 7 , 9 6}$ & $\mathbf{9 9 , 3 2}$ & $\mathbf{1 0 0 , 0 0}$ & $\mathbf{1 0 0 , 0 0}$ & $\mathbf{1 0 0 , 0 0}$ & $\mathbf{1 0 0 , 0 0}$ & $\mathbf{1 0 0 , 0 0}$ & $\mathbf{1 0 0 , 0 0}$ & $\mathbf{1 0 0 , 0 0}$ & $\mathbf{1 0 0 , 0 0}$ \\
\hline
\end{tabular}

- Os números em negrito indicam percentagem maior do que $50 \%$.

Ao limite de $800 \mathrm{~kg}$ de peso adulto, já encontrava-se uma média de convergência da ordem de 95\%. Em uma análise superficial, comparando-se os dados de convergência da Tabela 15 e Tabela 16, é de se esperar que o peso adulto dos machos seja maior do que o das fêmeas.

Novamente, pôde-se identificar 3 grupos de convergência: o primeiro composto das funções Logística, Gompertz, von Bertalanffy e Gompertz modificada apresentando alta percentagem de convergência com peso adulto baixo; o segundo grupo de convergência foi composto pelas funções de Brody modificada e de Brody, as quais apresentaram alta percentagem de convergência apenas com peso adulto elevado e um terceiro grupo de convergência que foi a função de Richards a qual não apresentou convergência satisfatória (Tabela 16). 
Quando a Tabela 17 foi analisada e comparada com a Tabela 16, pôde-se perceber que a facilidade de convergência foi maior para todas as curvas e desde o peso adulto limite de $500 \mathrm{~kg}$ apresentaram maiores taxas de percentagem de convergência.

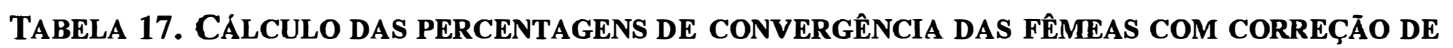
PESO FETAL E TECIDOS ANEXOS DA PLACENTA PARA CADA FUNÇÃO FIXANDO-SE O VALOR MÁXIMO DE PESO ADULTO.

\begin{tabular}{|c|c|c|c|c|c|c|c|c|c|c|c|c|}
\hline \multirow[t]{2}{*}{ Função } & \multicolumn{12}{|c|}{ Pesos Adulto } \\
\hline & 500 & 550 & 600 & 650 & 700 & 750 & 800 & 850 & 900 & 950 & 1000 & 1050 \\
\hline Broc & 53,06 & 69,39 & 78,23 & 83,67 & 87,07 & 88,44 & 90,48 & 91,84 & 93,20 & 93,20 & 93,20 & 95,92 \\
\hline Brody & 55,10 & $\mathbf{7 0 , 7 5}$ & 78,91 & 82,99 & 87,76 & 89,12 & 89,80 & 93,20 & 93,88 & 93,88 & 94,56 & 94,56 \\
\hline Logí & 88,44 & 94,56 & 95,92 & 97,28 & 97,96 & 97,96 & 98,64 & 99,32 & 99,32 & 100,00 & 100,00 & 100,00 \\
\hline Gom & 82,31 & 90,48 & 93,88 & 95,24 & 95,92 & 95,92 & 97,28 & 97,96 & 97,96 & 97,96 & 98,64 & 98,64 \\
\hline inffy & $\mathbf{7 6 , 8 7}$ & 87,07 & 91,84 & $\mathbf{9 3 , 8 8}$ & 95,24 & 95,24 & 95,92 & 95,92 & 97,28 & 97,28 & 97,96 & 97,96 \\
\hline Richards & 17,69 & 25,17 & 25,85 & 26,53 & 27,21 & 27,21 & 27,89 & 27,89 & 28,57 & 28,57 & 28,57 & 28,57 \\
\hline Gomp M & 91,16 & 96,60 & $\mathbf{9 7 , 9 6}$ & 99,32 & 100,00 & 100,00 & 100,00 & 100,00 & 100,00 & 100,00 & 100,00 & 100,00 \\
\hline
\end{tabular}

Comparando-se a Tabela 16 e Tabela 17 nota-se que a correção para peso fetal e tecidos anexos da placenta das fêmeas prenhas $\left(F_{a j}\right)$ aumentou a taxa de convergência e diminuiu proporcionalmente o peso adulto dos animais. Analisando-se o nível de $800 \mathrm{~kg}$ pôde-se notar que as fêmeas sem correção (F) que convergiram, perfaziam 88,4\% enquanto que as fêmeas com correção $\left(F_{a j}\right)$ perfaziam $90,5 \%$.

o quadro de análise de variância que avalia o modelo estatístico descrito pela Equação 16 está sumariado na Tabela 18 . 
TABELA 18. NíveIS dE SIGNIFICÂNCIA ENTRE AS VARIÁVEIS PARA SELEÇÃo dA FUNÇÃo E dOS PARÂMETROS DAS FUNÇÕES DE CRESCIMENTO.

\begin{tabular}{|c|c|c|c|c|c|c|}
\hline Causas de variação & GL & $\mathrm{SQr}$ & $\mathrm{R}^{2}$ & Syx & "A" & "k" \\
\hline Ano (A) & 1 & $*$ & $* * *$ & $* * *$ & & \\
\hline Tratamento (T) & 2 & $* * *$ & $* * *$ & $* * *$ & & $* * *$ \\
\hline $\mathrm{A}^{*} \mathrm{~T}$ & 1 & & & $*$ & & \\
\hline Grupo racial (R) & 6 & $* * *$ & $* * *$ & $* * *$ & $*$ & $* * *$ \\
\hline$A^{*} \mathrm{R}$ & 4 & $*$ & $* * *$ & $*$ & $* *$ & \\
\hline $\mathrm{T} * \mathrm{R}$ & 8 & $*$ & $* * *$ & $* *$ & $*$ & \\
\hline $\mathrm{A} * \mathrm{~T} * \mathrm{R}$ & 4 & & & & $* * *$ & $* * *$ \\
\hline Sexo (S) & 1 & $* * *$ & $* * *$ & $* * *$ & $* * *$ & $* * *$ \\
\hline$A * S$ & 1 & $* * *$ & $* *$ & & & \\
\hline $\mathrm{T} * \mathrm{~S}$ & 2 & $*$ & $* * *$ & $*$ & & $* * *$ \\
\hline $\mathrm{A}^{*} \mathrm{~T} * \mathrm{~S}$ & 1 & & $* *$ & $*$ & & \\
\hline $\mathrm{R} * \mathrm{~S}$ & 6 & $* * *$ & $* *$ & $* * *$ & $* * *$ & $* * *$ \\
\hline$A * R * S$ & 4 & $*$ & $* *$ & $*$ & & \\
\hline $\mathrm{T} * \mathrm{R} * \mathrm{~S}$ & 8 & & $*$ & & & \\
\hline $\mathrm{A}^{*} \mathrm{~T} * \mathrm{R} * \mathrm{~S}$ & 4 & & & & $* * *$ & $* * *$ \\
\hline Função (M) & 6 & $* * *$ & $* * *$ & $* * *$ & $* * *$ & $* * *$ \\
\hline $\mathrm{A} * \mathrm{M}$ & 6 & & & & & \\
\hline $\mathrm{T}^{*} \mathrm{M}$ & 12 & & $* *$ & & & $* * *$ \\
\hline $\mathrm{A}^{*} \mathrm{~T} * \mathrm{M}$ & 6 & & & & & \\
\hline $\mathbf{R} * \mathbf{M}$ & 36 & & & & & \\
\hline$A^{*} R^{*} M$ & 24 & & & & & \\
\hline$T^{*} \mathrm{R} * \mathrm{M}$ & 48 & & & & & \\
\hline $\mathrm{A}^{*} \mathrm{~T}^{*} \mathrm{R} * \mathrm{M}$ & 24 & & & & & \\
\hline $\mathrm{S}^{*} \mathrm{M}$ & 6 & $*$ & $* * *$ & $* * *$ & $* * *$ & $* * *$ \\
\hline$A * S * M$ & 6 & & & & & \\
\hline $\mathrm{T} * \mathrm{~S} * \mathrm{M}$ & 12 & & & $* *$ & & \\
\hline $\mathrm{A}^{*} \mathrm{~T} * \mathrm{~S} * \mathrm{M}$ & 6 & & & & $* *$ & \\
\hline $\mathrm{R} * \mathrm{~S} * \mathrm{M}$ & 33 & & & & & \\
\hline $\mathrm{A}^{*} \mathrm{R} * \mathrm{~S} * \mathbf{M}$ & 21 & & & & & \\
\hline $\mathrm{T} * \mathrm{R} * \mathrm{~S} * \mathrm{M}$ & 41 & & & & & \\
\hline $\mathrm{A}^{*} \mathrm{~T} * \mathrm{R} * \mathrm{~S} * \mathbf{M}$ & 16 & & & & $*$ & \\
\hline
\end{tabular}

Dessa forma o número de animais que foi utilizado para análise estatística dos parâmetros podem ser obtidos dessas tabelas. Por exemplo, para os machos a função de Brody com peso adulto de $800 \mathrm{~kg}$ aponta para 13,91\% dos dados; ou seja, 13,91\% de 151 machos resulta em apenas 21 animais que convergiram e obtiveram peso adulto inferior a $800 \mathrm{~kg}$.

Os resultados da Tabela 18 são muito complexos para serem analisados como um todo, basicamente devido às interações de 3으, 4으 e 5은 
graus. Através dessa tabela, pôde-se apenas concluir que as funções possuiam comportamentos diferentes para cada variável incluída no modelo $(\mathrm{P}<0,001)$ e, além do mais, possuiam interações altamente significativas com $O$ sexo $(\mathrm{P}<0,001)$. De forma geral o peso adulto (" $A$ ") não foi afetado pela suplementação (tratamento), independente da função utilizada enquanto que a taxa de maturidade foi influenciada pelo tipo de suplementação $(P<0,001)$. Nesse quadro de análise de variância, apenas o sexo das fêmeas ajustados para peso fetal e tecidos anexos da placenta $\left(F_{a j}\right)$ foram utilizados, devido às limitações operacionais do Software SAS®. A Tabela 19 mostra os quatro fatores que foram analisados para seleção da função.

TABELA 19. MÉdias AJUSTADAS dOS FATORES PARA SELEÇÃO DA FUNÇÃo DE CRESCIMENTO.

\begin{tabular}{|c|c|c|c|c|}
\hline Função & SQ resíduo & $\mathrm{R}^{2}$ & $\begin{array}{l}\text { Desvios da } \\
\text { Regressão }\end{array}$ & "A" \\
\hline Brody_M & $28298,6 \pm 1017,20^{\text {bc }}$ & $91,2 \pm 0,27^{\mathbf{b}}$ & $27,20 \pm 0,46^{\text {bcd }}$ & $596,3 \pm 8,76^{a}$ \\
\hline Brody & $29861,9 \pm 1045,97^{\mathbf{b}}$ & $90,9 \pm 0,28^{\mathbf{b}}$ & $28,10 \pm 0,49^{\mathbf{b}}$ & $571,0 \pm 8,96^{\mathbf{b}}$ \\
\hline Logística & $24957,7 \pm 750,68$ cd & $92,2 \pm 0,19^{a}$ & $27,05 \pm 0,33$ bcd & $482,6 \pm 4,83^{\text {ef }}$ \\
\hline Gompertz & $24233,4 \pm 812,27^{d}$ & $92,5 \pm 0,21^{\mathbf{a}}$ & $26,17 \pm 0,37^{\text {cd }}$ & $515,8 \pm 5,95^{\text {cd }}$ \\
\hline Bertalanffy & $24331,0 \pm 847,17^{d}$ & $92,5 \pm 0,22^{a}$ & $25,97 \pm 0,39^{d}$ & $536,8 \pm 6,84^{c}$ \\
\hline Richards & $55880,1 \pm 2006,18^{a}$ & $83,0 \pm 0,45^{\mathbf{b}}$ & $39,16 \pm 0,72^{a}$ & $493,2 \pm 8,10^{\text {de }}$ \\
\hline Gomp M & $27157,8 \pm 806,76^{\text {bed }}$ & $91,6 \pm 0,20^{a b}$ & $27,79 \pm 0,35^{\mathbf{b c}}$ & $462,1 \pm 3,16^{\mathbf{f}}$ \\
\hline
\end{tabular}

Letras distintas na mesma coluna indicam diferença estatística pelo teste de REGWF ao nível de $5 \%$.

o peso adulto apresentou interação significativa com outros fatores, portanto o valor médio colocado nessa tabela é apenas para comparação entre valores extremos e não deve ser utilizado em hipótese alguma como valor estimado. Essa tabela foi elaborada através do PROC MEANS sobre o modelo estatístico apenas com o fator Funçãom . Quanto à soma de quadrados do resíduo, as funções de Gompertz e de von Bertalanffy apresentaram menores valores $(P<0,05)$. Os valores de $R^{2}$ foram maiores, estatisticamente $(P<0,05)$, para as funções Logística, Gompertz e von Bertalanffy. Para os desvios de regressão as curvas de 
Brody modificada, Logística, Gompertz e von Bertalanffy, que não diferiram entre si, apresentaram os menores valores $(P<0,05)$. Para 0 peso adulto os valores extremos foram observados para as curvas de Brody modificada e Gompertz modificada $(P<0,05)$, respectivamente maior e menor valor.

Os dados da Tabela 15, Tabela 16 e Tabela 17 permitem avaliar a complexidade de convergência das funções ajustadas, principalmente, para a função de Richards, tanto para fêmeas quanto para os machos. Esse fato deve ser devido à falta de dados em períodos críticos da curva, que estão ao redor do ponto de inflexão, e à pequena longevidade dos dados de peso-idade dos animais, ou seja, animais jovens para convergência do peso adulto (Richards, 1950). A revisão de literatura mostrou que a dificuldade computacional para convergência dessa curva é muito grande (Brown et al., 1976; Fitzhugh, 1976; DeNise \& Brinks, 1985; Doren et al., 1989 e Perotto et al., 1992).

O Apêndice 3 mostra as correlações de Pearson entre os diversos parâmetros e entre as funções analisadas. De forma geral, altas correlações entre coeficientes é um indicativo de que os parâmetros estão medindo o mesmo efeito de crescimento do animal (Fitzhugh, 1976). As funções de von Bertalanffy e Gompertz apresentaram altas correlações tanto para peso adulto $(0,99)$ como para taxa de maturidade $(0,99)$. As funções de Brody e Brody modificada apresentaram, também, altas correlações entre o peso adulto $(0,96)$ e a taxa de maturidade $(0,97)$. As funções de Gompertz e Logística, também, apresentaram altas correlações entre o peso adulto $(0,98)$ e a taxa de maturidade $(0,98)$. A função de Gompertz e Gompertz modificada não apresentaram altas correlações entre os seus parâmetros, sendo que essa última não teve nenhum tipo de correlação com o seu parâmetro " $d$ ", mostrando que esse parâmetro mede efeitos diferentes em relação aos demais parâmetros das 
outras funções. A correlação entre os parâmetros das funções ajustadas mostram uma pequena correlação negativa entre o peso adulto (" $A$ ") e o fator de integração ("b") igual a $-0,28$, mas mostra uma correlação positiva e significativa entre os parâmetros " $b$ " e " $k$ ". Dessa forma, esses ajustes não concordam com a possível correlação encontrada entre o peso ao nascer (" $b ")$ e o peso adulto conforme citado por Bailey \& Mears (1990), mas confirma a correlação positiva entre peso ao nascer e taxa de maturidade.

Com relação à semelhança entre curvas, foi elaborado uma análise multivariável (distância Euclidiana) entre as curvas levando em consideração os seguintes parâmetros: soma de quadrado do residuo, desvios da regressão, coeficiente de determinação, peso adulto e taxa de maturidade utilizando-se O PROC CLUSTER do SAS® (1987). As funções de crescimento semelhantes entre si, quando todos os 5 parâmetros foram utilizados, foram (pela ordem de importância): Bertalanffy com Richards, Brody com Brody modificada, Gompertz com Gompertz modificada e, finalmente, Gompertz modificada com Logística. Quando apenas o peso adulto e a taxa de maturidade foram utilizados como parâmetros de comparação, as funções mais semelhantes foram (pela ordem de importância): Bertalanffy com Gompertz, Brody modificada com Gompertz, Brody com Gompertz, Brody com Brody modificada, Gompertz modificada com Richards e ,finalmente, Logística com Richards.

A função selecionada baseada nas porcentagens de convergência (assumindo peso adulto limite como sendo $1000 \mathrm{~kg}$ ), nos fatores estudados da Tabela 19 e na dificuldade computacional foi a de Gompertz, pois essa se enquadra melhor em relação às demais para descrever as curvas de crescimento dos dados estudados.

o Apêndice 2 mostra o quadro de análise de variância dos efeitos estudados para cada função de crescimento ajustada. De forma geral, 
para todas as curvas, foram obtidos 80 graus de liberdade para a curva contra 354 do resíduo. Mostra, ainda, todas as interações para todas as funções e principalmente para a função de Gompertz.

\title{
4.3. Estudo univariado da curva de crescimento selecionada
}

\begin{abstract}
Para o peso adulto (" $A$ ") as seguintes interações foram analisadas: anos, tratamentos e grupos raciais ( $A * T * G)$, e grupos raciais e sexos $\left(G^{\star} S\right)$. Para a taxa de maturidade (" $k^{\prime \prime}$ ) as seguintes interações foram consideradas: ano, tratamento e grupos raciais $\left(A^{*} T^{\star} G\right)$, tratamento e sexo $\left(T^{*} S\right)$, e grupos raciais e sexos $\left(G^{*} S\right)$. Para - fator de integração (" $b$ ") a seguinte interação foi discutida: tratamentos e sexos $\left(T^{*} S\right)$. Ainda para o parâmetro " $b$ ", o efeito principal: grupo racial (G) foi estudado.
\end{abstract}

\subsubsection{Análise da interação entre ano, tratamento e grupo racial}

Para analisar a interação entre ano, tratamento e grupo racial para peso adulto e taxa de maturidade foi realizado uma análise entre os tipos de suplementação (tratamentos) e grupos raciais para cada ano, pois a análise de interação de $3^{\circ}$ grau torna-se muito complicada. A Tabela 20 mostra essas interações para o ano de 1978 (A1). Os gráficos das funções de crescimento relacionadas aos parâmetro de crescimento da Tabela 20 estão no Apêndice 5 (Gráfico 4 até Gráfico 8) .

De forma geral, para o ano de 1978, apenas o grupo racial 3/4Guzerá x 3/4Pardo Suíço (3/4GS) apresentou diferença estatística ao nível de 5\% pelo teste de REGWF para efeito de suplementação no peso adulto, de forma que os animais que foram suplementados (S2) obtiveram peso adulto 
médio maior $(P<0,05)$. A taxa de maturidade não foi afetada pela suplementação (S2) .

TABela 20. EFeito de tratamento dentro de grupo RaCial NAS VARIÁVEIS PESO ADULTOE TAXA DE MATURIDADE PARA O ANO DE 1978.

\begin{tabular}{|c|c|c|c|c|}
\hline \multirow[t]{2}{*}{ Grupo racial } & \multicolumn{2}{|c|}{ "A" } & \multicolumn{2}{|c|}{ "k" } \\
\hline & S1 & S2 & S1 & S2 \\
\hline Guzerá & $544,0^{\text {a }}$ & $494,7^{a}$ & $0,0021^{a}$ & $0,0025^{\mathrm{a}}$ \\
\hline 3/4Guzerá x 1/4Pardo Suíço & $459,1^{b}$ & $534,8^{a}$ & $0,0030^{\mathrm{a}}$ & $0,0028^{a}$ \\
\hline $1 / 2$ Nelore x 1/4Guzerá x 1/4Pardo Suíço & $564,6^{a}$ & $535,4^{a}$ & $0,0026^{a}$ & $0,0030^{a}$ \\
\hline 1/2Guzerá x 1/2Pardo Suíço & $526,1^{\text {a }}$ & $528,1^{\text {a }}$ & $0,0036^{\mathrm{a}}$ & $0,0030^{a}$ \\
\hline $1 / 2$ Chianina $\times 1 / 4$ Guzerá $\times 1 / 4$ Pardo Suíço & $477,2^{\mathrm{a}}$ & $509,7^{a}$ & $0,0025^{\mathrm{a}}$ & $0,0023^{a}$ \\
\hline
\end{tabular}

A Tabela 21 mostra o efeito da suplementação dentro de cada grupo racial para o ano de 1979 (A2). Os gráficos das funções de crescimento estão no Apêndice 5 (Gráfico 9 até Gráfico 15).

TABEla 21. EFEITO DE TRATAMENTO DENTRO DE GRUPO RACIAL NAS VARIÁVEIS PESO ADULTO E TAXA DE MATURIDADE PARA O ANO DE 1979.

\begin{tabular}{|c|c|c|c|c|c|c|}
\hline \multirow[t]{2}{*}{ Grupo racial } & \multicolumn{3}{|c|}{ "A" } & \multicolumn{3}{|c|}{ "k" } \\
\hline & S1 & S2 & S3 & S1 & S2 & S3 \\
\hline Guzerá & $494,0^{2}$ & $481,2^{a}$ & $461,2^{a}$ & $0,0026^{b}$ & $0,0027^{b}$ & $0,0036^{\mathrm{a}}$ \\
\hline 3/4Guzerá x 1/4Pardo Suíço & $538,6^{\mathrm{a}}$ & $477,5^{b}$ & $463,3^{b}$ & $0,0025^{\mathrm{c}}$ & $0,0030^{b}$ & $0,0042^{a}$ \\
\hline $1 / 2$ Nelore $x$ 1/4Guzerá x 1/4Pardo Suíço & $532,2^{a}$ & $546,3^{a}$ & $516,8^{a}$ & $0,0028^{b}$ & $0,0027^{b}$ & $0,0037^{a}$ \\
\hline 1/2Guzerá x 1/2Pardo Suíço & $483,4^{a}$ & $484,0^{a}$ & & $0,0036^{a}$ & $0,0037^{a}$ & \\
\hline $1 / 2$ Chianina $\times 1 / 4$ Guzerá $\times 1 / 4$ Pardo Suíço & $610,5^{a}$ & $530,8^{b}$ & & $0,0020^{b}$ & $0,0028^{a}$ & \\
\hline 1⁄2Caracú x 1/2Guzerá & $524,5^{a}$ & $512,7^{\mathrm{a}}$ & & $0,0031^{a}$ & $0,0032^{a}$ & \\
\hline $1 / 2$ Caracú X 1/4Guzerá x 1/4Pardo Suíço & $510,1^{a}$ & $528,6^{a}$ & & $0,0028^{a}$ & $0,0029^{a}$ & \\
\hline
\end{tabular}

Inversamente ao ano 1 , os animais do grupo racial $3_{4}^{3}$ Guzerá $x$ 14 Pardo Suíço ( $3 / 4 G S)$, que foram suplementados, apresentaram peso adulto menor em relação aos que não foram suplementados $(P<0,05)$ tanto para suplementação apenas no período da seca (S2) como para suplementação no ano todo (S3). Os animais do grupo racial 1/2 Chianina x 1/4Guzerá x 1/4Pardo 
Suíço $(1 / 2 \mathrm{C}(\mathrm{SG}))$ apresentaram menor peso adulto $(\mathrm{P}<0,05)$ quando submetidos à suplementação durante o inverno (S2). Os três grupos raciais que receberam suplementação durante 0 ano todo (S3) apresentaram taxa de maturidade (" $k$ ") superior aos demais tratamentos $(P<0,05)$. Os animais 1/2Chianina $\times$ 1/4Guzerá $\times 1 / 4$ Pardo Suíço $(1 / 2 C(S G))$ e 3/4Guzerá x 3/4Pardo Suíço (3/4GS) apresentaram maior taxa de maturiade " $k$ " quando receberam suplementação no inverno (S2) $(P<0,05)$.

Com relação aos dados de grupo racial dentro de tratamento (tipo de suplementação), estes estão sumariados na Tabela 22. Os gráficos das funções de crescimento estão no Apêndice 5 (Gráfico 16 até Gráfico 20).

Para os animais que receberam suplementação (S2 e S3) não existiu diferença de peso adulto entre grupos raciais $(P>0,05)$ e a taxa de maturidade foi mais constante, embora tenha existido diferença significativa entre grupos raciais $(P<0,05)$. Para os animais que não receberam suplementação (S1) os valores para peso adulto e para taxa de maturidade apresentaram muita variação, conforme mostrado na Tabela 22 .

TABELA 22. EFEITO DE GRUPORACIAL DENTRO DE TRATAMENTO PARA OS PARÂMETROS PESO ADULTO E TAXA DE MATURIDADE NOS ANOS DE 1978 E 1979.

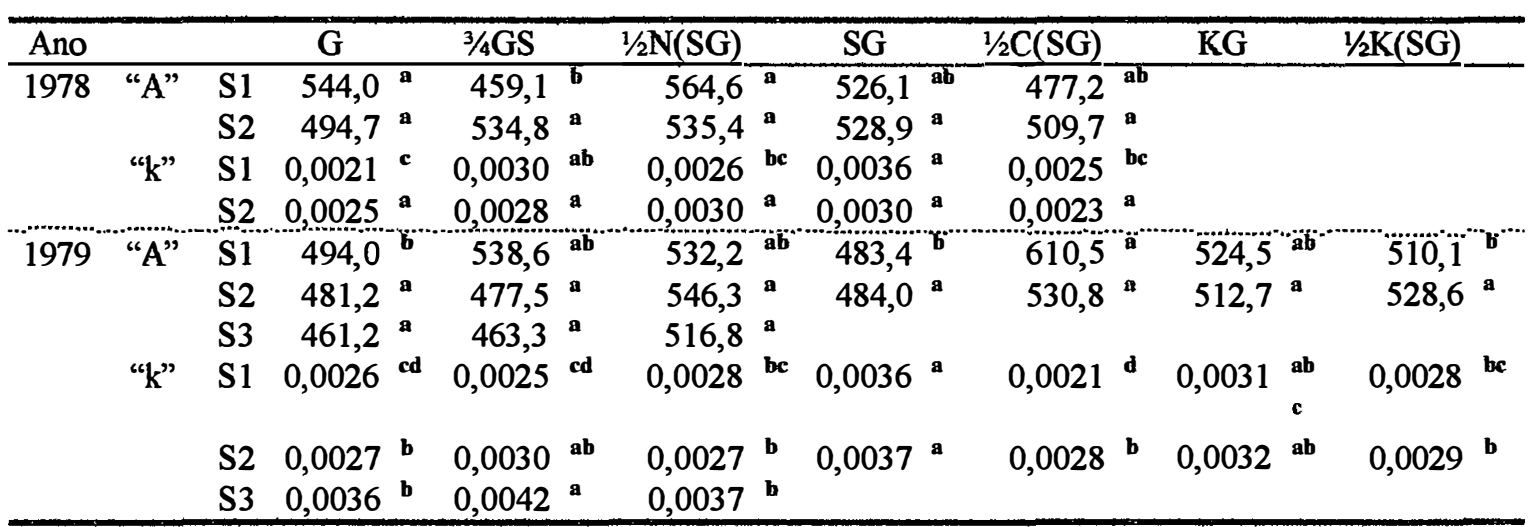

Letras distintas na mesma linha indicam diferença estatística pelo teste de REGWF ao nível de $5 \%$.

Com relação aos grupos raciais dentro de tratamentos quando não existe separação por ano, os resultados para os tratamentos S1, S2 e S3 
mostraram que não houve diferenças estatísticas para o peso adulto entre os grupos raciais $(525,1 ; 496,4 ; 549,6 ; 501,7 ; 557,1 ; 524,5$ e 510,1 para S1; 490,3; 507,9; 540,6; 505,0; 523,7; 512,7; 528,6 para S2 e 461,2; 463,3; 516,8 para S3; P > 0,05), respectivamente. Entretanto, para a taxa de maturidade os animais do grupo racial 1/2Guzerá x 3/2Pardo Suíço (SG) e 1/2Caracú x 1/2Guzerá (KG) apresentaram maiores taxas do que os demais grupos raciais $(P<0,05)$ para o tratamento sem suplementação

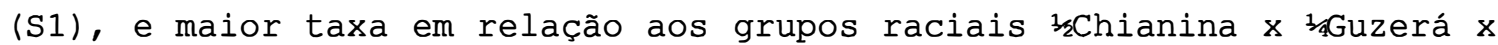
1/4Pardo Suíço (1/2C(SG)) e Guzerá (G) para o tratamento com suplementação durante $O$ inverno (S2) $(P<0,05)$. Para os animais com suplementação durante o ano todo (S3), a taxa de maturidade do grupo racial Guzerá (G) foi significativamente menor $(P<0,05)$ em relação aos grupos

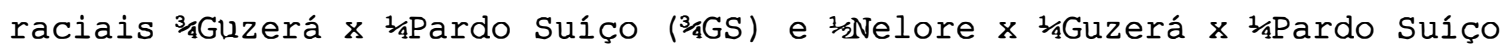
$(1 / 2 N(S G))$.

Em média, não existiram diferenças estatísticas ao nível de 5\% de probabilidade para o tratamento S1 entre o ano 1 e ano 2 tanto para peso adulto $(514,9$ e 533,4$)$ como para taxa de maturidade $(0,0027$ e 0,0027). Para a suplementação apenas no inverno (S2) não foi observado diferença significativa entre anos para peso adulto $(521,3$ e 510,9) mas foi observado para a taxa de maturidade $(0,0027$ e 0,0029; $P<0,01$, respectivamente). Quando foram analisados tratamentos dentro de ano, não houve diferença estatística nem para peso adulto nem para taxa de maturidade no ano 1 para os tratamentos S1 e S2 (514,9 e 521,3; 0,0027 e 0,0027; P > 0,05), respectivamente. Entretanto, para o ano 2, o peso adulto dos animais que receberam suplementação durante o ano todo (S3), foi inferior aos dos tratamentos com suplementação no inverno (S2) e sem suplementação (S1) (484,4; 504,5 e 525,3; P < 0,05) respectivamente. Para a taxa de maturidade o tratamento S3 apresentou 
maior valor do que o tratamento S2 e esse maior que o tratamento S1 $(0,0039 ; 0,0029 ; 0,0026 ; \mathrm{P}<0,05)$, respectivamente.

Os resultados mostram que a suplementação durante o inverno (S2) apresentou efeito consistente em aumentar a taxa de maturidade nos dois anos de experimento. A suplementação durante o ano todo (S3) aumentou a taxa de maturidade acima da observada para a suplementação durante o inverno (S2). A justificativa (hipótese) seria de que a composição corporal estava sendo afetada com a suplementação provavelmente devido à composição energética dos suplementos durante o experimento no ano base de 1979. Deve-se salientar que existe um confundimento entre efeito de ano e efeito de composição das suplementação entre anos.

Não obstante a isso, outra hipótese poderia ser a percentagem de animais que pariram, entre os animais suplementados durante o ano todo (S3), perfazem 88,2\%. Sabendo-se que as fêmeas que apresentaram parição possuíram menor peso adulto, talvez devido aos efeitos de lactação e de gestação que podem influenciar o crescimento desses animais.

\subsubsection{Análise da interação entre grupos raciais e sexos}

A interação grupos raciais e sexos foi significativa para o peso adulto e para a taxa de maturidade. A Tabela 23 e a Tabela 24 mostram os efeitos dessa interação. Os gráficos das funções de crescimento estão no Apêndice 5 (Gráfico 21 até Gráfico 30) .

Os machos do grupo racial 1/2Guzerá $x$ 1/2Pardo Suíço apresentaram maior peso adulto $(P<0,05)$ enquanto que os machos do grupo racial Guzerá $(G)$ apresentaram menor peso adulto $(P<0,05)$ embora as taxas da maturidade não tenham sido significativamente diferentes $(P>0,05)$. 
TABELA 23. EFEITO DE GRUPO RACIAL DENTRO DE SEXO PARA OS PARÂMETROS DE PESO ADULTO E TAXA DE MATURIDADE.

\begin{tabular}{|c|c|c|c|c|c|c|c|c|c|c|}
\hline & Sexo & G & $3 / 4 \mathrm{GS}$ & & ज) & & SG & $1 / 2 C$ & KG & \\
\hline \multirow[t]{3}{*}{ "A" } & $\bar{M}$ & 615 , & 621,3 & & 3,9 & 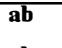 & 714,8 & 9 & 650,4 & 6,1 \\
\hline & F & & & & & ab & 41 & & & \\
\hline & $F_{a j}$ & & & b & & ab & $402,6^{\mathbf{b}}$ & $4^{a}$ & 423,9 & \\
\hline \multirow[t]{3}{*}{ "k" } & $\mathbf{M}$ & 020 & 0,00 & a & & a & $0^{a}$ & $2^{a}$ & 0022 & $20^{a}$ \\
\hline & $\mathrm{F}$ & 028 & cd 0,0033 & bc & 0,0033 & abc & $0,0041^{\mathbf{a}}$ & $5^{\mathrm{d}}$ & 0,0037 & \\
\hline & $\mathrm{F}_{\mathrm{aj}}$ & 0,0029 & be 0,0035 & ab & 0,0035 & ab & 0,0042 & $0,0026^{\mathbf{c}}$ & 0,0038 & $0,0036^{a}$ \\
\hline
\end{tabular}

Letras distintas na mesma linha indicam diferença estatística pelo teste de REGWF ao nivel de $5 \%$.

Para as fêmeas sem correção de peso vivo para peso do feto e tecidos anexos da placenta (F) e para as fêmeas com correção $\left(F_{a j}\right)$, o peso adulto do grupo racial 1/2Chianina x 1/4Guzerá x 1/4Pardo Suíço (1/2C(SG)) foi superior aos demais grupos raciais $(P<0,05)$, com exceção do grupo racial 1/2Nelore $\times$ 1/4Guzerá $\times$ 1/4Pardo Suíço $\left(1 \frac{1}{2} \mathrm{~N}(\mathrm{SG})\right)$. A taxa de maturidade apresentou-se muito variada, embora para as fêmeas do grupo $F_{a j}$ tenha sido mais homogênea do que para aquelas do grupo F.

Os dados da análise de sexo dentro de grupo racial estão sumariados na Tabela 24.

TABEla 24. EFEITO de SEXo dentro de GRUPo RACIAl PARA OS PARÂMETROS DE PESO ADULTO E TAXA DE MATURIDADE.

\begin{tabular}{|c|c|c|c|c|c|c|}
\hline \multirow{2}{*}{ Grupo racial } & \multicolumn{3}{|c|}{ "A" } & \multicolumn{3}{|c|}{ " $k "$} \\
\hline & $\mathbf{M}$ & $\mathrm{F}$ & $\mathrm{F}_{\mathrm{ai}}$ & $\mathbf{M}$ & $\mathrm{F}$ & $F_{a i}$ \\
\hline Guzerá & $615,8^{a}$ & $455,5^{b}$ & $443,0^{b}$ & $0,0020^{\mathbf{b}}$ & $0,0028^{a}$ & $0,0029^{a}$ \\
\hline 3/4Guzerá x 1/4Pardo Suíço & $621,3^{a}$ & $446,7^{b}$ & $430,3^{\mathbf{b}}$ & $0,0023^{\mathbf{b}}$ & $0,0033^{a}$ & $0,0035^{a}$ \\
\hline 1/2Nelore x $1 / 4$ Guzerá x $1 / 4$ Pardo Suíço & $638,9^{a}$ & $473,0^{\mathrm{b}}$ & $457,2^{\mathbf{b}}$ & $0,0023^{\mathbf{b}}$ & $0,0033^{a}$ & $0,0035^{a}$ \\
\hline 1/2Guzerá x 1/2Pardo Suíço & $714,8^{a}$ & $413,9^{b}$ & $402,6^{b}$ & $0,0020^{\mathbf{b}}$ & $0,0041^{a}$ & $0,0042^{a}$ \\
\hline 1/2Chianina $\times 1 / 4$ Guzerá $\times 1 / 4$ Pardo Suíço & $588,9^{a}$ & $537,9^{\text {ab }}$ & $520,4^{\mathbf{b}}$ & $0,0020^{\mathbf{b}}$ & $0,0025^{a}$ & $0,0026^{\mathbf{a}}$ \\
\hline 1⁄2Caracú x 1/2Guzerá & $650,4^{\mathrm{a}}$ & $438,9^{b}$ & $423,9^{b}$ & $0,0022^{\mathbf{b}}$ & $0,0037^{a}$ & $0,0038^{a}$ \\
\hline 1/2Caracú x 1/4Guzerá x 1/4Pardo Suíço & $616,1^{\mathbf{a}}$ & $442,1^{\mathbf{b}}$ & $429,7^{\mathrm{b}}$ & $0,0020^{\mathbf{b}}$ & $0,0036^{\mathbf{a}}$ & $0,0036^{\mathrm{a}}$ \\
\hline
\end{tabular}

Letras distintas na mesma linha para cada parâmetro indicam diferença estatística pelo teste de REGWF ao nível de $5 \%$.

Quando foi analisado o fator sexo dentro de grupos raciais, observou-se que as taxas de maturidade das fêmeas tanto do grupo $F$ quanto do grupo $F_{a j}$ foram maiores que a taxa de maturidade dos machos $(P<0,05)$. Entre os grupos de fêmeas $\left(F\right.$ e $\left.F_{a j}\right)$ não ocorreram 
diferenças significativas $(P>0,05)$, embora $O$ " $k$ " do grupo $F_{a j}$ tendesse a ser maior do que o $\mathrm{F}$.

Em relação ao peso adulto, os machos apresentaram peso adulto superior ao das fêmeas tanto do grupo $F$ quanto do grupo $F_{a j}(P<0,05)$. Entre as fêmeas não houve diferença entre os grupos $F$ e $F_{a j}(P>0,05)$, embora as fêmeas do grupo $F_{a j}$ tenderam a apresentar menor valor para

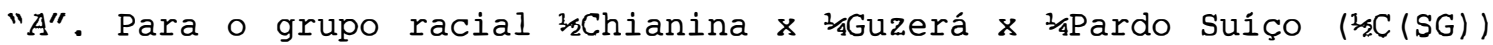
não houve diferença entre o peso adulto dos machos e das fêmeas do grupo $F$, mostrando que realmente as fêmeas do grupo $F$ tenderam a apresentar um peso adulto maior que as fêmeas do grupo $F_{a j}$.

\subsubsection{Análise da interação entre tratamentos e sexos}

A interação entre tratamento e sexo para a taxa de maturidade e para o fator de integração estão representados na Tabela 25. Os gráficos das funções de crescimento da Tabela 25 estão no Apêndice 5 (Gráfico 31 até Gráfico 36).

TABELA 25. EFEITO DE SEXO DENTRO DE TRATAMENTO E DE TRATAMENTO DENTRO DE SEXO PARA OS PARÂMETROS TAXA DE MATURIDADE E O FATOR DE INTEGRAÇÃO.

\begin{tabular}{|c|c|c|c|c|c|c|}
\hline \multirow[b]{2}{*}{ Tratamento } & \multicolumn{3}{|c|}{ "k" } & \multicolumn{3}{|c|}{ "b" } \\
\hline & $\overline{\mathbf{M}}$ & $\bar{F}$ & $\overline{F_{a i}}$ & $\mathbf{M}$ & $\bar{F}$ & $\mathrm{~F}_{\mathrm{ai}}$ \\
\hline Sem suplementação (S1) & $0,0020^{\mathrm{b}}$ & 0,0030 & $0,0030^{a}$ & $2,12^{b}$ & $2,35^{\mathrm{a}}$ & $\frac{1,32^{a}}{2,3}$ \\
\hline Com suplementação inverno (S2) & $0,0023^{b}$ & 0,0031 & $0,0032^{a}$ & $2,16^{\mathrm{a}}$ & $2,26^{\mathrm{a}}$ & $2,22^{a}$ \\
\hline Com suplementação ano todo (S3) & $0,0027^{\mathrm{b}}$ & 0,0044 & $0,0046^{\mathrm{a}}$ & $2,23^{\mathrm{b}}$ & $3,16^{\mathrm{a}}$ & $3,16^{a}$ \\
\hline Sexo & S1 & S2 & S3 & S1 & $\mathrm{S} 2$ & S3 \\
\hline Macho (M) & $0,0020^{b}$ & 0,0023 & $0,0027^{\mathrm{a}}$ & $2,12^{\mathrm{a}}$ & $2,16^{\mathrm{a}}$ & $2,23^{\mathrm{a}}$ \\
\hline Fêmeas sem correção de PV para feto (F) & $0,0030^{\mathrm{b}}$ & 0,0031 & $0,0044^{a}$ & $2,35^{b}$ & $2,26^{\mathrm{b}}$ & $3,16^{\mathrm{a}}$ \\
\hline Fêmeas com correção de $P V$ para feto $\left(F_{\mathrm{aj}}\right)$ & $0,0030^{\mathrm{b}}$ & 0,0032 & $0,0046^{\mathrm{a}}$ & $2,32^{\mathrm{b}}$ & $2,22^{b}$ & $3,16^{\mathrm{a}}$ \\
\hline
\end{tabular}

As taxas de maturidade não diferiram entre os grupos de fêmeas ( $F$ e $\left.F_{a j} ; P>0,05\right)$. Entretanto, os valores para as fêmeas $\left(F\right.$ e $\left.F_{a j}\right)$ foram superiores às dos machos $(\mathrm{P}<0,05)$ para todos os níveis de tratamento (S1, S2 e S3). Quando analisados dentro de sexos, o tratamento com 
suplementação durante $O$ ano todo (S3) apresentou maior taxa de maturidade para os três níveis de sexo $\left(\mathbb{M}, F\right.$ e $\left.F_{a j}\right)(P<0,05)$. A suplementação na seca (S2) não afetou a taxa de maturidade em relação ao tratamento sem suplementação $(\mathrm{S} 1)(\mathrm{P}>0,05)$. Essas observações condizem com os resultados anteriores, pois quanto maior a taxa de maturidade menor é o peso adulto, ou melhor, menor é o peso assintótico representado por " $A$ ". Dessa forma, os animais que receberam 0 suplementação durante $O$ ano todo (S3) provavelmente atingiram a composição corporal adulta mais cedo que os animais dos demais tratamentos, conforme citado por Owens et al. (1995).

Para o fator de integração, os grupos de fêmeas ( $F$ e $\left.F_{a j}\right)$ não diferiram entre si e foram superiores aos machos nos tratamentos S1 e S3 $(P<0,05)$, enquanto que para o tratamento S2 não houve diferença estatística entre sexos $(P>0,05)$. Quando analisado dentro de sexo, os machos não apresentaram diferença entre tratamentos $(P>0,05)$ enquanto que para as fêmeas, o tratamento $\mathrm{S} 3$ foi superior aos demais $(P<0,05)$.

\subsubsection{Análise do fator grupo racial}

Para o fator de integração houve diferença estatística entre grupos raciais, de forma que, foram gerados três grupos distintos entre si. O primeiro grupo é formado pelos grupos raciais 1/2Guzerá x 1/2Pardo Suíço (SG), 1/2Caracú x 1/2Guzerá (KG) e Guzerá (G), o segundo pelos grupos raciais 1/2Nelore x 1/4Guzerá x 1/4Pardo Suíço (1/2/2N(SG)), 3/4Guzerá x 1/4Pardo Suíço (3/4GS) e $1 / 2$ Caracú x $3 / 4$ Guzerá x $3 / 4$ Pardo Suíço (1/2K(SG)) e, finalmente, - terceiro pelo grupo racial 1/2Chianina $x$ 1/4Guzerá x 13/4Pardo Suíço $(1 / 2 C(S G))$. O grupo 1 (SG, KG e G), foi superior ao grupo $2(1 / 2 N(S G)$, $3 / 4 G S$ e $1 / 2 K(S G)$ ) e esse foi superior ao grupo $3(1 / 2 C(S G))$ com valores de $2,53^{a}$; $2,49^{\mathrm{a}} ; 2,47^{\mathrm{a}} ; 2,27^{\mathrm{b}} ; 2,26^{\mathrm{b}} ; 2,25^{\mathrm{b}} ; 2,09^{\mathrm{c}} ; \mathrm{P}<0,05$, respectivamente). $\mathrm{O}$ 
gráfico da curva de crescimento dos grupos raciais está no Apêndice 5 (Gráfico 37) .

o fator de integração possui pouco interesse, pois ele está relacionado ao valor do peso inicial, nesse caso, peso ao nascer, apenas para ajuste da curva de crescimento. Deve-se salientar que a relação entre o fator de integração (" $b$ ") e o peso ao nascer é inversa, ou seja, animais com maior valor de " $b$ " tendem a apresentar menor peso ao nascer.

\subsubsection{Estudo do efeito de parição nos parâmetros da função de crescimento}

Conforme observado por alguns pesquisadores, a parição exerce uma influência sobre os parâmetros da função de crescimento. A Tabela 26 mostra o quadro de variância com inclusão do fator parição.

TABELA 26. QUADRO DE ANÁLISE dE VARIÂNCIA COM O FATOR DE PARIÇÃo.

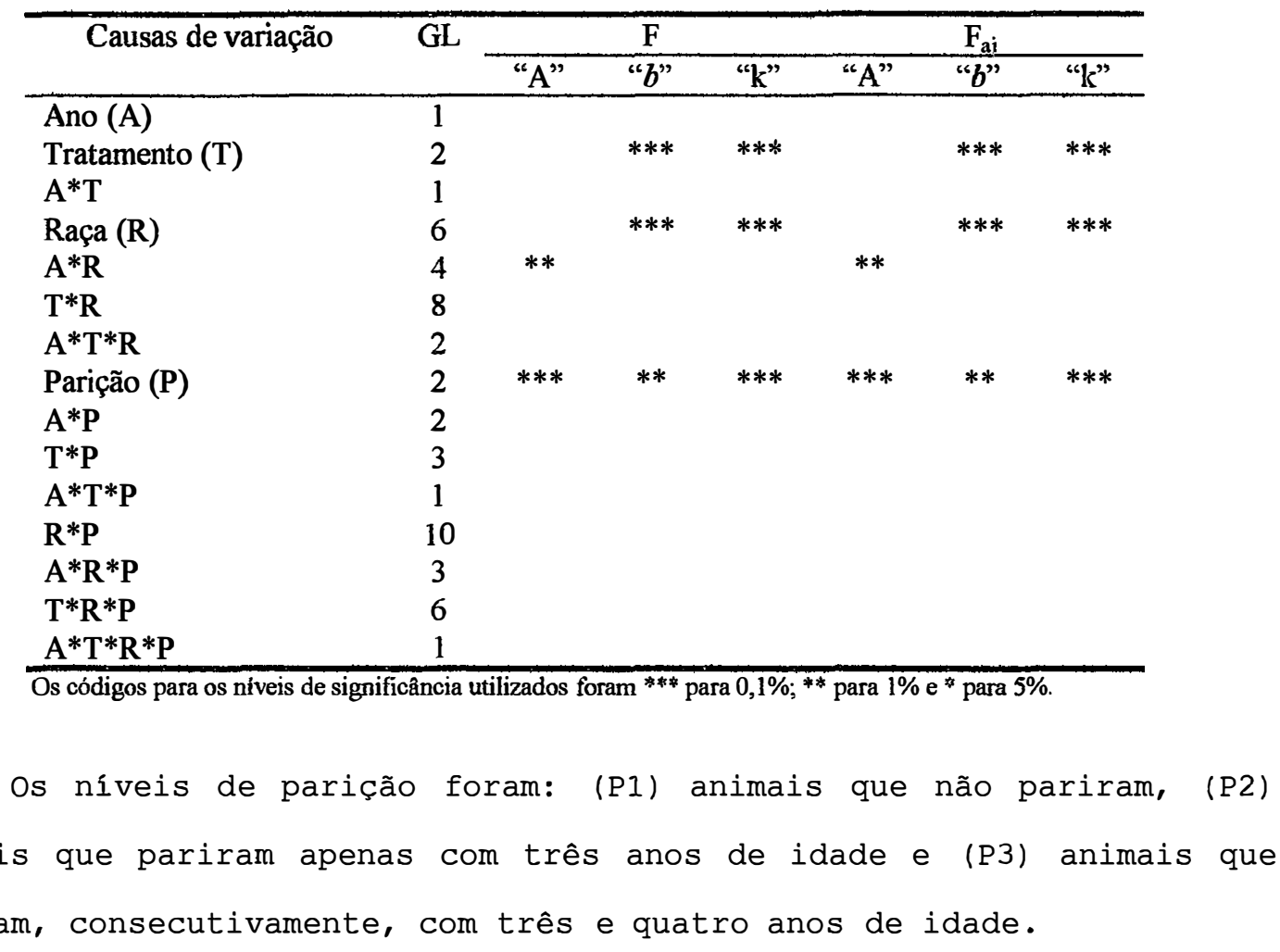


O efeito de parição, tanto no peso adulto como na taxa de maturidade, mostrou-se altamente significativo $(P<0,001)$. Para $O$ parâmetro " $b$ " foi significativo $(P<0,01)$ tanto para as fêmeas sem correção de peso (F) como para as fêmeas com correção de peso $\left(F_{a j}\right)$.

- Fêmeas sem correção de peso fetal e tecidos anexos (F).

Os animais que não pariram (P1) apresentaram peso adulto superior em relação aos animais que pariram, P2 e P3 (540,1; $440,9 ; 454,0 ; P<0,05)$, respectivamente.

o efeito de tratamento na taxa de maturidade foi significativo sendo que os animais do tratamento com suplementação durante o ano todo (S3) apresentaram maior valor do que os animais com suplementação apenas no inverno (S2) ou sem suplementação (SI) $(0,0044 ; 0,0031 ; 0,0030 ; P<0,05)$ respectivamente. O mesmo foi observado para o fator de integração, os animais do tratamento $\mathrm{S} 3$ apresentaram maior valor de " $b$ " em relação aos do tratamento S2 e S1 $(3,16 ; 2,26 ; 2,35 ; \mathrm{P}<0,05)$, respectivamente.

Os animais do grupo racial 1/2Guzerá x 1/2Pardo Suíço (SG) apresentaram taxa de maturidade superior aos do grupo racial Guzerá (G), 3/4Guzerá x 1/4Pardo Suíço (3/4GS) e 1/2Chianina x 1/4Guzerá x $\frac{1}{1 / 4}$ Pardo Suíço $(1 / 2 C(S G)) \quad(P<0,05)$. O grupo racial $1 \frac{1}{2}$ Caracú $x$ 1/2Guzerá (KG) apresentou maior valor para o parâmetro "b" do que os animais do grupo racial 1/2Chianina x 1/4Guzerá x 1/4Pardo Suíço $(1 / 2 \mathrm{C}(\mathrm{SG})) \quad(\mathrm{P}<0,05)$. O efeito de grupo racial na taxa de maturidade e no fator de integração estão sumariados na Tabela 27 .

O efeito de parição na taxa de maturidade mostrou que os animais que não pariram (P1) apresentaram taxa de maturidade 
inferior em relação aos animais que pariram com três (P2) ou com três e quatro anos de idade (P3) $(0,0023 ; 0,0034 ; 0,0034 ; \mathrm{P}<$ $0,05)$, respectivamente. Da mesma forma para o parâmetro " $b$ ", os animais que não pariram (P1) apresentaram menor " $b$ " em relação aos que pariram com três (P2) ou com três e quatro anos de idade (P3) $(2,22 ; 2,47 ; 2,42 ; \mathrm{P}<0,05)$.

\section{- Fêmeas com correção de peso fetal e tecidos anexos $\left(F_{a j}\right)$.}

Os animais que não pariram (P1) apresentaram peso adulto superior em relação aos animais que pariram, P2 e P3 (540,10; $423,21 ; 434,66 ; P<0,05)$, respectivamente.

o efeito de tratamento na taxa de maturidade foi significativo sendo que os animais do tratamento com suplementação durante o ano todo (S3) apresentaram maior valor do que os animais com suplementação apenas no inverno (S2) ou sem suplementação (S1) $(0,0046 ; 0,0032 ; 0,0030 ; \mathrm{P}<0,05)$ respectivamente. o mesmo foi observado para o fator de integração, os animais do tratamento S3 apresentaram maior valor de " $b$ " em relação aos do tratamento $\mathrm{S} 2$ e $\mathrm{S} 1(3,16 ; 2,22 ; 2,31 ; \mathrm{P}<0,05)$ respectivamente.

Os animais do grupo racial $\frac{1}{2} / 2$ Guzerá $x$ 1/2Pardo Suíço (SG) apresentaram taxa de maturidade superior aos do grupo racial Guzerá (G) e 1/2Chianina x 1/4Guzerá x 1/4Pardo Suíço (1/2C(SG)) (P < 0,05). Os grupos raciais Guzerá (G), 1/26uzerá x 1/2Pardo suíço (3/4GS) e $1 / 2$ Caracú $x$ 1/2Guzerá (KG) apresentaram maior valor para 0 parâmetro " $b$ " do que os animais do grupo racial $1 / 2$ Chianina $x$ $1 \frac{1}{4}$ Guzerá $x$ 1/4Pardo Suíço $(1 / 2 / 2(S G)) \quad(P<0,05)$. O efeito de grupo racial na taxa de maturidade e no fator de integração estão sumariados na Tabela 27. 


\begin{abstract}
O efeito de parição na taxa de maturidade mostrou que os animais que não pariram (P1) apresentaram taxa de maturidade inferior em relação aos animais que pariram com três (P2) ou com três e quatro anos de idade (P3) $(0,0023 ; 0,0035 ; 0,0035 ; \mathrm{P}<$ $0,05)$, respectivamente. Da mesma forma para o parâmetro "b", os animais que não pariram (P1) apresentaram menor "b" em relação aos que pariram com três (P2) ou com três e quatro anos de idade (P3) $(2,22 ; 2,41 ; 2,41 ; \mathrm{P}<0,05)$.
\end{abstract}

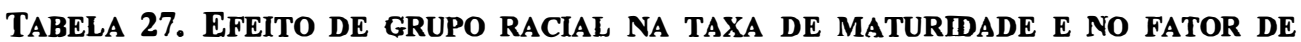
INTEGRAÇ̃̃o EM CADA SEXO PARA O MODELO ESTATISTTICO COM EFEITO DE PARIÇÃO.

\begin{tabular}{|c|c|c|c|c|}
\hline \multirow[t]{2}{*}{ Raças } & \multicolumn{2}{|c|}{$F$} & \multicolumn{2}{|c|}{$F_{a i}$} \\
\hline & $" k "$ & "b" & "k" & "b" \\
\hline Guzerá & $0,0028 \mathrm{~cd}$ & $2,56^{\mathrm{ab}}$ & $0,0029^{\mathbf{b c}}$ & $2,54^{\mathrm{a}}$ \\
\hline 3/4Guzerá x 1/4Pardo Suíço & $0,0033^{\mathbf{b c}}$ & $2,34^{b c}$ & $0,0035^{a b c}$ & $2,32^{\mathbf{a b}}$ \\
\hline 1/2Nelore x 1/4Guzerá x 1/4Pardo Suíço & $0,0033^{\text {abc }}$ & $2,38^{\text {abc }}$ & $0,0035^{\text {abc }}$ & $2,36^{\mathrm{ab}}$ \\
\hline 1/2Guzerá x 1/2Pardo Suíço & $0,0041^{a}$ & $2,65^{\mathbf{a b}}$ & $0,0042^{a}$ & $2,60^{\mathrm{a}}$ \\
\hline 1/2Chianina $\times$ 1/4Guzerá x 1/4Pardo Suíço & $0,0025^{d}$ & $2,13^{\mathrm{c}}$ & $0,0026^{c}$ & $2,10^{\mathrm{b}}$ \\
\hline 1/2Caracú x 1/2Guzerá & $0,0037^{\text {ab }}$ & $2,68^{a}$ & $0,0038^{\text {ab }}$ & $2,59^{a}$ \\
\hline 1/2Caracú x 1/4Guzerá x 1/4Pardo Suíço & $0,0036^{\text {abc }}$ & $2,47^{\text {abc }}$ & $0,0036^{\mathrm{ab}}$ & $2,40^{\text {ab }}$ \\
\hline
\end{tabular}

Letras distintas na mesma coluna indicam diferença estatística pelo teste de REGWF ao nivel de $5 \%$.

Os gráficos das funções de crescimento dos parâmetros analisados pela Tabela 27 estão no Apêndice 5 (Gráfico 38 e Gráfico 39) .

\title{
4.3.6. Análise da relação entre os parâmetros " $k$ " $e$ " $A$ "
}

Analisando as correlações de Pearson entre os parâmetros e entre as funções ajustadas, verifica-se que o parâmetro " $A$ " e o parâmetro " $k$ " apresentam alta correlação negativa, da ordem de -0,77. Esse resultado está de acordo com a maioria dos resultados obtidos por diversos autores (Fitzhugh, 1976), incluíndo os dados de Ahunu et al. (1994) selecionando as funções de Richards e Gompertz como sendo as melhores 
funções para descrever os valores observados com $R^{2}$ de 96,2 e 96,0\%, respectivamente.

Efetuando-se uma regressão logarítmica entre " $k$ " e " $A$ " para todos os dados obtidos (Equação 17), os valores de a e b foram, respectivamente, $0,7953 \pm 0,1106$ e $-1,2435 \pm 0,0409$ apresentando um coeficiente de determinação de $68 \%$

\section{EQUAÇÃo 17}

$$
\log (k)=a+b \cdot \log (A)
$$

A transformação da Equação 17 para uma equação alométrica resulta na Equação 18 .

\section{EQUAÇÃo 18}

$$
k=\frac{6,2418}{A^{1,2435}}
$$

CSIRO (1990) utiliza a equação descrita por Taylor (1965, 1968, 1985) para estimar a taxa de maturidade quando o peso adulto é fornecido. Taylor (1968) analisou várias espécies de aves e mamíferos e em média encontrou a seguinte relação entre " $k$ " e " $A$ ":

\section{EquaÇÃo 19}

$$
\begin{gathered}
\mathrm{k}=\frac{0,47}{\mathrm{~A}^{0,27}} \text {, para o tempo em meses; e } \\
\mathrm{k}=\frac{0,015 \hat{6}}{\mathrm{~A}^{0,27}} \text {, para o tempo em dias }
\end{gathered}
$$

Quando fixou-se o peso adulto dos animais do presente trabalho para $A^{0,27}$ a seguinte equação geral foi obtida: 


\section{EQUAÇÃo 20}

$$
k=\frac{0,0156726}{A^{0,27}}
$$

Esse resultado mostra que os animais apresentaram uma relação entre " $A$ " e " $k$ " muito semelhante à da equação de Taylor (1965, 1968, 1985), embora o valor seja forçado para o peso adulto elevado ao expoente 0,27 .

A Tabela 28 mostra os diversos valores que foram obtidos entre o parâmetro " $k$ " e o parâmetro " $A$ " para a Equação 17 no presente trabalho. A Tabela 29 mostra os valores do numerador para a Equação 20 .

TABELA 28. DIVERSOS VALORES PARA AS VARIÁVEIS DA EQUAÇÃo 17.

\begin{tabular}{|c|c|c|c|}
\hline Itens & $\mathbf{a}$ & $\mathrm{b}$ & $\mathrm{R}^{2}$ \\
\hline \multicolumn{4}{|l|}{ Sexo } \\
\hline Machos & $0,2429 \pm 0,2290$ & $-1,0414 \pm 0,0819^{* * *}$ & 0,53 \\
\hline Fêmeas (F) & $1,4692 \pm 0,2663$ *** & $-1,4985 \pm 0,1000^{* * *}$ & 0,61 \\
\hline Fêmeas $\left(\mathrm{F}_{\mathrm{aj}}\right)$ & $1,4262 \pm 0,2619^{* * *}$ & $-1,4847 \pm 0,0989^{* * *}$ & 0,61 \\
\hline \multicolumn{4}{|l|}{ Raça } \\
\hline Guzerá & $0,7830 \pm 0,2571^{* *}$ & $-1,2595 \pm 0,0954^{* * *}$ & 0,69 \\
\hline 3/4Guzerá x 1/4Pardo Suíço & $0,8173 \pm 0,2275^{* * *}$ & $-1,2505 \pm 0,0847^{* * *}$ & 0,65 \\
\hline $1 / 2$ Nelore $x 1 / 4$ Guzerá $x$ 1/4Pardo Suíço & $0,7541 \pm 0,1935^{* * *}$ & $-1,2147 \pm 0,0711^{* * *}$ & 0,74 \\
\hline 1/2Guzerá x 1/2Pardo Suíço & $0,8783 \pm 0,1952^{* * *}$ & $-1,2544 \pm 0,0727^{* * *}$ & 0,92 \\
\hline 1/2Chianina x 1/4Guzerá x 1/4Pardo Suíço & $0,8518 \pm 0,2884^{* *}$ & $-1,2824 \pm 0,1059^{* * *}$ & 0,73 \\
\hline $1 / 2$ Caracú $\times 1 / 2$ Guzerá & $0,8366 \pm 0,1958$ *** & $-1,2416 \pm 0,0724^{* * *}$ & 0,91 \\
\hline 1/2Caracú x 1/4Guzerá x 1/4Pardo Suíço & $1,3660 \pm 0,4247^{* *}$ & $-1,4534 \pm 0,1568^{* * *}$ & 0,87 \\
\hline \multicolumn{4}{|l|}{ Ano } \\
\hline 1978 & $0,3428 \pm 0,1580^{*}$ & $-1,0866 \pm 0,0584^{* * *}$ & 0,67 \\
\hline 1979 & $1,1514 \pm 0,1403^{* * *}$ & $-1,3682 \pm 0,0519^{* * *}$ & 0,73 \\
\hline \multicolumn{4}{|l|}{ Tratamento } \\
\hline Sem suplementação (S1) & $0,8888 \pm 0,1349^{* * *}$ & $-1,2891 \pm 0,0498^{* * *}$ & 0,78 \\
\hline Com suplementação no inverno (S2) & $0,2866 \pm 0,1551$ & $-1,0547 \pm 0,0574^{* * *}$ & 0,64 \\
\hline Com suplementação total (S3) & $1,1998 \pm 0,2972^{* * *}$ & $-1,3559 \pm 0,1109^{* * *}$ & 0,75 \\
\hline
\end{tabular}

Os niveis de significância utilizados foram $5 \%\left({ }^{*}\right), 1 \%\left({ }^{* *}\right)$ e $0,1 \%\left({ }^{* * *}\right)$ para os valores que diferem de zero.

O Gráfico 2 mostra a Equação 19 (Taylor, 1968) e a Equação 18 (ajustada) para estimar a taxa de maturidade através do peso adulto. A equação de Taylor (1968) subestima a taxa de maturidade para os animais 
com peso adulto inferior a $400 \mathrm{~kg}$ e superestima quando o peso adulto é superior a $700 \mathrm{~kg}$.

TABEla 29. Coeficientes ObTidos PARA O NUMERAdOR DA EQUAÇÃo 20.

\begin{tabular}{|c|c|}
\hline Itens & Coeficiente \\
\hline \multicolumn{2}{|l|}{ Sexo } \\
\hline Machos & $0,01259 \pm 0,00022$ \\
\hline Fêmeas (F) & $0,01674 \pm 0,00036$ \\
\hline Fêmeas $\left(F_{a j}\right)$ & $0,01718 \pm 0,00037$ \\
\hline \multicolumn{2}{|l|}{ Raça } \\
\hline Guzerá & $0,01394 \pm 0,00043$ \\
\hline 3/4Guzerá x 1/4Pardo Suíço & $0,01642 \pm 0,00043$ \\
\hline 1/2Nelore x 1/4Guzerá x 1/4Pardo Suíço & $0,01615 \pm 0,00041$ \\
\hline 1/2Guzerá x 1/2Pardo Suíço & $0,01857 \pm 0,00088$ \\
\hline $1 \frac{1}{2}$ Chianina $\times 1 / 4$ Guzerá $\times 1 / 4$ Pardo Suíço & $0,01341 \pm 0,00050$ \\
\hline $1 / 2$ Caracú x 1/2Guzerá & $0,01706 \pm 0,00068$ \\
\hline 1⁄2Caracú x 1/4Guzerá x 1/4Pardo Suíço & $0,01548 \pm 0,00106$ \\
\hline \multicolumn{2}{|l|}{ Ano } \\
\hline 1978 & $0,01454 \pm 0,00029$ \\
\hline 1979 & $0,01644 \pm 0,00029$ \\
\hline \multicolumn{2}{|l|}{ Tratamento } \\
\hline Sem suplementação (S1) & $0,01461 \pm 0,00031$ \\
\hline Com suplementação no inverno (S2) & $0,01531 \pm 0,00025$ \\
\hline Com suplementação total (S3) & $0,02072 \pm 0,00069$ \\
\hline
\end{tabular}

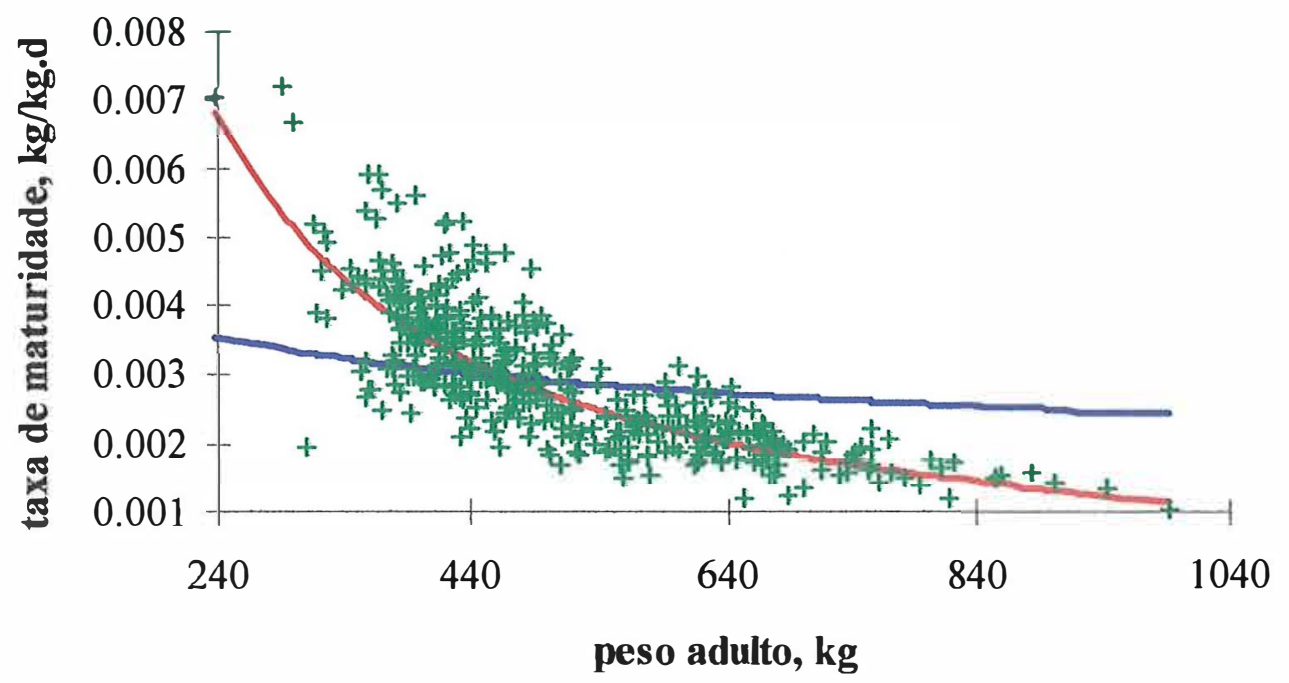

Taylor (1968) — Ajustado + Observado

GRÁfiCo 2. REGRESSÃo ENTRE O PESO AdULTO (A) E A TAXA DE MATURIDADE (K). 


\subsubsection{Comparação entre a média dos parâmetros e os parâmetros médios}

Quando os animais foram tratados como repetição dentro de cada grupo de interesse houve diferença significativa para idade entre os vários grupos $(P<0,05)$. Uma alternativa utilizada para ajustar as funções de crescimento para cada animal foi ajustar as idades de cada animal pelas datas de pesagens e pelas datas de nascimento. Dessa forma as idades de pesagens quase sempre foram diferentes entre os animais.

Merrel1 ${ }^{8}$ citado por Perotto et al. (1992) afirma que a média dos parâmetros estimados de cada animal como sendo uma curva geral pode não, necessariamente, gerar uma outra curva não linear.

Essa afirmativa parece um tanto quanto inconsistente, pois na verdade o que ocorre é que a média dos parâmetros de cada animal do grupo de interesse pode não ser, necessariamente, idêntica à estimativa média para o grupo de interesse. Quaisquer valores próximos aos valores encontrados podem gerar uma curva não linear.

Com o intuito de averiguar essa relação entre a média dos parâmetros estimados para cada animal e o parâmetro médio estimado para o grupo de animais, O PROC TTEST (SAS®, 1987) foi utilizando. Os resultados da comparação estão sumariados na Tabela 30 .

Quando as variâncias não se apresentaram homogêneas o cálculo do número de graus de liberdade foi efetuado através do método de Cochran e Cox (SAS®, 1987), mais conservativo do que o método de Satterthwaite.

Os seguintes grupos de animais não foram utilizados: machos dos grupos raciais $1 / 2$ Guzerá $x$ 1/2Pardo Suíço (SG) e $\frac{1}{2}$ Chianina $x$ 1/4Guzerá $x$ 3/4Pardo Suíço ( $\frac{1}{2} \mathrm{C}(\mathrm{SG})$ ) para o tratamento $\mathrm{S} 1$ do ano 1; machos dos grupos raciais 3/4Guzerá x 3/4Pardo Suíço (3/4GS), 1/2Nelore x 3/4Guzerá x 3/4Pardo Suíço

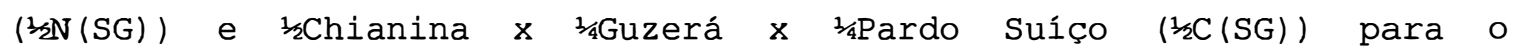
tratamento S2 do ano 1; machos dos grupos raciais Guzerá (G), 3/4Guzerá x 
1/4/4Pardo Suíço (3/4GS), 1/2Guzerá x 1/2Pardo Suíço (SG), 1/2Caracú x 1/2Guzerá (KG) e 1/2Caracú x 1/4Guzerá x 1/4Pardo Suíço (13/2K(SG)) para o tratamento S1 do ano 2 e machos dos grupos raciais Guzerá (G) e $3 / 4$ Guzerá x 1/4Pardo Suíço (3/4GS) para o tratamento S2 do ano 2. As causas de não utilização podem ter sido não convergência, peso adulto superior a $1000 \mathrm{~kg}$ ou erro padrão superior a $10 \%$ do peso adulto. Veja Apêndice 4 .

TABela 30. COMPARAÇÃo ENTRE A MÉdia dos PaRÂMETROS PARA CADA ANIMAL E OS PARÂMETROS MÉDIOS ESTIMADOS PARA OS GRUPOS DE ANIMAIS.

\begin{tabular}{ccccccc}
\hline Itens & \multicolumn{2}{c}{ " $A$ " } & \multicolumn{3}{c}{ " $b$ " } & \multicolumn{2}{c}{ " $k$ " } \\
\cline { 2 - 7 } & $\begin{array}{c}\text { Parâmetro } \\
\text { Médio }\end{array}$ & $\begin{array}{c}\text { Média dos } \\
\text { parâmetros }\end{array}$ & $\begin{array}{c}\text { Parâmetro } \\
\text { médio }\end{array}$ & $\begin{array}{c}\text { Média dos } \\
\text { parâmetros }\end{array}$ & $\begin{array}{c}\text { Parâmetro } \\
\text { médio }\end{array}$ & $\begin{array}{c}\text { Média dos } \\
\text { parâmetros }\end{array}$ \\
\hline Geral & 484,22 & 526,46 & 2,2741 & 2,2695 & 0,0030 & $0,0027^{* *}$ \\
Ano & & & & & & \\
1 & 480,62 & 522,65 & 2,1749 & 2,2234 & 0,0027 & 0,0026 \\
2 & 486,27 & 528,70 & 2,3305 & 2,2965 & 0,0031 & $0,0027^{* *}$ \\
Trat & & & & & & \\
S1 & 478,09 & 528,10 & 2,2418 & 2,2705 & 0,0029 & 0,0026 \\
S2 & 494,37 & 528,80 & 2,1957 & 2,1876 & 0,0029 & 0,0027 \\
S3 & 469,01 & 510,61 & 2,6485 & 2,5926 & 0,0038 & 0,0032 \\
Sexo & & & & & & \\
F & 446,75 & 476,03 & 2,3091 & 2,1616 & 0,0032 & $0,0028{ }^{*}$ \\
Faj & 446,75 & 458,45 & 2,3091 & $2,1288 *$ & 0,0032 & 0,0029 \\
M & 619,11 & 644,89 & 2,1483 & $2,5179 * *$ & 0,0022 & 0,0022 \\
Grupo & & & & & & \\
Racial & & & & & & \\
1 & 477,35 & 527,10 & 2,4355 & 2,4357 & 0,0027 & 0,0024 \\
2 & 457,12 & 511,87 & 2,1819 & 2,1451 & 0,0032 & 0,0028 \\
3 & 502,04 & 537,39 & 2,2141 & 2,1701 & 0,0030 & 0,0028 \\
4 & 464,74 & 503,47 & 2,4146 & 2,4776 & 0,0035 & 0,0031 \\
5 & 530,91 & 558,78 & 2,0344 & 2,1019 & 0,0021 & 0,0022 \\
6 & 494,48 & 519,95 & 2,4204 & 2,4086 & 0,0032 & 0,0029 \\
7 & 459,86 & 521,83 & 2,2191 & 2,1922 & 0,0032 & 0,0027 \\
\hline
\end{tabular}

Os códigos para os niveis de significância utilizados foram ${ }^{* * *}$ para $0,1 \% ;{ }^{* *}$ para $1 \% \mathrm{e}$ * para $5 \%$ na mesma linha entre colunas do mesmo parâmetro.

De forma geral, pela Tabela 30, verifica-se uma diferença significativa $(P<0,01)$ entre os pesos adultos $e$ as taxas de maturidade estimadas através da média para cada animal e do ajuste para

\footnotetext{
${ }^{8}$ MERREL,M. The relationship of individual growth to average growth. Human Biology, n.3, p. 37-70, 1931.
} 
o grupo de animais. A não existência de diferença significativa (P > $0,10)$ entre os pesos adultos quando separados por ano e por grupos raciais pode ser atribuido à alta variabilidade devido aos valores calculados para machos e fêmeas. São observadas grandes diferenças entre os valores, entretanto sem diferença significativa.

Vale notar que, o peso adulto calculado através da média dos parâmetros obtidos para cada animal é sempre maior do que o parâmetro médio ajustado para o grupo de animais, e que, a taxa de maturidade geralmente é menor.

Os valores dos parâmetros estimados para cada grupo racial, tratamento, sexo e ano estão listados no Apêndice 4.

\subsection{Estudo multivariado da curva de crescimento selecionada}

De forma geral, a análise multivariada seria indicada quando existe um alta correlação entre as variáveis estudadas na análise univariada. Dessa forma, sabendo-se que a correlação entre o peso adulto e a taxa de maturidade mostrou-se alta nesse trabalho, o estudo da análise multivariada nesses dados é perfeitamente correto.

Crew et al. (1996) utilizaram modelo multivariado (MANOVA) para analisar os três parâmetros da curva de Brody obtendo resultados semelhantes com os resultados para os modelos univariados. A análise multivariada permitiu relacionar o efeito de cada um dos três parâmetros com as datas de coleta do peso vivo (idades do animal). Os autores concluiram que a taxa de maturidade estava positiva e negativamente correlacionada com $\circ$ peso às idades anteriores e posteriores aos 24 meses de idade, respectivamente. 


\subsubsection{Análise para o ano base de 1978}

Os fatores que apresentaram diferenças estatísticas multivariada foram: o efeito de sexo $(P<0,001)$ e a interação entre tratamento e grupo racial $(P<0,001)$. Para o efeito de sexo, os contrastes multivariados mostraram que as fêmeas sem ajuste para peso fetal e tecidos anexos (F) não diferiram das fêmeas com ajuste $\left(F_{a j}\right)$. Entretanto a curva de crescimento das fêmeas ( $F$ e $\left.F_{a j}\right)$ diferiram das curvas dos machos (M) $(P<0,001)$ conforme está mostrado no Gráfico 40 . o efeito da interação entre tratamento e grupo racial foi analisado para os níveis de cada fator. Quando analisado dentro dos níveis do fator tratamento (S1 e S2), apenas os grupos raciais G e ${ }_{1 / 2}^{1 / 2}(\mathrm{SG})$ não diferiram entre si $(\mathrm{P}>0,10)$ para o tratamento $\mathrm{S} 1$ (sem suplementação), de fato, a Tabela 22 mostra que nem o peso adulto nem a taxa de maturidade para esses grupos raciais foram diferentes entre si $(P<0,05)$. Dentro do nível de suplementação durante o inverno (S2), os grupos raciais $3 / 4 G S, 1 / 2 N(S G)$ e $S G$ não diferiram entre si $(P>0,15)$, conforme mostra a Tabela 22 esses animais não diferiram entre si $(\mathrm{P}<$ 0,05) para peso adulto e taxa de maturidade. Essas comparações podem ser analisadas no Gráfico 16 e no Gráfico 17. O Gráfico 17 mostra claramente o resultado estatístico, entretanto o Gráfico 16 mostra que a curva de crescimento dos animais $G$ e ${ }_{3 / 2}(\mathrm{SG})$ são semelhantes apenas até os 1000 dias, a partir do qual torna-se muito semelhante com a curva do animal 3/4GS. Talvez devido a variação ou número de repetição.

Para a análise do efeito de suplementação dentro de cada grupo racial, apenas os grupos raciais $3 / 4 G S$ e SG sem suplementação mostraram crescimento diferentes em relação aos animais com suplementação ( $\mathrm{P}$ < 0,01). A Tabela 20 mostra que apenas para o peso adulto do grupo racial 3/4GS houve diferença significativa $(P<0,05)$. O Gráfico 4 até o Gráfico 8 mostram as curvas de crescimento desses animais. Da mesma forma que a 
análise anterior, o Gráfico 7 (grupo racial SG) não mostra claramente esse efeito de diferença entre tratamentos.

\subsubsection{Análise para o ano base de 1979}

Para esse ano, os seguintes fatores apresentaram diferenças estatísticas multivariada: tratamento $(P<0,03)$, sexo $(P<0,001)$ e grupo racial $(\mathrm{P}<0,001)$.

Para o efeito de tratamento, a curva de crescimento dos animais que receberam suplementação foi diferente dos animais que não receberam $(P<0,03)$ conforme mostra o Gráfico 41. Os animais tenderam a atingir um peso maior mais jovens, ou seja, precocidade (principalmente devido a taxa de maturidade maior) e apresentar um peso adulto menor, conforme foi discutido nas páginas 71 e 72 .

Da mesma forma que no ano base de 1978, as fêmeas ( $F$ e $F_{a j}$ ) não diferiram entre si mas apresentaram crescimento diferente dos machos ( $P$ $<0,001)$, conforme mostra o Gráfico 42 .

Pela análise multivariada, os grupos raciais $3 / 46 S, 3 / 2 \mathrm{~N}(\mathrm{SG})$ e $3 \cdot 2 \mathrm{~K}(\mathrm{SG})$ não diferiram entre si $(P>0,10)$ assim como os grupos $\mathrm{SG}$ e KG não diferiram entre si $(P>0,15)$. As curvas de crescimento desses animais estão esquematizadas no Gráfico 18 e Gráfico 19.

\subsubsection{Análise da suplementação total}

Quando analisado os efeitos dos três níveis de tratamento apenas aos grupos raciais $\mathrm{G}, 3 / 4 \mathrm{GS}$ e $3 / 2 \mathrm{~N}(\mathrm{SG})$ notou-se uma diferença significativa multivariada entre grupos raciais e a interação entre tratamento e sexo.

A análise do efeito da interação tratamento e sexo mostrou que independente dos níveis de tratamento, as fêmeas sem (F) e com ( $\left.F_{a j}\right)$ ajuste de peso não diferiram entre $\mathrm{si}(\mathrm{P}>0,10)$ mas diferiram dos 
machos $(P<0,01)$. Entretanto, quando analisados dentro dos níveis $F$ e $F_{a j}$ de sexo, os tratamentos $\mathrm{S} 1$ e $\mathrm{S} 2$ não diferiram entre $\mathrm{si}(\mathrm{P}>0,10)$ mas diferiram do tratamento S3 $(\mathrm{P}<0,01)$. Para os machos $(\mathrm{M})$, apenas 0 tratamento $\mathrm{S} 1$ diferiu do S3 $(\mathrm{P}<0,01)$.

Para o efeito de grupo racial, os grupos $3 / 4 G S$ e $3 / 2 \mathbb{N}(S G)$ não diferiram entre si $(P>0,20)$, mas diferiram do grupo racial $G(P<$ 0,01). As curvas de crescimento estão esquematizadas no Gráfico 43.

Para o efeito de suplementação, os animais cruzados tendem a utilizar melhor a disponibilidade de suplementação para crescimento do que o Guzerá, embora não tenha sido encontrado diferença estatística na análise multivariada,

De forma geral, as fêmeas $\operatorname{com}\left(F_{a j}\right)$ e sem $(F)$ correção para o peso fetal e os tecidos anexos da placenta não apresentaram diferenças entre si, mas foram diferentes dos machos (M). Os resultados expressos nas Tabelas 23 e 24 suportam os resultados obtidos para o efeito de sexo na análise multivariada.

Quando analisou-se o efeito de uma terceira suplementação (S3 suplementação durante o ano todo) notou-se que houve um efeito significativo ao crescimento dos animais em relação aos demais tratamentos. Nesse caso, para todos os tratamentos, os grupos raciais $\frac{3}{4} / 4 S$ e $1 / 2 N(S G)$ apresentaram crescimento distintos do Guzerá $(P<0,01)$.

\subsection{Outros aspectos relacionados às funções de crescimento}

\subsubsection{Relação entre taxa de maturidade e peso adulto}

Quando se compara os valores das variáveis da Equação 17 para todas as funções de crescimento ajustadas, percebe-se que, cada função gera uma relação diferente entre os parâmetro " $A$ " e " $k$ " entre funções, além de apresentarem altas variações no coeficiente de determinação, o 
que caracteriza a diferença de convergência dos valores observados entre as funções estudadas. Além do que, as curvas citadas na Tabela 31 apresentam diferentes correlações entre os parâmetros " $A$ " $e$ " $k$ ", respectivamente: $\quad-0,85 ;-0,84 ;-0,77 ;-0,53 ;-0,69 ;-0,83$ e $-0,78$ (Apêndice 3). Os coeficientes de determinação da regressão log-log (Equação 17) entre o peso adulto e a taxa de maturidade foram, respectivamente: $80,8 \% ; 79,0 \% ; 68,1 \% ; 27,6 \% ; 55,6 \% ; 73,4 \%$ e $72,9 \%$.

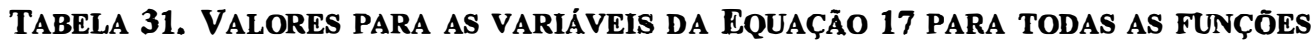
AJUSTADAS,

\begin{tabular}{lrrrr}
\hline Funcão & Animais & a & \multicolumn{1}{c}{ b } & \multicolumn{1}{c}{$\mathbf{R}^{2}$} \\
\hline Brody & 334 & $-1,4753 \pm 0,0394$ & $1,1834 \pm 0,1081$ & $80,8 \%$ \\
Brody modificada & 368 & $-1,3309 \pm 0,0359$ & $0,7789 \pm 0,0991$ & $79,0 \%$ \\
Gompertz & 435 & $-1,2435 \pm 0,0409$ & $0,7953 \pm 0,1106$ & $68,1 \%$ \\
Gompertz modificada & 445 & $-0,6272 \pm 0,0483$ & $-0,7937 \pm 0,1286$ & $27,6 \%$ \\
Logística & 444 & $-1,0168 \pm 0,0432$ & $0,3272 \pm 0,1156$ & $55,6 \%$ \\
Richards & 308 & $-2,9906 \pm 0,1019$ & $5,2459 \pm 0,2733$ & $73,4 \%$ \\
Bertalanffy & 426 & $-1,3447 \pm 0,0398$ & $1,0098 \pm 0,1081$ & $72,9 \%$ \\
\hline
\end{tabular}

Além dessas regressões apresentarem comportamentos completamente específicos, os numeradores da Equação 20 também apresentaram-se distintos, e na maioria das vezes muito diferente (respectivamente: $0,00839 \pm 0,000145 ; 0,007794 \pm 0,000126 ; 0,01567 \pm 0,000213 ; 0,01831$ $\pm 0,000129 ; 0,02224 \pm 0,000243 ; 0,01112 \pm 0,000211$ e $0,01345 \pm$ 0,000212) do valor citado por Taylor (1968), como sendo 0,01566 (para o tempo dado em dias).

No Gráfico 3 pode-se perceber o comportamento de cada regressão (curva alométrica) entre os parâmetros " $A$ " e " $k$ " para cada função de crescimento. A regressão entre Brody e Brody modificada apresenta pequena diferença entre a relação de " $A$ " e " $k$ " apenas para peso adulto inferior a $500 \mathrm{~kg}$. As regressões entre Gompertz e Gompertz modificada 
apresentam maior digervência, na estimativa de " $k$ ", conforme aumenta o peso adulto. As regressões Logística, Gompertz e Bertalanddy apresentam-se quase paralelas, sendo que a primeira tende a superestimar valores de " $k$ " e a última tendendo a subestima-los. A regressão de Richards está completamente diferente de qualquer curva, apresentando um comportamento ímpar. Embora existam diferenças entre os valores regredidos de " $k$ " em relação à " $A$ ", todas as curvas mostram claramente a tendência de diminuição da taxa de maturidade conforme o peso adulto é aumentado.

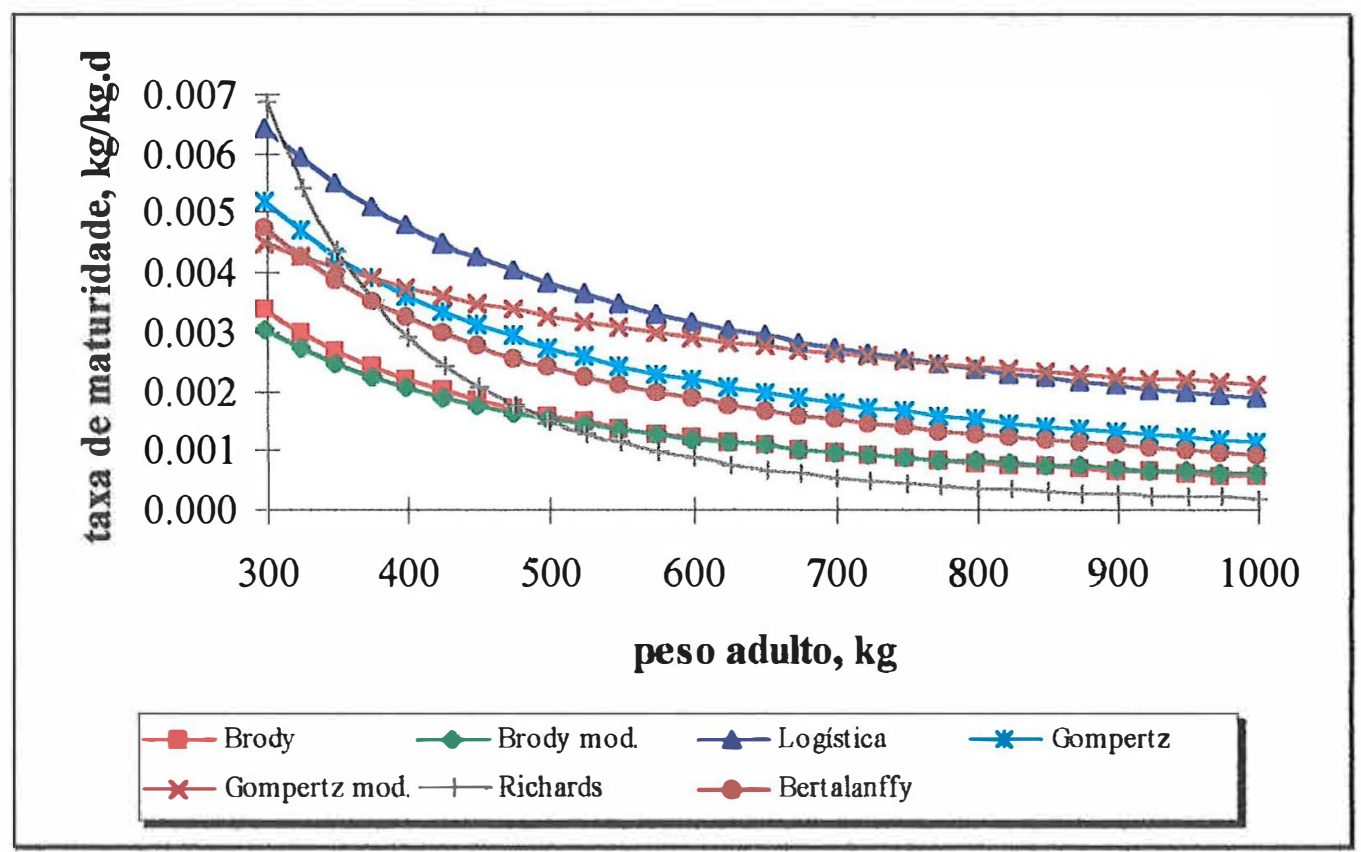

GRÁfico 3. CuRVAS dA RELAÇ̃̃o ENTRE O PESO ADULTO (A) E A TAXA DE MATURIDADE (K) DAS FUNÇÕES DE CRESCIMENTO AJUSTADAS.

Para um mesmo valor de peso adulto, de forma geral, as funções de Gompertz modificada e Logística tendem a apresentar maiores taxas de maturidade, seguidas das funções de Gompertz e Bertalanffy, e finalmente, das duas curvas de Brody. 


\subsubsection{Comparação entre os métodos de estimativa da taxa de maturidade}

A Equação 7 permite estimar a taxa de maturidade sem a necessidade de se utilizar ferramentas de computação. Quando se compara os valores ajustados (computados) com valores estimados através de diversos períodos de ganho de peso ( 0 até 8 e 8 até $12(\mathrm{k} 1), 8$ até 12 e 12 até $16(\mathrm{k} 2), 12$ até 16 e 16 até $20(\mathrm{k} 3), 16$ até 20 e 20 até $24(\mathrm{k} 4)$, 20 até 24 e 24 até $28(\mathrm{k} 5), 24$ até 28 e 28 até $32(\mathrm{k} 6), 0$ até 16 e 16 até 32 (k7), e, finalmente, 0 até 18 e 18 até 36 ( $k 8$ ) meses de idade), constata-se que é possível estimar a taxa de maturidade, através do k8 ( 0 até 18 e 18 até 36 meses de idade) apenas para as fêmeas ( $\mathrm{P}$ < 0,001), obtendo um $\mathrm{R}^{2}$ de 70,03\%:

\section{EQUAÇÃo 21}

$$
\mathrm{k}=0,001551+0,7607 . \mathrm{k} 8
$$

Para os demais períodos ( $k 1$ até $k 7)$ não houve regressão significativa com os valores de $\mathrm{k}$ ajustados. Portanto, quanto maior for a diferença entre idades para cálculo da taxa de maturidade (calculada), maior será a tendência de obter-se um valor próximo ao $\mathrm{k}$ ajustado através de computação iterativa.

Embora a Equação 7 tenha sido derivada para a função de Brody modificada, essa mostrou-se bastante eficaz para os valores da taxa de maturidade obtidos com a função de Gompertz. A relação entre as taxas de maturidade de Gompertz e Brody modificada, para todos os animais, apresentou $R^{2}$ de $82,96 \%$ e foi a seguinte:

\section{EQUAÇ̃̃o 22}

$(\mathrm{k}$ de Gompertz $)=0,001122+1,40723 .(\mathrm{k}$ de Brody Modificada $)$ 


\subsubsection{Cálculo do número de repetições para experimentos futuros}

A necessidade de informações da quantidade de repetições a serem utilizadas num experimento é uma das principais causas que podem provocar o aparecimento de resultados sem expressão, ou mesmo, sem resultados esperados que possam ser comparados com a literatura.

A Tabela 32 mostra o número necessário de repetições para cada nível do poder de teste e de significância indicados, para percentagens de variação entre tratamentos de 5; 10 e 15\%, segundo a metodologia indicada por Berndtson (1991).

TABELA 32. EsTIMATIVA dO NUMERO NECESSÁRIO DE REPETIÇŌES PARA EXPERIMENTOS FUTUROS, VARIANDO O NÍVEL DE SIGNIFICÂNCIA E PODER DO TESTE PARA TRÊS DIFERENÇAS PERCENTUAIS ENTRE TRATAMENTOS.

\begin{tabular}{|c|c|c|c|c|c|c|c|c|c|c|c|c|c|c|}
\hline \multirow[b]{6}{*}{ Sexo } & \multirow[b]{6}{*}{ Ítem } & \multirow[b]{6}{*}{ CV } & \multicolumn{12}{|c|}{ Poder do teste } \\
\hline & & & \multicolumn{6}{|c|}{$95 \%$} & \multicolumn{6}{|c|}{$90 \%$} \\
\hline & & & \multicolumn{6}{|c|}{ Nível de significância } & \multicolumn{6}{|c|}{ Nível de Significância } \\
\hline & & & \multicolumn{3}{|c|}{$1 \%$} & \multicolumn{3}{|c|}{$5 \%$} & \multicolumn{3}{|c|}{$1 \%$} & \multicolumn{3}{|c|}{$5 \%$} \\
\hline & & & \multicolumn{3}{|c|}{$\Delta$ Tratamentos } & \multicolumn{3}{|c|}{$\Delta$ Tratamentos } & \multicolumn{3}{|c|}{$\Delta$ Tratamentos } & \multicolumn{3}{|c|}{$\Delta$ Tratamentos } \\
\hline & & & $5 \%$ & $10 \%$ & $15 \%$ & $5 \%$ & $10 \%$ & $15 \%$ & $5 \%$ & $10 \%$ & $15 \%$ & $5 \%$ & $10 \%$ & $15 \%$ \\
\hline \multirow[t]{3}{*}{$\bar{F}$} & "A" & 19,39 & 537 & 135 & 61 & 392 & 99 & 45 & 449 & 113 & 51 & 317 & 80 & 36 \\
\hline & "k" & 29,51 & 1243 & 312 & 139 & 907 & 228 & 102 & 1038 & 201 & 117 & 733 & 184 & 82 \\
\hline & "b" & 18,69 & 499 & 126 & 57 & 364 & 92 & 42 & 417 & 105 & 48 & 295 & 75 & 34 \\
\hline \multirow{3}{*}{$F_{a j}$} & "A" & 20,25 & 586 & 148 & 66 & 428 & 108 & 49 & 490 & 124 & 56 & 346 & 87 & 39 \\
\hline & "k" & 29,27 & 1222 & 307 & 137 & 892 & 224 & 100 & 1021 & 256 & 115 & 721 & 181 & 81 \\
\hline & "b" & 19,39 & 537 & 135 & 61 & 392 & 99 & 45 & 449 & 113 & 51 & 317 & 80 & 36 \\
\hline \multirow{3}{*}{ M } & "A" & 15,40 & 340 & 86 & 39 & 248 & 63 & 29 & 284 & 72 & 33 & 201 & 51 & 23 \\
\hline & "k" & 24,30 & 843 & 212 & 95 & 615 & 155 & 69 & 704 & 177 & 80 & 498 & 125 & 56 \\
\hline & "b" & 8,67 & 109 & 28 & 13 & 79 & 21 & 10 & 91 & 24 & 11 & 64 & 17 & 8 \\
\hline
\end{tabular}

Pela tabela acima, pode-se concluir que ao nível de 90\% para 0 poder do teste e 5o para o nível de significância, para detectar-se uma diferença entre tratamentos de 15\%, seriam necessários pelo menos 82 repetições por tratamento devido ao coeficiente de variação da taxa de maturidade ser maior que a dos demais parâmetros. Quando consideramos apenas os machos, somente 56 seriam suficientes. 


\subsection{Considerações finais}

O Gráfico 44 até o Gráfico 46 (Apêndice 7) mostram a evolução do peso vivo em jejum das fêmeas com correção de peso $\left(F_{a j}\right)$ dos grupos raciais G (Guzerá), 3/4GS (3/4Guzerá x 1/4Pardo Suíço) e 1//2N(SG) (1/2Nelore x 3/4Guzerá x 3/4Pardo Suíço), nascidos em 1979, para os três tipos de suplementação estudados (S1, S2 e S3). Para as três raças, os animais que receberam suplementação durante o ano todo, apresentaram maiores pesos durante a maior parte da fase de crescimento. Os animais que receberam apenas suplementação durante o inverno, mostraram um crescimento mais "linear" em relação aqueles sem suplementação, nos períodos de inverno. Os animais sem suplementação tenderam a compensar o peso, em relação aos outros animais, na fase final de crescimento, porventura, devido ao crescimento compensatório (Ryan, 1990; Hogg, 1991).

As fêmeas Guzerá não responderam tão bem à suplementação total e de inverno, quanto as fêmeas 1/4Europeu (3/4Guzerá x 1/4Pardo Suíço e 1/2/2Nelore x 1/4Guzerá x 3/4Pardo Suíço). Mesmo para os animais com suplementação durante o ano todo ou somente no inverno existiu um declínio nas curvas de peso-idade nos períodos de ocorrência de inverno, embora menos acentuado em relação aos animais sem qualquer tipo de suplementação.

O Gráfico 47 até o Gráfico 51 (Apêndice 7) mostram o crescimento de fêmeas com correção para peso fetal $\left(F_{a j}\right)$ dos grupos raciais estudados para cada tipo de suplementação, divididos em anos de nascimento (1978 e 1979). Pode-se notar que os animais da raça Guzerá apresentaram menor peso em relação às demais raças, embora, tendesse a compensar no final da curva em algumas situações. Os animais do ano base de 1979 apresentaram curva de peso-idade mais homegêneas do que os animais de 1978. Quando se compara o Gráfico 50 com o Gráfico 51, 
percebe-se que a suplementação durante $\circ$ ano todo não apresenta vantagem no padrão de crescimento dos animais em relação à suplementação estratégica de inverno. 


\section{CONCLUSÕES}

- Todas as funções de crescimento puderam ser ajustadas. O nível de dificuldade de ajuste foi maior para a função de Richards. A função selecionada, através dos índices de comparação entre curvas, foi a de Gompertz;

- Os machos não apresentaram idade suficiente para obtenção de um ajuste adequado. Não houve diferença significativa entre as estimativas dos parâmetros das funções de crescimento para as fêmeas sem correção e com correção de peso fetal e tecidos anexos ( $\mathrm{P}$ > 0,05), embora as fêmeas com correção tenderam a possuir menor peso adulto e maior taxa de maturidade além de possuíram menor variação;

- De forma geral, a suplementação de inverno não modificou o peso adulto dos animais em relação aos animais sem suplementação, mas aumentou a taxa de maturidade apenas nos animais que receberam a suplementação mais energética (Ano 2), mostrando a relação entre a taxa de maturidade e de manejo;

- No geral, os animais que receberam suplementação durante o ano todo, apresentaram menor peso adulto e maior taxa de maturidade em relação aos demais animais, sugerindo uma influência da composição corporal no peso adulto;

- Apenas os animais do grupo racial $3 / 4$ Guzerá x $3 / 4$ Pardo Suíço (3/4GS) tenderam a apresentar alguma influência devido ao manejo de suplementação no peso adulto. Nos tratamentos onde houve suplementação, não existiu diferença estatística no peso adulto, entre os grupos raciais; 
- A parição mostrou alta correlação com os parâmetros da função de crescimento, tanto para fêmeas com e sem correção de peso fetal e tecidos anexos, modificando o peso adulto assintótico;

- Devido à alta correlação entre o parâmetro " $A$ " (peso adulto) e " $k$ " (taxa de maturidade) foi possível produzir uma regressão entre esses dois parâmetros com coeficiente de determinação elevado (68\%) a qual apresentou maior acurácia que a função de Taylor (1968);

- As regressões do peso adulto em relação à taxa de maturidade das demais funções apresentaram resultados diferentes entre si, mas todas tenderam a diminuir a taxa de maturidade conforme o peso adulto era incrementado;

- De fato, existiu diferença entre os parâmetros médios e a média dos parâmetros calculados para cada grupo de animais e para cada animal, respectivamente. Parece que o uso da média dos parâmetro tende a ser a mais correto em detrimento ao uso do parâmetro médio;

- O uso da análise multivariada foi possível devido a alta correlação entre os parâmetros da função de crescimento utilizada;

- Algumas relações encontrada pela análise multivariada não foram confirmadas pela análise univariada e vice-versa;

- A relação entre a taxa de maturidade da função de Gompertz e Brody modificada sugere que entre funções de crescimento, o valor dos parâmetros não são idênticos. Portanto, a comparação de trabalhos utilizando diferentes funções pode não estar correta. 


\section{IMPLICAÇÕES}

- Raças devem ser incluídas nos próximos experimentos para poder comparar as variações genéticas de gerações com os seus respectivos cruzamentos e estimar os valores de herdabilidade tanto do peso adulto como da taxa de maturidade;

- Para uma melhor estimativa do peso adulto, os animais devem possuir pelo menos 4,5 anos consecutivos de coleta de peso para que o ajuste seja adequado, portanto, experimentos de longa duração com animais de ambos os sexos devem ser propostos;

- Maior quantidade de repetições por tratamento (animais) devem ser considerados em pesquisas futuras, tendo como base, a variação encontrada nos dados desse estudo;

- Experimentos paralelos de composição corporal devem ser efetuados, afim de, traçar curvas de crescimento e exigência de nutrientes, para confecção de modelos de simulação;

- O abate de fêmeas e touros adultos de descarte, também, pode ser efetuado para melhor acompanhar o aumento do tamanho corporal do rebanho e as estimativas de peso adulto através das funções de crescimento;

- A utilização de modelos de crescimento múltiplos (estágios) deve ser abordado em futuros estudos. As correlações entre cada estágio deve ser analisada e discutida;

- Análises multivariadas de parâmetros de funções polinomiais podem/devem ser utilizadas para os animas que não apresentarem a idade mínima para convergência das funções não lineares. 


\section{REFERÊNCIAS BIBLIOGRÁFICAS}

AHUNU,B.K.; KABUGA,J.D.; GWAYA,P.; TEYE-AYAN,G. A comparison of nonlinear models for describing growth in N'Dama cattle. Discovery and Innovation, v. 6, n. 1, p. 78-83, 1994. /Resumo em CAB Abstracts on CD-ROM, v. 4A, $1993-94 /$.

ARNOLD,R.N.; BENNETT,G.L. Evaluation of four simulation models of cattle growth and body composition. I. Comparison and characterization of the models. Agricultural Systems, v. 35, n. 3, p. 401-432, 1991a.

ARNOLD,R.N.; BENNETT,G.L. Evaluation of four simulation models of cattle growth and body composition. II. Simulation and comparison with experimental growth data. Agricultural Systems, v. 36, n.1, p.17-41, 1991 b.

BAILEY,C.B.; MEARS,G.J. Birth weight in calves and its relation to growth rates from birth to weaning and weaning to slaughter. Canadian Journal of Animal Science, v. 70, n.1, p.167-173, 1990.

BELL,A.W.; SLEPETIS,R.; EHRHARDT,R.A. Growth and accretion of energy and protein in the gravid uterus during late pregnancy in Holstein cows. Journal of Dairy Science, v. 78, n.9, p. 1954-1961, 1995.

BELTRAN,J.J.; OLSON,T.A.; ADAMS,E.L. Effect of reproductive history on estimating growth curve parameters in Angus cow. In: ANNUAL MEETING OF THE AMERICAN SOCIETY OF ANIMAL SCIENCE, 83., Forth Worth, 1991. Abstracts. Journal of Animal Science, v. 69, p. 5, 1991.

BELTRAN,J.J.; BUTTS Jr,W.T.; OLSON,T.A.; KOGER,M. Growth patterns of two lines of Angus cattle selected using predicted growth parameters, Journal of Animal Science, v. 70, n. 3, p. 734-741, 1992. /Resumo em CAB Abstracts on CD-ROM, v. $3 \mathrm{~B}, 1992 /$.

BERNDTSON,W.E. A simple, rapid and reliable method for selecting or assessing the number of replicates for animal experiments. Journal of Animal Science, v. 69, n. 1, p. 67-76, 1991.

BERTALANFFY,L. von. A quantitative theory of organic growth. Human Biology, v. 10, p. $181-213,1938$.

BIANCHINI SOBRINHO,E. Estudo da curva de lactação em vacas da raça Gir. Ribeirão Preto, 1984. 88p. Tese (Doutorado) - Faculdade de Medicina de Ribeirão Preto, Universidade de São Paulo. 
BIANCHINI SOBRINHO,E; DUARTE,F.A.M. Modelos matemáticos aplicados ao crescimento de bovinos da raça Nelore. In: REUNIÃO ANUAL DA REGIÃO BRASILEIRA DA SOCIEDADE INTERNACIONAL DE BIOMETRIA, 36., Goiânia, 1991. Resumos. Goiânia: EMBRAPA; UFG, 1991. p. 24.

BRODY,S. Bioenergetics and growth. New York: Reinhold, 1945. 1023p.

BROWN,J.E.; BROWN,C.J.; BUTTS,W.T. A discussion of the genetic aspects of weight, mature weight and rate of maturing in Hereford and Angus cattle. Journal of Animal Science, v. 34, p. 525-532, 1972.

BROWN,J.E.; FITZHUGH JÚNIOR,H.A.; CARTWRIGHT,T.C. A comparison of nonlinear models for describing weight-age relationships in cattle. Journal of Animal Science, v.42, n.4, p.810-818, 1976.

BUTTS,W.T.; McCURLEY,J.R.; BOVARD,K.P. Growth patterns of Angus, Hereford and Shorthorn cattle. II. Relationship of growth patterns of dams with progeny performance, Journal of Animal Science, v. 59, n. 5, p. 1205-1212, 1984.

CALO,L.L.; McDOWELL,R.E.; VAN-VLECK,L.D. van; MILLER,P.D. Parameters of growth of Holstein-Friesian bulls. Journal of Animal Science, v. 37, n. 2, p. 417422, 1973. /Resumo em CAB Abstracts on CD-ROM, v. 0A, 1972-75/.

CAMFIELD,P.K.; BROWN,A.H.; LEWIS,P.K.; JOHNSON,Z.B.; BROWN,C.J. Effect of growth type on carcass composition of beef steers developed on forage or grain diets. In: ANNUAL MEETING OF THE AMERICAN SOCIETY OF ANIMAL SCIENCE, 88., Rapid City, 1996. Abstracts. Journal of Animal Science, v. 74, suppl. 1, p. 1, 1996a.

CAMFIELD,P.K.; BROWN,A.H.; LEWIS,P.K.; JOHNSON,Z.B.; BROWN,C.J. Effect of growth type on carcass data of beef steers developed on forage or grain diets. In: ANNUAL MEETING OF THE AMERICAN SOCIETY OF ANIMAL SCIENCE, 88., Rapid City, 1996. Abstracts. Journal of Animal Science, v. 74, suppl. 1, p. 6, $1996 b$.

CARRIJO,S.M. Descrição e comparação de parâmetros de crescimento de animais das raças Chianina e Nelore. Ribeirão Preto, 1988. 116p. Dissertação (Mestrado) Faculdade de Medicina de Ribeirão Preto, Universidade de São Paulo.

COLEMAN,S.W.; EVANS,B.C.; GUENTHER,J.J. Body and carcass composition of Angus and Charolais steers as affected by age and nutrition. Journal of Animal Science, v.71, n. 1, p. 86-95, 1993. 
COMMONWEALTH SCIENTIFIC AND INDUSTRIAL RESEARCH ORGANISATION. Feeding standards for Australian livestock: ruminants. Melbourne, 1990. 266p.

CORTARELLI,A. Estudo da curva de crescimento de machos da raça Nelore, através de quatro modelos estocásticos. Jaboticabal, 1973. 179p. Tese (Doutorado) Faculdade de Medicina Veterinária e Agronomia de Jaboticabal, Universidade Estadual Paulista "Júlio de Mesquita Filho".

CREW,D.H.; FRANKE,D.E.; HABET.O. Weights and rate of maturing among Angus, Brahman and Polled Hereford cows. In: ANNUAL MEETING OF THE AMERICAN SOCIETY OF ANIMAL SCIENCE, 88., Rapid City, 1996. Abstracts. Journal of Animal Science, v. 74, suppl. 1, p. 1, 1996.

CRÓCOMO,C.R. Análise econométrica do crescimento ponderal de gado bovino: Canchim - Nelore - Charolês. Piracicaba, 1973. 138p. Dissertação (Mestrado) Escola Superior de Agricultura "Luiz de Queiroz", Universidade de São Paulo.

DeNISE,R.S.K.; BRINKS,J.S. Genetic and environmental aspects of the growth curve parameters in beef cows. Journal of Animal Science, v.61, n.6, p.1431-1440, 1985.

DOREN,P.E.; BAKER,J.F. LONG,C.R.; CARTWRIGHT,T.C. Estimating parameters of growth curves of bulls. Journal of Animal Science, v.67, n.6, p.1432-1445, 1989.

DUARTE,F.A.M. Estudo da curva de crescimento de animais da raça Nelore (Bos taurus indicus) através de cinco modelos estocásticos. Ribeirão Preto, 1975. 284p. Tese (Livre-Docência) - Faculdade de Medicina de Ribeirão Preto, Univeridade de São Paulo.

FERRELL,C.L. Factors influencing fetal growth and birth weight in cattle. In: ESTADOS UNIDOS. DEPARTMENT OF AGRICULTURE. Beef Research Progress Report no 4. Washington: USDA, Agriculture Research Service, 1993. p. 104-107. (ARS, 71)

FERRELL,C.L.; JENKINS,T.G. A note on energy requirements for maintenance of lean and fat Angus, Hereford and Simmental cows. Animal Production, v.39, p. 305-310, 1984.

FERRELL,C.L.; GARRET,W.N.; HINMAN,N. Growth, development and composition of the udder and gradid uterus of beef heifers during pregnancy. Journal of Animal Science, v. 42, n. 6, p. 1477-1489, 1976a.

FERRELL,C.L.; GARRET,W.N.; HINMAN,N.; GRICHTING,G. Energy utilization by pregnant and non-pregnant heifers. Journal of Animal Science, v. 42, n. 4, p. 937951, 1976b. 
FITZHUGH,H.A. Analysis of growth curves and strategies for altering their shapes. Journal of Animal Science, v. 42, n. 4, p. 1036-1051, 1976.

FITZHUGH,H.A.; TAYLOR,C.S. Genetic analysis of degree of maturity. Journal of Animal Science, v. 33, n. 4, p. 717-725, 1971.

FOX,D.G.; BLACK,J.R. A system for predicting body composition and performance of growing cattle. Journal of Animal Science, v. 58, n. 3, p. 725-739, 1984.

FOX,D.G.; SNIFFEN,C.J.; O'CONNOR,J.D.; RUSSEL,J.B.; VAN SOEST,P.J. The cornell net carbohydrate and protein system for evaluating cattle diets. I. A model for predicting cattle requirements and feedstuffs. Ithaca:Cornell University Press, 1990. 128p. (Search Agriculture, 34).

FREITAS,A.F. de; DURÃES,M.C.; TEIXEIRA,N.M. Funções de crescimento de animais da raça Holandesa, mantidos em regime de confinamento. In: REUNIÃO ANUAL DA SOCIEDADE BRASILEIRA DE ZOOTECNIA, 32., Brasília, 1995. Anais. Brasília: Sociedade Brasileira de Zootecnia, 1995. p.662-665.

FRIES,L.A. Seleção pela performance em bovinos. In: SIMPÓSIO SOBRE MELHORAMENTO GENÉTICO DE BOVINOS. 2., Jaboticabal, 1977. Anais. Jaboticabal: FCAV, 1977. p. 130-161.

GIANNONI,M.A.; GIANNONI,M.L. Genética e melhoramento de rebanhos nos trópicos. 2. ed. São Paulo: Nobel, 1989. 463p.

GOONEWARDENE,L.A.; BERG,R.T.; HARDIN,R.T. A growth study of beef cattle. Canadian Journal of Animal Science, v. 61, n. 4, p.1041-1048, 1981.

GREEN,R.D.; CUNDIFF,L.V.; DICKERSON,G.E.; JENKINS,T.G. Biological efficiency differences among Bos taurus $\mathrm{x}$ Bos taurus and Bos indicus $\mathrm{x}$ Bos taurus $\mathrm{F}_{1}$-cross cows. In: ESTADOS UNIDOS. DEPARTMENT OF AGRICULTURE. Beef Research Progress Report no 4. Washington: USDA, Agriculture Research Service, 1993. p. 55-56. (ARS, 71)

HARTLEY,H.O. The modified Gauss-Newton method for the fitting of nonlinear regression functions by least squares. Technometric, v. 3, n. 2, p.269-280, 1961.

HOOG,B.W. Compensatory growth in ruminants. In: PEARSON,A.M.; DUTSON,T.R. (Ed.). Growth regulation in farm animals. London: Elsevier Science, 1991. v. 7, cap. 5, p. 103-134.

JANDEL SCIENTIFIC. Tablecurve 2D: Automated curve fitting software for Windows. 1994. 1v. 
JENKINS,C.L.; FERRELL,T.G. Conversion efficiency through weaning of nine breeds of cattle. In: ESTADOS UNIDOS. DEPARTMENT OF AGRICULTURE. Beef Research Progress Report no 4. Washington: USDA, Agriculture Research Service, 1993. p. 156-157. (ARS, 71)

JENKINS,T.G.; KAPS,M.; CUNDIFF,L.V.; FERRELL,C.L. Estimates of mature weights and maturing rates for breed crosses. In: ESTADOS UNIDOS. DEPARTMENT OF AGRICULTURE. Beef Research Progress Report $\mathrm{n}^{\mathbf{0}}$ 4. Washington: USDA, Agriculture Research Service, 1993. p. 160-161. (ARS, 71)

JENKINS,T.G.; LEYMASTER,K.A. Estimates of maturing rates and masses at maturity for body componentes of sheep. Journal of Animal Science, v. 71, n. 11, p.29522957, 1993.

JENKINS,T.G.; LONG,C.R.; CARTWRIGHT,T.C.; SMITH,G.C. Characterization of cattle of a five-breed diallel. IV. Slaughter and carcass characters of serially slaughtered bulls. Journal of Animal Science, v. 53, n. 1, p. 62-79, 1981.

JOANDERT,G.E.; CARTWRIGHT,T.C. Estimation of efficiency of beef production. Journal of Animal Science, v. 29, p. 862-868, 1969.

JOHNSON,Z.B.; BROWN,C.J.; BROWN Jr,A.H. Evaluation of growth patterns of beef cows. Arkansas: University Press, Arkansas Agricultural Experiment Station, 1990. 41p. (Bulletin, 923) /Resumo em CAB Abstracts on CD-ROM, v. 3A, 1990$91 /$.

JOHNSON,Z.B.; BROWN,C.J.; BROWN Jr,A.H. Optimun beef cow size for production resources in north Arkansas. Arkansas: University Press, Arkansas Agricultural Experiment Station, 1991. p. 43-7. (Special Reports, 151) /Resumo em CAB Abstracts on CD-ROM, v. 3A, 1990-91/.

JOHNSON,Z.B.; BROWN Jr,A.H.; ROSENKRANS,C.F. Genetic and environmental paramenters for mature and maturing rate and other growth measures in a herd of Angus cattle. In: ANNUAL MEETING OF THE AMERICAN SOCIETY OF ANIMAL SCIENCE, 87., Orlando, 1995. Abstracts. Journal of Animal Science, v. 73, suppl. 1, p. 3, 1995.

KEELE,J.W.; WILLIAMS,C.B.; BENNETT,G.L. A Computer model to predict the effects of level of nutrition on composition of empty body gain in beef cattle. I. Theory and development. Journal of Animal Science, v. 70, p. 841-857, 1992.

KOCH,R.M.; DICKERSON,G.E.; CUNDIFF,L.V.; GREGORY,K.E. Heterosis retained in advanced generations of crosses among Angus and Hereford cattle. Journal of Animal Science, v. 60, p. 1117-1132, 1985. 
KOOPS,W.J.; GROSSMAN,M. Multiphasic growth and allometry. Growth, Development and Aging, v. 55, n. 3, p. 203-212, 1991. /Resumo em CAB Abstracts on CD-ROM, v. 3A, 1990-91/.

KORVER,S.; TESS,M.W.; JOHNSON,T. A model of growth and growth composition for beef bulls of different breeds. Agricultural Systems, v. 27, n. 4, p.279-294, 1988.

LAWTON,W.H.; SYLVESTRE.E.A.; MAGGIO,M.S. Self modeling nonlinear regression. Technometrics, v. 14, n. 3, p. 513-532, 1972.

LISKI,E.P. A growth curve analysis for bulls tested at station. Biometrical Journal, v. 29, n. 3 , p.331-343, 1987.

LUDWIG,A. Ajustamento de curvas exponenciais ao crescimento de gado Nelore e análise de seus parâmetros. Viçosa, 1977. 84p. Dissertação (M.S.) - Universidade Federal de Viçosa.

LUDWIG,A.; SILVA,M.A. e; OLIVEIRA,L.M. de. Ajustamento de modelos estatísticos exponenciais ao crescimento de gado Nelore. Pesquisa Agropecuária Brasileira, v. 16 , n. 2, p.297-302, 1981.

MARSHALL,T.E.; MOHLER,M.A.; STEWART,T.S. Relationship of lifetime productivity with mature weight and maturation rate in Red Poll cows. Animal Production, v. 39, n. 3, p. 383-387, 1984.

McCALLUM,D.A.; DIXON,P.M. Reducing bias in estimating of the Richards growth function shape parameter. Growth, Developing and Aging, v. 54, n. 4, p. 135-141, 1990. /Resumo em CAB Abstracts on CD-ROM, v. 3A, 1990-91/.

McCUEN,R.H. Statistical methods for engineers. Englewood Clifs: Prentice-Hall, 1985. 439p.

McCURLEY,J.R.; BUTTS Jr.,W.T.; BOVARD,K.P. Growth patterns of Angus, Hereford and Shorthorn cattle. I. Comparison of inbred and noningred lines, changes in patterns over time and effects of level of inbreeding and reproductive performance. Journal of Animal Science, v. 59, n. 3, p. 1194-1204, 1984.

McLAREN,J.B.; MORROW,R.E.; BUTTS,W.T. Impact of numbers and frequency of weighings on bovine weight-age curve parameters. Journal of Animal Science, v. 54, n. 1, p.51-57, 1982.

MENCHACA,M.A. The use of stage models for describing animal growth curves. Cuban Journal of Agricultural Science, v. 24, n. 1, p.31-36, 1990. 
MENCHACA,M.A. Modelling of the bovine weight growth. 1. An intrinsically linear model for growth representation. Cuban Journal of Agricultural Science, v. 25 n. 2, p. 125-127, $1991 \mathrm{a}$.

MENCHACA,M.A. Modelling of the bovine weight growth. 2. Multiplicative model controlling the growth curve and other effects. Cuban Journal of Agricultural Science, v. 25, n. 5, p. 494-501, 1991 b.

MENCHACA,M.A. Modelling of the bovine weight growth. 3. Growth stagemultiplicative model. Cuban Journal of Agricultural Science, v. 26, n. 2, p.105109, 1992.

MENCHACA,M.A.; VALDES,G.; BRITO,M. A study on the performance of grazing animals through the use of a growth multiplicative model. Cuban Journal of Agricultural Science, v. 27, n. 1, p. 11-16, 1993.

MENCHACA,M.A.; CHASE JÚNIOR,C.C.; OLSON,T.A.; HAMMOND,A.C. Evaluation of growth curves of Brahman cattle of varying frame sizes. Journal of Animal Science, v. 74, n. 9, p. 2140-2151, 1996.

MENCHACA,M.A.; CHASE JÚNIOR,C.C.; OLSON,T.A.; HAMMOND,A.C. Evaluation of growth curves of Brahman cattle of varying frame sizes. In: ANNUAL MEETING OF THE AMERICAN SOCIETY OF ANIMAL SCIENCE, 87., Orlando, 1995. Abstracts. Journal of Animal Science, v. 73, suppl. 1, p. 9, 1995.

MILBURN,C.T.; GREENE,B.B.; DeROUEN,S.M.; TURPIN,J.M.; OLIVER,W.M. Relationships of growth curve parameters to performance in Hereford, BrahmanHereford and Brown Swiss-Hereford heifers. In: ANNUAL MEETING OF AMERICAN SOCIETY OF ANIMAL SCIENCE, 84., Lexington, 1992. Abstracts. Journal of Animal Science, v. 70, suppl. 1, p. 5, 1992.

MISCHAN,M.M. Análise econométrica de crescimento de gado bovino. Botucatú, 1972. 141p. Tese (Doutorado) - Escola Superior de Agricultura "Luiz de Queiroz", Universidade de São Paulo.

MOLINA,A.; SERRANO,M.I.; BURGOS,A.; JIMÉNEZ,J.M.; SALADO,F.M.; CABEZA DE VACA,F.; ESPÁRRAGO,E.; RODERO,A. Estimacion de la curva de crecimiento en vacuno Retinto; aspectos practicos para la tipificacion de pesos. Archivos de Zootecnia, v. 41, n. 154, p.543-548, 1992.

MONTGOMERY,D.C. Design and analysis of experiments. 2.ed. Singapore: John Wiley, 1984, 538p.

MOORE,A.J. A mathematical equation for animal growth from embryo to adult. Animal Production, v. 40 , n. 3, p. 441-453, 1985. 
MORROW,R.E.; McLAREN,J.B.; BUTTS,W.T. Effect of age on estimates of bovine growth-curve parameters. Journal of Animal Science, v. 47, n. 2, p. 352-357, 1978.

NACIONAL RESEARCH COUNCIL. Nutrient requirements of beef cattle. 7.ed. Washington: Nacional Academy Press, 1996. 242 p.

NATH,S.R.; MOORE,F.D. Growth analysis by the first, second, and third derivatives of the Richards function. Growth, Developing and Aging, v. 56, n. 4, p. 237-247, 1992. /Resumo em CAB Abstracts on CD-ROM, v. 3B, 1992/.

NOBRE,P.R.C.; ROSA,A.N.; SILVA,L.O.C. da; EVANGELISTA,S.R.M. Curvas crescimento de gado Nelore ajustadas para diferentes frequências de pesagens. Pesquisa Agropecuária Brasileira, v. 22, n. 9/10, p. 1027-1037, 1987.

O'DONOVAN,P.B. Compensatory gain in cattle and sheep. Nutrition Abstracts and Reviews. Series B, v. 54, p. 389-410, 1984.

OLIVEIRA,H.N.; LOBO,R.; PEREIRA,C.S.; SMITH,C.; GAVORA,J.S.; BENKEL,B.; CHESNAIS,J.; FAIRFULL,W.; GIBSON,J.P.; KENNEDY,B.W.; BURNSIDE, E.B.; Relationships among growth curve parameters, weights and reproductive traits in Guzera beef cows. In: WORLD CONGRESS ON GENETICS APPLIED TO LIVESTOCK PRODUCTION, 5., Guelph, 1994. Proceedings. Guelph: University Press, 1994. p. 189-192.

OWENS,F.N.; GILL,D.R.; SECRIST,D.S.; COLEMAN,S.W. Review of some aspects of growth and development of feedlot cattle. Journal of Animal Science, v. 73, n. 10, p. 3152-3172, 1995.

PASTERNAK,H.; SHALEV,B.A. The effect of a feature of regression disturbance on the efficiency of fitting growth curves. Growth, Developing and Aging, v. 58, n. 1, p. 33-39, 1994. /Resumo em CAB Abstracts on CD-ROM, v. 4A, 1993-94/.

PEREIRA,A.R.; ARRUDA,H.V. Ajuste prático de curvas na pesquisa biológica. Campinas: Fundação Cargill, 1987. 50p.

PEROTTO,D. CUE,R.I. LEE,A.J. Comparison of nonlinear functions for describing the growth curve of three genotypes of dairy cattle. Canadian Journal of Animal Science, v. 72, n. 4, p.773-782, 1992.

PEROTTO,D.; CUE,R.I.; LEE,A.J.; McALLISTER,A.J.; BATRA,T.R.; LIN,C.Y.; ROY,G.L.; WAUTHY,J.M. Additive and non-additive genetic effects of growth curve parameters of Holstein, Ayrshire and crossbred females. Canadian Journal of Animal Science, v. 74, n. 3, p. 401-409, 1994. 
PRIOR,R.L.; LASTER,D.B. Development of the bovine fetus. Journal of Animal Science, v. 48, n. 6, p. 1546-1553, 1979.

QUAAS,R.L. Genetic variation in growth curves of Hereford females. Dissertation Abstracts International, v. 44, n. 4, p. 1006, 1983. /Resumo em CAB Abstracts on CD-ROM, v. 0D, 1982-83/.

RANDEL,R.D. Unique reproductive traits of Brahman and Brahman based cows. In: BEEF CATTLE SHORT COURSE, 39., Gainsville, 1990. Proceedings. Gainsville: University of Florida, 1990. p.60-81.

RATKOWSKY,D.A. Handbook of nonlinear regression models. Nova York:Marcel Dekker, v.107, 1990. 241p.

RICHARDS,F.J. A flexible growth function for empirical use. Journal of Experimental Botany, v. 10, n. 20, p. 290-300, 1959.

ROSA,A. do N; SILVA,M. de A.; LUDWIG,A. Parâmetros genéticos e fenotípicos de pesos corporais ajustados pela curva de crescimento de animais da raça Nelore. Revista da Sociedade Brasileira de Zootecnia, v. 7, n. 2, p. 329-345, 1979.

RYAN,W.J. Compensatory growth in cattle and sheep. Nutrition Abstracts and Reviews. Series B, v. 60, p. 653-664, 1990.

SAS INSTITUTE. SAS/STATTM Guide for personal computers. 6.ed. Cary, 1987. $1028 \mathrm{p}$.

SLVEIRA JÚNIOR,P. Estudos de alguns modelos experimentais no crescimento de bovinos da raça Ibajé. Piracicaba, 1976. 174p. Dissertação (Mestrado) - Escola Superior de Agricultura "Luiz de Queiroz", Universidade de São Paulo.

SILVEIRA JÚNIOR,P.; MORAES,R.S. Estudo de alguns modelos exponenciais no crescimento de bovinos da raça Ibajé. In: SIMPÓSIO NACIONAL DE PROBABILIDADE E ESTATÍSTICA, 3., 1978. São Paulo. Atas. São Paulo: USP, Instituto de Matemática e Estatística, 1978. p.15-23.

SILVEIRA JÚNIOR,P.; GREINER,L.C.; RAMOS,J.C. Modelo de crescimento de bovinos da raça Flamenga adicionado de componente periódico. In: REUNIÃO ANUAL DA REGIÃO BRASILEIRA DA SOCIEDADE INTERNACIONAL DE BIOMETRIA, 38., Porto Alegre, 1993. Anais. Porto Alegre: Sociedade Brasileira de Biometria, 1993. p.204-222.

SMITH,G.M.; CUNDIFF,L.V. Genetic analysis of relative growth rate in crossbred and straightbred Hereford, Angus e Shorthorn steers. Journal of Animal Science, v. 43, n. 6, p.1171-1175, 1976. 
SMITH,G.M.; $\quad$ FITZHUGH,H.A.; $\quad$ CUNDIFF,L.V.; $\quad$ CARTWRIGHT,T.C.; GREGORY.K.E. A genetic analisys of maturing patterns in straightbred and crossbred Hereford, Angus ans Shorthorn cattle. Journal of Animal Science, v. 43, n. 2, p. 389-395, 1976.

SOUZA,J.C.; BIANCHINI SOBRINHO,E. Estimativa do peso de bovinos de corte, aos 24 meses, da raça Nelore, usando funções de crescimento. Revista da Sociedade Brasileira de Zootecnia, v. 23, n. 1, p. 85-91, 1994.

STEWART,T.S.; MARTIN,T.G. Mature weight, maturation rate, maternal performance and their inter-relationships in purebred and crossbred cows of Angus and Milking Shorthorn parentage. Journal of Animal Science, v. 52, n. 1, p. 51-56, 1981.

SUBRT,J.; CHROUSTOVA,O.; SCHIMIDT,I. Growth of crossbred heifers from Bohemian Red Pied cows mated to Charolais and Limousin bulls. ZivocisnaVyroba, v. 39, n. 11, p. 937-948, 1994. /Resumo em CAB Abstracts on CD-ROM, v. 4 A, $1993-94 /$.

TAYLOR,C.S. A relation between mature weight and time taken to mature in animals. Animal Production, v. 7, p. 203-208, 1965.

TAYLOR,C.S. Time taken to mature in relation to mature weight for sexes, strains and species of domesticated mamals and birds. Animal Production, v. 10, n. 2, p. 157$169,1968$.

TAYLOR,C.S. Use of genetic size-scaling in evaluation of animal growth. In: CURRENT CONCEPS OF ANIMAL GROWTH, 1. Ontario, 1982. Current concepts of animal growth. Champaign: ASAS, 1985. p.118-143.

TAYLOR,C.S.; FITZHUGH,H.A. Genetic relationships between mature weight and time taken to mature within a breed. Journal of Animal Science, v. 33, p. 726-732, 1971.

TORRE,G.L.; RANKIN,B.J. Factors affecting growth curve parameters of Hereford and Brangus cows. Journal of Animal Science, v. 46, n. 3, p. 604-613, 1978.

TORRE,G.L.; CANDOTTI,J.J.; VASCO,P.; GARCIA,L.; MARTIN,M.; PÉREZ,S. Effect of growth curve parameters on cow efficiency. In: ANNUAL MEETING OF THE AMERICAN SOCIETY OF ANIMAL SCIENCE, 82., Little Rock, 1990. Abstracts. Journal of Animal Science, v. 68, suppl. 1, p. 251, 1990.

TORRE,G.L.; CANDOTTI,J.J.; REVERTER,A.; BELLIDO,M.M.; VASCO,P.; GARCIA,L.J.; BRINKS,J.S. Effects of growth curve parameters on cow efficiency. Journal of Animal Science, v. 70, n. 9, p. 2668-2672, 1992. 
VERA,R.R. Growth and conception in continuously underfed Brahman heifers. Animal Production, v. 53, n. 1, p. 45-50, 1991.

VIEIRA,S. Estudo de funções assintótico-sigmóides. Piracicaba, 1975. 105p. Tese (Livre-Docência) - Faculdade de Odontologia de Piracicaba, Universidade Estadual de Campinas.

WARREN,J.H. Growth curves of Polled Hereford cows. Dissertation Abstracts International, v. 37, n. 9, p. 4238, 1977. /Resumo em CAB Abstracts on CDROM, v. 0B, 1976-78/.

WEBSTER,A.J.F.; AHMED,A.A.M.; FRAPPELL,J.P. A note of growth rates and maturation rates in beef bulls. Animal Production, v. 35, n. 2, p. 281-286, 1982.

WILLIAMS,C.B.; BENNETT,G.L. Application of a computer model to predict optimum slaughter end points for different biological types of feeder cattle. Journal of Animal Science, v.73, n.10, p.2903-2915, 1995.

WILLIAMS,C.B.; BENNETT,G.L.; KEELE,J.W. Simulated influence of postweaning production system on performance of different biological types of cattle. I. Estimation of model parameters. Journal of Animal Science, v. 73, n. 3, p. 665-673, 1995a.

WILLIAMS,C.B.; BENNETT,G.L.; KEELE,J.W. Simulated influence of postweaning production system on performance of different biological types of cattle. II. Carcass composition, retail product and quality. Journal of Animal Science, v. 73, n.3, p. 674-685, $1995 \mathrm{~b}$.

WILLIAMS,C.B.; BENNETT,G.L.; KEELE,J.W. Simulated influence of postweaning production system on performance of different biological types of cattle. III. Biological efficiency. Journal of Animal Science, v. 73, n. 3, p. 686-698, 1995c.

WILLIAMS,C.B.; KEELE,J.W.; BENNETT,G.L. A Computer model to predict the effects of level of nutrition on composition of empty body gain in beef cattle. II. Evaluation of the model. Journal of Animal Science, v. 70, p. 858-866, 1992. 


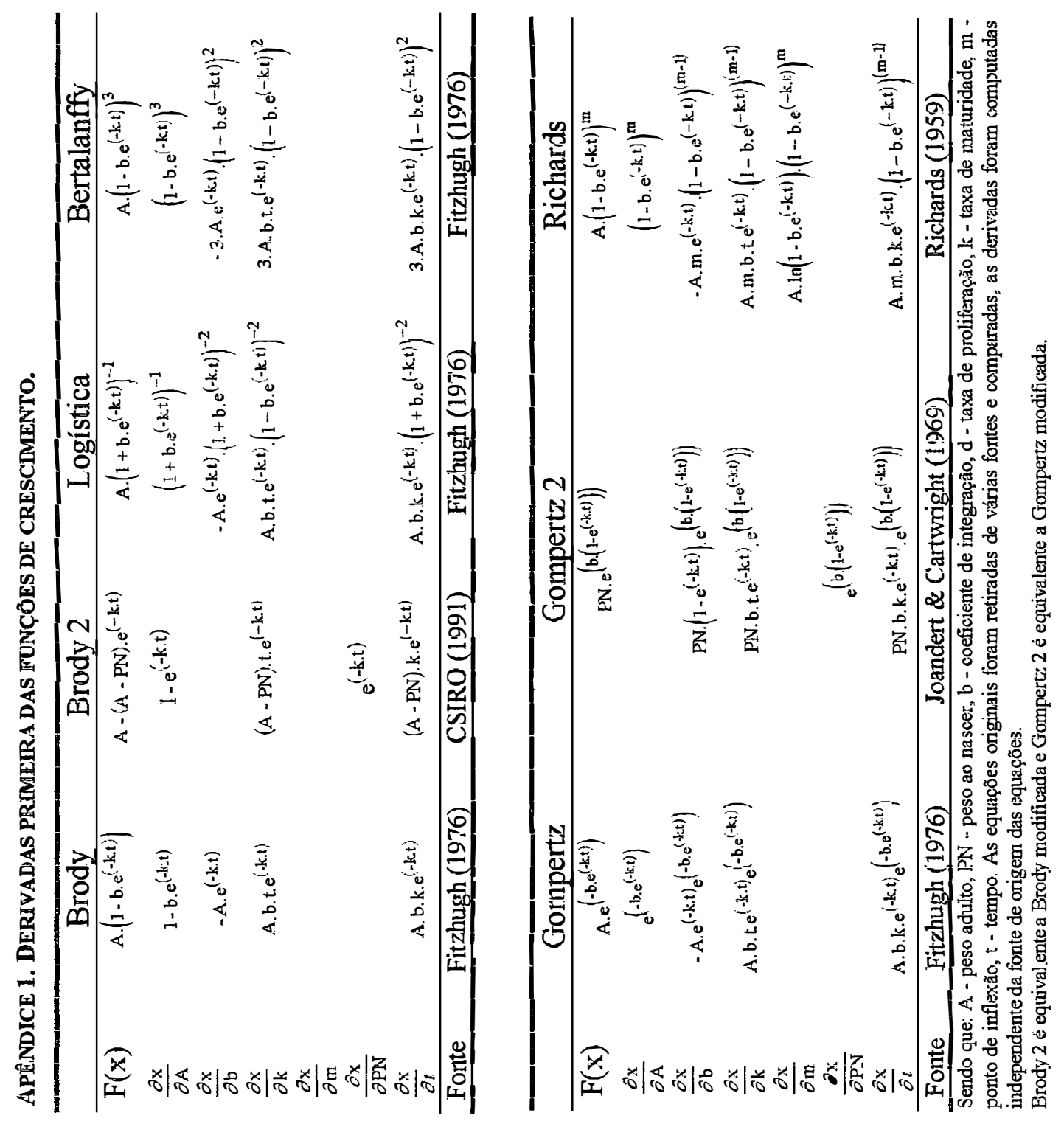




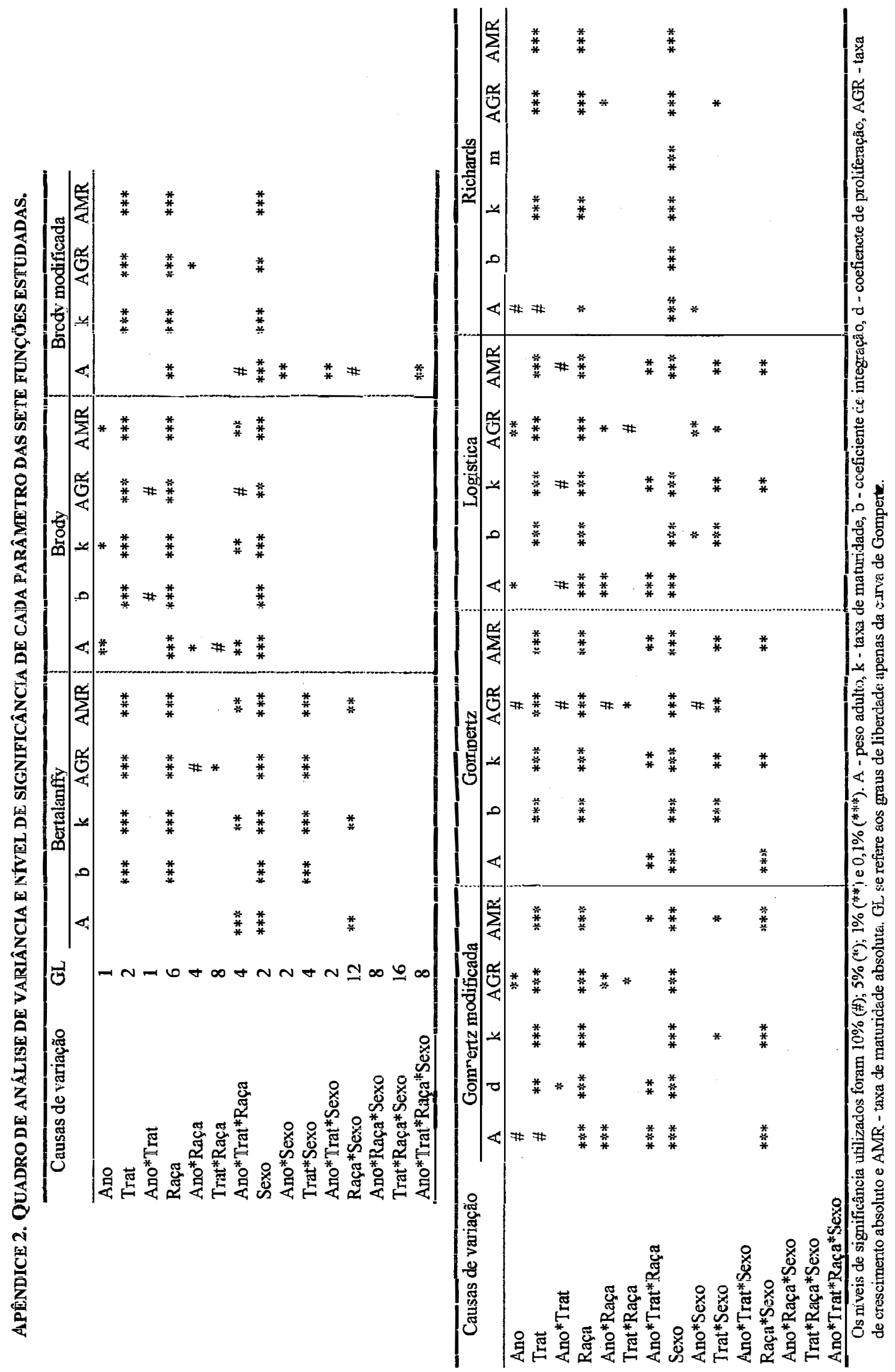




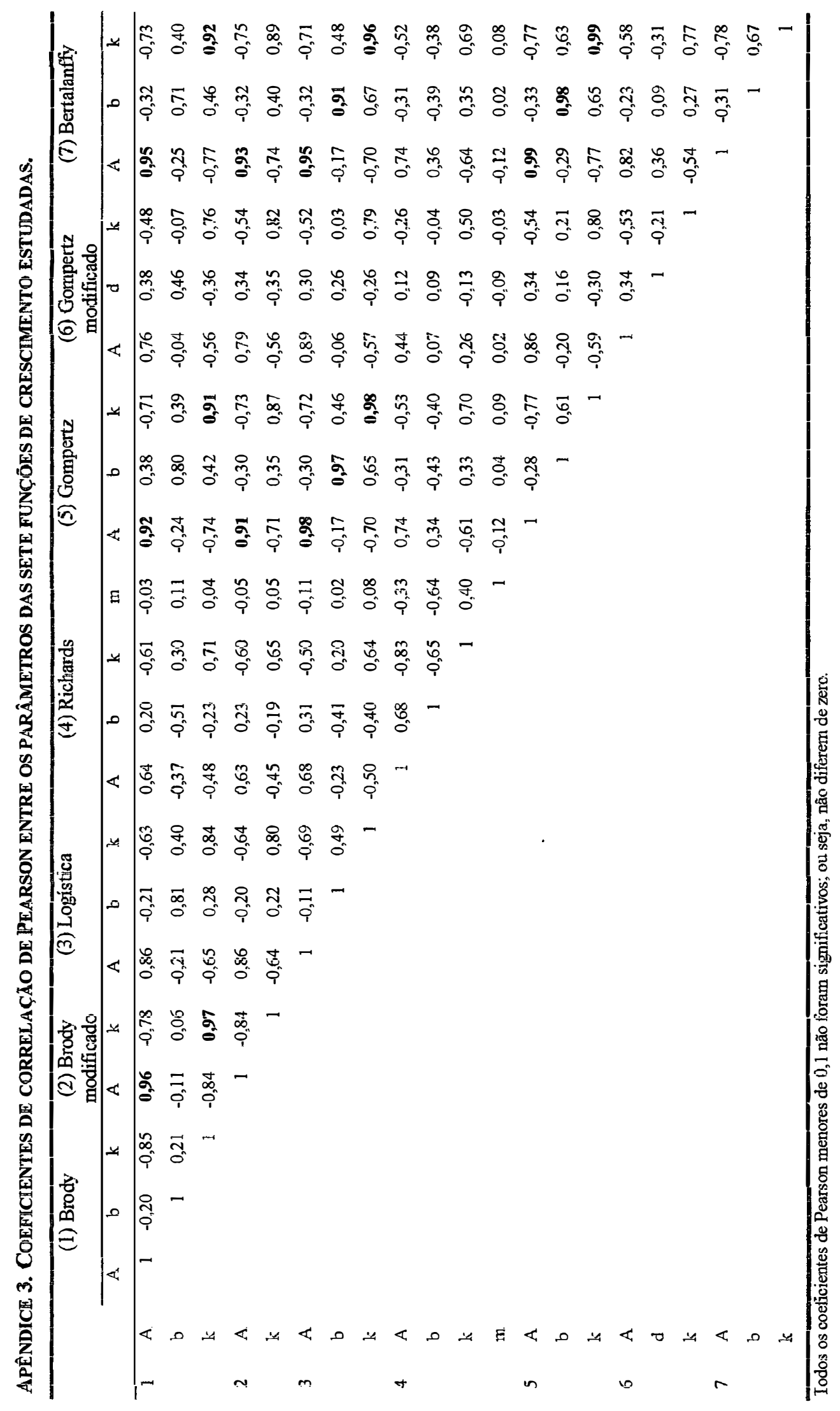




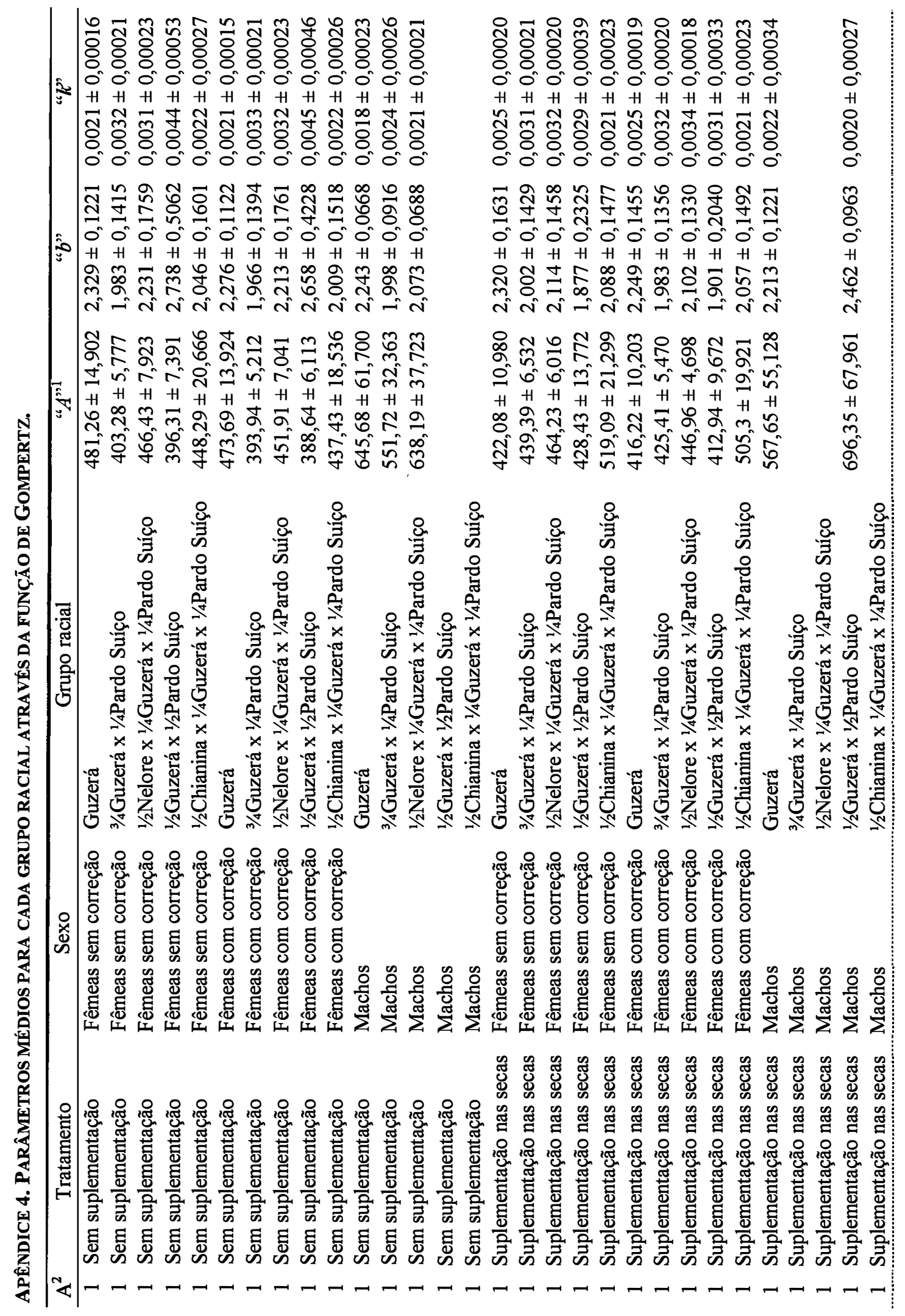


$\stackrel{m}{=}$

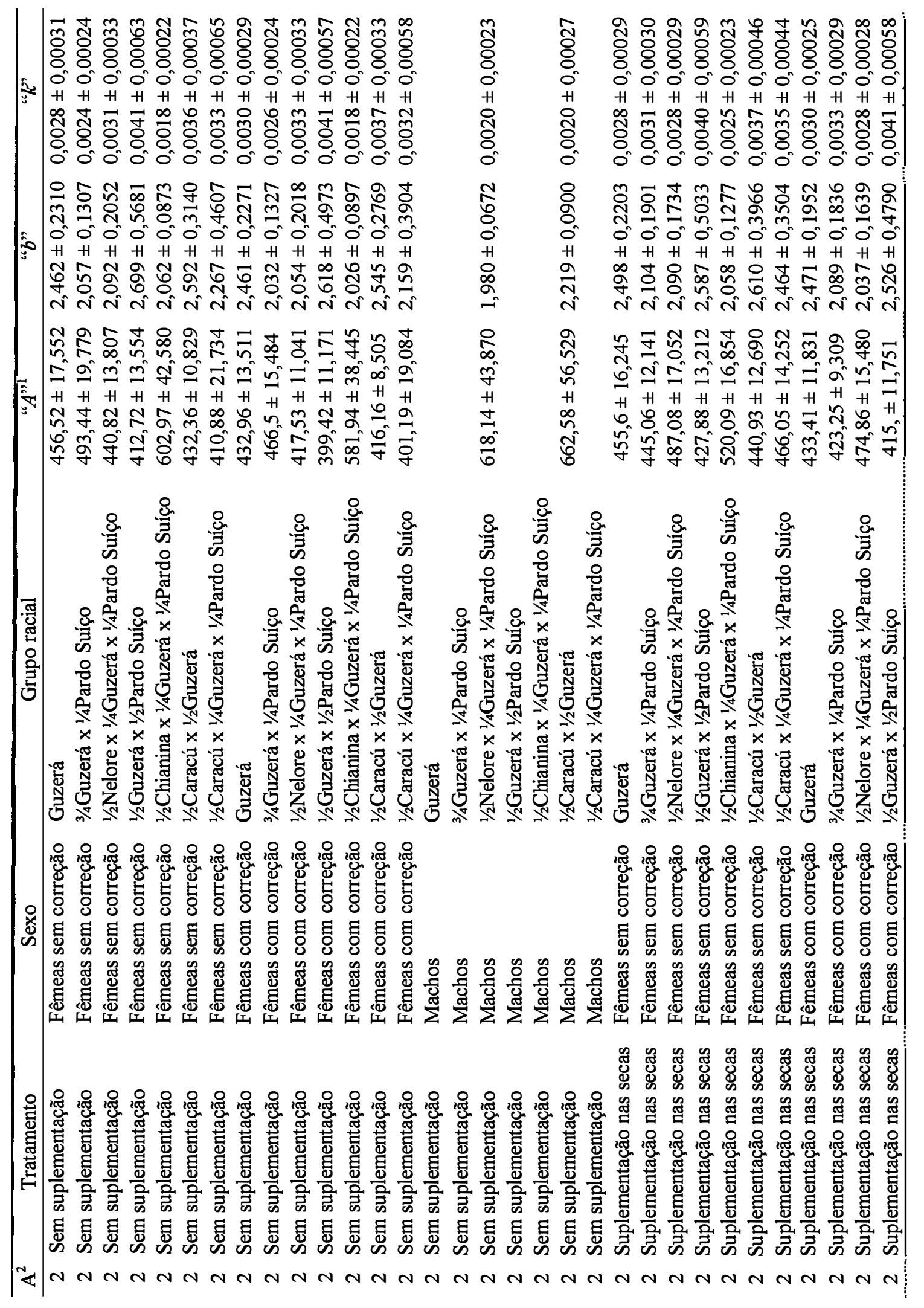


$\Xi$

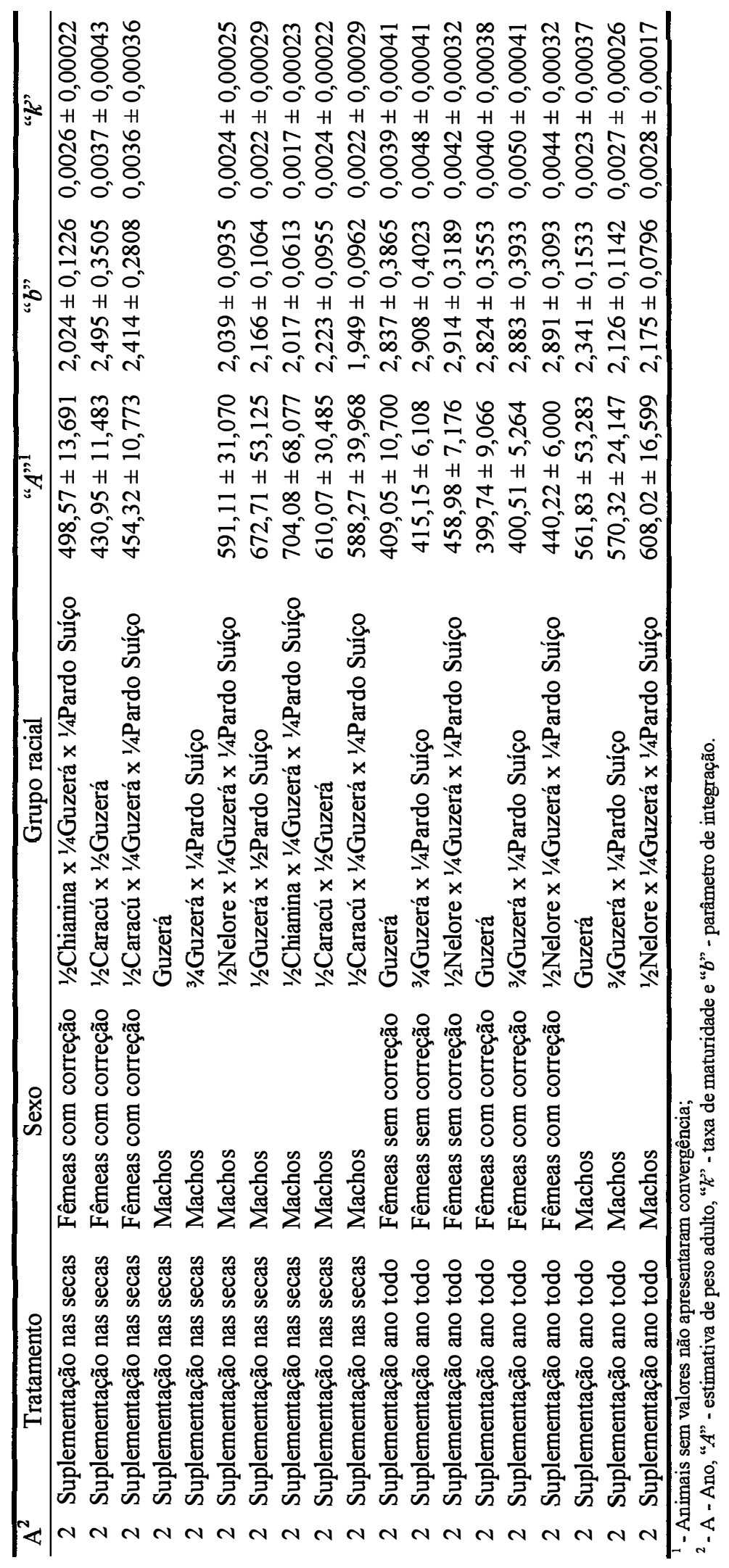


APÊNDICE 5. GRÁFICOS DAS FUNÇÇŌES DE CRESCIMENTO DE GOMPERTZ.

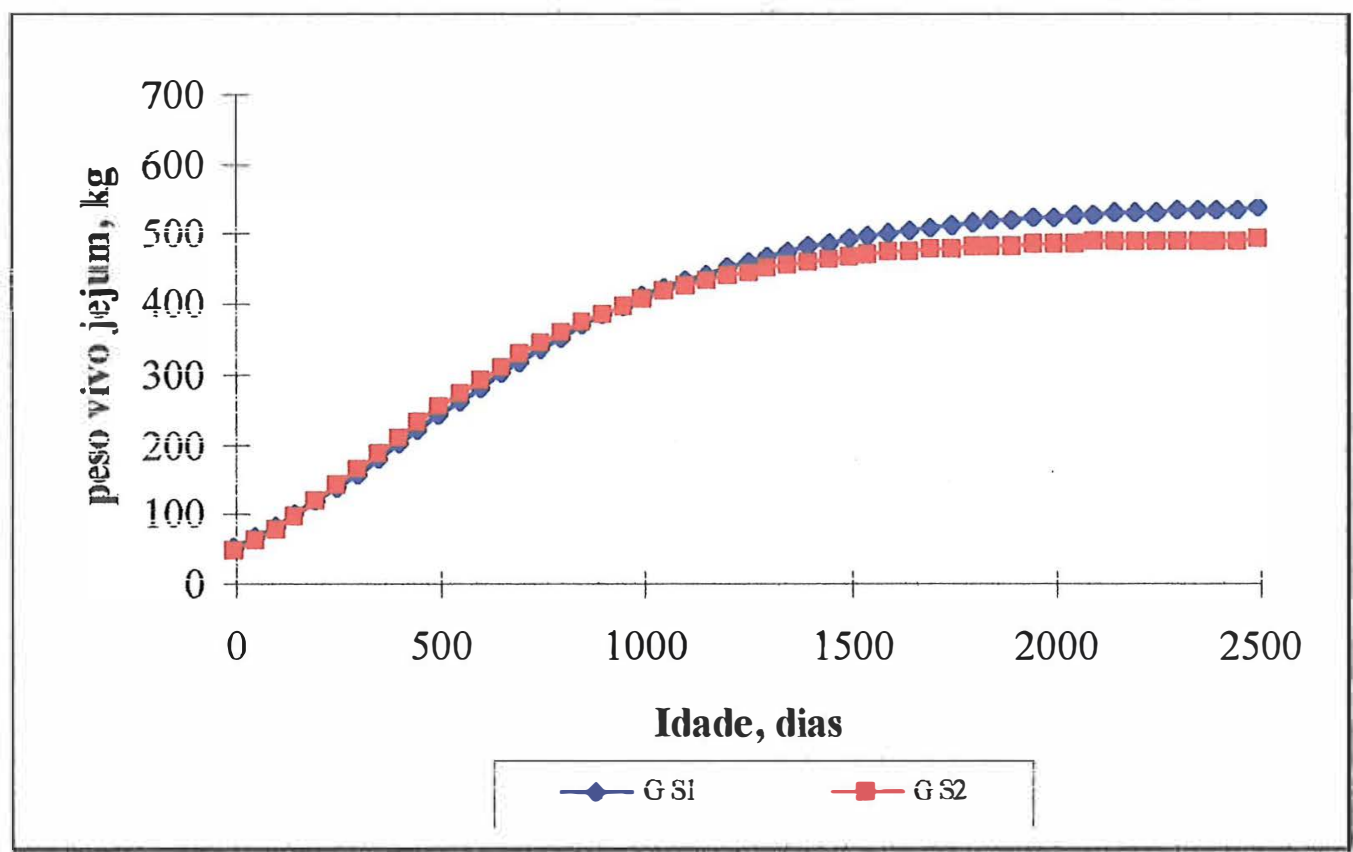

Gráfico 4. Curva de Crescimento da RaÇa GuZerá (G) SEM SuPlementaÇão (S1) E COM SUPLEMENTAÇÃO NA SECA (S2), ANO DE 1978.

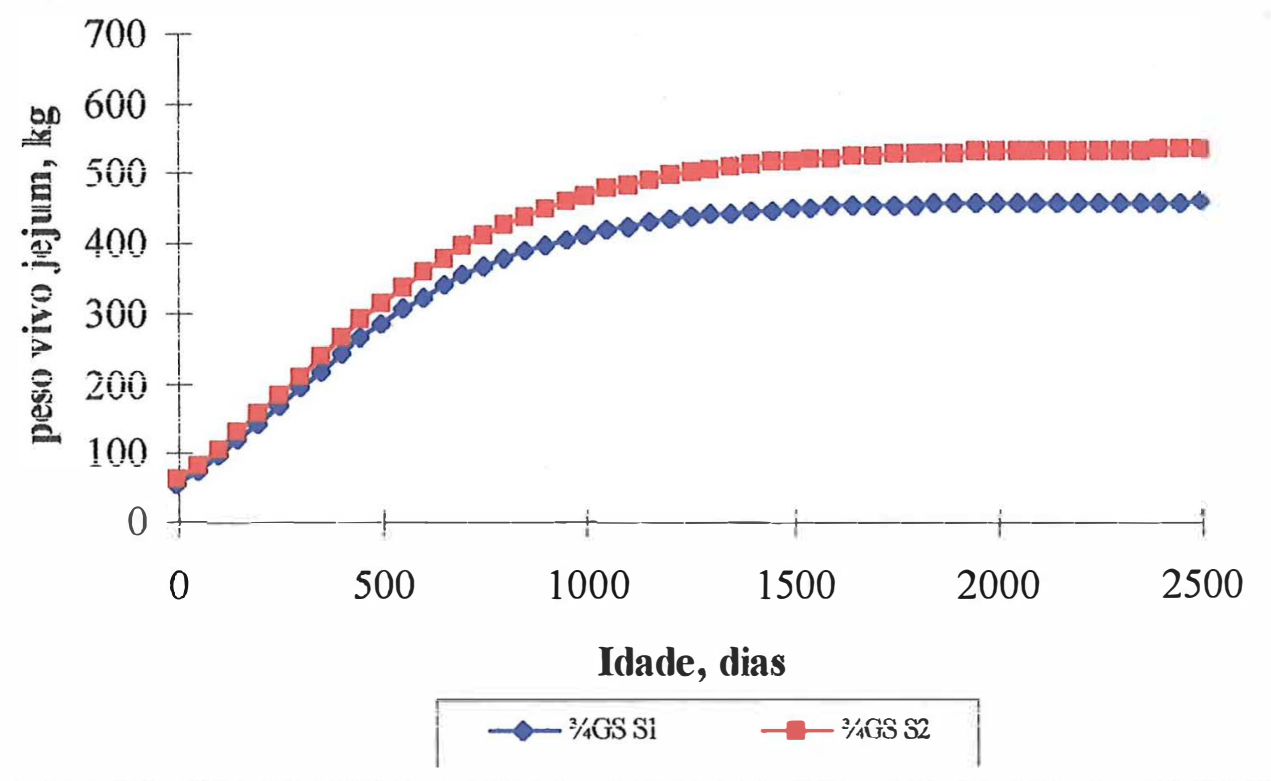

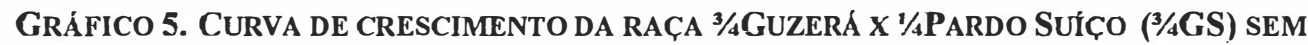
SUPLEMENTAÇ̃̃o(S1) E COM SUPLEMENTAÇ̃̃o NA SECA (S2), ANO DE 1978. 


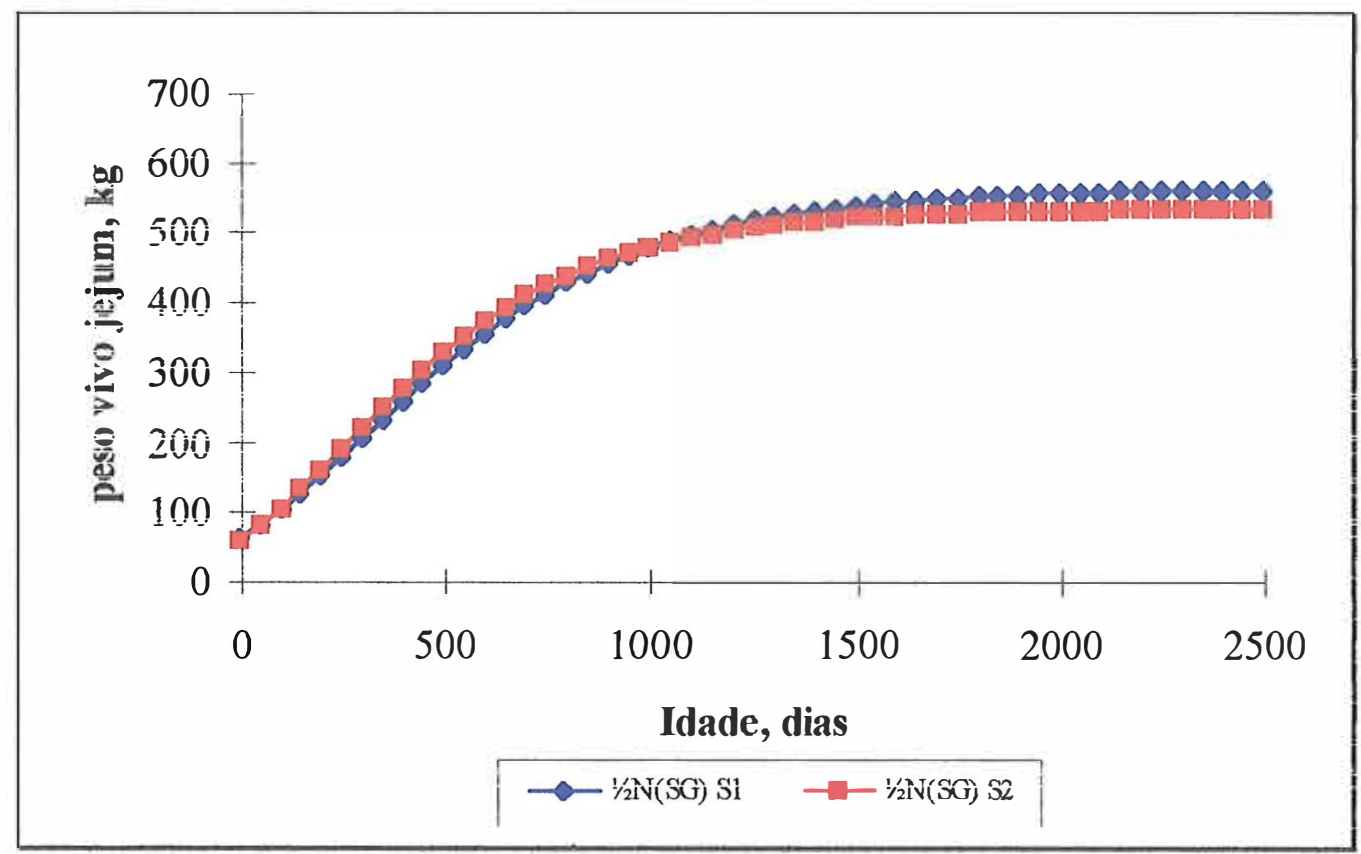

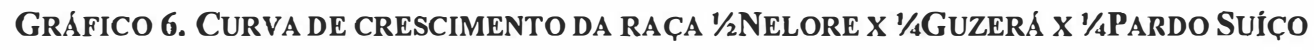
(1⁄2N(SG)) SEM SUPLEMENTAÇÃo (S1) E COM SUPLEMENTAÇÃO NA SECA (S2), ANO DE 1978.

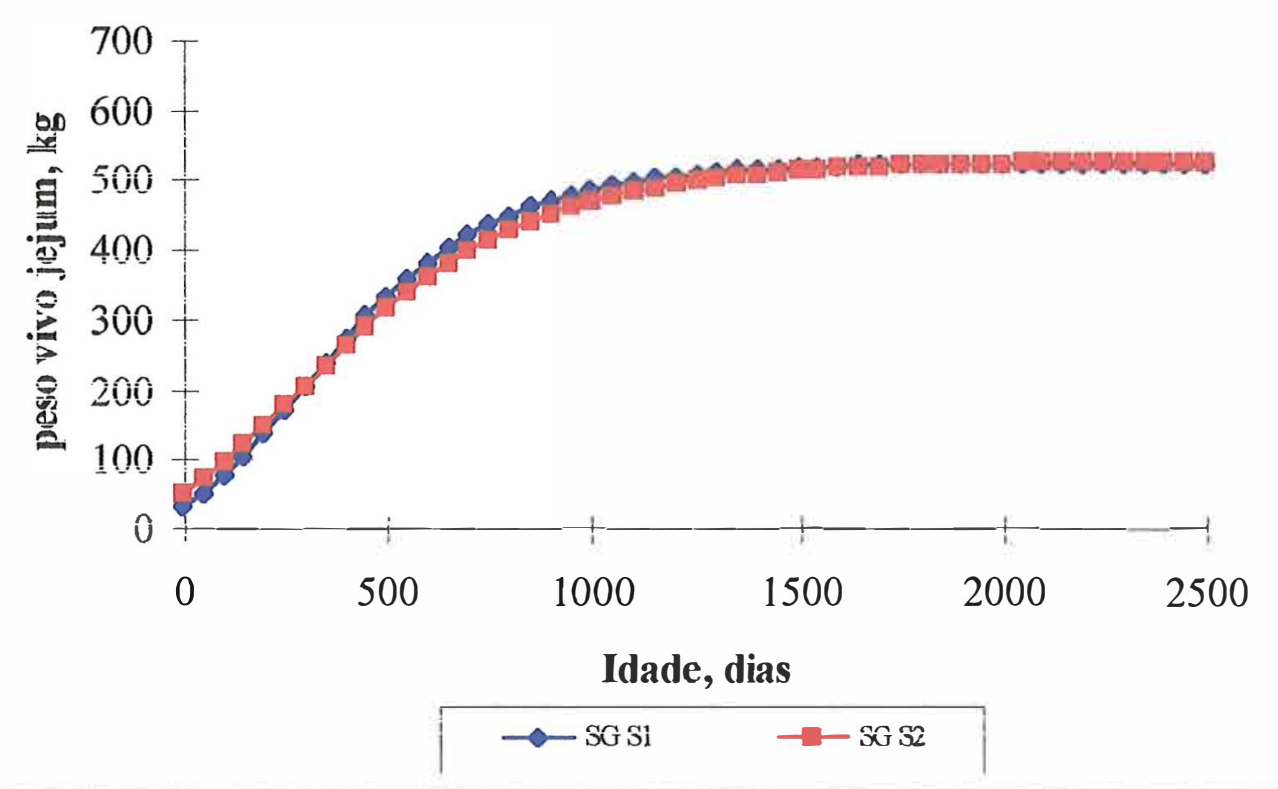

Gráfico 7. CuRVa de CRESCIMENTO da RAÇA 1/2GuZERÁ X 1/2PARdo Suíço (SG) SEM SUPLEMENTAÇÃo(S1) E COM SUPLEMENTAÇÃo NA SECA (S2), ANO DE 1978. 


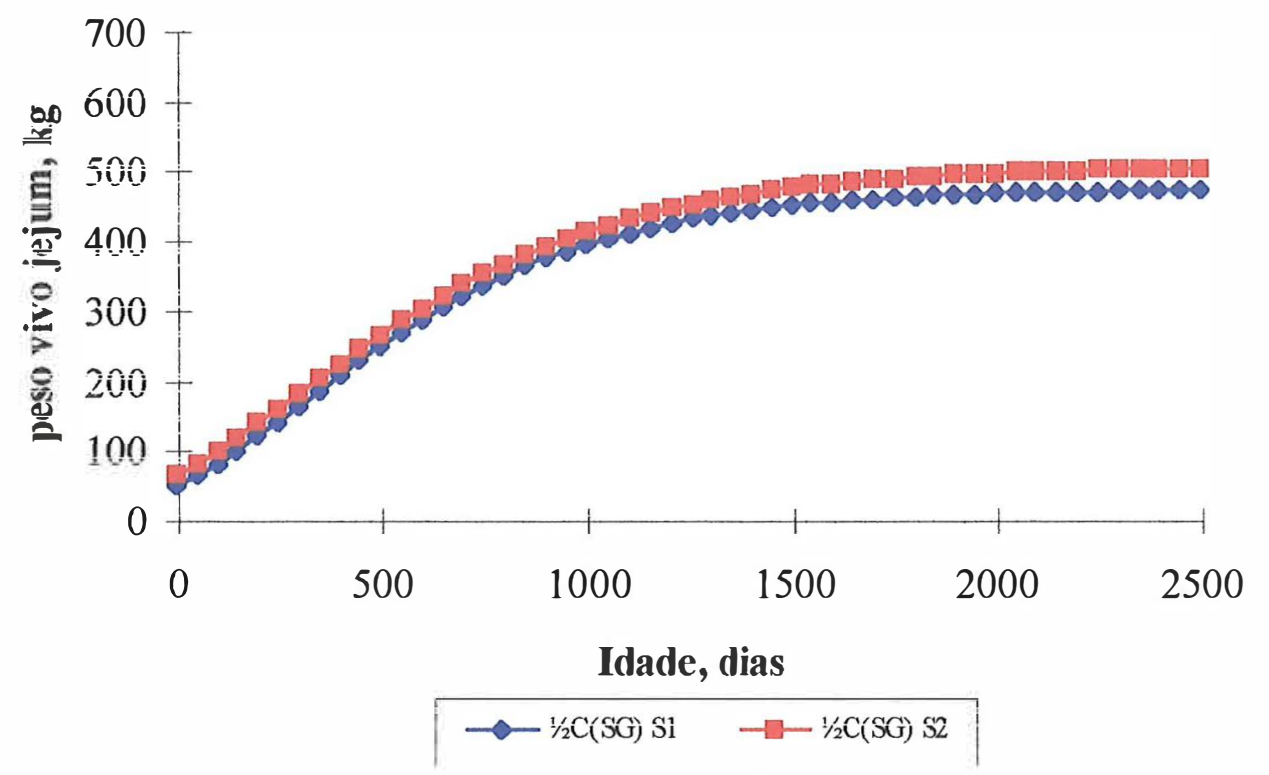

GRÁfico 8. CURVA DE CRESCIMENTO DA RAÇA $1 / 2$ CHIANINA X $1 / 4$ GUZERA X $1 / 4$ PARDO SUIÇO (11/2C(SG)) SEM SUPLEMENTAÇÃo (S1) E COM SUPLEMENTAÇÃO NA SECA (S2), ANO DE 1978.

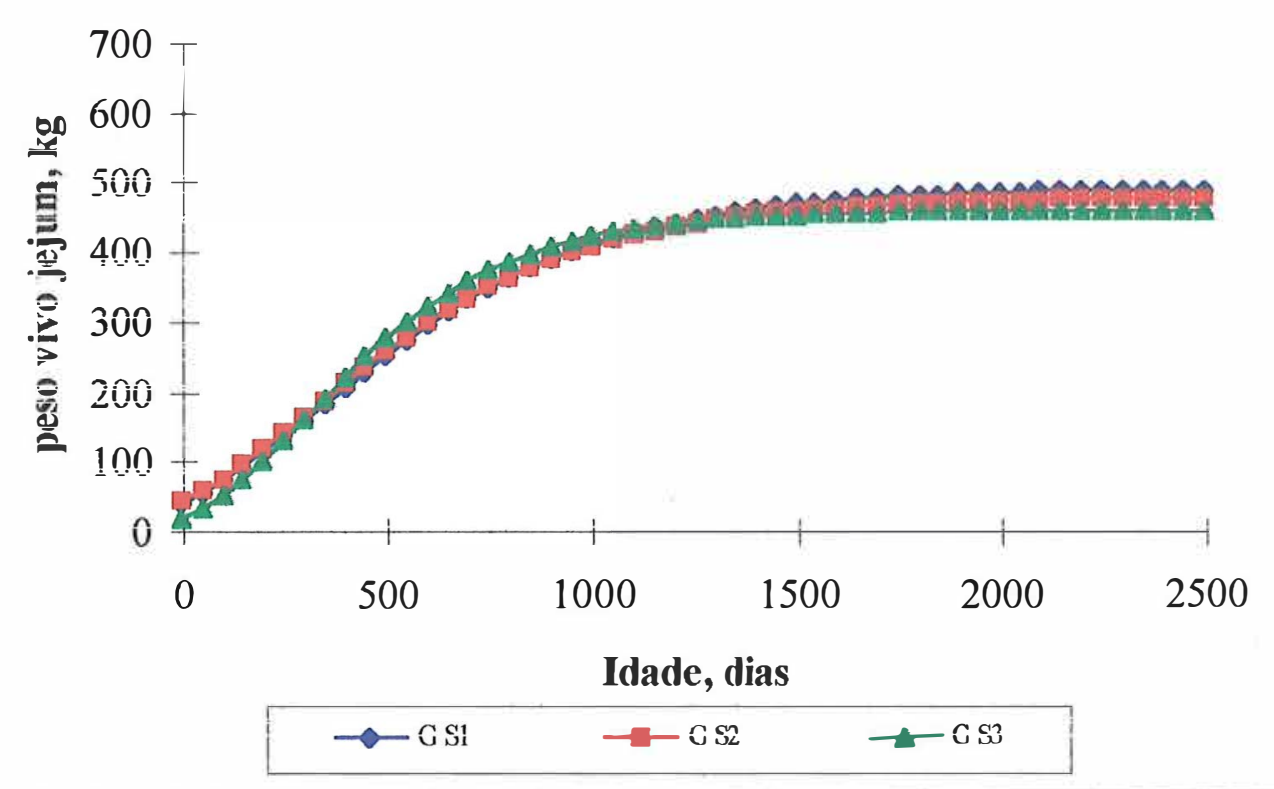

Gráfico 9. CuRVa de CRESCIMENTo da RAÇA GUZERÁ (G) SEM SUPLEMENTAÇÃo (S1), COM SUPLEMENTAÇÃo NA SECA (S2) E DURANTE O ANO (S3), ANO DE 1979. 


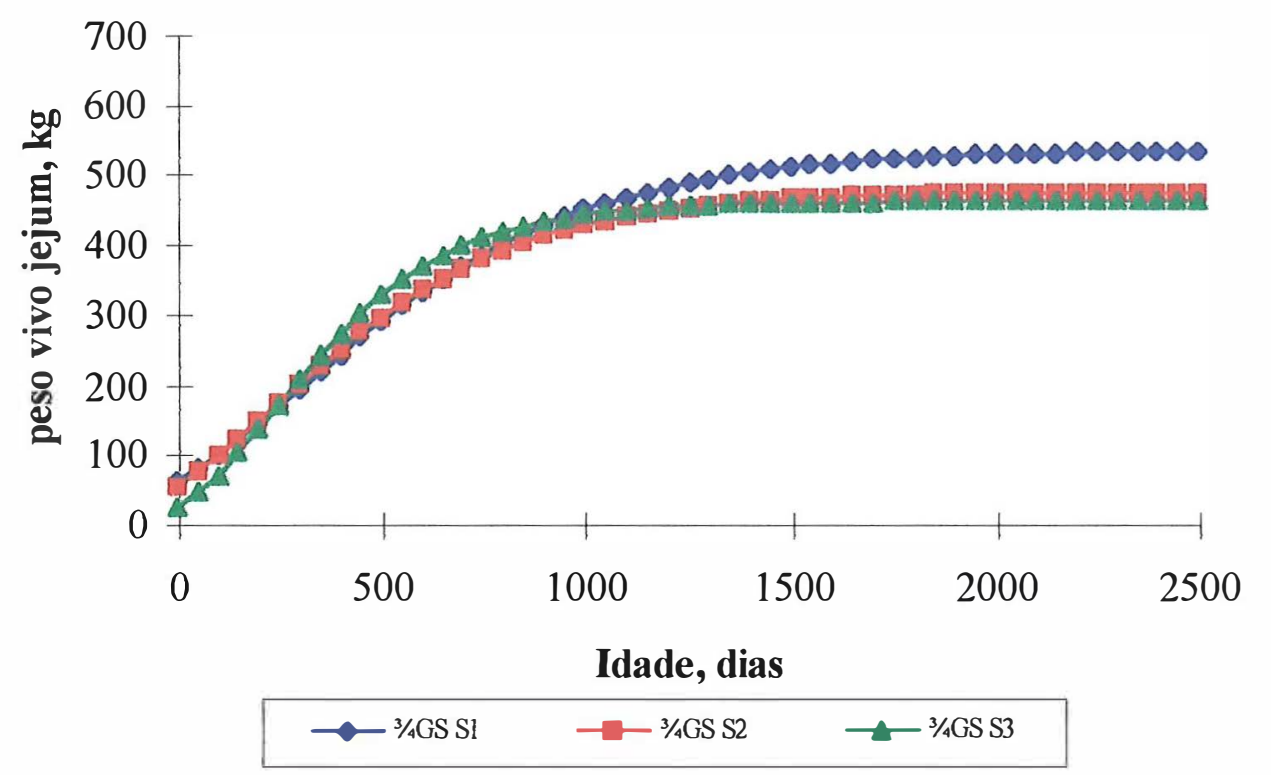

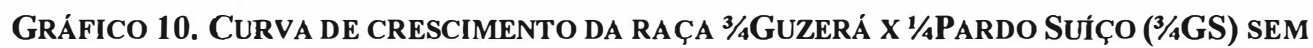
SUPLEMENTAÇÃO(S1), COM SUPLEMENTAÇÃO NA SECA (S2) E DURANTE O ANO(S3), ANO DE 1979.

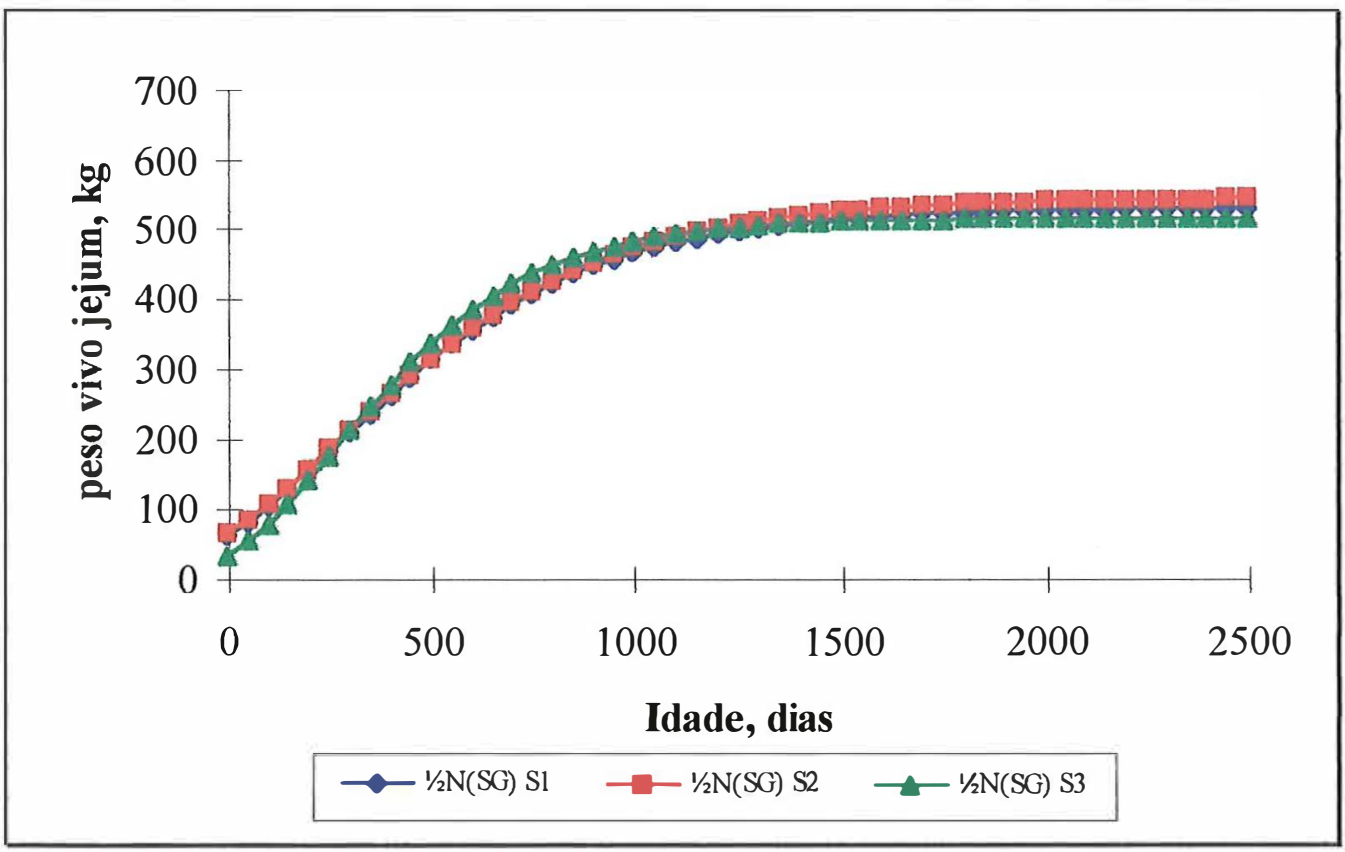

GRÁFICO 11. CURVA DE CRESCIMENTO Da RAÇA 1/2NELORE X 1/4GUZERÁ X 1/4PARDO SUÍço (1/2N(SG)) SEM SUPLEMENTAÇÃO (S1), COM SUPLEMENTAÇÃO NA SECA (S2) E DURANTE O ANO (S3), ANO DE 1979. 


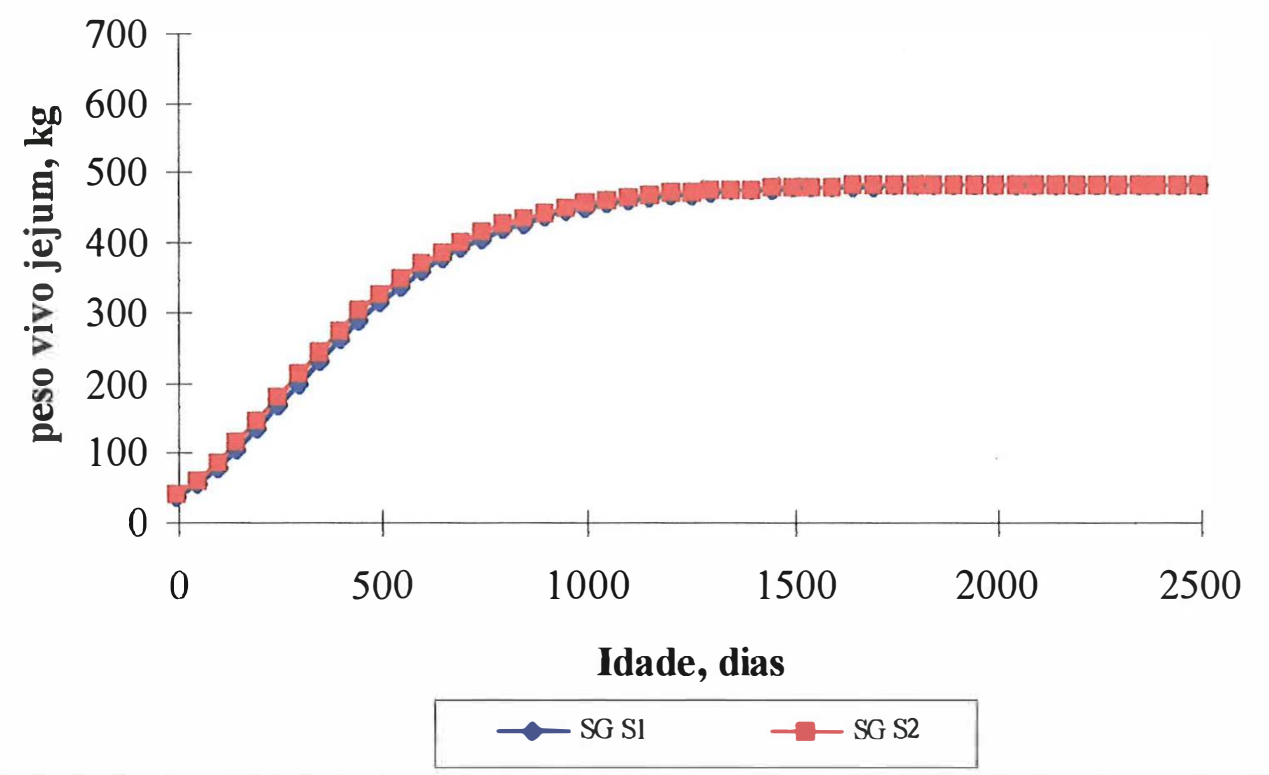

GrÁFICO 12. CuRVA DE CRESCIMENTO DA RAÇA 1/2GUZERÁ X $1 / 2$ PARDO SUÍÇO(SG) SEM SUPLEMENTAÇÃO (S1) E COM SUPLEMENTAÇÃO NA SECA (S2), ANO DE 1979.

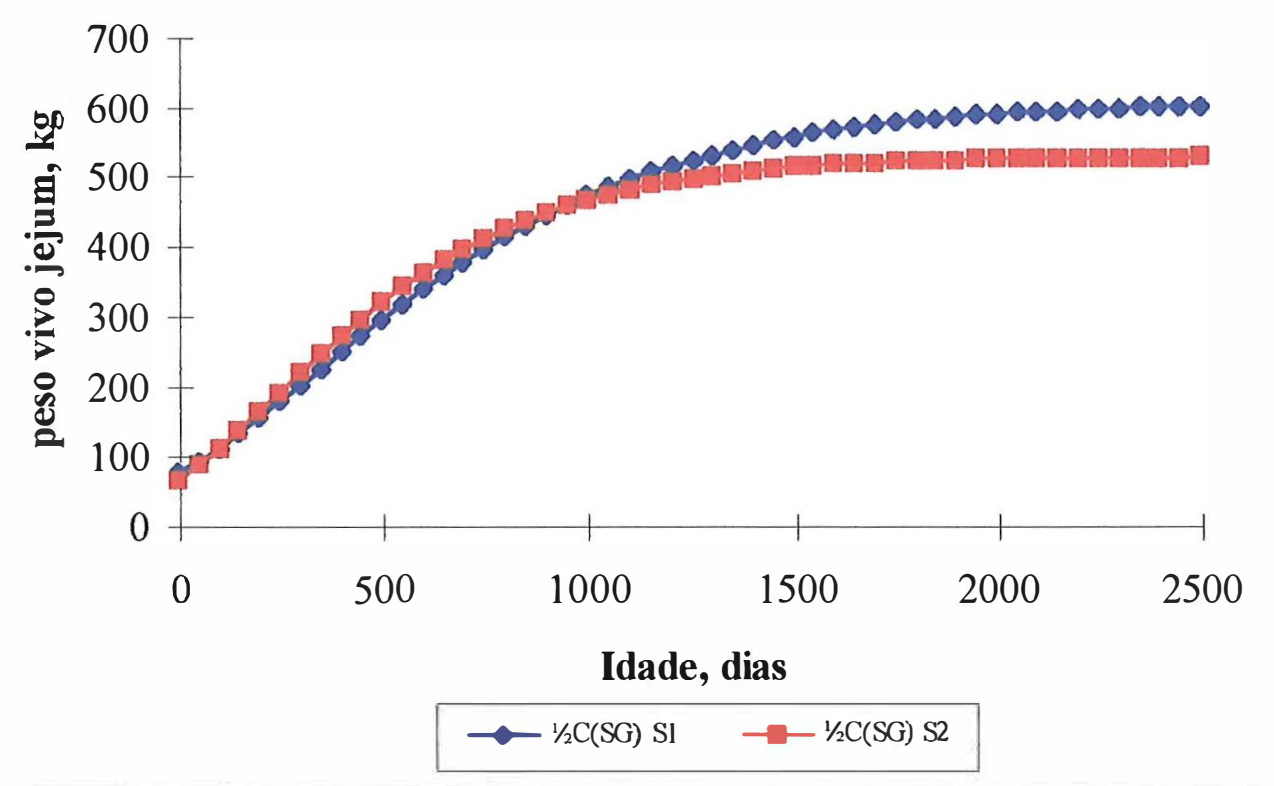

GrÁFICO 13. CURVA DE CRESCIMENTO DA RAÇA 1/2CHIANINA X 1/4GUZERÁ X 1/4PARDO SUİÇO (1/2C(SG)) SEM SUPLEMENTAÇÃO (S1) E COM SUPLEMENTAÇÃO NA SECA (S2), ANO DE 1979. 


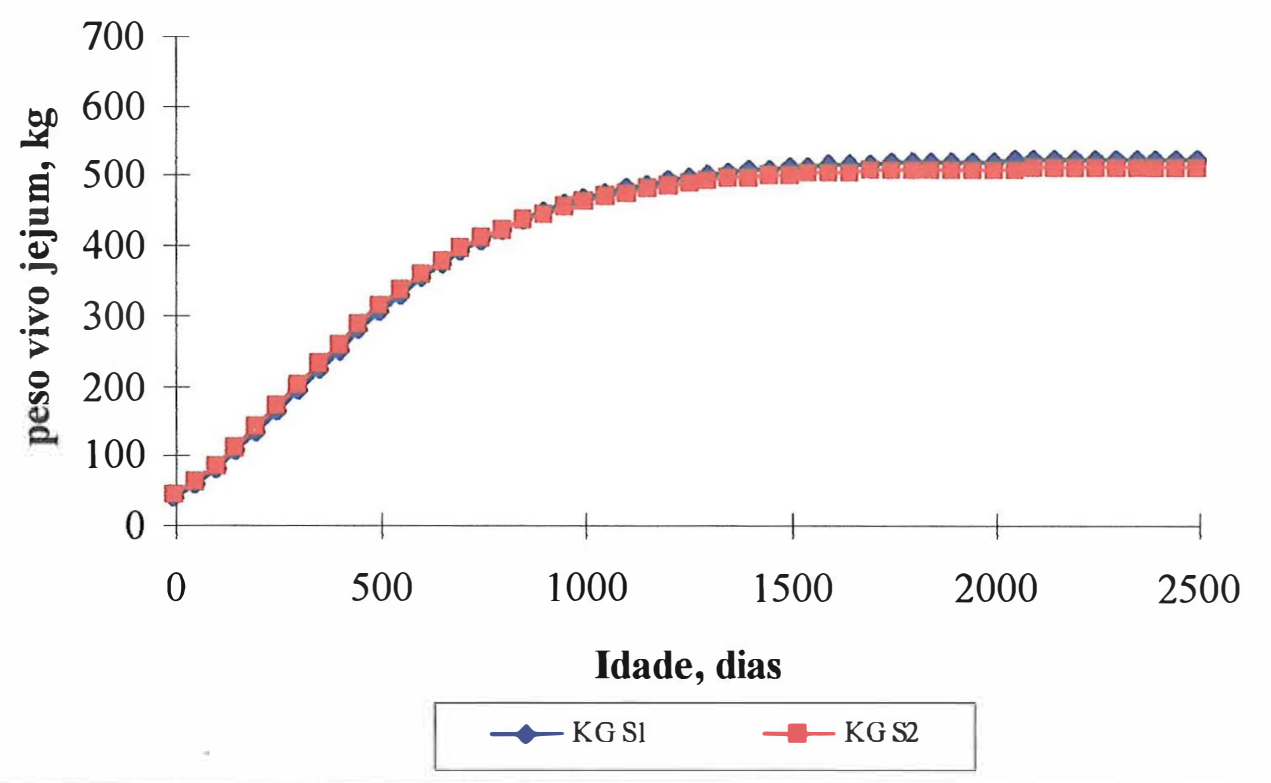

GRÁFICO 14. CuRVA de CRESCIMENTO dA RAÇA 1/2CARACÚ X 1/2GUZERÁ (KG) SEM SUPLEMENTAÇÃO (S1) E COM SUPLEMENTAÇÃO NA SECA (S2), ANO DE 1979.

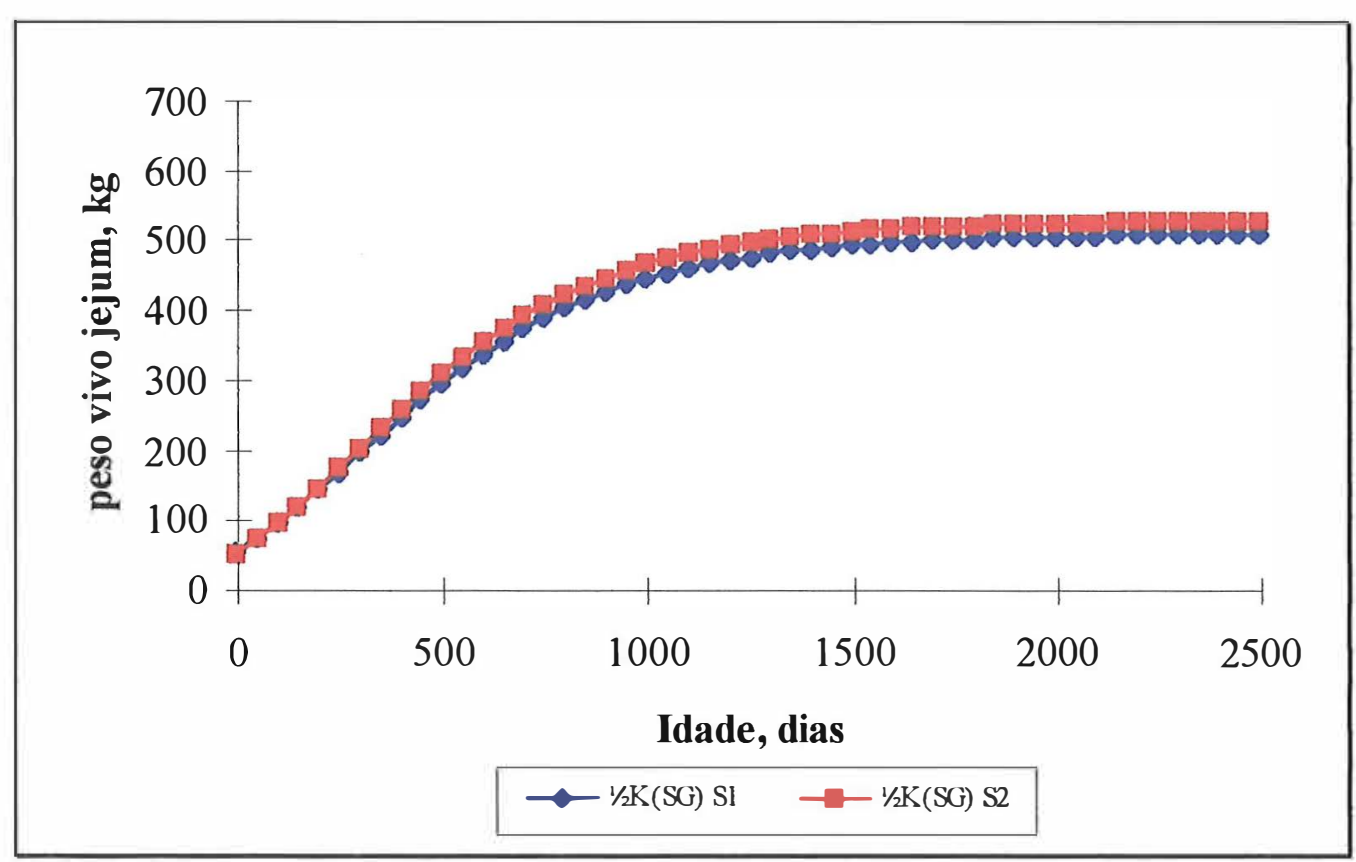

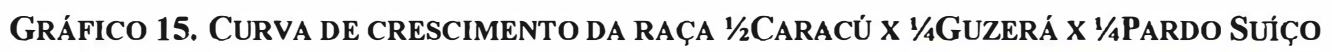
(1/2K(SG)) SEM SUPLEMENTAÇÃO (S1) E COM SUPLEMENTAÇÃO NA SECA (S2), ANO DE 1979. 


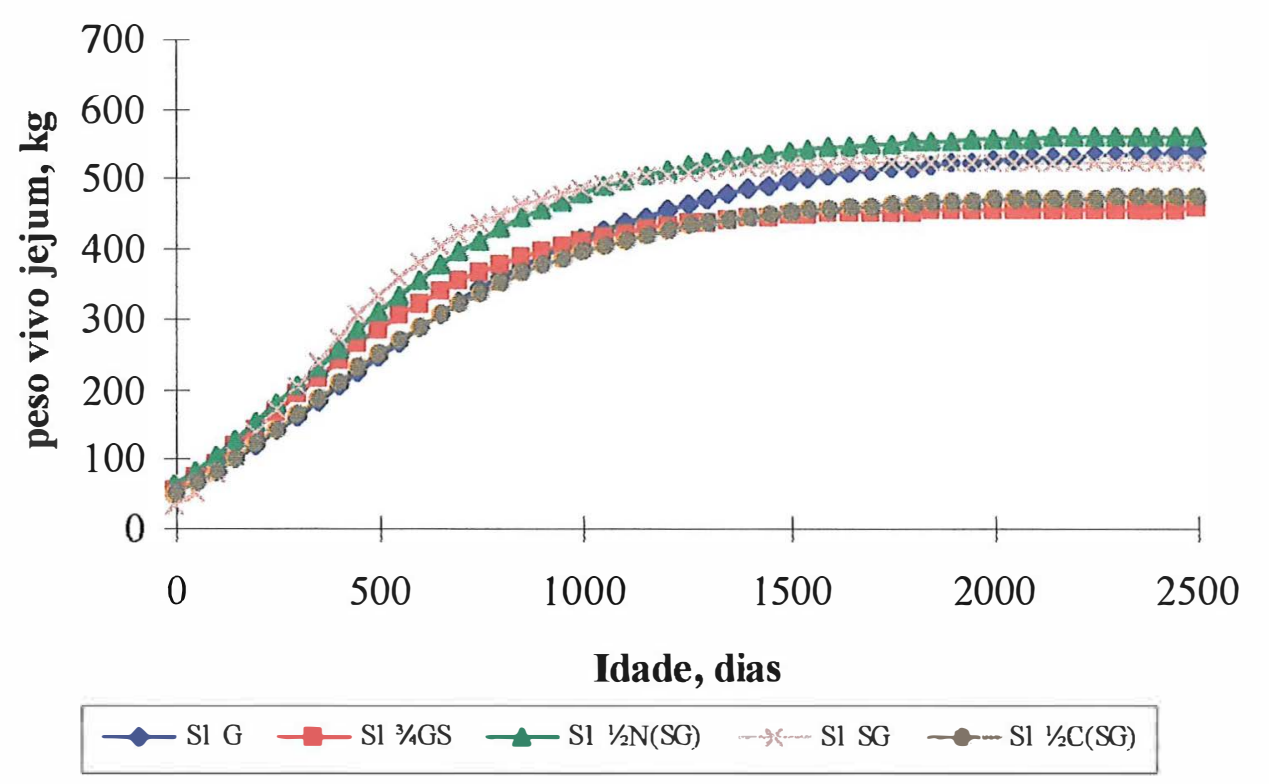

GrÁFICO 16. CuRVA de CRESCIMENTO dAS RAÇAS G, 3/4GS, 1/2N(SG), SG E 1/2C(SG) SEM SUPLEMENTAÇÃO (S1), ANO DE 1978.

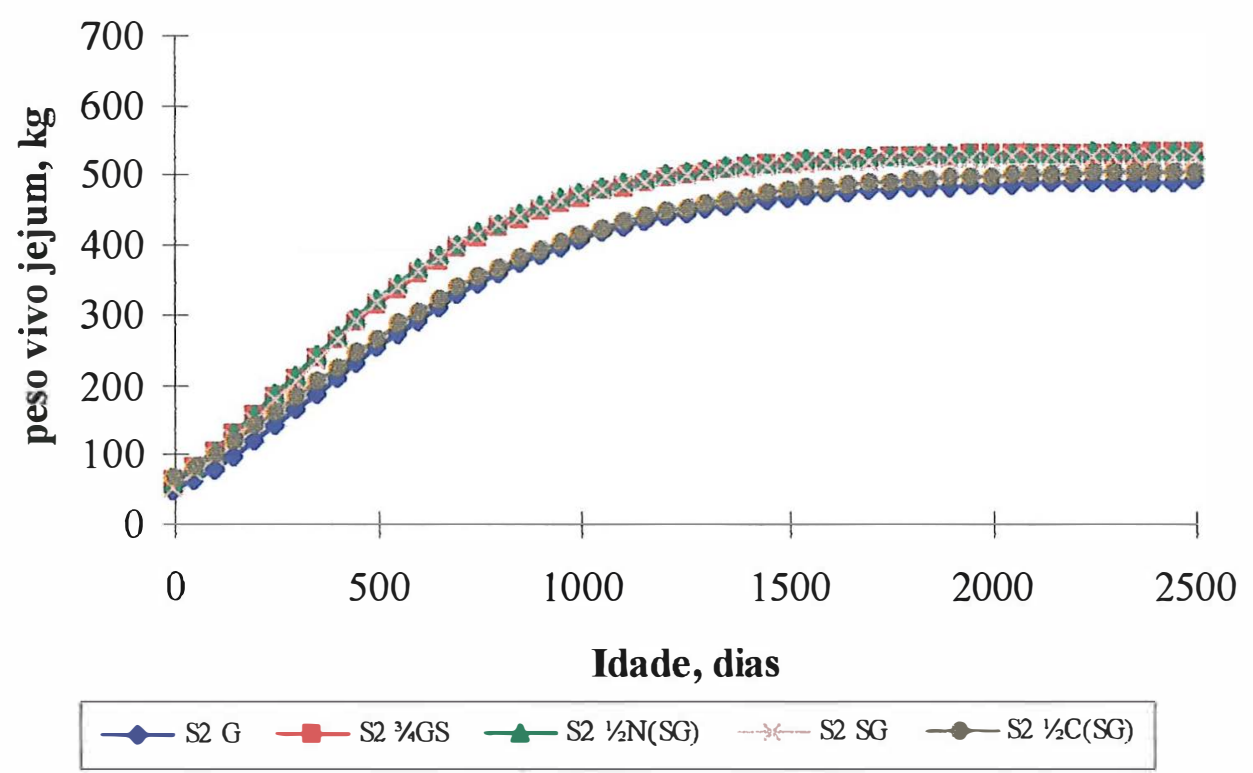

GrÁFICO 17. CURVA DE CRESCIMENTO DAS RAÇAS G, 3/4GS, 1/2N(SG), SG E 1/2C(SG) COM SUPLEMENTAÇÃO NA SECA (S2), ANO DE 1978. 


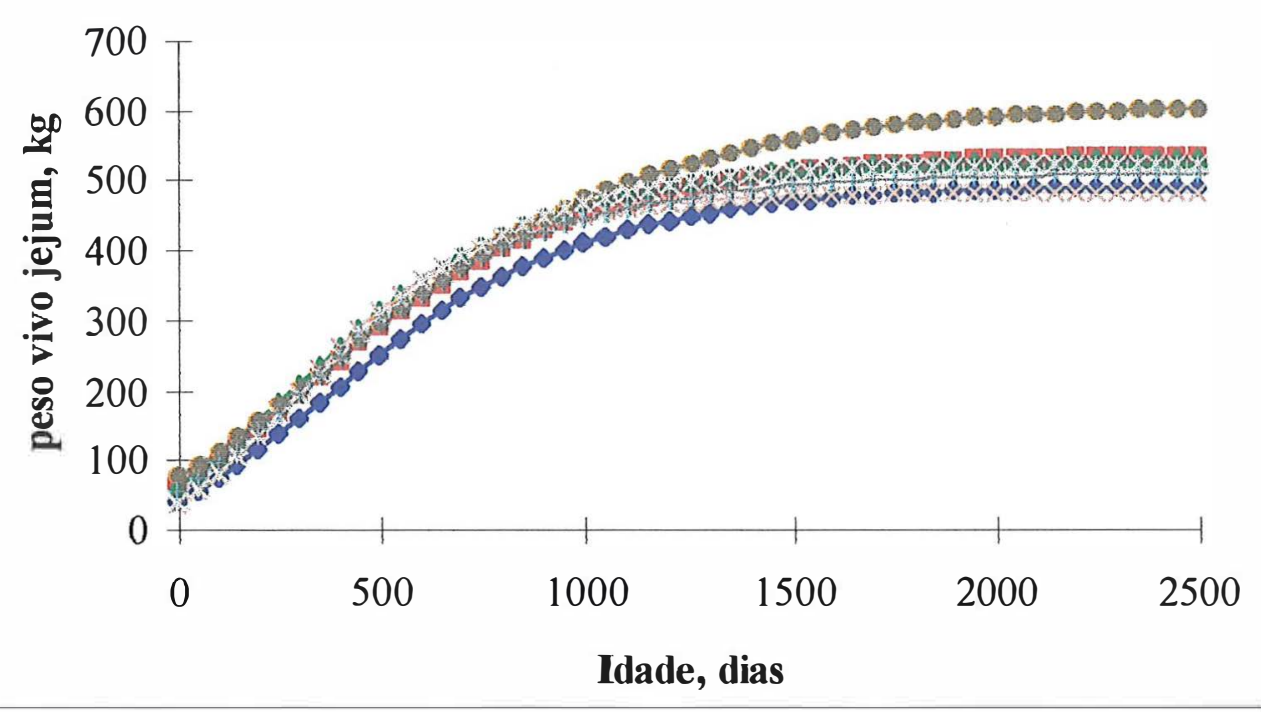

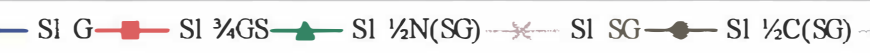
Sl KG—-Sl $1 / 2 \mathrm{~K}$ (SG)

GRÁfico 18. CuRVA DE CRESCIMENTO dAS RAÇAS G, 3/4GS, 1/2N(SG), SG, 1/2C(SG), KG E 1/2K(SG) SEM SUPLEMENTAÇÃO(S1), ANO DE 1979.

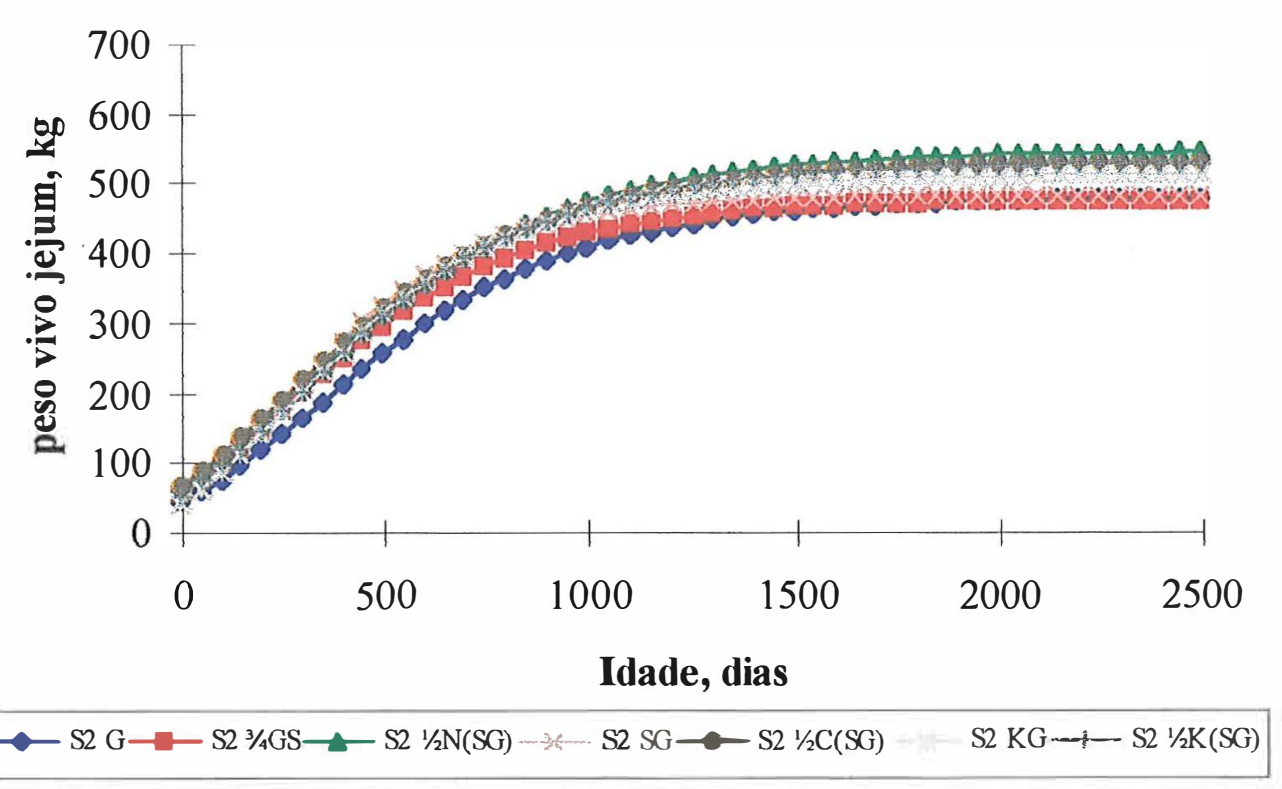

GRÁFICO 19. CURVA DE CRESCIMENTO DAS RAÇAS G, 3/4GS, 1/2N(SG), SG, 1/2C(SG), KG E 1/2K(SG) COM SUPLEMENTAÇÃO NA SECA (S2), ANO DE 1979. 


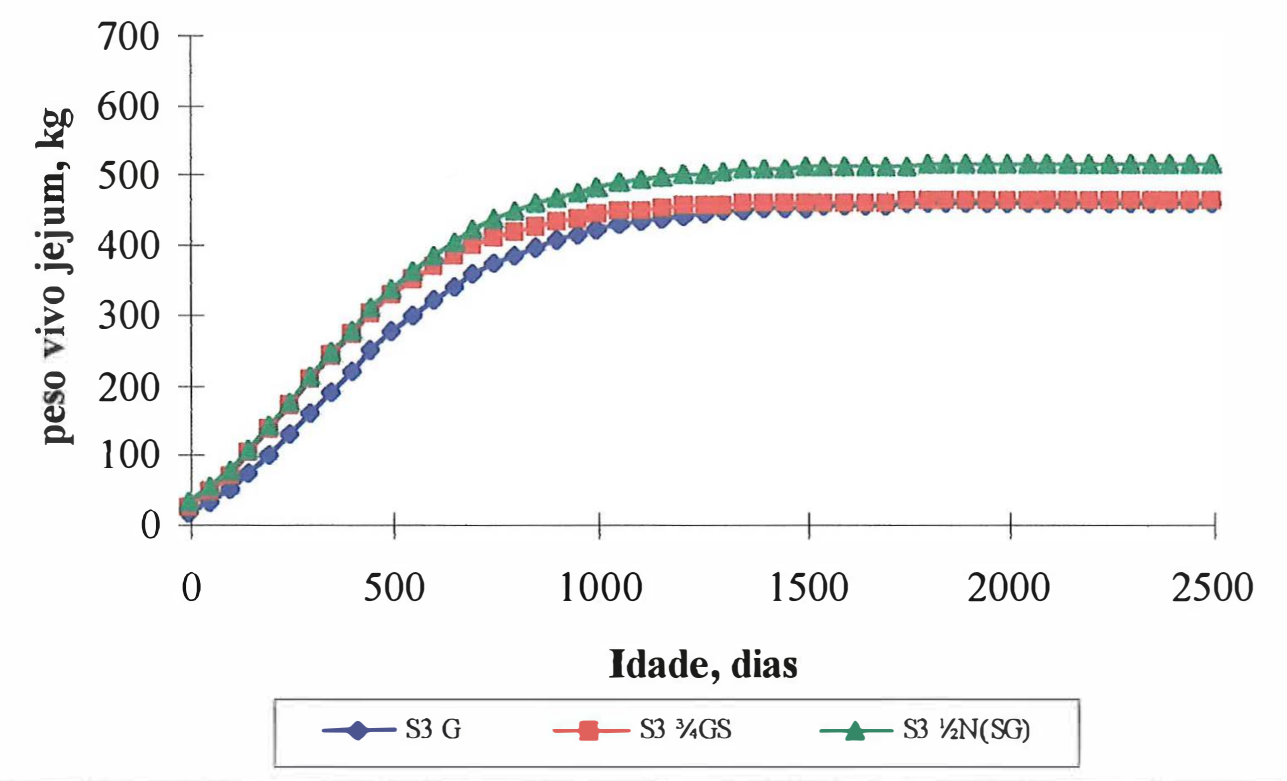

GRÁFICO 20. CURVA DE CRESCIMENTO DAS RAÇAS G, 3/4GS E 1/2N(SG) COM SUPLEMENTAÇ̃̃O DURANTE O ANO(S3), ANO DE 1979.

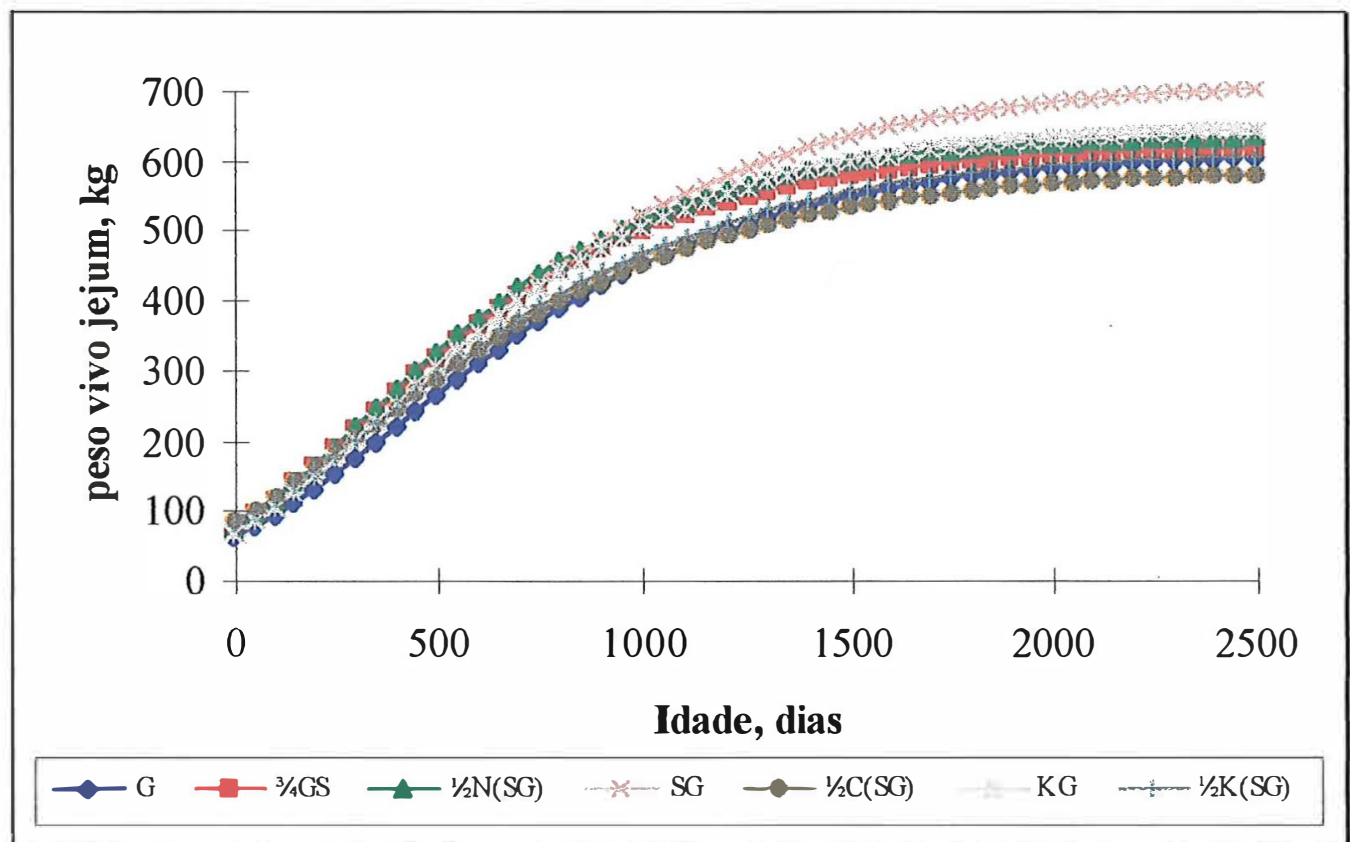

Gráfico 21. CuRVa de CRESCIMENTo dos MACHOS (M) DaS RaÇAS G, 3/4GS, 1/2N(SG),

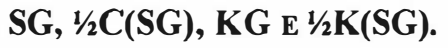




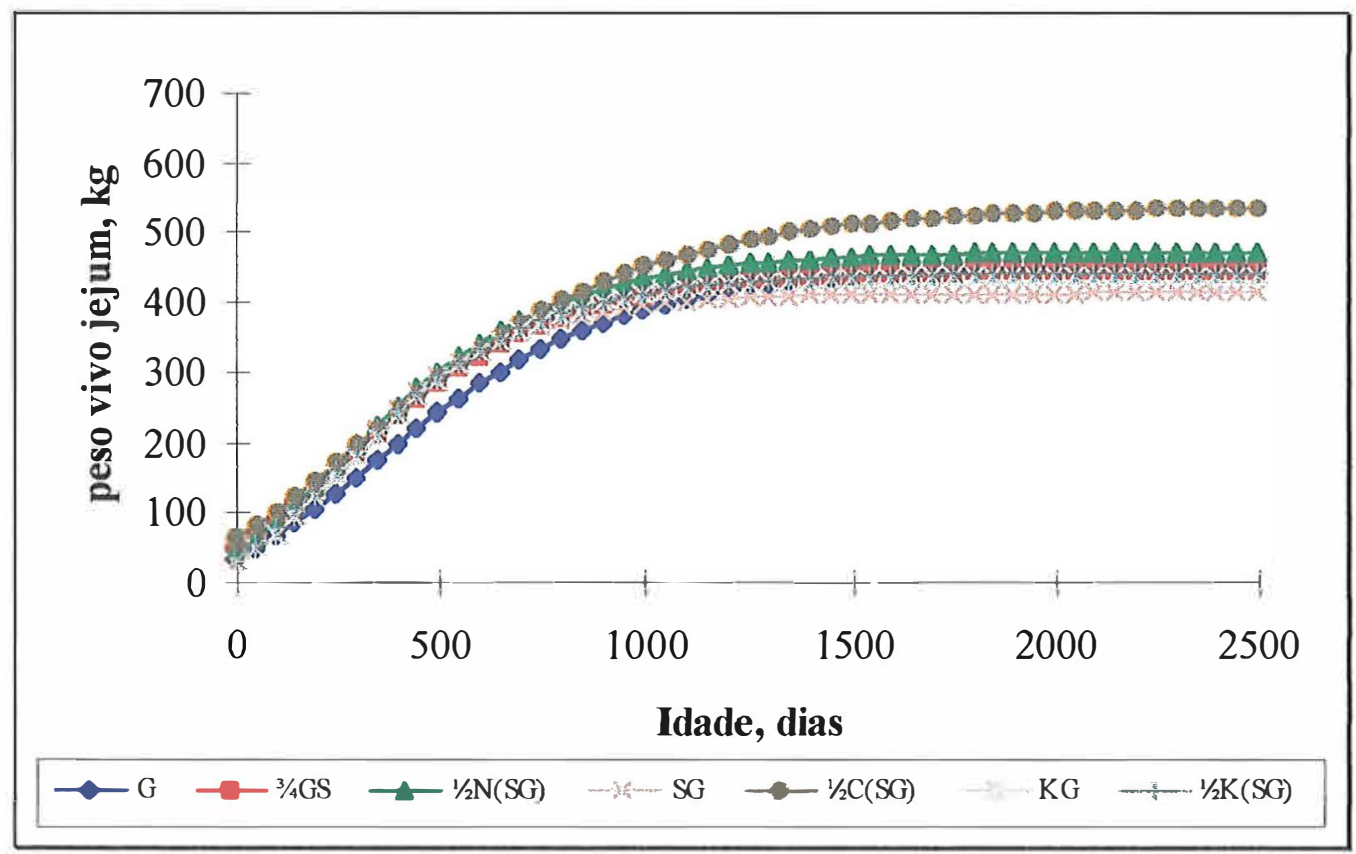

GRÁFICO 22. CURVA DE CRESCIMENTO DAS FÊMEAS SEM CORREÇão (F) DO PESO FETAL E TECIDOS ANEXOS DA PLACENTA DAS RAÇAS G, 3/4GS, 1/2N(SG), SG, 1/2C(SG), KG E $1 / 2 \mathbf{K}(\mathrm{SG})$.

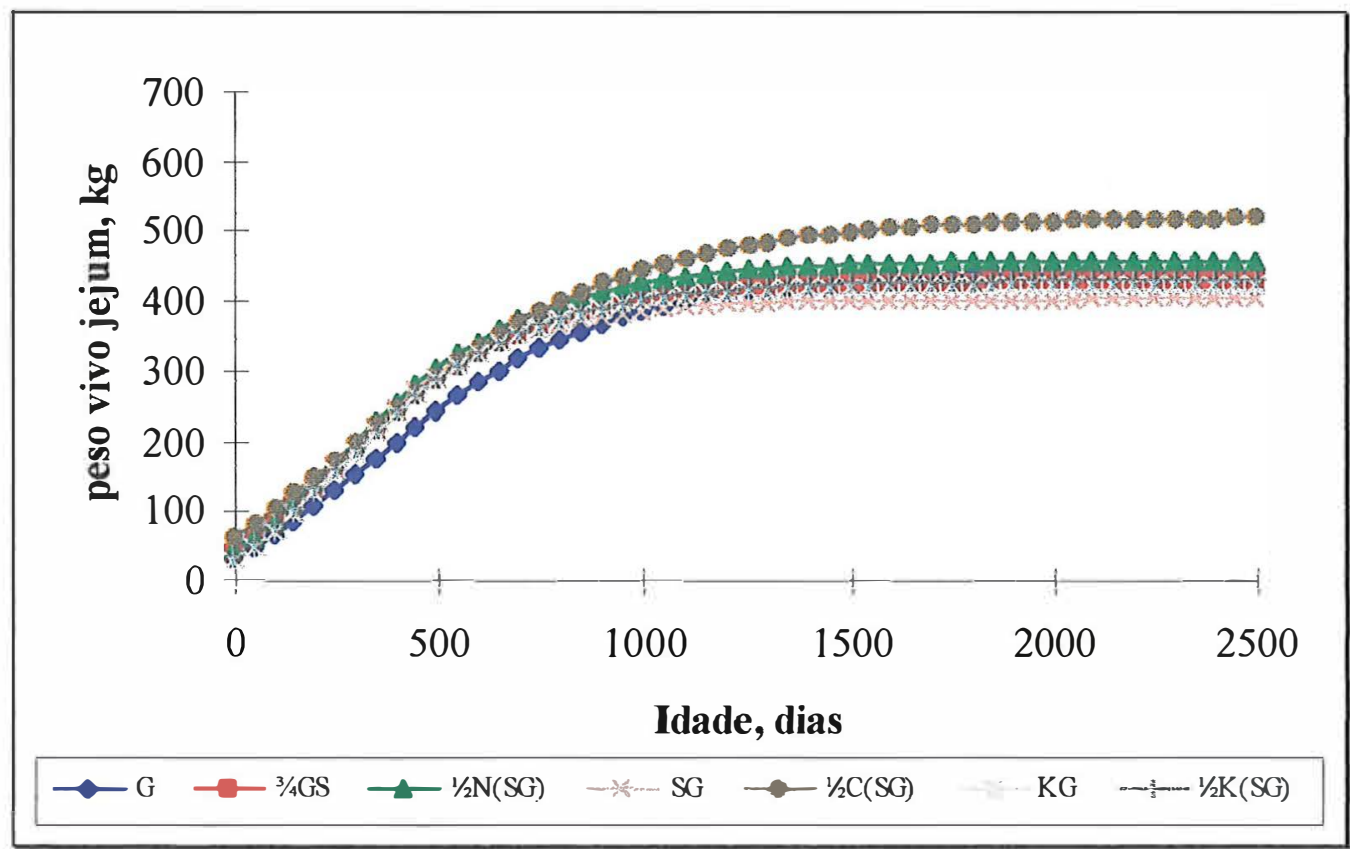

Gráfico 23. CuRVA de CRESCIMENTO dAS FÊMEAS COM CORREÇão $\left(F_{\text {AJ }}\right)$ do PESO FETAL E TECIDOS ANEXOS DA PLACENTA DAS RAÇAS G, 3/4GS, 1/2N(SG), SG, 1/2C(SG), KG E $1 / 2$ K(SG). 


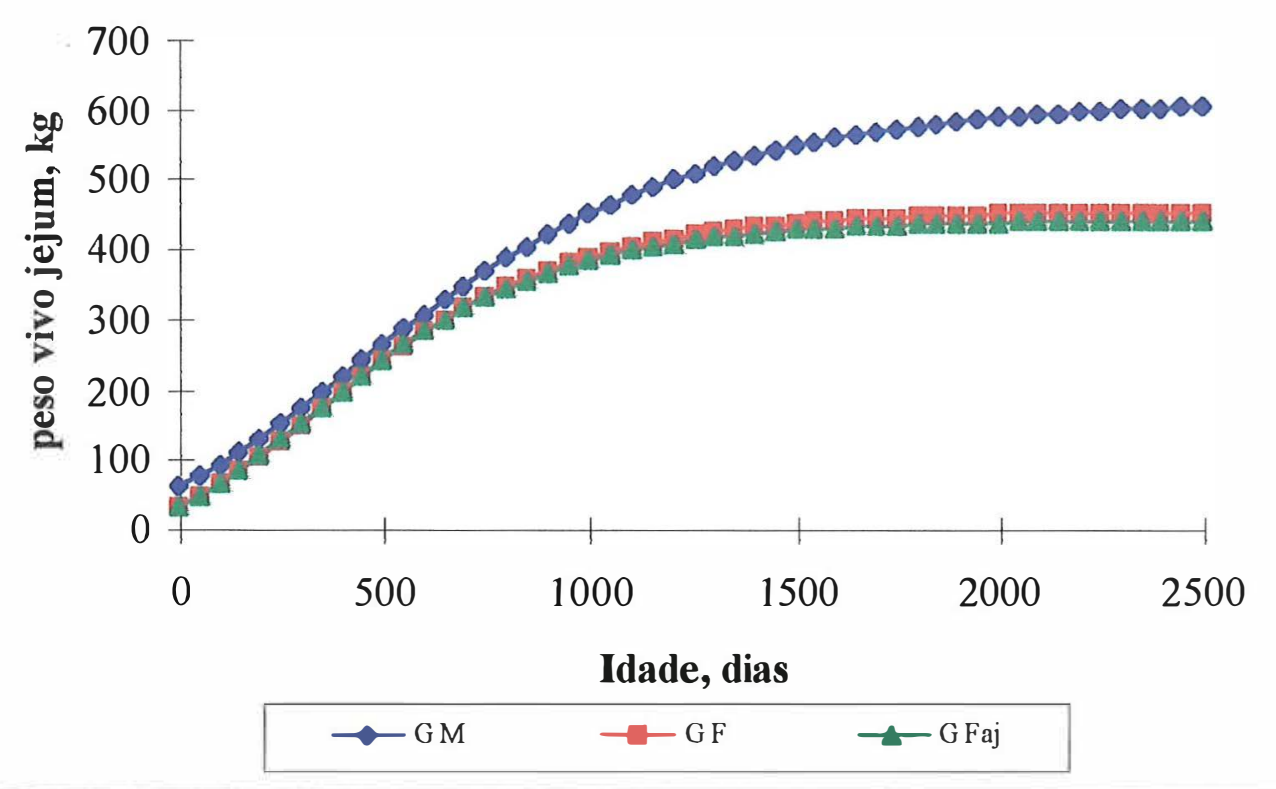

Gráfico 24. Curva de CREscimento da RaÇA GuZerá (G) PARA OS MACHOS (M), FÊMEAS SEM (F) E COM $\left(F_{A J}\right)$ CORREÇÃO DO PESO FETAL.

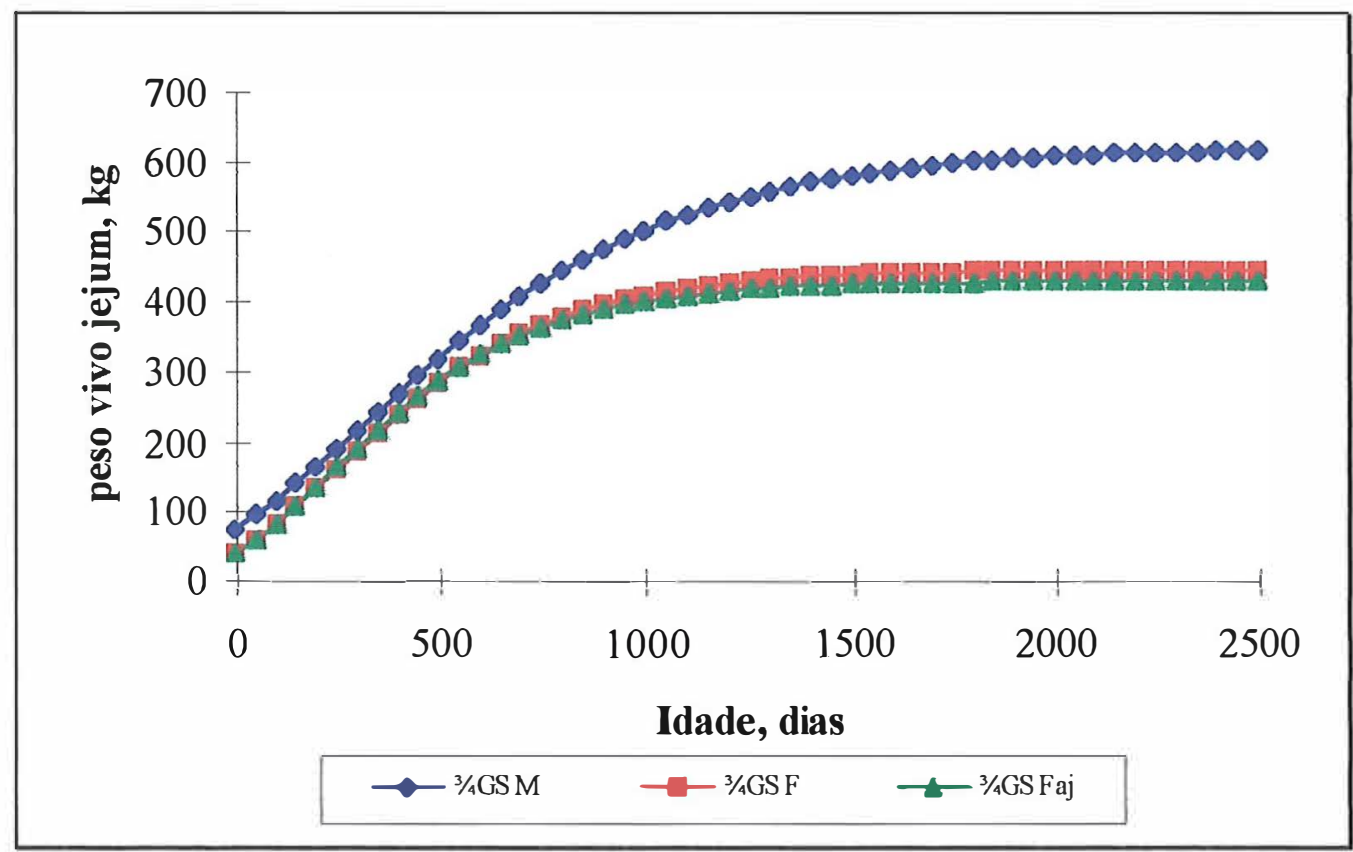

GRÁfico 25. CuRVA de CRESCIMENTO da RAÇA 3/4GUZERÁ X 1/4PARDo Suiço (3/4GS) PARA OS MACHOS $(M)$, FÊMEAS SEM (F) E COM $\left(F_{A J}\right)$ CORREÇĀO DO PESO FETAL. 


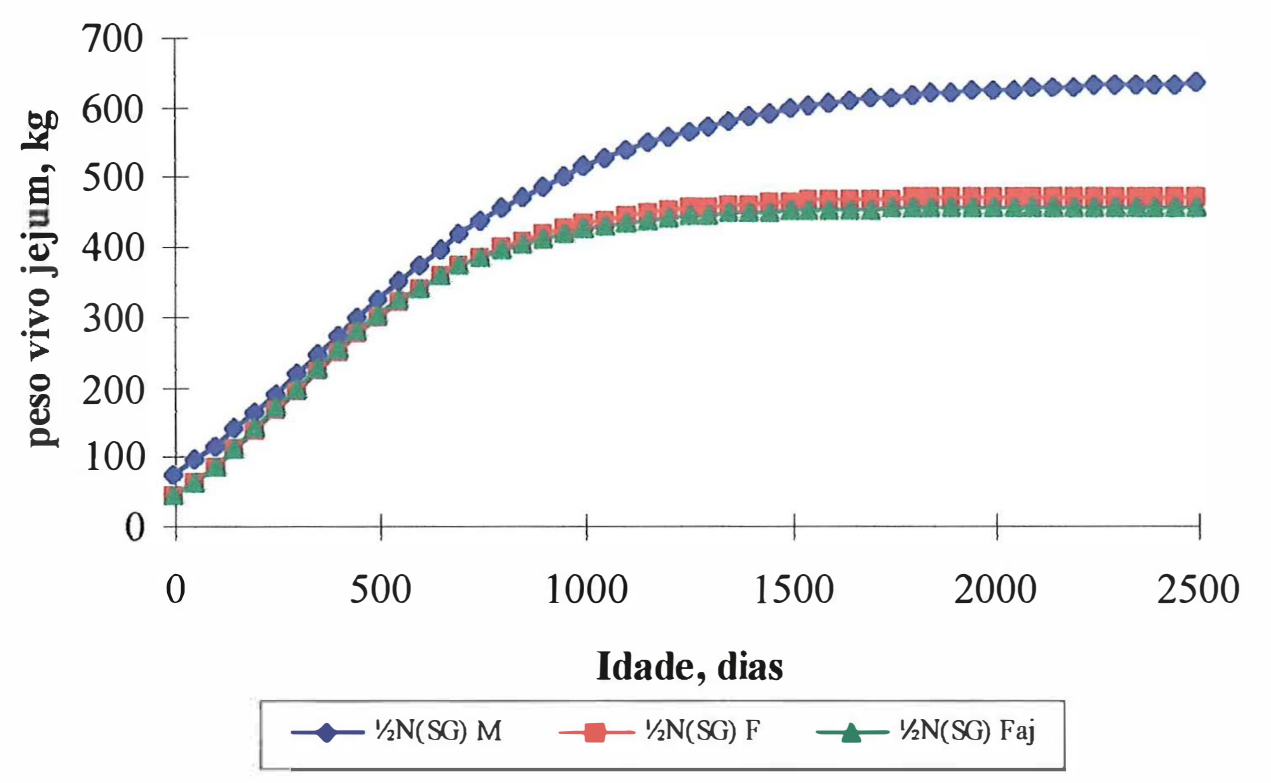

GrÁFICO 26. CURVA DE CRESCIMENTO DA RAÇA 1/2NELORE X 1/4GUZERÁ X 1/4PARDO SUÍÇO (1/2N(SG)) PARA OS MACHOS (M), FÊMEAS SEM (F) E COM (F F $_{\text {JJ }}$ CORREÇĀO DO PESO FETAL.

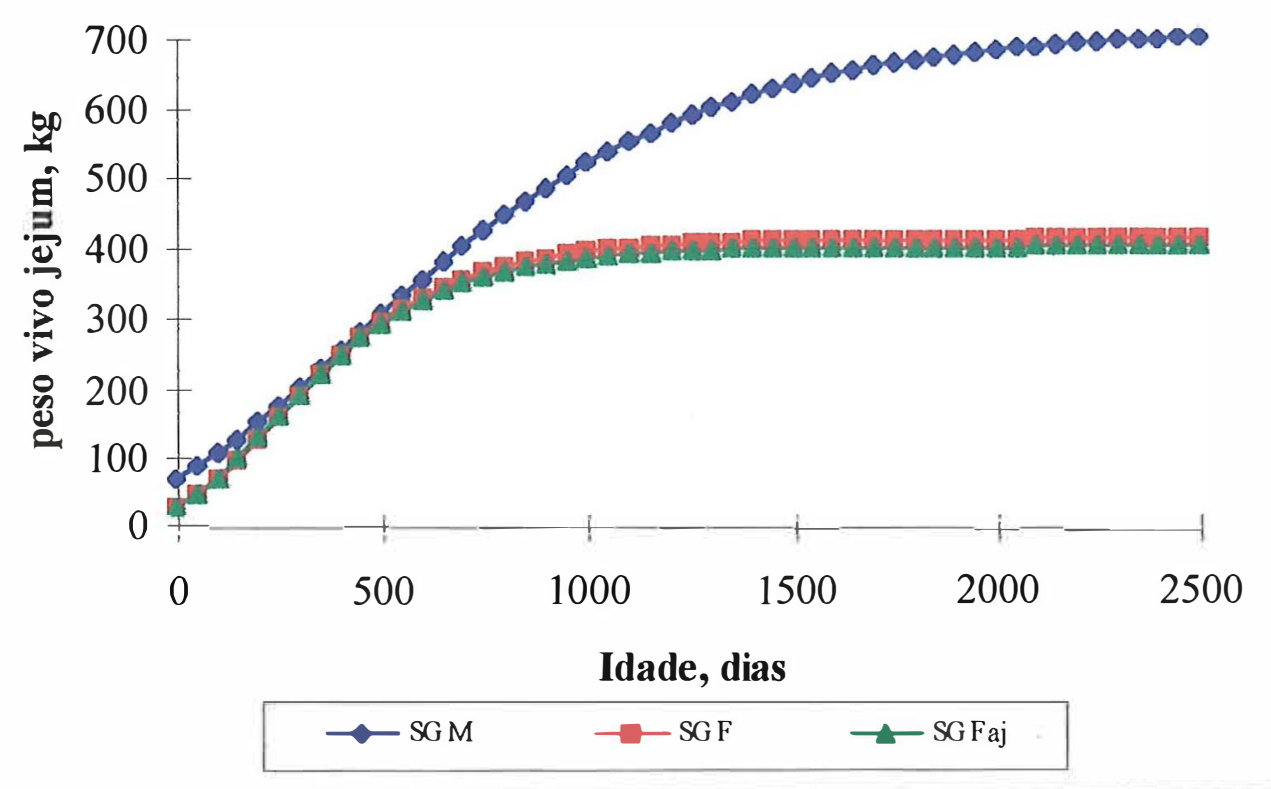

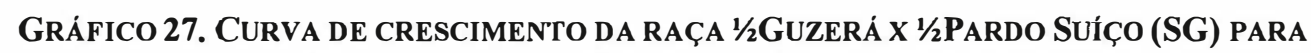
OS MACHOS (M), FÊMEAS SEM (F) E COM $\left(F_{A J}\right)$ CORREÇÃO DO PESO FETAL. 


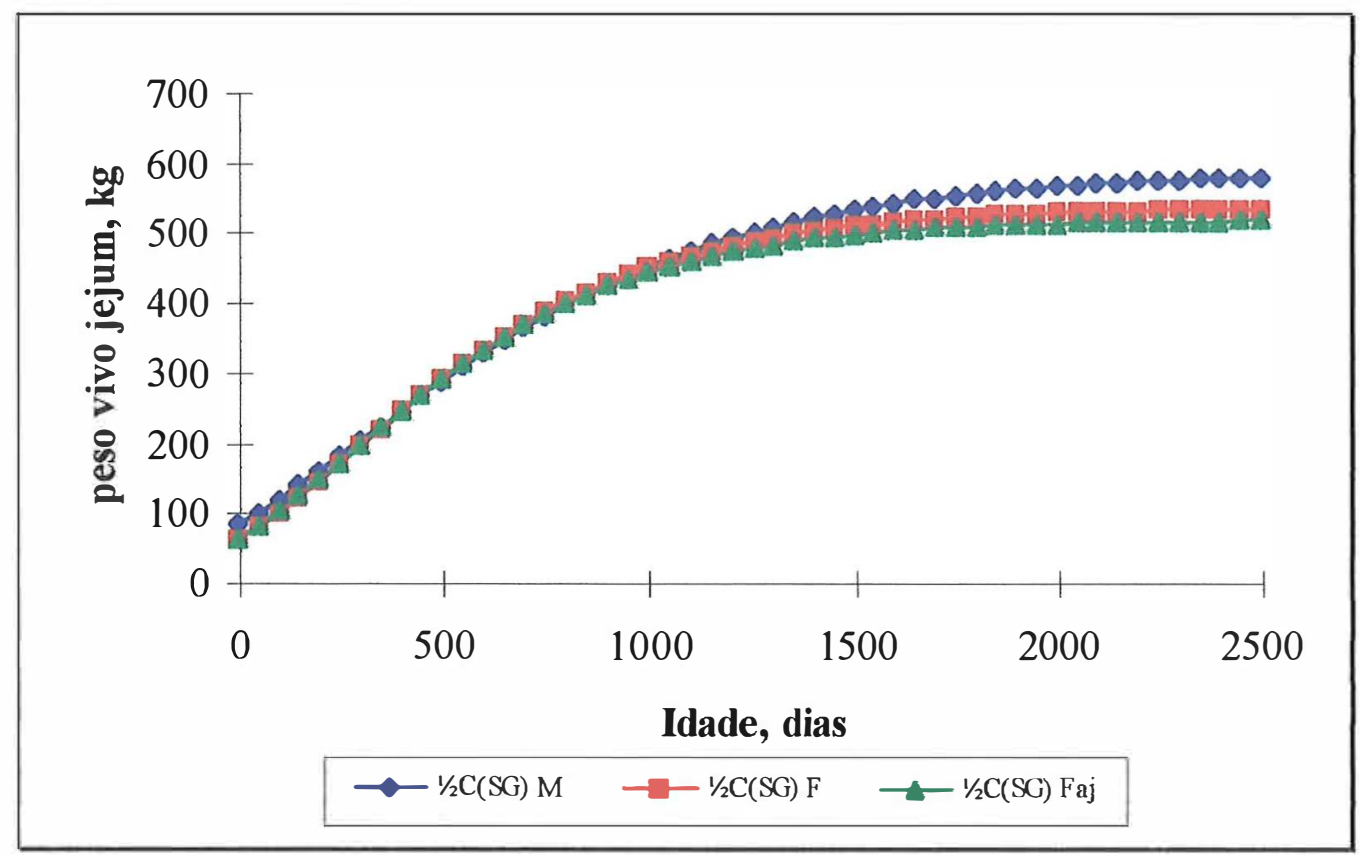

GRÁFICO 28. CURVA DE CRESCIMENTO DA RAÇA $1 \frac{1}{2}$ CHIANINA $X 1 / 4$ GUZERÁ $X 1 / 4$ PARDO SUIÇO $(1 / 2 C(S G))$ PARA OS MACHOS (M), FÊMEAS SEM (F) E COM $\left(F_{A J}\right)$ CORREÇÃO DO PESO FETAL.

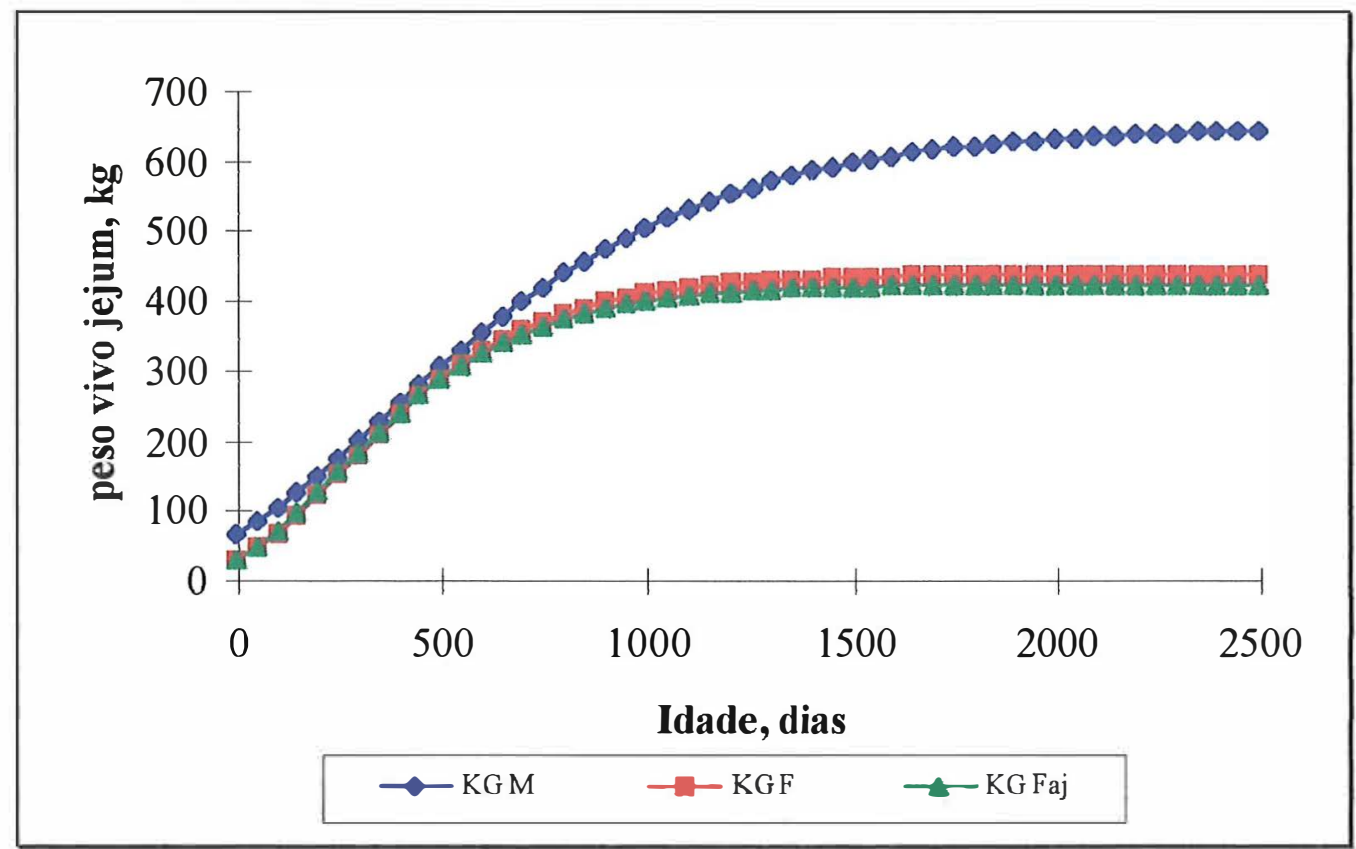

GRÁFICO 29. CURVA DE CRESCIMENTO DA RAÇA 1/2 CARACÚ X $1 \frac{1}{2}$ GUZERÁ (KG) PARA OS MACHOS (M), FÊMEAS SEM (F) E COM ( $\left.F_{A J}\right)$ CORREÇÃO DO PESO FETAL. 


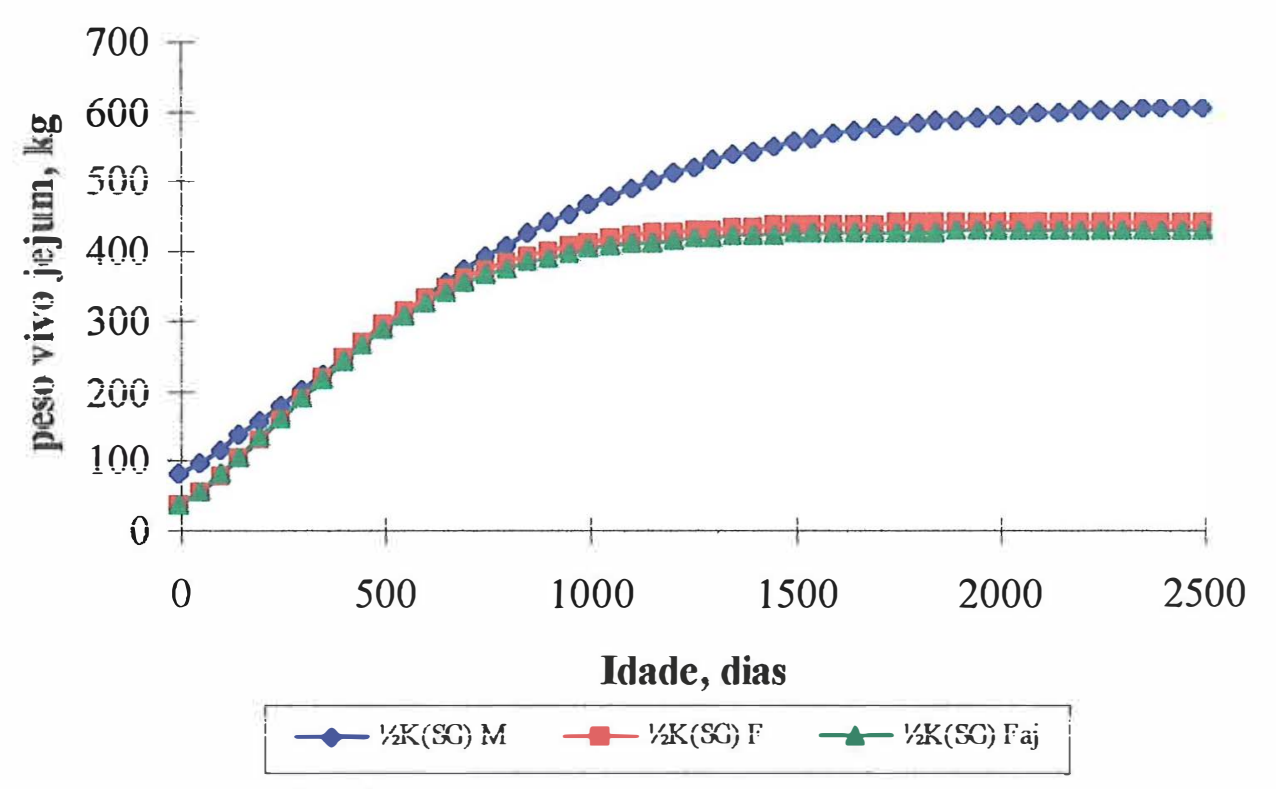

Gráfico 30. CuRVA DE CRESCIMENTO Da RAÇA 1/2CARACÚ X 1/4GUZERÁ X 1/4PARDo Suiço (1⁄2K(SG)) PARA OS MACHOS (M), FÊMEAS SEM (F) E COM $\left(F_{A J}\right)$ CORREÇÃO DO PESO FETAL.

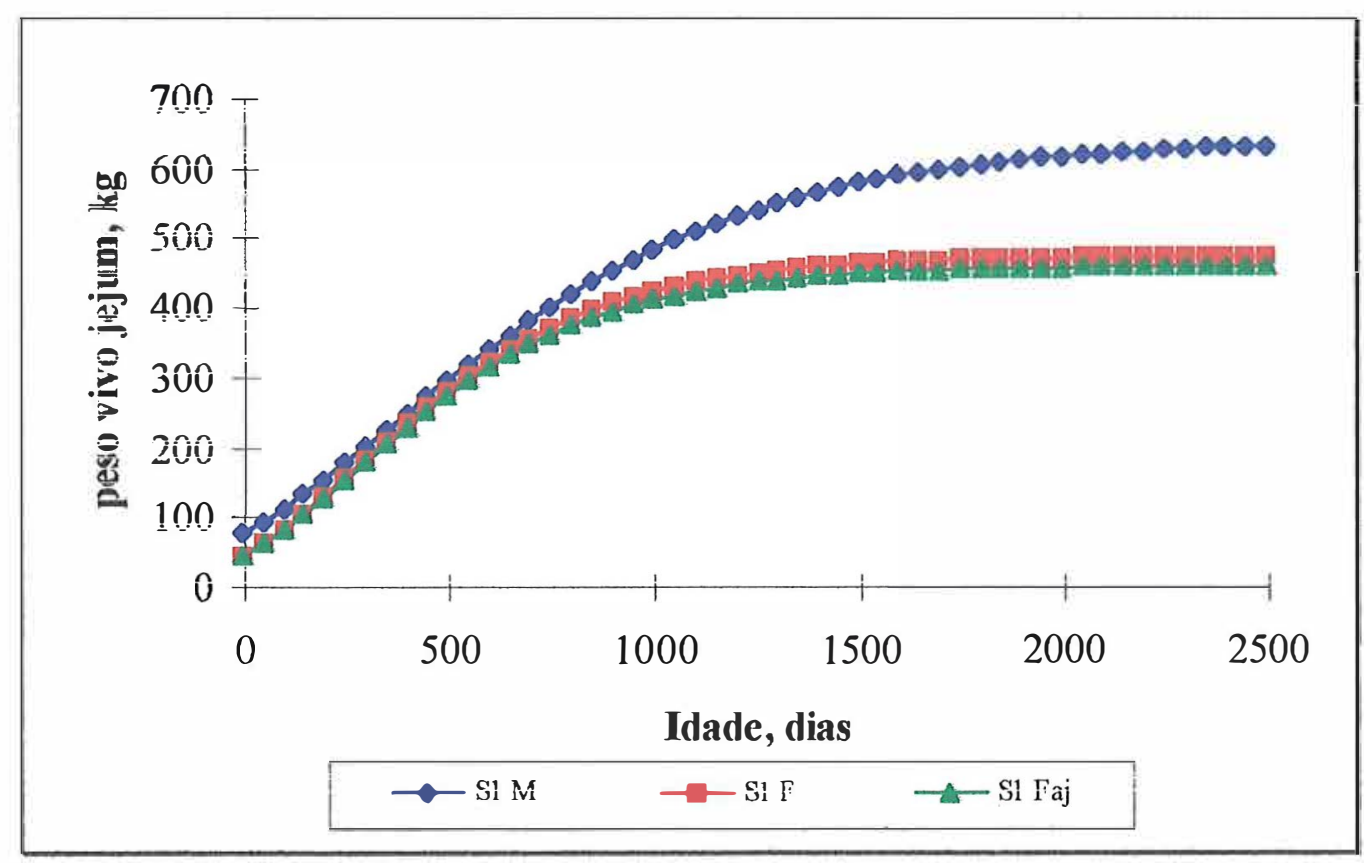

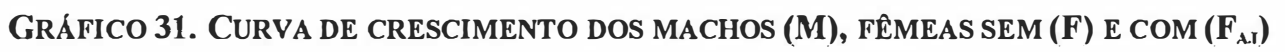
CORREÇÃO DO PESO FETAL SEM SUPLEMENTAÇÃO. 


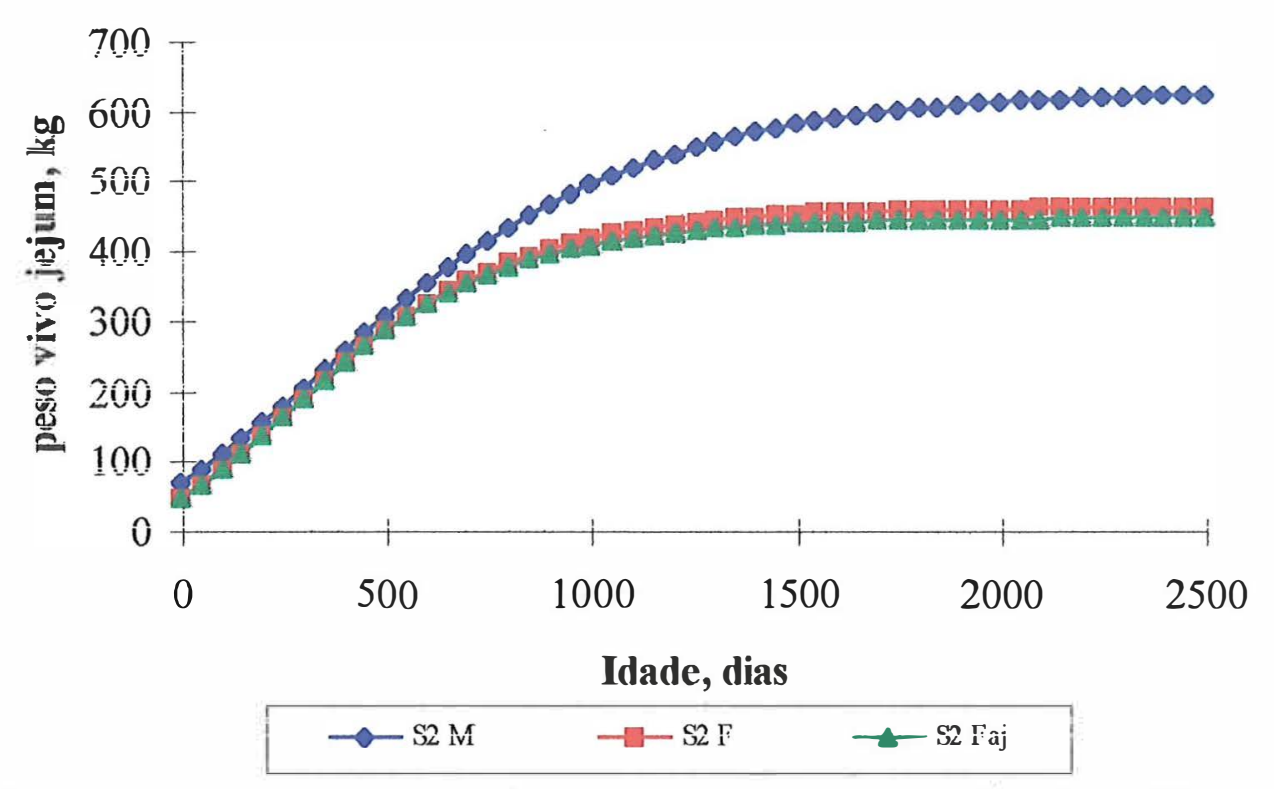

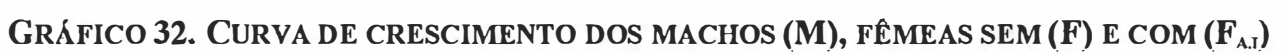
CORREÇÃO DO PESO FETAL COM SUPLEMENTAÇÃO NA SECA.

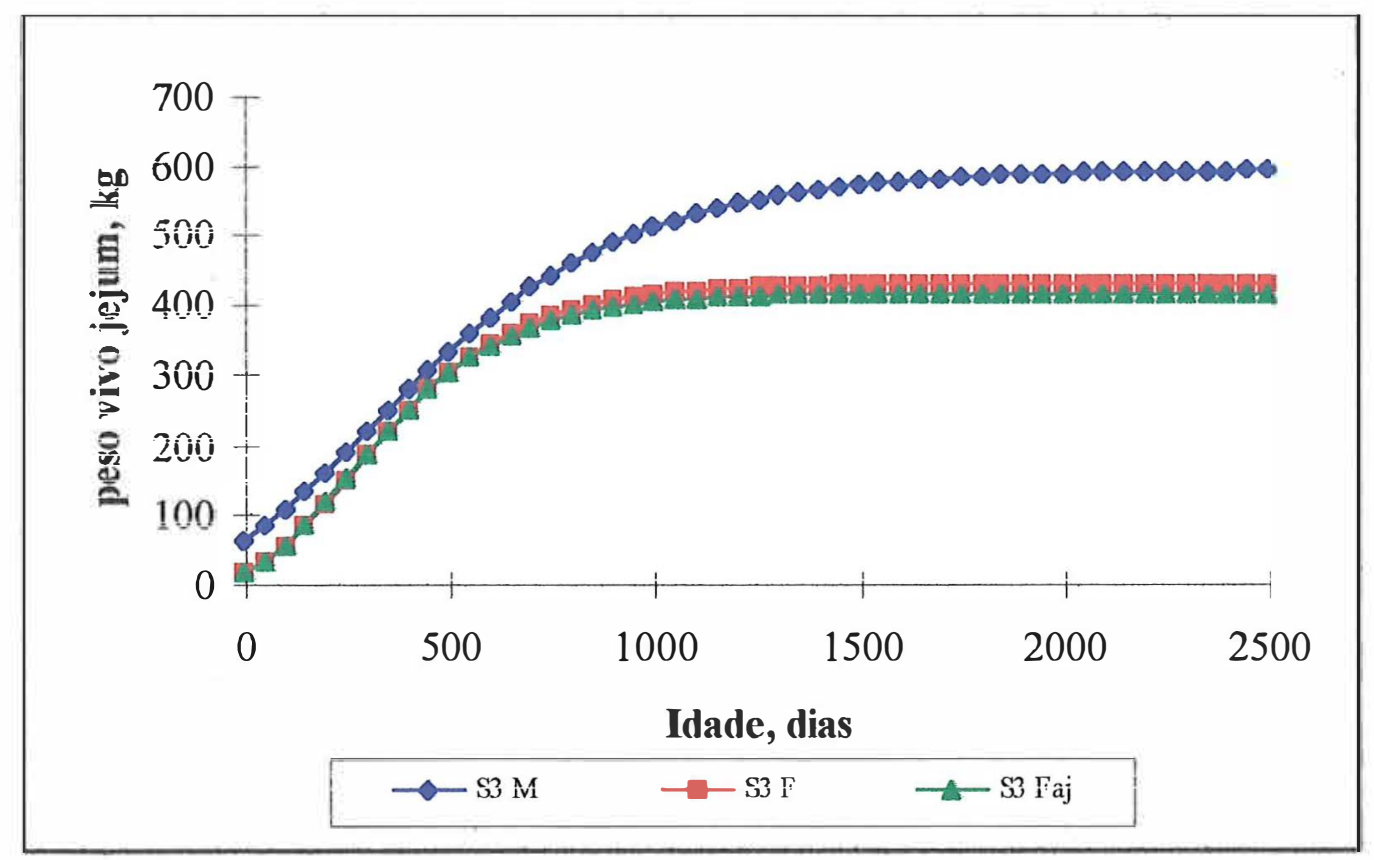

GrÁfico 33. CuRVA DE CRESCIMENTO dos MACHOS (M), FÊMEAS SEM (F) E COM ( F.I. $_{\text {. }}$ ) CORREÇÃO DO PESO FETAL COM SUPLEMENTAÇÃO DURANTE O ANO. 


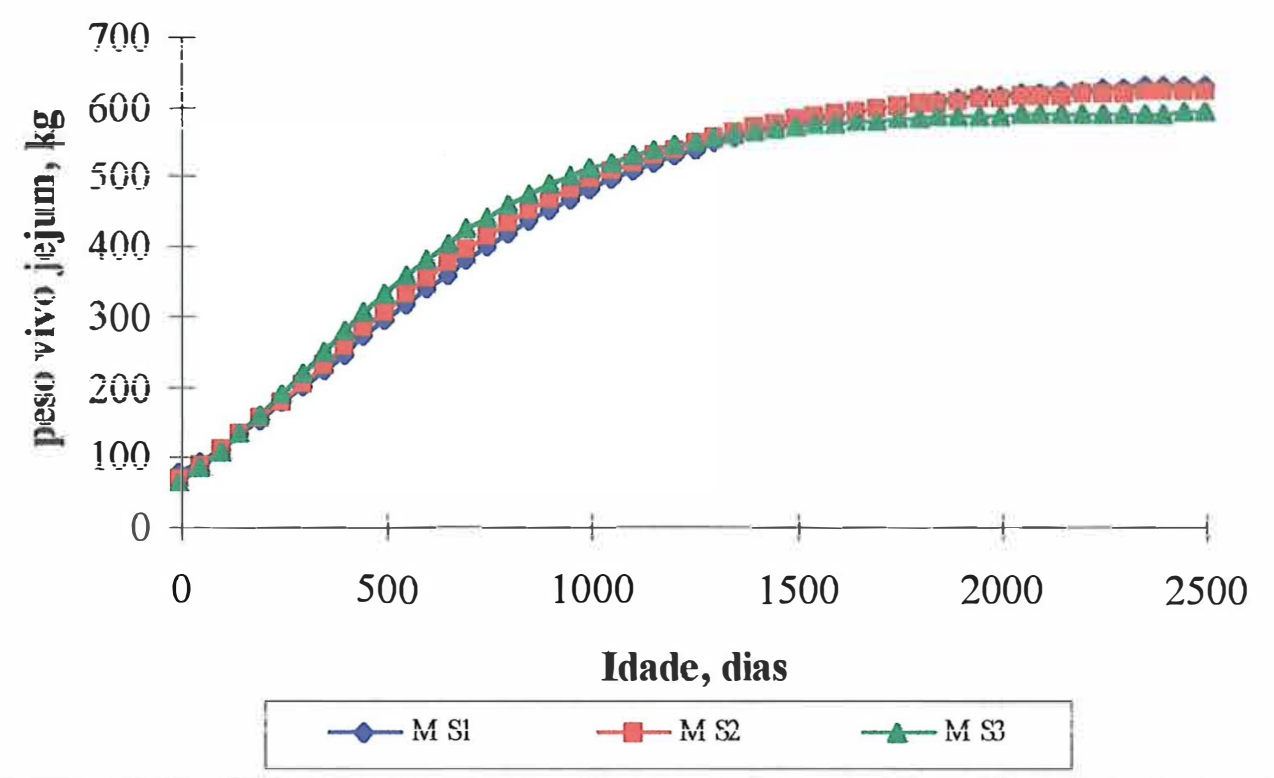

GrÁFico 34. CuRVA de CRESCIMENTO dos MACHOS (M) SEM SUPLEMENTAÇ̃̃o (S1), COM SUPLEMENTAÇÃO NA SECA (S2) E DURANTE O ANO (S3).

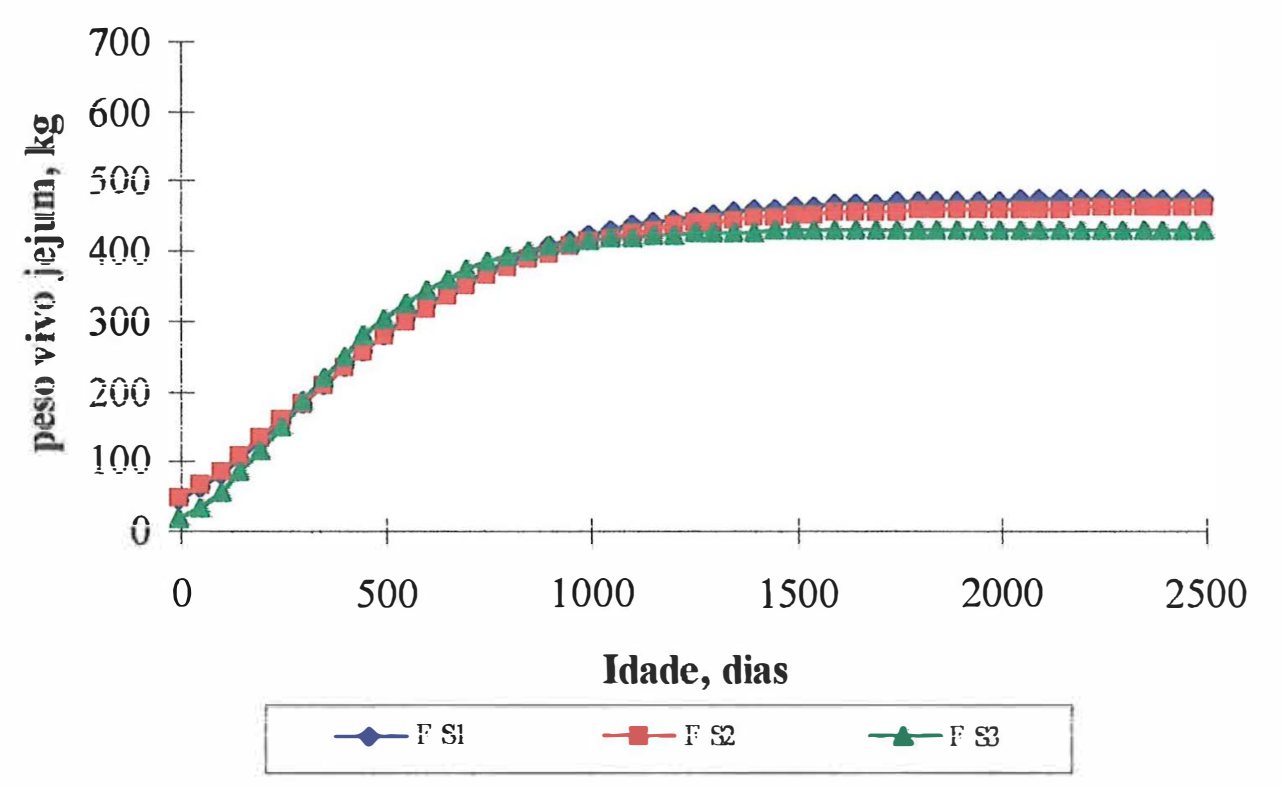

GrÁFICO 35. CuRVA de CRESCIMENTO dAS FÊMEAS SEM CORREÇÃo do PESO FETAL (F) SEM SUPLEMENTAÇÃO (S1), COM SUPLEMENTAÇÃO NA SECA (S2) E DURANTE O ANO (S3). 


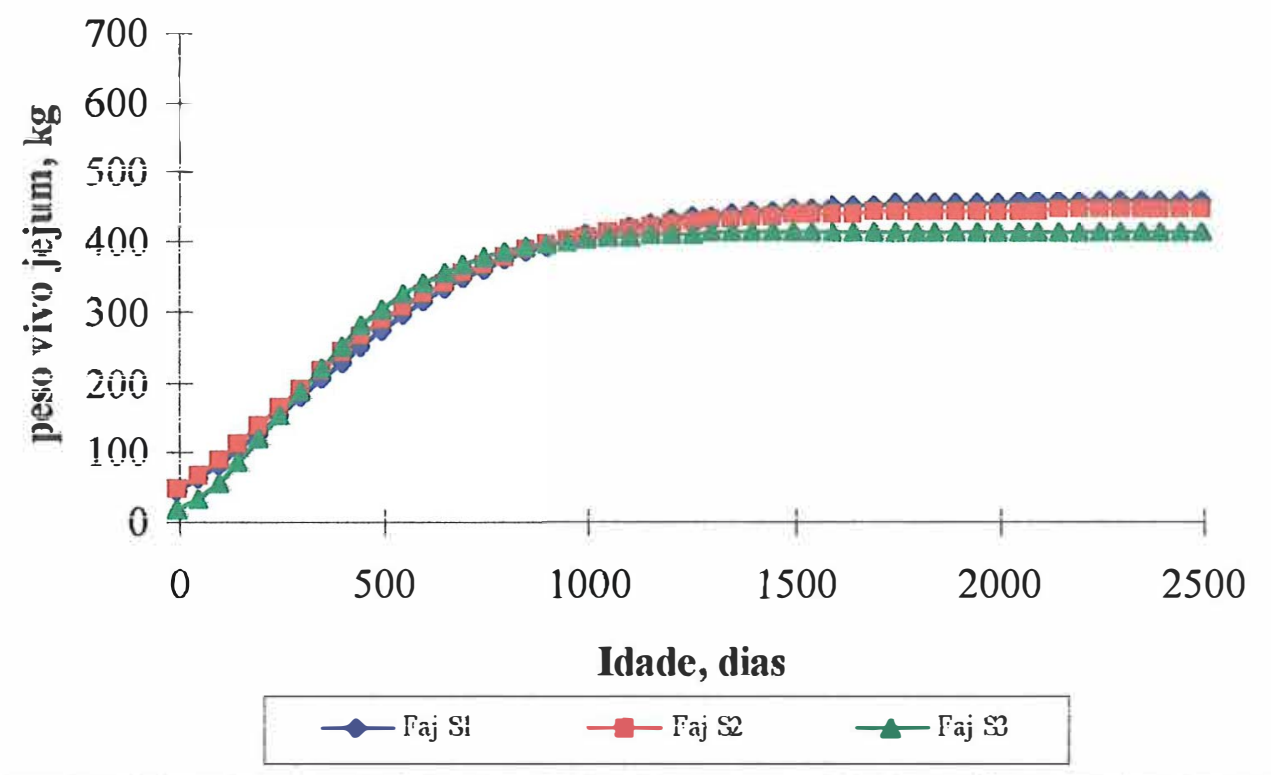

GRÁFICO 36. CURVA DE CRESCIMENTO DAS FÊMEAS COM CORREÇÃo DO PESO FETAL $\left(\mathrm{F}_{\mathrm{At}}\right)$ SEM SUPLEMENTAÇÃo (S1), COM SUPLEMENTAÇÃO NA SECA (S2) E DURANTE O ANO (S3).

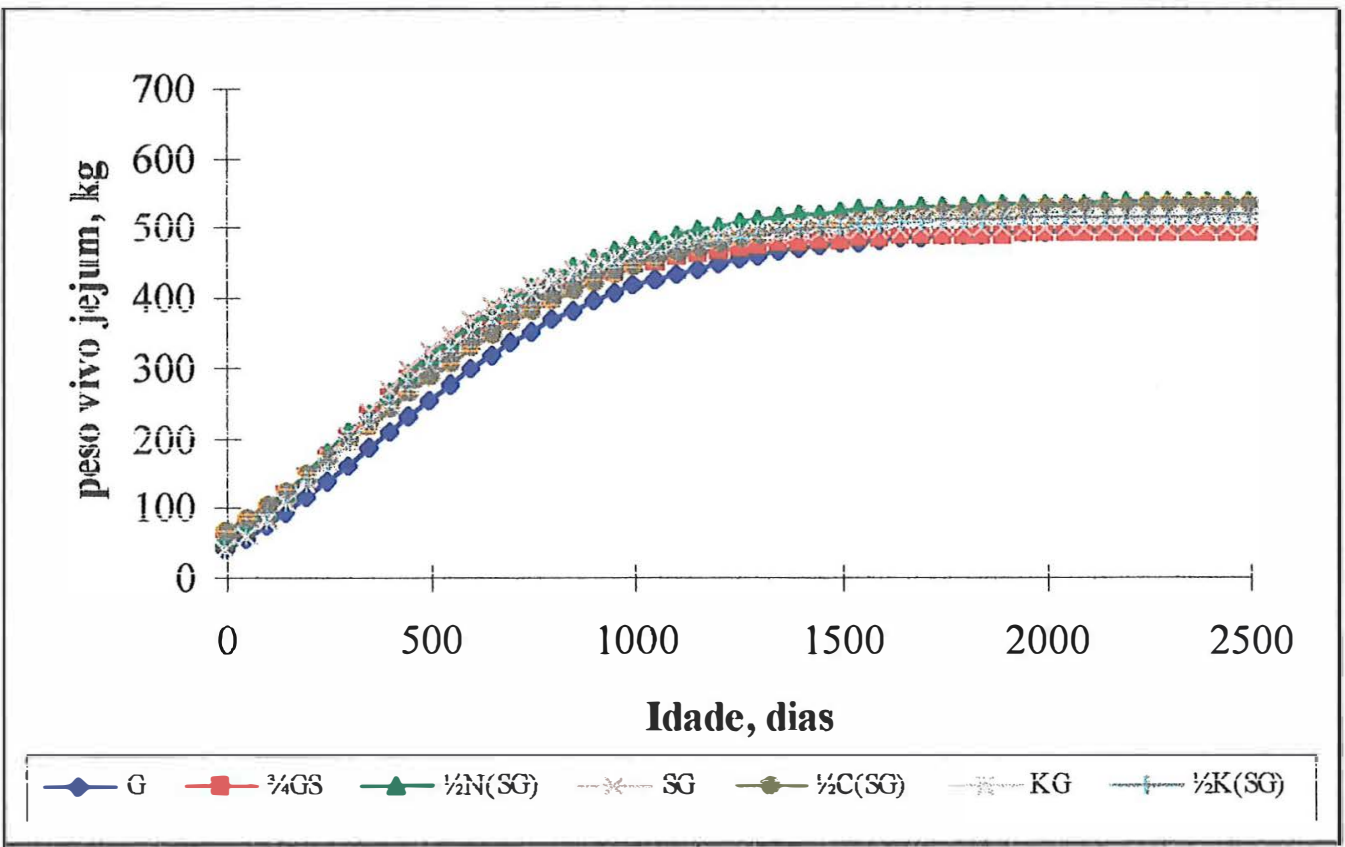

Gráfico 37. CuRVA de CRESCIMENTo das RAÇAS G, 3/4GS, 1/2N(SG), SG, 1/2C(SG), KG E $1 / 2 \mathbf{K}$ (SG) 


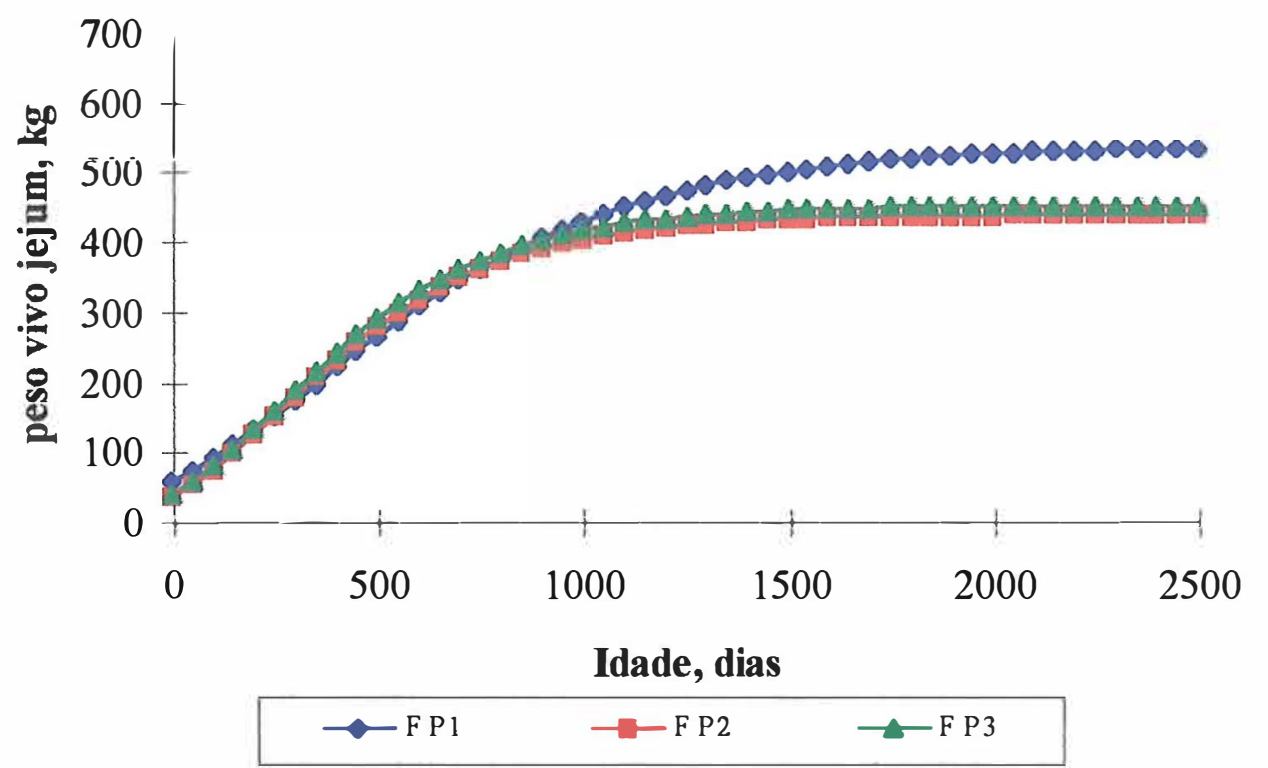

GRÁFICO 38. CURVA DE CRESCIMENTO DAS FÊMEAS SEM CORREÇÃo (F') DO PESO FETAL PARA ANIMAIS SEM PARIÇÃo(P1), PARIÇÃo AOS 3 ANOS (P2) E AOS 3 E 4 ANOS (P3).

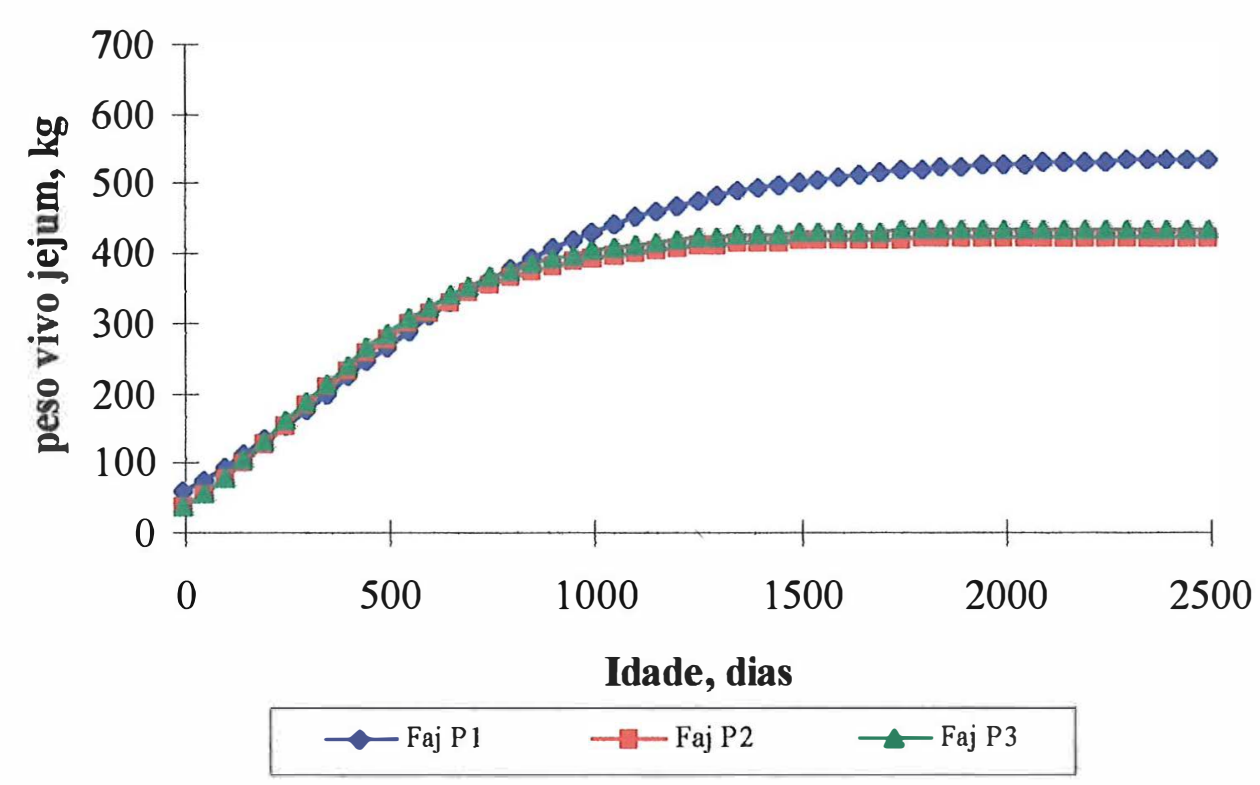

GRAFICO 39. CURVA DE CRESCIMENTO DAS FÊMEAS COM CORREÇÃO $\left(F_{\text {AJ }}\right)$ DO PESO FETAL PARA ANIMAIS SEM PARIÇÃo (P1), PARIÇÃo AOS 3 ANOS (P2) E AOS 3 E 4 ANOS (P3). 


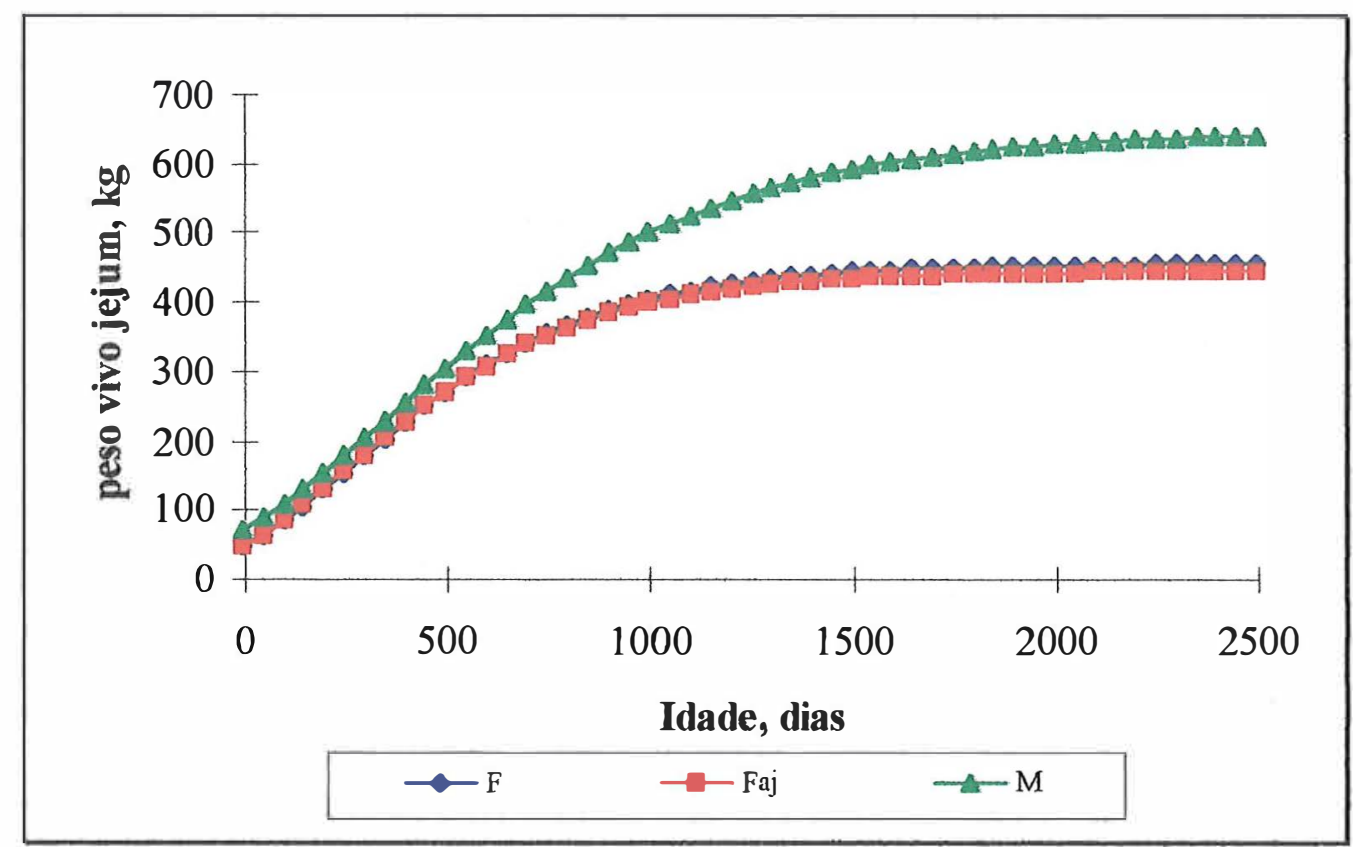

GRÁFICO 40. CURVA DE CRESCIMENTO DOS MACHOS E DAS FÊMEAS SEM (F) E COM (F CORREÇÃO DO PESO VIVO PARA O PESO FETAL E TECIDOS ANEXOS PARA O ANO DE 1978.

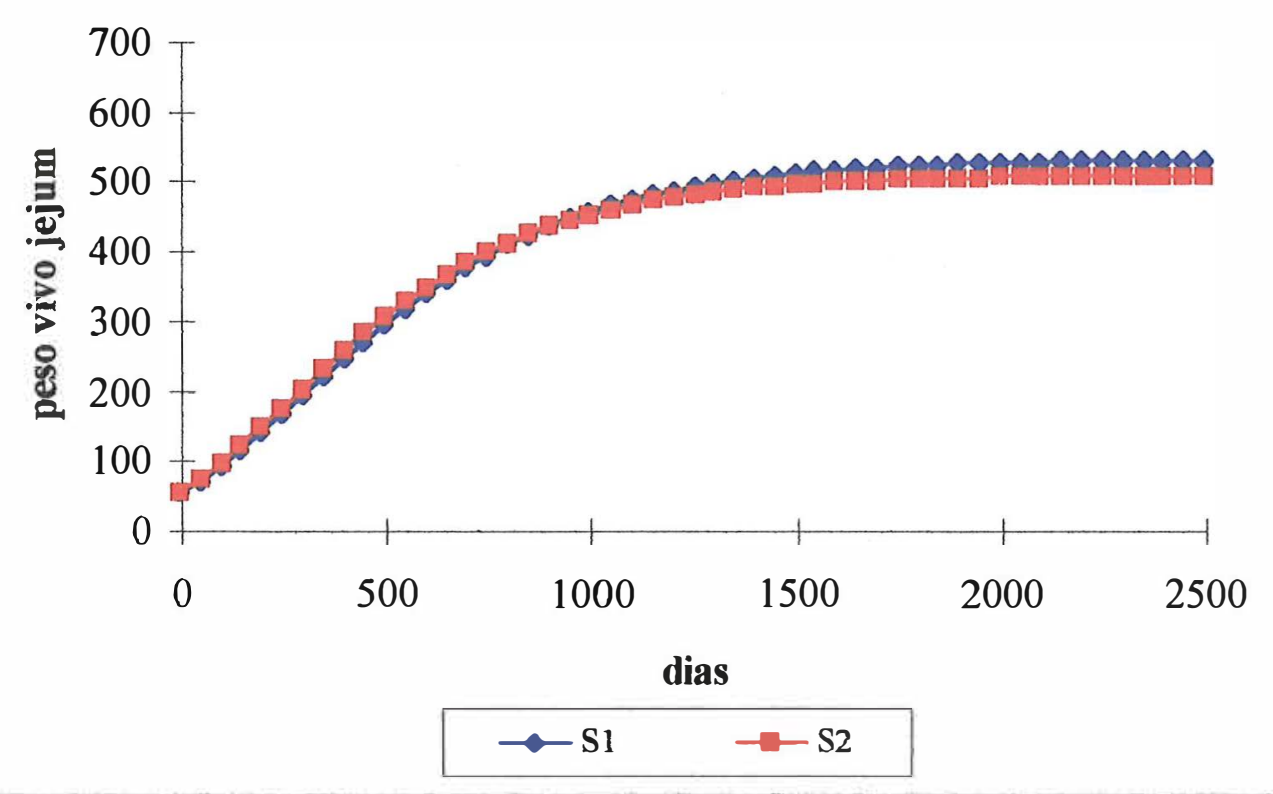

GRÁFICO 41. CuRVA DE CRESCIMENTO dOS ANIMAIS SEM SUPLEMENTAÇÃo (S1) E COM SUPLEMENTAÇÃO DURANTE O INVERNO (S2) PARA O ANO DE 1978. 


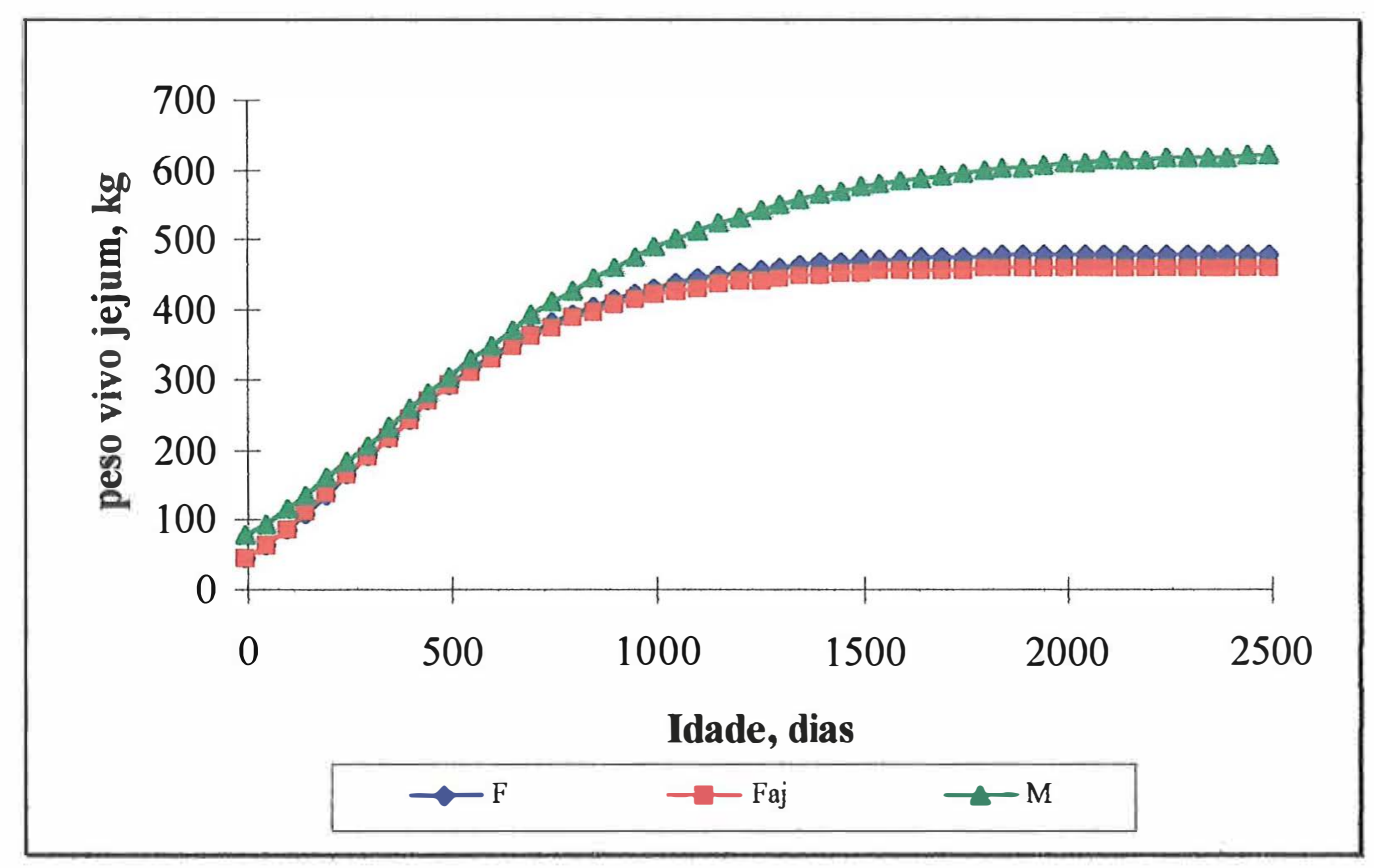

GrÁFico 42. CuRVA de CRESCIMENTO dos MACHOS E dAS FÊMEAS SEM (F) E COM $\left(F_{A I}\right)$ CORREÇÃO DO PESO VIVO PARA O PESO FETAL E TECIDOS ANEXOS PARA O ANO DE 1979.

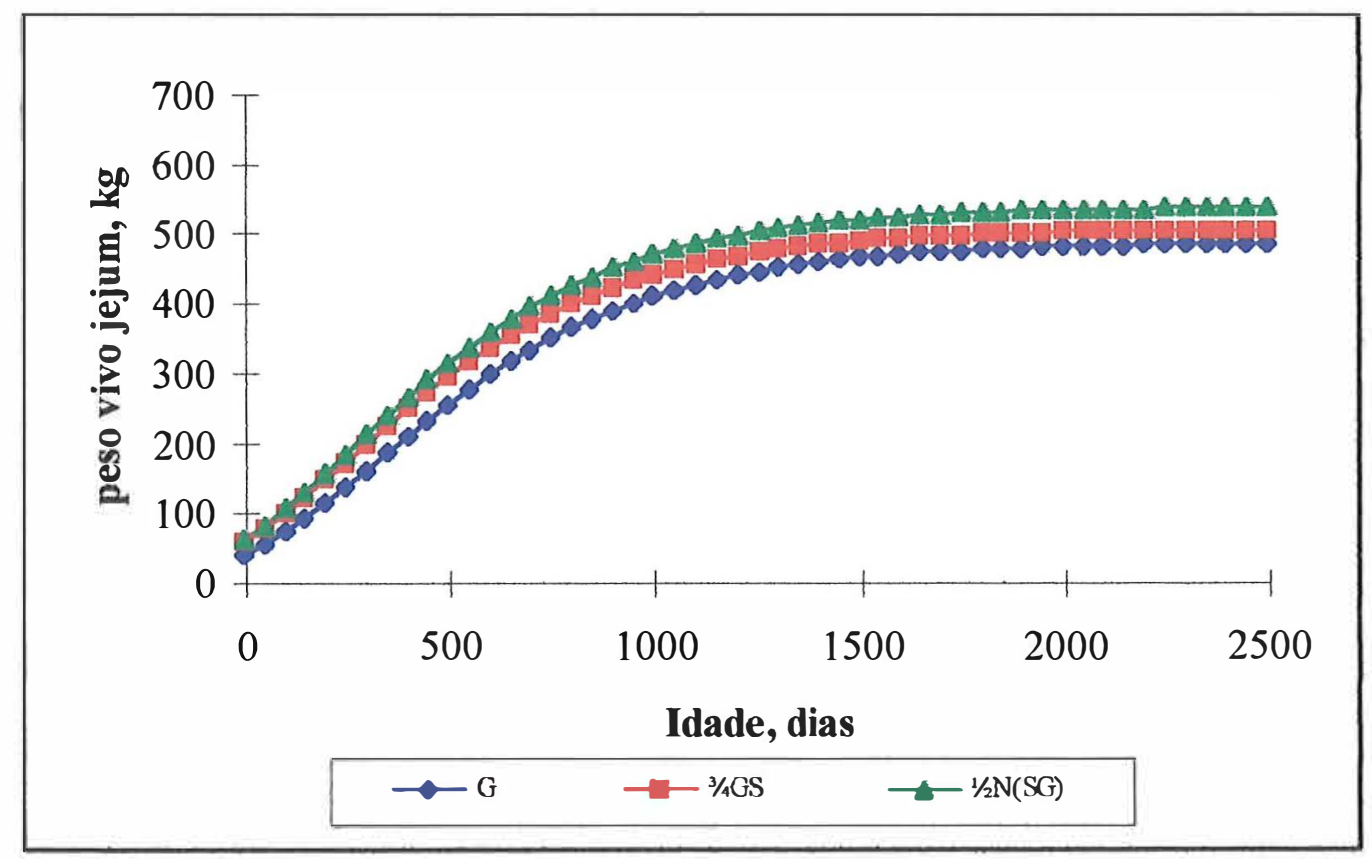

GRÁFICO 43. CURVA DE CRESCIMENTO DOS GRUPOS RACIAIS G, 3/4GS E 1/2N(SG) PARA O ANO ED 1979 CONSIDERANDO OS TRÊS NIVEIS DE SUPLEMENTAÇÃO. 
APÊNDICE 6. RESUMO dOS PARÂMETROS PESO ADULTO E DA TAXA DE MATURIDADE DE VARIAS RAÇAS E SEXOS PARA DIFERENTES FUNÇÕES DE CRESCIMENTO ENCONTRADOS POR DIVERSOS PESQUISADORES.

\begin{tabular}{|c|c|c|c|c|c|}
\hline Grupo racial $^{\mathrm{T}}$ & $\mathrm{Sexo}^{2}$ & Função $^{3}$ & $\mathrm{~A}^{4}$ & $\mathrm{k}^{5}$ & Autores \\
\hline $1 / 4 \mathrm{BR} \times 3 / 4 \mathrm{HE}$ & $\mathbf{F}$ & $\mathrm{Be}$ & 515,0 & 0,0028 & Brown et al. (1976) \\
\hline $1 / 4 \mathrm{BR} \times 3 / 4 \mathrm{HE}$ & $\mathbf{F}$ & Bo & 542,0 & 0,0020 & Brown et al. (1976) \\
\hline $1 / 4 \mathrm{BR} \times 3 / 4 \mathrm{HE}$ & F & Go & 506,0 & 0,0035 & Brown et al. (1976) \\
\hline $1 / 4 \mathrm{BR} \times 3 / 4 \mathrm{HE}$ & $\mathbf{F}$ & Lo & 496,0 & 0,0039 & Brown et al. (1976) \\
\hline $1 / 4 \mathrm{BR} \times 3 / 4 \mathrm{HE}$ & $\mathbf{F}$ & $\mathbf{R i}$ & 533,0 & 0,0029 & Brown et al. (1976) \\
\hline $1 / 2 \mathrm{AN} \times 1 / 2 \mathrm{AN} / \mathrm{HE}$ & $\mathbf{F}$ & Bo & 511,8 & 0,0018 & Jenkins et al. (1993) \\
\hline $1 / 2 \mathrm{BR} \times 1 / 2 \mathrm{AN} / \mathrm{HE}$ & $\mathbf{F}$ & Bo & 550,0 & 0,0020 & Jenkins et al. (1993) \\
\hline $1 / 2 \mathrm{BS} \times 1 / 2 \mathrm{AN} / \mathrm{HE}$ & F & Bo & 520,0 & 0,0018 & Jenkins et al. (1993) \\
\hline $1 / 2 \mathrm{CH} \times 1 / 2 \mathrm{AN} / \mathrm{HE}$ & $\mathbf{F}$ & Bo & 554,1 & 0,0017 & Jenkins et al. (1993) \\
\hline $1 / 2 \mathrm{CI} \times 1 / 2 \mathrm{AN} / \mathrm{HE}$ & F & Bo & 589,1 & 0,0016 & Jenkins et al. (1993) \\
\hline $1 / 2 \mathrm{GE} \times 1 / 2 \mathrm{AN} / \mathrm{HE}$ & $\mathbf{F}$ & Bo & 538,6 & 0,0018 & Jenkins et al. (1993) \\
\hline $1 / 2 \mathrm{HE} \times 1 / 2 \mathrm{AN} / \mathrm{HE}$ & $\mathbf{F}$ & Bo & 500,0 & 0,0020 & Jenkins et al. (1993) \\
\hline $1 / 2 \mathrm{JE} \times 1 / 2 \mathrm{AN} / \mathrm{HE}$ & F & Bo & 425,0 & 0,0020 & Jenkins et al. (1993) \\
\hline $1 / 2 \mathrm{LI} x \mathrm{1} / 2 \mathrm{AN} / \mathrm{HE}$ & $\mathbf{F}$ & Bo & 515,9 & 0,0017 & Jenkins et al. (1993) \\
\hline $1 / 2 \mathrm{MA} \times 1 / 2 \mathrm{AN} / \mathrm{HE}$ & $\mathbf{F}$ & Bo & 583,2 & 0,0016 & Jenkins et al. (1993) \\
\hline $1 / 2 \mathrm{PZ} \times 1 / 2 \mathrm{AN} / \mathrm{HE}$ & F & Bo & 525,0 & 0,0022 & Jenkins et al. (1993) \\
\hline $1 / 2 R P \times 1 / 2$ AN/HE & $\mathrm{F}$ & Bo & 510,9 & 0,0016 & Jenkins et al. (1993) \\
\hline $1 / 2 \mathrm{SD} \times 1 / 2 \mathrm{AN} / \mathrm{HE}$ & F & Bo & 511,8 & 0,0018 & Jenkins et al. (1993) \\
\hline $1 / 2 \mathrm{SA} \times 1 / 2 \mathrm{AN} / \mathrm{HE}$ & F & Bo & 485,9 & 0,0021 & Jenkins et al. (1993) \\
\hline $1 / 2$ SI $x 1 / 2 \mathrm{AN} / \mathrm{HE}$ & F & Bo & 514,1 & 0,0019 & Jenkins et al. (1993) \\
\hline $1 / 2 \mathrm{TA} \times 1 / 2 \mathrm{AN} / \mathrm{HE}$ & F & Bo & 519,1 & 0,0021 & Jenkins et al. (1993) \\
\hline $3 / 8 \mathrm{BR} \mathrm{x} 5 / 8 \mathrm{HE}$ & $\mathrm{F}$ & $\mathrm{Be}$ & 515,0 & 0,0035 & Brown et al. (1976) \\
\hline $3 /{ }_{8} \mathrm{BR} x^{5} / 8 \mathrm{HE}$ & $\mathrm{F}$ & Bo & 499,0 & 0,0024 & Brown et al. (1976) \\
\hline $3 / 8 \mathrm{BR} \mathrm{x} 5 / 8 \mathrm{HE}$ & $\mathrm{F}$ & Go & 474,0 & 0,0039 & Brown et al. (1976) \\
\hline $3 /{ }_{8} \mathrm{BR} \mathrm{x}^{5} /{ }_{8} \mathrm{HE}$ & $\mathrm{F}$ & Lo & 467,0 & 0,0045 & Brown et al. (1976) \\
\hline $3 /{ }_{8} \mathrm{BR} x^{5} / 8 \mathrm{HE}$ & $\mathrm{F}$ & $\mathrm{Ri}$ & 494,0 & 0,0032 & Brown et al. (1976) \\
\hline AN & F & Bo & 412,0 & 0,0019 & Johnson et al. $(1990,1991)$ \\
\hline AN & $\mathbf{F}$ & Bo & 421,0 & 0,0019 & Stewart \& Martin (1981) \\
\hline AN & F & Bo & 447,5 & 0,0029 & Doren et al. (1989) \\
\hline AN & $\mathbf{F}$ & Bo & 493,0 & 0,0021 & Morrow et al. (1978) \\
\hline AN & Mi & Bo & 689,2 & 0,0031 & Doren et al. (1989) \\
\hline AN & Mi & Bo & 1002,0 & 0,0012 & Webster et al. (1982) \\
\hline$A N \times B R$ & $\mathrm{~F}$ & Bo & 500,2 & 0,0028 & Doren et al. (1989) \\
\hline $\mathrm{AN} \times \mathrm{BR}$ & Mi & Bo & 695,3 & & Doren et al. (1989) \\
\hline $\mathrm{AN} \times \mathrm{HO}$ & $\mathbf{F}$ & Bo & 507,9 & 0,0030 & Doren et al. (1989) \\
\hline $\mathrm{AN} \times \mathrm{HO}$ & Mi & Bo & 812,6 & & Doren et al. (1989) \\
\hline $\mathrm{AN} \times \mathrm{JE}$ & F & Bo & 437,3 & 0,0027 & Doren et al. (1989) \\
\hline $\mathrm{AN} \times \mathrm{JE}$ & Mi & Bo & 686,6 & & Doren et al. (1989) \\
\hline AY & F & $\mathbf{R i}$ & 537,1 & 0,0024 & Perotto et al. (1992) \\
\hline BA & F & Bo & 432,4 & 0,0024 & Torre \& Rankin (1978) \\
\hline BR & $\mathbf{F}$ & Bo & 500,6 & 0,0026 & Doren et al. (1989) \\
\hline BR & $\mathrm{F}$ & EM & 523,5 & & Menchaca et al. (1996) \\
\hline BR & $\mathbf{F}$ & EM & 568,5 & & Menchaca et al. (1996) \\
\hline BR & F & EM & 578,5 & & Menchaca et al. (1996) \\
\hline BR & Mi & Bo & 730,9 & 0,0021 & Doren et al. (1989) \\
\hline $\mathrm{BR} \times \mathrm{HE}$ & $\mathbf{F}$ & $\mathrm{Be}$ & 533,0 & 0,0025 & Brown et al. (1976) \\
\hline $\mathrm{BR} \times \mathrm{HE}$ & $\mathbf{F}$ & Bo & 543,0 & 0,0019 & Brown et al. (1976) \\
\hline $\mathrm{BR} \times \mathrm{HE}$ & F & Go & 541,0 & 0,0028 & Brown et al. (1976) \\
\hline
\end{tabular}




\begin{tabular}{|c|c|c|c|c|c|}
\hline Grupo racial $^{T}$ & $\mathrm{Sexo}^{2}$ & Função ${ }^{3}$ & $\mathrm{~A}^{4}$ & $\mathrm{k}^{5}$ & Autores \\
\hline $\mathrm{BR} \times \mathrm{HE}$ & $\mathbf{F}$ & Lo & 524,0 & 0,0032 & Brown et al. (1976) \\
\hline BR $\times$ HE & $\mathbf{F}$ & $\mathbf{R i}$ & 549,0 & 0,0029 & Brown et al. (1976) \\
\hline $\mathrm{CH}$ & Mi & Bo & 1113,0 & 0,0021 & Webster et al. (1982) \\
\hline FR & Mi & Bo & 1000,0 & 0,0019 & Webster et al. (1982) \\
\hline $\mathrm{HE}$ & $\mathbf{F}$ & Bo & 479,0 & 0,0016 & Johnson et al. $(1990,1991)$ \\
\hline $\mathrm{HE}$ & $\mathbf{F}$ & $\mathrm{Ri}$ & 476,2 & 0,0016 & Goonewardene et al. (1981) \\
\hline $\mathrm{HE}$ & $\mathbf{F}$ & Bo & 463,8 & 0,0019 & Goonewardene et al. (1981) \\
\hline $\mathrm{HE}$ & $\mathbf{F}$ & $\mathrm{Be}$ & 433,0 & 0,0032 & Goonewardene et al. (1981) \\
\hline $\mathrm{HE}$ & $\mathbf{F}$ & Lo & 419,6 & 0,0055 & Goonewardene et al. (1981) \\
\hline $\mathrm{HE}$ & $\mathbf{F}$ & $\mathrm{Be}$ & 488,0 & 0,0022 & Brown et al. (1976) \\
\hline $\mathrm{HE}$ & $\mathbf{F}$ & Bo & 508,0 & 0,0016 & Brown et al. (1976) \\
\hline $\mathrm{HE}$ & $\mathbf{F}$ & Bo & 463,0 & 0,0028 & Doren et al. (1989) \\
\hline $\mathrm{HE}$ & $\mathbf{F}$ & Bo & 443,4 & 0,0020 & Torre \& Rankin (1978) \\
\hline $\mathrm{HE}$ & $\mathbf{F}$ & Go & 498,0 & 0,0023 & Brown et al. (1976) \\
\hline $\mathrm{HE}$ & $\mathbf{F}$ & Lo & 481,0 & 0,0028 & Brown et al. (1976) \\
\hline $\mathrm{HE}$ & $\mathbf{F}$ & $\mathbf{R i}$ & 505,0 & 0,0017 & Brown et al. (1976) \\
\hline $\mathrm{HE}$ & Mi & Bo & 699,1 & 0,0027 & Doren et al. (1989) \\
\hline $\mathrm{HE}$ & Mi & Bo & 947,0 & 0,0019 & Webster et al. (1982) \\
\hline HE $x$ HO & F & Bo & 523,7 & 0,0031 & Doren et al. (1989) \\
\hline HE x HO & Mi & Bo & 817,0 & 0,0027 & Doren et al. (1989) \\
\hline HO & F & Bo & 517,3 & 0,0028 & Doren et al. (1989) \\
\hline $\mathrm{HO}$ & F & $\mathbf{R i}$ & 613,2 & 0,0022 & Perotto et al. (1992) \\
\hline HO & Mi & Bo & 858,7 & & Doren et al. (1989) \\
\hline $\mathrm{HO} \times \mathrm{AY}$ & $\mathbf{F}$ & $\mathbf{R i}$ & 586,5 & 0,0023 & Perotto et al. (1992) \\
\hline $\mathrm{JE}$ & $\mathbf{F}$ & $\mathrm{Be}$ & 416,0 & 0,0021 & Brown et al. (1976) \\
\hline $\mathrm{JE}$ & $\mathbf{F}$ & Bo & 454,0 & 0,0015 & Brown et al. (1976) \\
\hline $\mathrm{JE}$ & $\mathbf{F}$ & Bo & 384,8 & 0,0028 & Doren et al. (1989) \\
\hline $\mathrm{JE}$ & $\mathbf{F}$ & Go & 414,0 & 0,0025 & Brown et al. (1976) \\
\hline JE & $\mathbf{F}$ & Lo & 401,0 & 0,0029 & Brown et al. (1976) \\
\hline JE & $\mathbf{F}$ & $\mathbf{R i}$ & 424,0 & 0,0019 & Brown et al. (1976) \\
\hline JE & Mi & Bo & 615,7 & 0,0024 & Doren et al. (1989) \\
\hline $\mathrm{NE}$ & Mc & Bo & 529,2 & 0,0014 & Nobre et al. (1987) \\
\hline $\mathrm{NE}$ & Mi & $\mathrm{Ri}$ & 817,2 & 0,0016 & Duarte et al. (1975) \\
\hline $\mathrm{NE}$ & Mi & $\mathbf{R i}$ & 850,5 & 0,0016 & Duarte et al. (1975) \\
\hline RE & $\mathbf{F}$ & Bo & 650,0 & 0,0019 & Torre et al. (1992) \\
\hline SH & $\mathbf{F}$ & Bo & 409,0 & 0,0022 & Stewart \& Martin (1981) \\
\hline
\end{tabular}

- BR - Brahman; HE - Hereford, AN - Angus; HO - Holstein; JE - Jersey; AY - Ayrshire; BA - Brangus; CH - Charolais; FR Friesian; NE - Nelore; RE - Retinra; SH- Shorthom; BS - Brown Swiss; CI - Chianina; GE - Gelbvieh; LI - Limousin; MA Maine Anjou; PZ - Pinzgauer; RP - Red Poll; SA - Sahiwal; SI - Simental; SD - South Devon; TA - Tarantaisse.

${ }^{2}$ - F - fềmeas; $\mathrm{Mi}$ - machos não castrados; $\mathrm{Mc}$ - machos castrados.

3 - Be - von Bertalanffy; Bo - Brody; Go - Gompertz; Lo - Logistica; Ri - Richards; EM - Estágios multiplos.

4 - A - peso adulto em $\mathrm{kg}$.

$\mathrm{s}$ - $\mathrm{k}$ - taxa de maturidade em $\mathrm{kg} / \mathrm{kg}$.dia. 
APÊNDICE 7. GRÁFICOS DE PESO-IDADE MÉdIO dOS ANIMAIS ESTUDADOS.

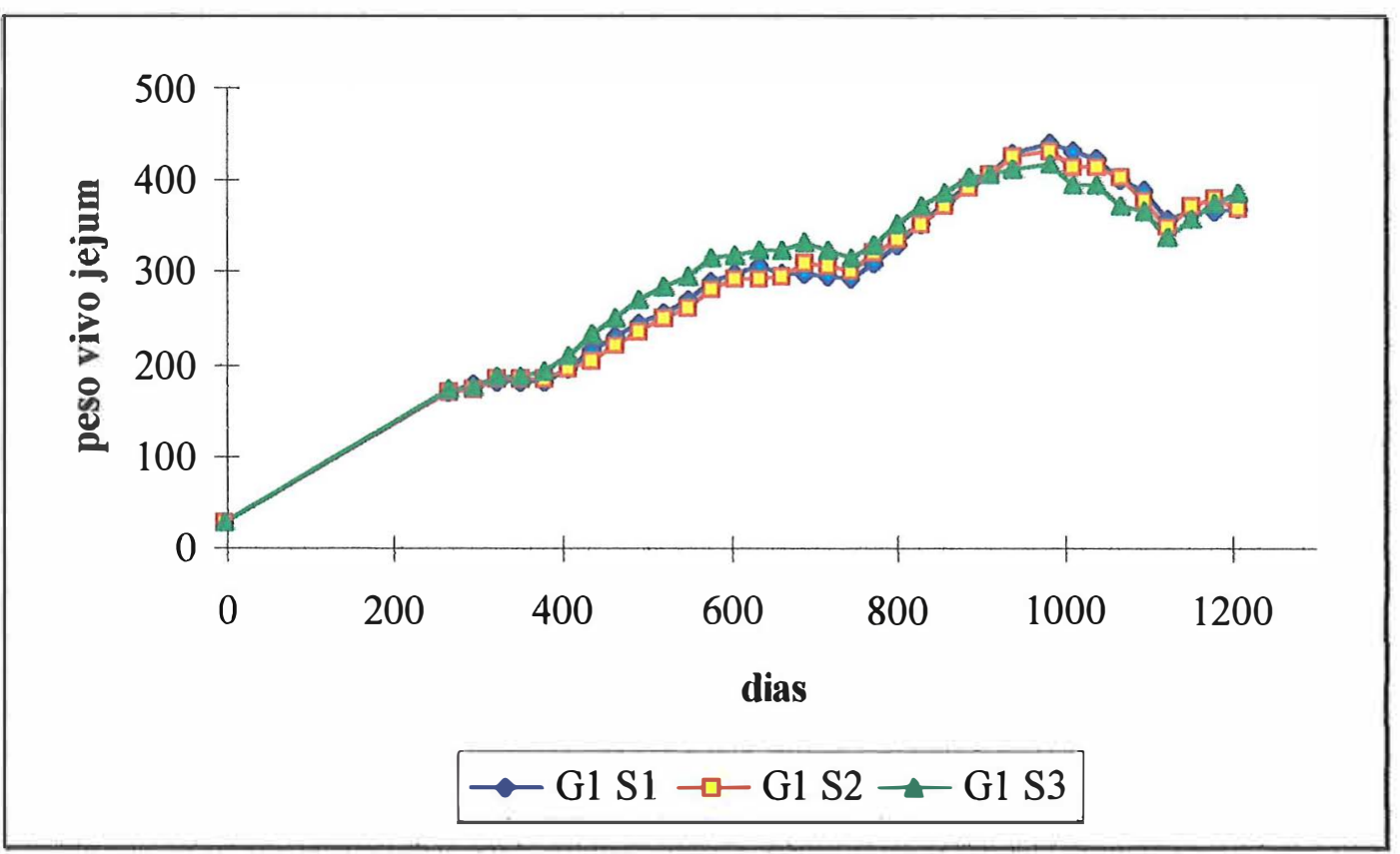

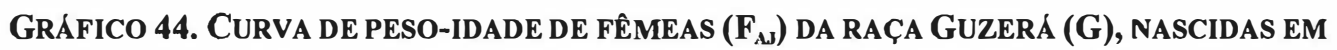
1978, PARA OS TRÊS TIPOS DE SUPLEMENTAÇÃo (S1, S2 E S3).

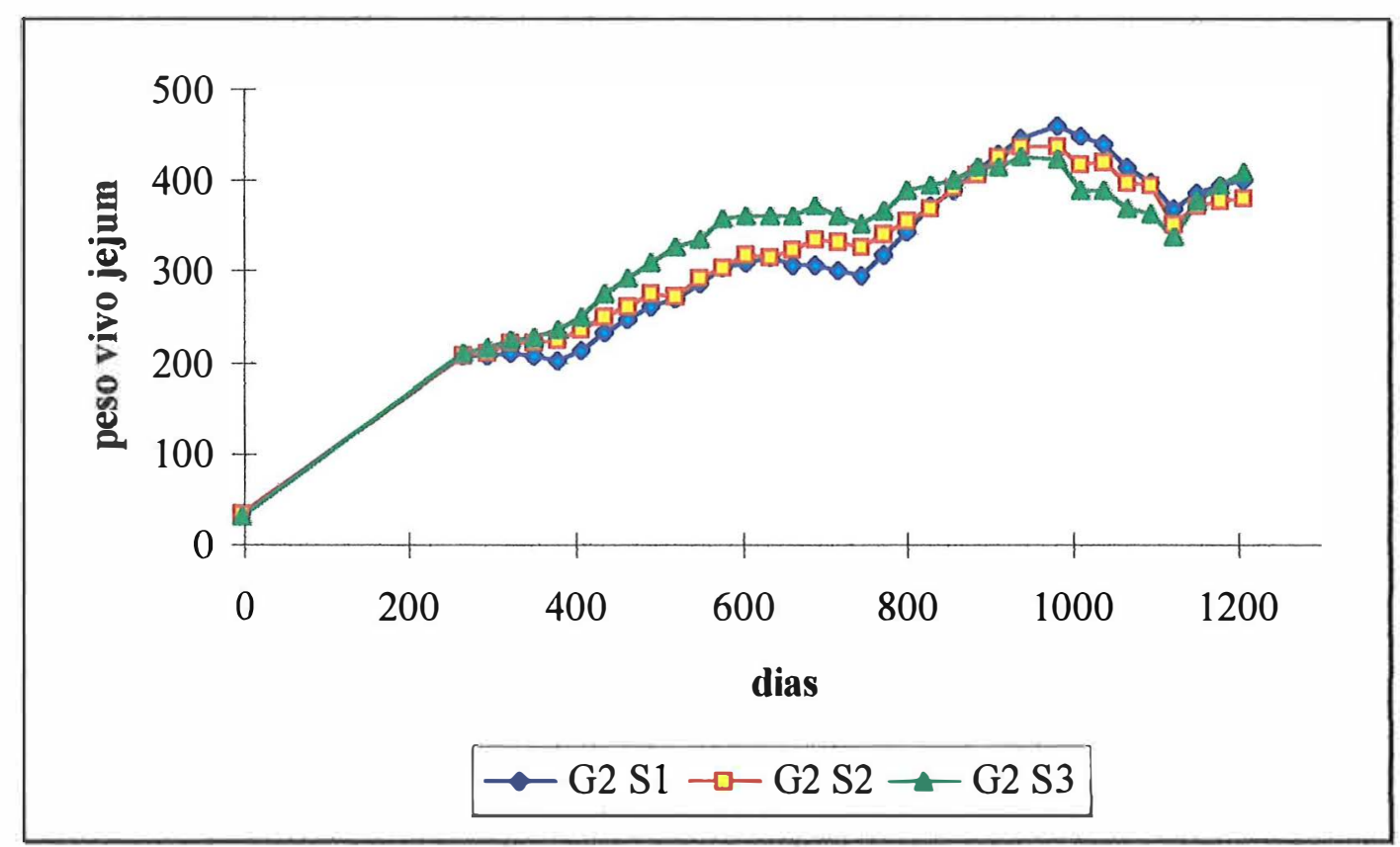

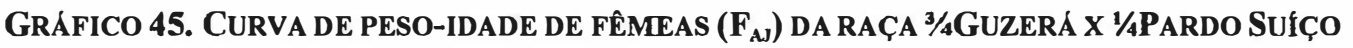
(3/4GS), NASCIDAS EM 1978, PARA OS TRÊS TIPOS DE SUPLEMENT AÇÃo (S1, S2 E S3). 


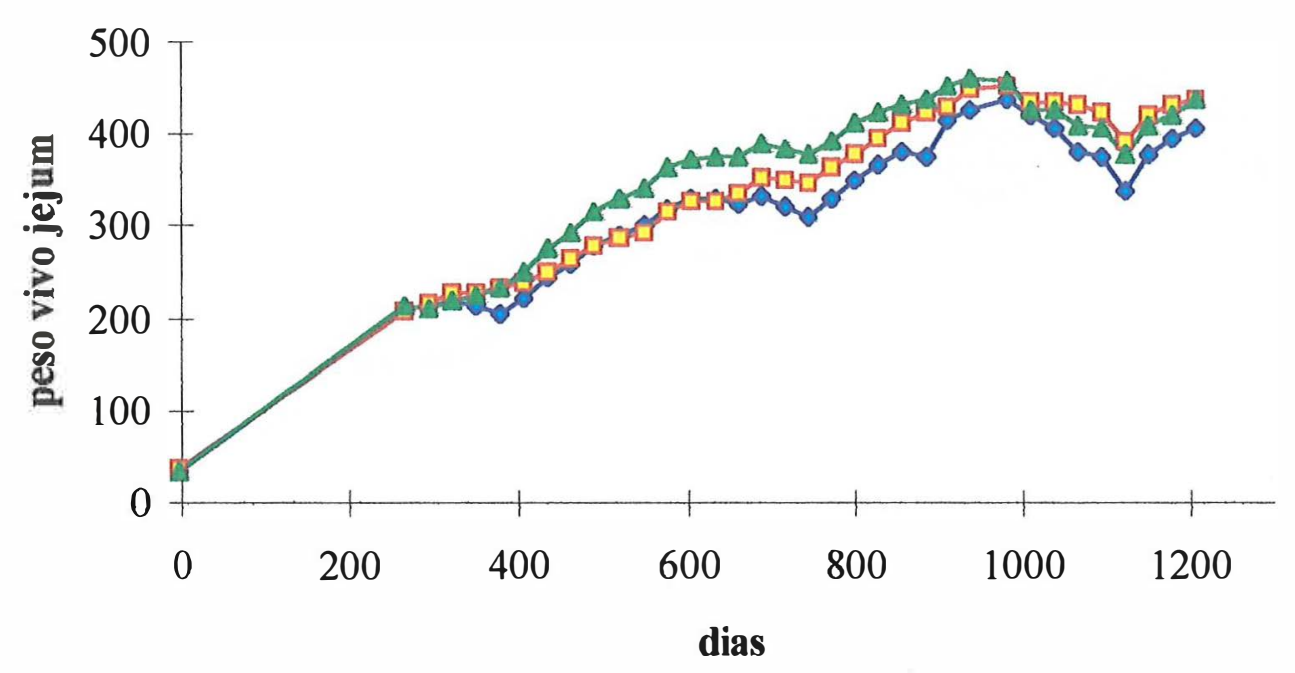$$
\prec \mathrm{G} 3 \mathrm{~S} 1 \multimap-\mathrm{G} 3 \mathrm{~S} 2 \multimap \mathrm{G} 3 \mathrm{~S} 3
$$

GRÁFICO 46. CURVA DE PESO-IDADE DE FÊMEAS $\left(F_{A J}\right)$ DA RAÇA 1/2NELORE X 1/4GUZERÁ X 1/4PARDO SUIÇC (1/2N(SG)), NASCIDAS EM 1978, NOS TRÊS TIPOS DE SUPLEMENTAÇÃo (S1, S2 E S3).

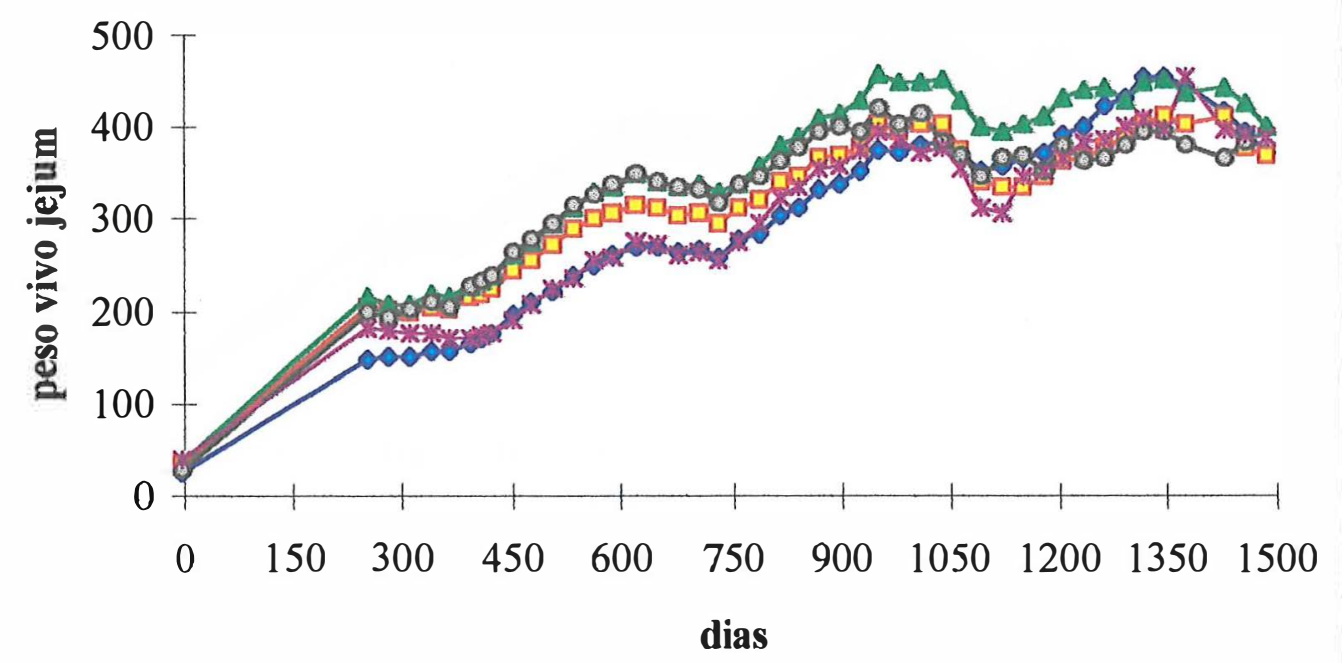

$\prec \mathrm{G} 1 \mathrm{~S} 1 \multimap \mathrm{G} 2 \mathrm{~S} 1 \multimap \mathrm{G} 3 \mathrm{~S} 1 \multimap \mathrm{G} 4 \mathrm{~S} 1 \rightarrow \mathrm{G} 5 \mathrm{~S} 1$

GRÁFICO 47. CURVA DE PESO-IDADE DE FÊMEAS ( F $\left._{\text {AJ }}\right)$, NASCIDAS EM 1977, DAS RAÇAS G, 3/4GS, 1/2N(SG), SG E 1 1/2C(SG) SEM SUPLEMENTAÇÃO(S1). 


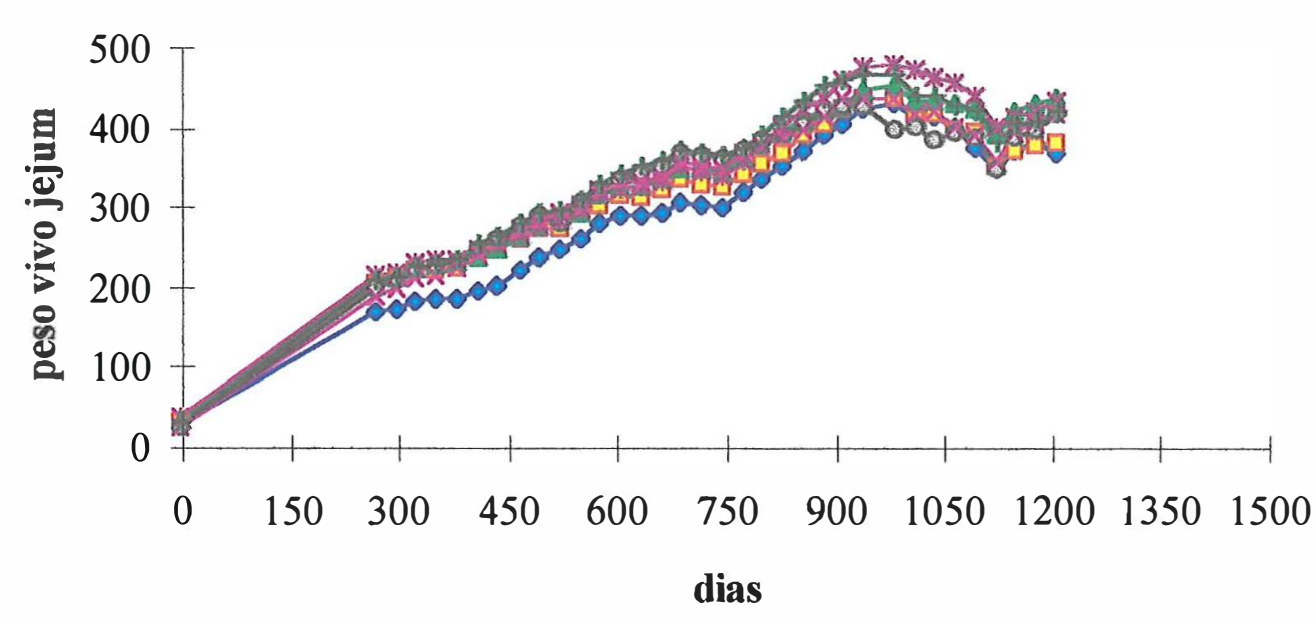

$\rightarrow$ G1 S2 $\rightarrow-\mathrm{G} 2 \mathrm{~S} 2 \rightarrow \mathrm{G} 3 \mathrm{~S} 2 \multimap \mathrm{G} 4 \mathrm{~S} 2 \rightarrow \mathrm{G} 5 \mathrm{~S} 2$ $\rightarrow \mathrm{G} 6 \mathrm{~S} 2 \rightarrow \mathrm{G} 7 \mathrm{~S} 2$

GRÁFICO 50. CURVA dE PESO-IDADE DE FÊMEAS ( F $_{\mathrm{AJ}}$ ), NASCIDAS EM 1978, DAS RAÇAS G, $3 / 4 G S, 1 / 2 N(S G), S G, 1 / 2 C(S G), K G$ E $1 / 2 K(S G)$ COM SUPLEMENTAÇĀO DURANTE A SECA (S2).

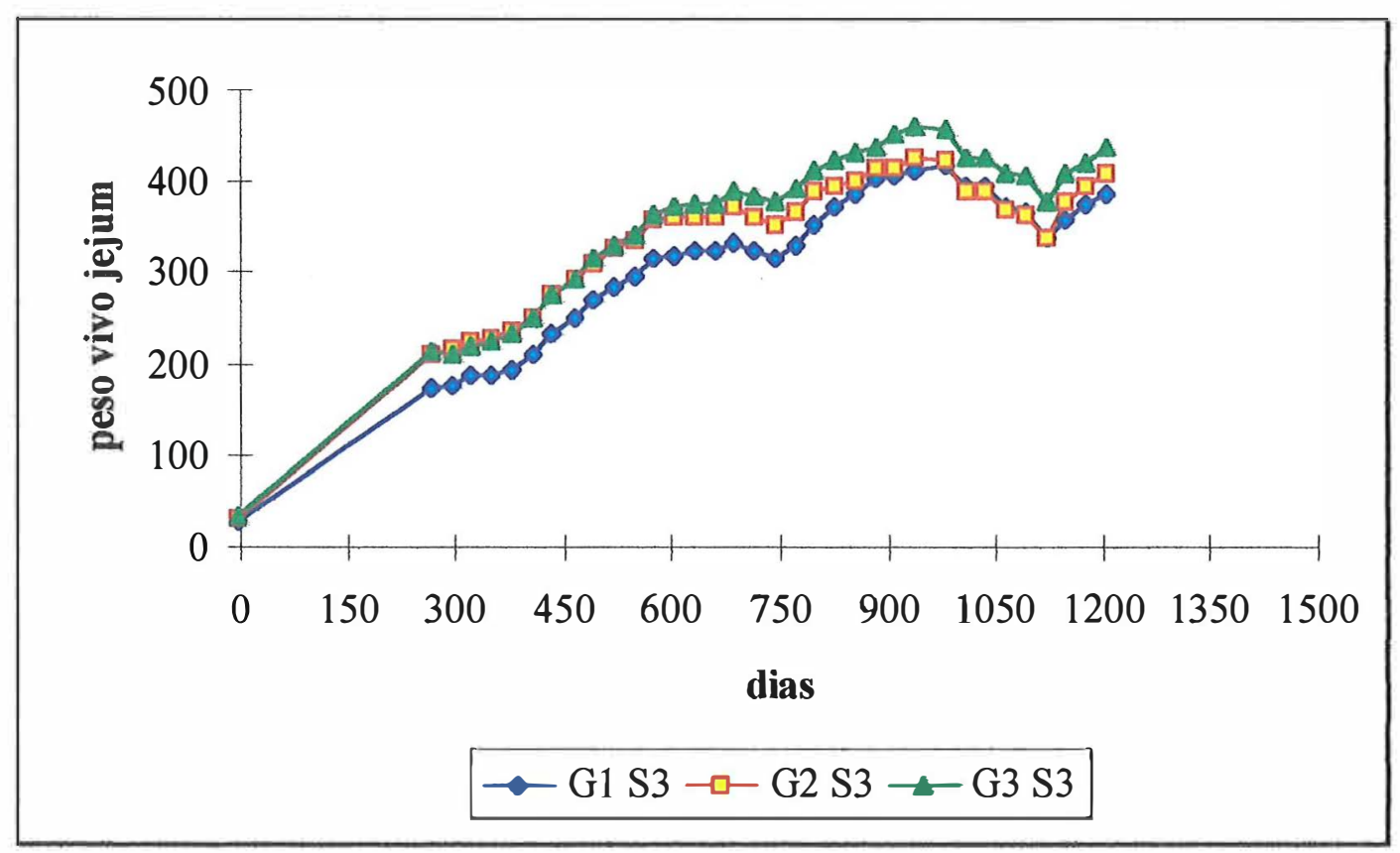

GráfICO 51. CURVA DE PESO-IDAdE de FÊMEAS ( F $_{\text {AJ }}$ ), NASCIDAS EM 1978, DAS RAÇAS G,

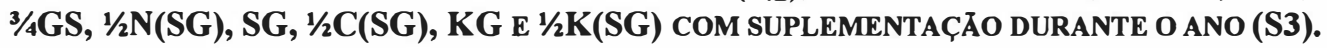

